\title{
The multiple effects of exposure to antenatal inflammation on the fetal lung
}

Citation for published version (APA):

Kramer, B. W. W. (2007). The multiple effects of exposure to antenatal inflammation on the fetal lung. [Doctoral Thesis, Maastricht University]. Datawyse / Universitaire Pers Maastricht. https://doi.org/10.26481/dis.20071010bk

Document status and date:

Published: 01/01/2007

DOI:

10.26481/dis.20071010bk

Document Version:

Publisher's PDF, also known as Version of record

\section{Please check the document version of this publication:}

- A submitted manuscript is the version of the article upon submission and before peer-review. There can be important differences between the submitted version and the official published version of record.

People interested in the research are advised to contact the author for the final version of the publication, or visit the DOI to the publisher's website.

- The final author version and the galley proof are versions of the publication after peer review.

- The final published version features the final layout of the paper including the volume, issue and page numbers.

Link to publication

\footnotetext{
General rights rights.

- You may freely distribute the URL identifying the publication in the public portal. please follow below link for the End User Agreement:

www.umlib.nl/taverne-license

Take down policy

If you believe that this document breaches copyright please contact us at:

repository@maastrichtuniversity.nl

providing details and we will investigate your claim.
}

Copyright and moral rights for the publications made accessible in the public portal are retained by the authors and/or other copyright owners and it is a condition of accessing publications that users recognise and abide by the legal requirements associated with these

- Users may download and print one copy of any publication from the public portal for the purpose of private study or research.

- You may not further distribute the material or use it for any profit-making activity or commercial gain

If the publication is distributed under the terms of Article $25 \mathrm{fa}$ of the Dutch Copyright Act, indicated by the "Taverne" license above, 
THE MULTIPLE EFFECTS OF

EXPOSURE TO ANTENATAL INFLAMMATION ON THE FETAL LUNG 
Printing of this thesis was financially supported by B. Braun Medical bv, Oss, The Nederland, Fisher \& Paykel, Auckland, New Zealand, Nycomed bv, Hoofddorp, the Netherlands, and the Stichting Bevordering Kindergeneeskunde, Maastricht, the Netherlands.

ISBN 9789052786650

(C) Copyright BWW Kramer, Maastricht 2007

Production: Datawyse bv / Universitaire Pers Maastricht

Cover: Sanne Bastin (Datawyse), Carlos Blanco. Painting of Nicolas Garcia Uriburu, Argentina. 


\section{THE MULTIPLE EFFECTS OF EXPOSURE TO ANTENATAL INFLAMMATION ON THE FETAL LUNG}

\section{PROEFSCHRIFT}

Ter verkrijging van de graad van doctor aan de Universiteit Maastricht, op gezag van de Rector Magnificus, prof.mr. G.P.M.F. Mols, ingevolge het besluit van het College van Decanen, in het openbaar te verdedigen op woensdag 10 oktober 2007 om 14.00 uur.

door

BORIS WILLY WERNER KRAMER

geboren op 8 oktober 1970 te Böblingen - Duitsland

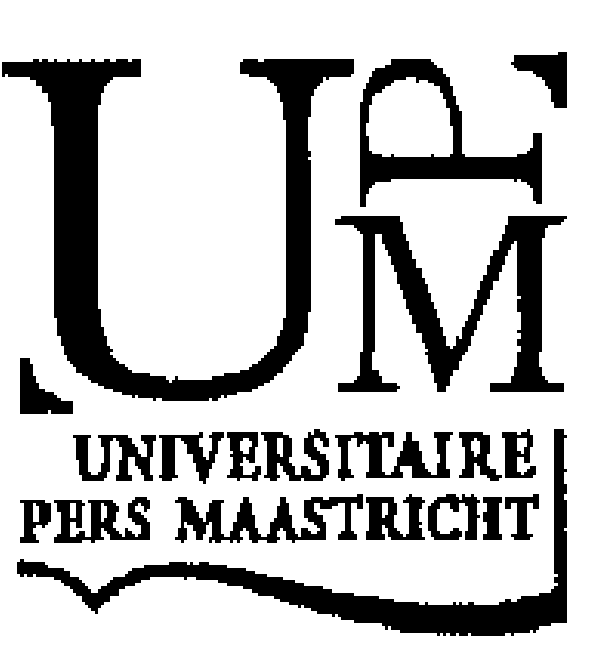




\section{Promotores}

Prof.dr. L.J.I. Zimmermann

Prof.dr. A.H. Jobe, University of Cincinnati - Ohio - USA

\section{Beoordelingscommissie}

Prof.dr. J. de Haan (voorzitter)

PD dr.dr. Y. Garnier, University of Cologne - Germany

Prof.dr. B. Kremer

Prof.dr. J.G. Nijhuis

Prof.dr. C.P. Speer, University of Würzburg - Germany 


\section{Contents}

$\begin{array}{lll}\text { Chapter } 1 & \text { Introduction } & 7\end{array}$

Chapter 2 Animal model of chorioamnionitis 23

Chapter 3 Dose and time response after intraamniotic endotoxin in preterm lambs. $\quad 29$ Kramer, B.W., Moss, T.J., Willet, K.E., Newnham, J.P., Sly, P.D., Kallapur, S.G., Ikegami, M., Jobe, A.H.

Am. J. Respir. Crit. Care Med. 2001; 164: 982-988

Chapter 4 Injury, inflammation and remodeling in fetal sheep lung after intraamniotic endotoxin.

Kramer, B.W., Kramer, S., Ikegami, M., Jobe, A.H.

Am. J. Physiol. 2002; 283: L452-L459

Chapter 5 Antenatal inflammation induced TGF-beta1 but suppressed CTGF in preterm lungs.

Kunzmann S., Speer C.P., Jobe A.H., Kramer B.W.

Am. J. Physiol. 2007; 292: L223-231

Chapter 6 Surfactant protein A recruits neutrophil granulocytes into the lungs of ventilated preterm sheep.

Kramer, B.W., Jobe, A.H., Bachurski, C.J., Ikegami, M.

Am. J. Respir. Crit. Care Med. 2001; 163: 158-165

Chapter 7 The clever fetus: responding to inflammation to minimize lung injury.

Kramer B.W., Jobe A.H.

Biol. Neonate. 2005; 88: 202-207

Chapter 8 Intratracheal endotoxin induces systemic inflammation in ventilated preterm lambs.

Kramer, B.W., Ikegami, M., Jobe, A.H.

Am. J. Respir. Crit. Care Med. 2002; 165:463-469

Chapter 9 Monocyte function in preterm, near term and adult sheep.

Kramer, B.W., Jobe, A.H., Ikegami, M.

Pediatr. Res. 2003; 54: 52-57

Chapter 10 Antenatal betamethasone changes cord blood monocyte responses to endotoxin in preterm lambs.

Kramer, B.W., Ikegami, M., Moss, T.J.M, Nitsos, I., Newnham, J.P., Jobe, A.H.

Pediatr. Res. 2004; 55:764-768 
Chapter 11 Endotoxin induced chorioamnionitis modulates innate immunity of monocytes in preterm sheep.

Kramer B.W., Ikegami M., Moss T.J.M., Nitsos I., Newnham, J.P., Jobe, A.H.

Am. J. Respir. Crit. Care Med. 2005; 171: 73-77

Chapter 12 Summary and Outlook

Samenvatting

Acknowledgement

Curriculum vitae 
CHAPTER

Introduction 
Preterm birth is the major problem in reproductive medicine. Preterm birth causes problems for the preterm baby, the mother, the family and the health care system despite the increased survival rate of preterm infants in recent years $(85,87)$. On a population basis preterm birth is the major variable that results in neonatal death and adversely affects the developmental potential of children and adults $(55,77$, 93). The progress in the treatment of preterm babies has not been matched in the reduction of preterm delivery which in fact has increased in the past decades $(11,86)$. After reviewing the epidemiology and the multifactorial causes for preterm births, the role of infections of the membranes and amniotic fluid (chorioamniontis) will be discussed. An animal model will be introduced to study effects of chorioamnionitis on lung function, lung development and the immune system. Chorioamnionitis will be discussed as a disease with multiple effects on the fetal lung.

\section{A. Epidemiology of preterm birth}

The correct incidence of preterm birth can only be assessed with a consistent definition of preterm birth and a population-based approach $(7,11,21)$. The reported incidence of preterm births are therefore affected by the method of assessment of gestational age and by differing definitions of viability and thus the registration of the preterm delivery as a live-born (49). Preterm birth occurs in an extremely heterogenous group of patients since preterm delivery may occur close to 37 weeks of gestation with no pathological cause and few clinical problems or it may occur at the extremes of prematurity at 24 weeks of gestation with low survival rates and a high risk for morbidity in the survivors (11). There is agreement that prematurity is defined by a gestational age below 37 weeks (see below), however there is little agreement on the minimal gestational age and on the subdivision of the preterm period into intervals defined by outcomes (113). In addition, the determination of gestational age can be quite inaccurate unless early ultrasound scanning is performed (8). This holds especially true in women of low socioeconomic status where the lack of prenatal healthcare is one of the risk factors for preterm birth. These limitations render the comparison of the incidence and outcomes of preterm birth in different countries particularly problematic.

The definition of preterm birth according to the World Health Organisation (WHO) is birth before the com- pletion of 37 weeks of gestation (259 days) from the first day of the last menstrual period (11). Earlier WHO guidelines were by birthweight since it is more accurately ascertained. However, gestational age is much more predictive of outcome than birthweight (16). The formerly used terms of "low birth weight" and "extremely low birth weight" fail to reflect prematurity adequately (75). These definitions include babies of relatively late gestations with severe in utero growth restriction (IUGR). The term of extreme low gestational age newborn (ELGAN) states the importance of gestational age (26) but does not provide a lower limit for gestational age either. The lower limit of preterm birth is therefore defined by legislation in most countries. The legal definition often takes into account the availability of neonatal intensive care units, local definitions of viability and varies considerably between countries. The United Kingdom has the legal defintion of 24 weeks and above for viability. Scotland however includes all births greater than 20 weeks in official statistics on the assumption that the causes for pregnancy lost between 20 and 24 weeks are likely similar to those causing preterm birth at 24 to 26 weeks gestation (15).

The date of conception is usually unknown unless the pregnancy resulted from assisted fertilization. The last day of the menstrual period is used to estimate gestational age. This estimation is based on the correct recall of the last day of menstruation, a 28 day menstruational cycle and on the assumption that conception occurred mid-cycle (49). Irregularity of the menstruational cycle due to individual differences or hormonal drugs, amenorrhea because of breastfeeding or failure to recall the last day can affect this method. Ultrasound examination in early pregnancy is very accurate since there is little biological variation in fetal size during this time of pregnancy. The use of early ultra-sound examinations is however limited to the developed world. Even in developed countries women of low socio-economic status or educational backgrounds are likely to attend antenatal care so late in the antenatal period that ultrasound estimated gestational age are no longer reliable (31).

The incidence of preterm birth is reported to be between 5 and $13 \%$ in the developed world $(7$, $11,49)$. In the developed world the rate has dropped in very few countries but has been static or on the rise in the majority of all countries for the past 20 years. In New Zealand the rate of single- 


\author{
Table 1 Conditions resulting in preterm delivery \\ Maternal \\ Severe pre-eclampsia or eclampsia \\ Major antepartum haemorrhage \\ Chorioamnionitis with maternal symptoms \\ Maternal disease: cardiac \\ respiratory \\ renal \\ psychiatric \\ Fetal \\ Multiple pregnancy \\ Rhesus (or other) isoimmunisation \\ Severe intrauterine growth restriction \\ Fetal compromise: anaemia \\ hypoxia/acidosis \\ cardiac/other organ failure \\ Cord entanglement (monoamniotic twins)
}

ton preterm birth has risen from $4.3 \%$ in 1980 to 5.8 $\%$ in 1999 which is an increase of $37 \%$ overall (22). The increase was only $3.5 \%$ in the lower socio-economic group but $72 \%$ in high socio-economic group (22). Delay in child bearing among affluent career women and an increase in assisted reproduction have been suggested as explanations. Similar trends were shown in Canada $(107,108)$. The proportion of births to women over 35 years increased from $8.4 \%$ in 1990 to $12.6 \%$ in 1996 . The preterm delivery rate increased among those mothers to $14 \%$. The increase in assisted reproduction also resulted in an increase in multiple births which added to the increase in preterm birth rate. The rate of twin pregnancies in the United Kingdom increased from $0.9 \%$ in 1980 to $1.2 \%$ in 1993 to $2 \%$ in 2002 (12). The rate of triplet and higher order births in the UK and in France has increased from 10 per 100,000 pregnancies before 1975 to 35 per 100,000 in 1993. Estimates range from 15 to $20 \%$ in twin pregnancies and up to $69 \%$ in higher order pregnancies result from assisted reproduction (12).

\section{B. Causes for preterm birth}

\section{Maternal and fetal indications}

Among all preterm deliveries $30 \%$ are indicated for maternal reasons in the developed world (83). Clinicians will consider preterm delivery if the continuation of the pregnancy will be a greater risk for the life or the well being of mother and/or fetus (56). Maternal conditions include pre-eclampsia or eclampsia, haemorrhage, chorioamnionitis with maternal symptoms such as fever, or other severe maternal organ dysfunction (table 1) (83). Detection of intra-uterine growth restriction (IUGR) or other fetal problems resulting in prompt delivery include rhesus isoimmunisation, fetal anemia, hypoxia/acidosis or organ failure (table 1). The underlying idea is to remove the fetus from an adverse environment or to treat the underlying disease exutero (9).

The decision for continuing the pregnancy is complicated by the fact that every day the pregnancy is continued is associated with an increase in stillbirth (107). Moreover, the clinical diagnosis of preterm labour may not necessarily prompt preterm delivery. In randomized controlled trials of tocolytics many women with apparent preterm labour were given placebo and did not deliver before term (105). Expectant management of preterm labour, the threshold for caeserean section and breech presentation may affect the rate of preterm deliveries in such a situation (105).

\section{Previous preterm birth}

A previous preterm delivery is the most important risk factor for subsequent preterm delivery $(4,5$, 51). The risk factor has been estimated to be 4 fold higher $(14,51)$. A further subgroup analysis identified women with chorioamnionitis to be at a more than $50 \%$ risk to deliver preterm in the following pregnancy with subsequent diagnosis of chorioamnionitis (81). However, the population group that suffer most preterm births have usually more than one risk factor contributing to the increased risk of preterm birth $(22,91)$. Genetic factors have been indentified to be part of the multifactorial contributors to preterm birth (27).

\section{Cervical incompetence}

The diagnosis is made by the appearance of a cervix dilatation in the absence of labour. The true incidence of cervix incompetence is difficult to determine but risk factors include previous surgery and congential malformations (74). Ascending infections may cause increases in prostaglandins and thus soften the cervix. In a randomized controlled trial only 1 in 25 women thought to have cervix incompetence profited from cervix cerclage (74). 


\section{Infection}

Considerable evidence suggests a link between infection and preterm birth (92). Infections associated with preterm delivery may be in lower genital tract, intrauterine or extra-uterine (generalized maternal infection). A causative link is plausible in some cases and is supported by the efficiency of antibiotic therapy (38).

\section{Lower genital tract infections}

Bacterial vaginosis (BV) occurs in 10 to $25 \%$ of pregnant women (62). The normal vaginal microflora of predominantly lactobacilli is replaced by other organisms, especially by anerobic bacteria, Gardnerella vaginalis and mycoplasmas. Women with $B V$ are at risk to give preterm birth with an odds ratio of 2.19 (95\% confidence interval $1.54-3.12)(72)$. Genetic polymorphism in women is associated with this kind of microflora and preterm birth (91). A systemic review of randomized controlled trials identified the subgroup of women with a previous preterm birth to benefit from antibiotic treatment (76).

\section{Asymptomatic bacteriuria}

The presence of asymptomatic bacteriuria is an indication for antibiotic treatment since untreated bacteriuria is associated with a $30 \%$ incidence of pyelonephritis later in pregnancy and a $30 \%$ to $50 \%$ increase in preterm birth (98). Antibiotic treatment reduces the risk of pyelonephritis (odds ratio $0.24,95 \%$ confidence interval $0.19-0.32$ ) and preterm birth (odds ratio $0.60,95 \%$ confidence interval $0.45-0.85$ ) (98).

\section{Group B streptococcus}

Group B streptococcus (GBS) is a common vaginal pathogen but it is not clear that it is a pathogen for non-pregnant women. GBS has had a major impact on perinatal care (82). The early onset sepsis (within the first 3 days of life) by GBS occurs in 0.5 to 3 per 1000 live births in the USA (81). The pathogen is transmitted during birth to the baby. Therefore, maternal colonization, a previous infant who had GBS sepsis, antenatal GBS asymptomatic bacteriuria, rupture of membranes greater than 12 hours, intrapartum fever, and gestational age less than 37 weeks are established risk factors for early onset GBS sepsis (50). GBS sepsis is very dangerous since the case-fatality rate is very high especially in preterm infants (50). Many survivors will have long-term neurodevelopmental handicaps. Intrapartum antibiotic treatment will reduce the incidence of early onset GBS sepsis but has no effect on the incidence of late onset GBS sepsis (81). Conflicting data exist about GBS colonization as a cause of preterm delivery. The prevalence of GBS in women delivering preterm is not increased (69) but GBS is more frequently detected in women with preterm labor and preterm prelabour rupture of membranes (81).

\section{Chlamydia trachomatis}

Genital chlamydial infection is detected in $5 \%$ to $15 \%$ of all women in child-bearing age, making Chlamydia trachomatis one of the most commonly sexually transmitted diseases in developed countries, especially among young women $(36,63)$. The associated risk for preterm delivery is 3 fold higher after controlling for confounding variables (89).

\section{Chorioamnionitis}

Inflammation of the amniotic fluid and membranes is called chorioamnionitis. Chorioamnionitis is caused by a variety of bacterial species. The clinical course can be distinguished between a systemic inflammatory response of the mother with increased leukocyte counts and fever (amnionitis inflammatory syndrome) which is treated by delivery of the fetus and antibiotic therapy, and a clinically silent chorioamnionitis with no symptoms in the mother (38). The predominant form at early gestational age is clinically silent which is usually diagnosed postnatally by pathological review of the placenta $(61,70)$. If the umbilical cord vessels have inflammatory changes the chorioamnionitis is thought to have progressed to fetal inflammation or funisitis (23). The incidence of clinically silent, histological chorioamnionitis has been reported to be up to $60 \%$ in extermely preterm infants throughout different populations (figure 1) (70). The diagnosis of chorioamnionitis is however a major challenge. Steel et al., 2005, showed with bacterial 165 ribosomal RNA probes to detect DNA from bacteria that the bacterial invasion of the membranes and placenta did not necessarily induce an inflammatory response (104). They reported that 25 of 29 


\section{Histologic Diagnosis Chorioamnionitis [ \% ]}

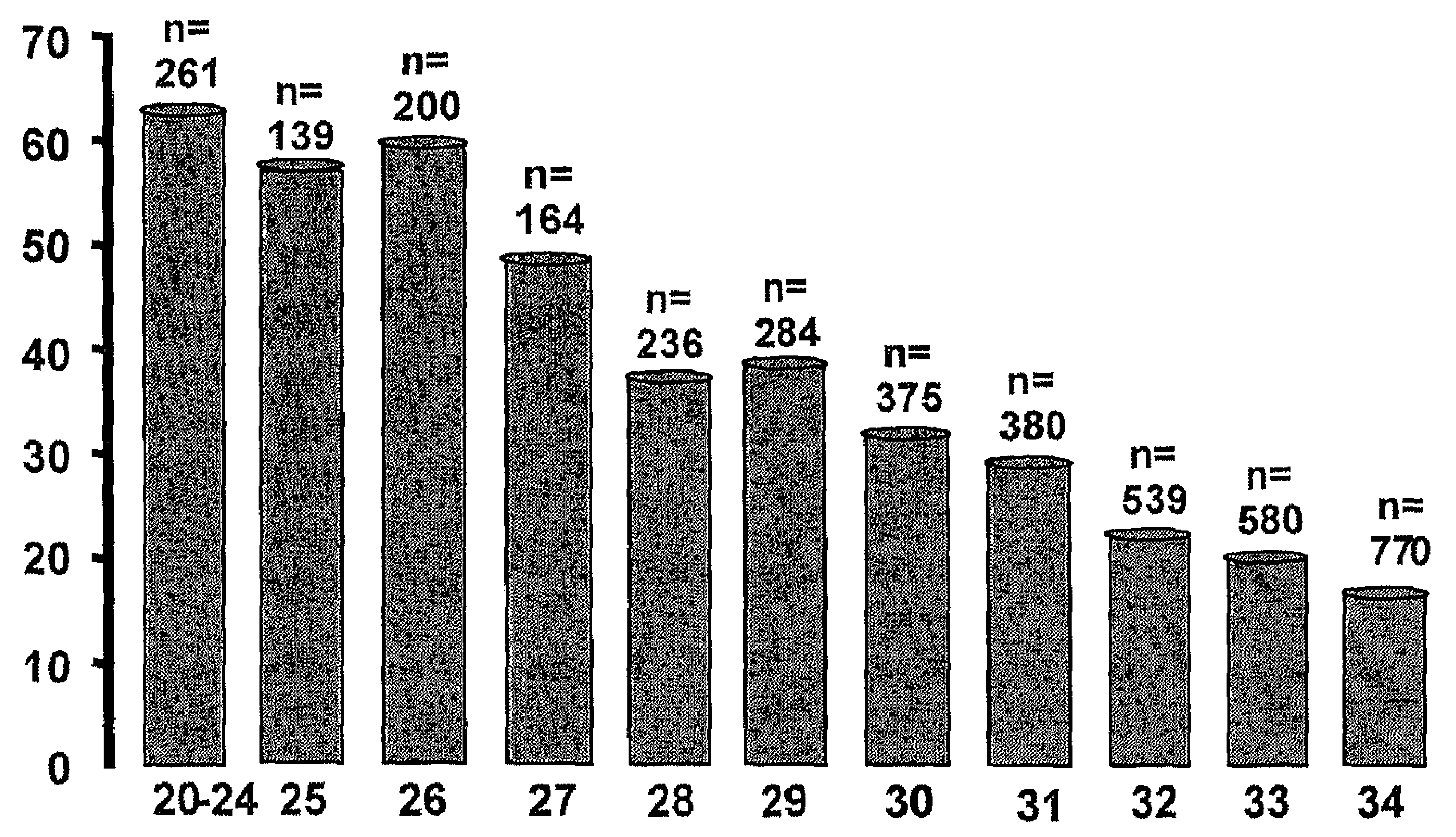

\section{Complete weeks post- conceptional age}

Figure 1: Incidence of histologic chorioamnionitis in preterm deliveries at the University of Sydney, Australia, Numbers of samples are given per gestational age. Modified according to Lahra und Jeffrey, Am. J. Ob. Gyn, 190: 147 pp., 2004.

fetuses that delivered prematurely had bacteria that were deep within intact fetal membranes and in $25 \%$ of all cases there was no associated inflammation. The majority of preterm infants delivered without ruptured membranes had evidence of colonized membranes using this bacterial probe.

The possible explanations for this finding are numerous. First of all, there is little to no information on the time course of chorioamnionitis relating the invasion of microbes with the time necessary for an inflammatory response $(3,104)$. Secondly, the interaction of the microbes with the immune system of the host is not well understood. In the case of chorioamnionitis the host is the mother and the fetus and mechanism that might prevent or control inflammatory response have not been studied (38). Thirdly, the function of the immune system may be primed or modulated by previous exposures to proinflammatory agonists (116). The initial exposure to a non-lethal dose of endotoxin for example reduced the response of the immune cells to a second usually lethal dose of endotoxin in experimental animal models (116). This phenomenon, called endotoxin tolerance, is considered as a major cause for morbidity in adult intensive care units. Previous exposures to proinflammatory stimuli renders the immune system of patients tolerant. A secondary infection with living bacteria is therefore not addressed adequately by the immune systems which gives the bacteria a competitive advantage (116). Little information is available on the effects of the indolent chronic infection of chorion and amniotic fluid on the function of the immune cells (65).

\section{Bacterial invasion of the amniotic cavity}

Until recently, the placenta, membranes and fetus were considered to be sterile in most cases and during much of the pregnancy (38). This general understanding has been challenged by a number of clinical studies. Sophisticated sampling of the endometrium and subsequent microbiological analysis yielded in most cases viable bacteria in the endometrium 3 months after delivery (3). There was no difference in the incidence of preterm delivery with respect to bacterial infection (table 2).

The amniotic cavity thus appears to be more frequently exposed to bacterial invasion without problems in conception or resulting necessarily in preterm birth (3). This view was previously suggested by results from Perni et al. (84). Samples of amniotic fluid for genetic analysis were analysed for Ureaplasma urealyticum and Mycoplasma hominis. Ureaplasma urealyticum were 
Table 2: Endometrial microbial colonization 3 months after pregnancy

\begin{tabular}{llll}
\hline & \multicolumn{2}{c}{ Delivery } \\
\cline { 2 - 4 } & Normal term & Spontaneous preterm & Indicated preterm \\
\hline Number of patients & 303 & 375 & 142 \\
Gestational age at delivery (weeks) & 39.6 & 26.4 & 27.2 \\
Positive endometrial cultures & $81 \%$ & $85 \%$ & $79 \%$ \\
\hline
\end{tabular}

According to Andrews et al., Am. J. Obstet. Gynecol. 193, pp. 739-745, 2005

Table 3: Detection by polymerase chain reaction of Ureaplasma urealyticum or Mycoplasma hominis in amniotic fluids collected at 15 to 19 weeks from 179 asymptomatic women

\begin{tabular}{lll}
\hline & Ureaplasma urealyticum & Mycoplasma hominis \\
\hline Amnionitic fluid positive & $22(13 \%)$ & $11(6 \%)$ \\
Preterm premature rupture of membranes \& preterm birth & $3(14 \%)$ & $2(18 \%)$ \\
Term birth & $19(86 \%)$ & $9(82 \%)$ \\
\hline
\end{tabular}

According to Perni et al., Am. J. Obstet. Gynecol. 191, pp. 1382-1386, 2004

found in $13 \%$ of all samples (table 3 ). Preterm premature rupture of membranes and subsequent preterm birth occurred only in 3 of the $22(14 \%)$ women that tested positive for Ureaplasma urealyticum. Thus the majority (19 of $22 ; 86 \%$ ) of the women who tested positive for Ureaplasma urealyticum delivered at term. Similar results were obtained for Mycoplasma hominis (table 3). Therefore, the presence of microbacteria in the amniotic cavitiy may not necessarily result in preterm birth (35). Taken together these reports suggest that fetal coexistence with commensal organisms may be the rule and not the exception.

\section{Importance of Chorioamnionitis to Neonatal Mortality and Morbidity}

The importance of antenatal exposure to inflammation for preterm infants is a complex issue (100). Clinical trials suggest that chorioamnionitis is beneficial for the survival of extremely preterm infants probably by induction of early lung maturation $(20,114)$. In contrast, exposure to funisitis or a systemic inflammatory response has been associated with bad neurodevelopment and pulmonary outcomes (78, 79,112 ). Among the possible mechanisms suggested by animal experiments are an increased susceptability to hypoxia and ischemia after expo- sure to antenatal inflammation (45). There also may be direct effects on the vasculature $(23,67)$.

\section{Lung outcomes after very preterm birth}

Lung immaturity and lung injury are major contributors to the morbidity and mortality of premature infants less than 30 weeks of gestation (52). The two major adverse outcomes are respiratory distress syndrome (RDS) caused by surfactant deficiency and structural lung immaturity resulting in early death, and bronchopulmonary dysplasia (BPD). The mortality of RDS has been estimated to be $40 \%(48,122)$. RDS has been the most common cause of mortality in preterm infants until the introduction of surfactant replacement therapy and the wide-spread use of antenatal maternal corticosteroid therapy (48). The cause of RDS is the immaturity of the lung in preterm infants. Capillaries and air conducting structures come close to each other at the beginning of the saccular phase of lung development at around 22-24 weeks of post menstrual age (64). The diffusion of gases from air saccules to the capillaries and vice versa is not possible at an earlier stage of lung development. Therefore, all efforts of oxygenation and carbon dioxide elimination via diffusion are restricted by this gestational age or more precisely by this stage of lung development. From the second trimester alveolar type II cells produce a complex mixture of lipids and proteins, which is secreted into the air space $(40,68)$. This mixture 


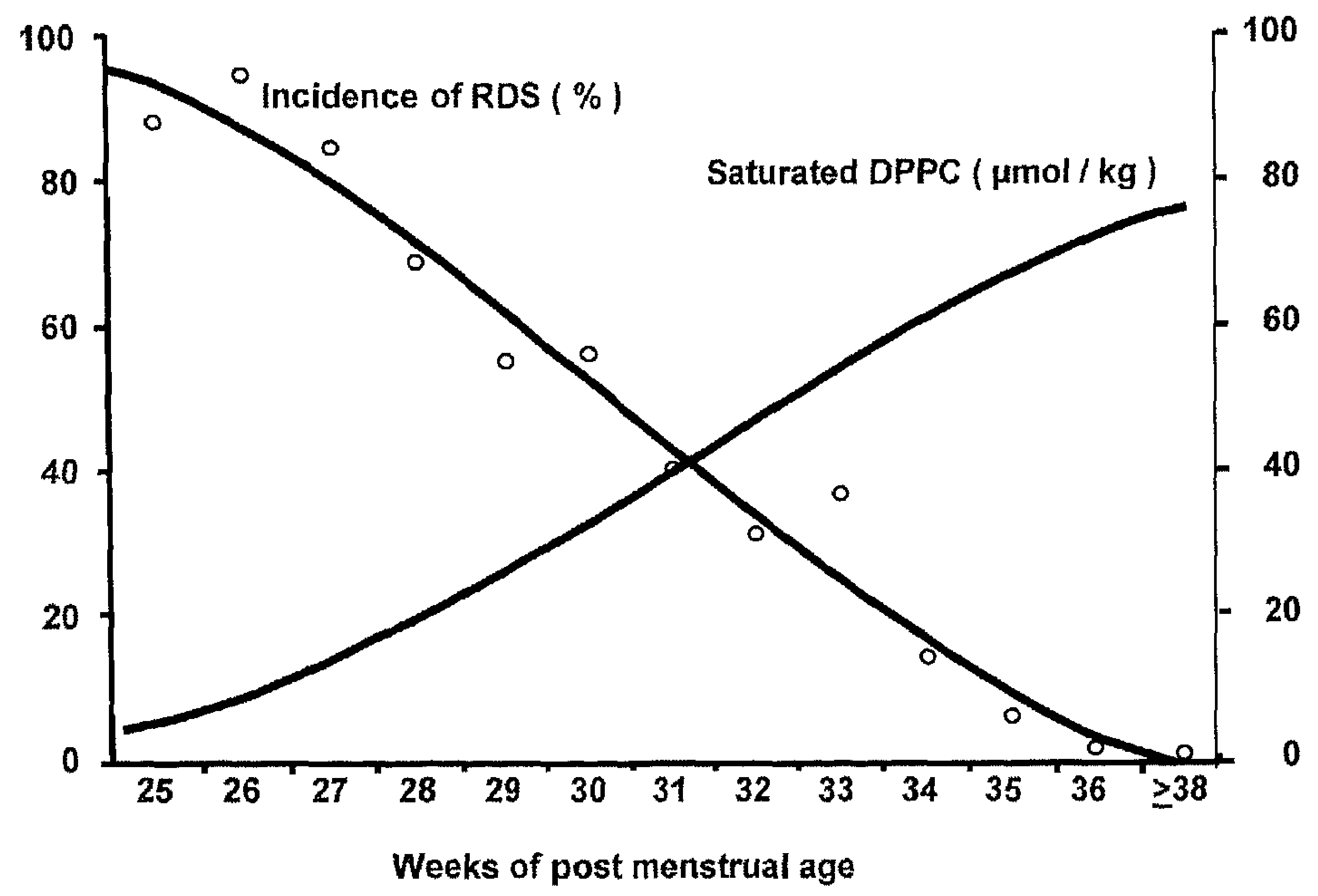

Figure 2: Incidence of resiratory distress syndrome (RDS) is inversely correlated with gestational age and increase in surfactant pool size. Surfactant pool size was quantified by saturated dipalmityiphosphatidylcholine (DPPC) the major component of surfactant. Modified from Jobe AH. Pathophysiology of RDS. In: Fotal and Neonatal Physiology, edited by Polin and Fox. Philadelphia: Saunders, 1998 , p. $1299-1314$.

reduces the surface tension and is therefore called surfactant which stands for surface active agent(s) (122). Surfactant maintains the alveoli open during the cyclic changes in surface area and tension during inspiration and expiration. The incidence of RDS decreases with gestational age as the lung structure matures and the surfactant pool increases (figure 2) (122). Preterm infants have little surfactant in both the air space and in the alveolar type II cells. The barrier between air and water in the alveoli mandates the presence of surfactant to remain intact. Delayed or impaired surfactant synthesis is at the beginning of RDS.

\section{Bronchopulmonary Dysplasia}

$B P D$ is a chronic lung injury and inflammation syndrome in very preterm infants that results in disrupted development of the saccular lung intra- and extrauterinely (1). The lung development is in a very immature state at 24 weeks gestation and is referred to as the saccular phase (64). Air containing structures and blood vessels come close to each other for the first time in gestation. Babies that have BPD have a lower number of alveoli than normal (53). In addition, the individual size of the alveoli is bigger in babies with BPD (53). The changes induced in the post-natal lung development with a chronic inflammation in the airways are shown in figure 3. Alveolar septation and microvasculature development are reduced in babies with BPD. Therefore, the lung development is severely impaired resulting in less surface area for gas exchange and impaired gas exchange $(10,18,53,71)$. BPD is therefore defined clinically by the need for supplemental oxygen (58). A workshop of the National Institute of Child Health and Human Development/National Heart, Lung, and Blood Institute proposed a severitybased definition of BPD for infants $<32$ weeks' gestational age (GA) in 2000 (58). Mild BPD was defined as a need for supplemental oxygen $\left(\mathrm{O}_{2}\right)$ until or for over 28 days but not at 36 weeks' postmenstrual age (PMA) or discharge. Moderate $B P D$ was considered as oxygen dependency until or for over 28 days plus treatment with below $30 \%$ $\mathrm{O}_{2}$ at 36 weeks' PMA, and severe BPD as $\mathrm{O}_{2}$ for oxygen dependency for until or for over 28 days plus more than $30 \% \mathrm{O}_{2}$ and/or positive airway pressure at 36 weeks' PMA. The impaired lung development represents the most common adverse outcome of preterm birth. The categorization of BPD by this definition is predictive for adverse pulmonary and neurodevelopmental outcomes in early infancy (28). Infants with BPD are significantly more likely than their gestational age counterparts without BPD to be rehospitalized within the first year of life, to develop long-term neurologic disability, and they consume twenty 


\section{Normal lung development}

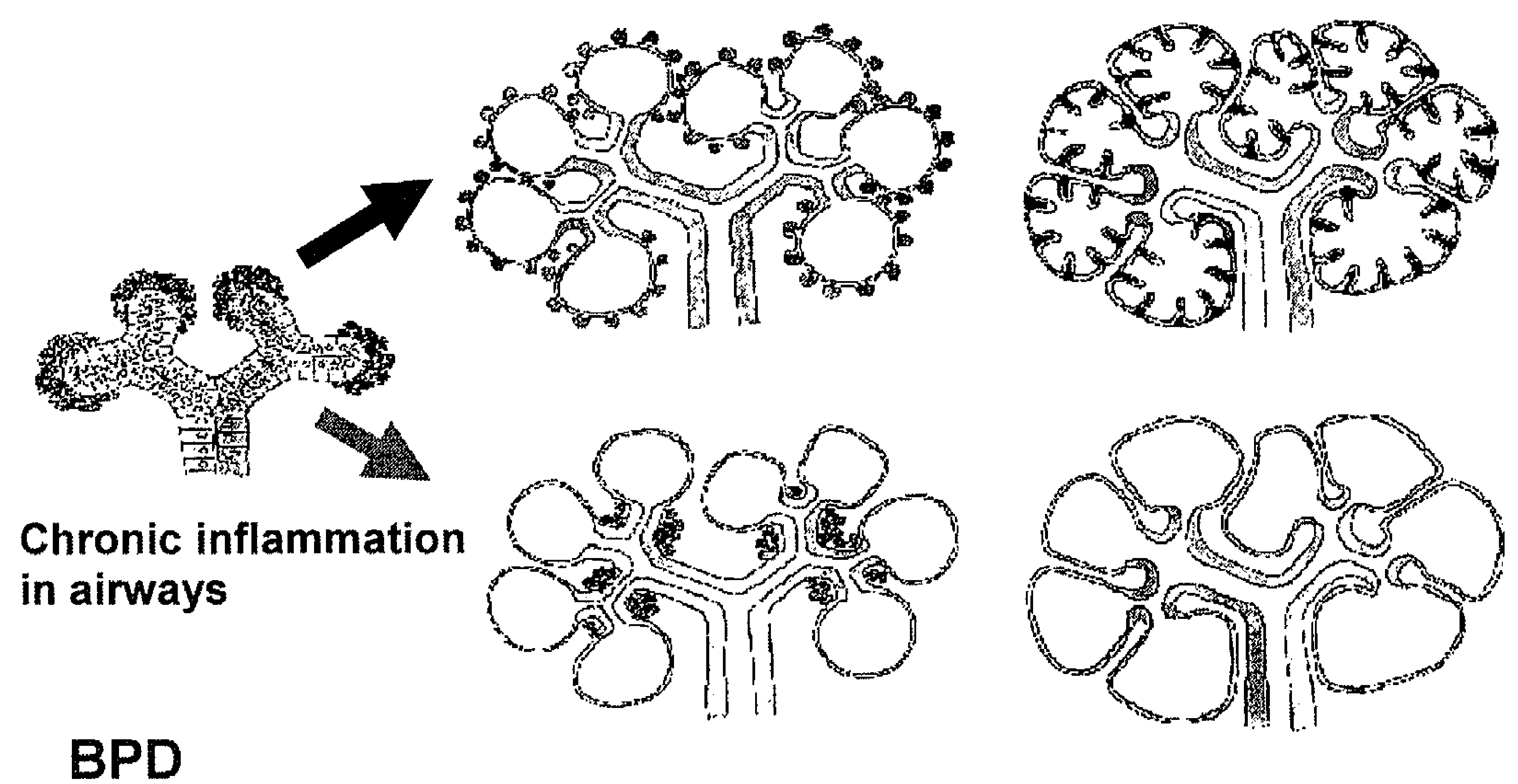

Figure 3: The normal development of the lung is depicted on the upper part of the cartoon. During late pregnancy and early childhood alveoli are formed which provide the increase in area for gas exchange to meet the demand by growth. Alveoli do not form in the same pattern in infants suffering from BPD which is depicted on the lower part. Chronic exposure to proinflammatory cytokines in the airways impairs development of alveoli and microvasculature thus reducing the area for gas exchange and making supplementary oxygen necessary. Modified from Husain et al., Hum. Pathol., 29: 710-727, 1998 and from Groneck et al., Pediatrics, 93: 712-718, 1994.

times more annualized health care resources than unaffected children in the USA $(55,77,93,99)$. Approximately $5.9 \%$ of all resources spent for children from 0 to 18 years of age are consumed by infants with BPD in the USA $(55,93,99)$.

$B P D$ is associated with a chronic inflammatory response in the airways of preterm babies. This inflammatory response may be initiated antenatally by chorioamnionitis and/or sustained by postnatal interventions such as resuscitation, oxygen toxicity, and mechanical ventilation with baro- or volutrauma (41, $42,94)$. The oxygen concentration of preterm infants is depicted in figure 4 during the first weeks of life. Analyses of antenatal risk factors associated for example low gestational age, absence of maternal steroids and chorioamnionitis with the development of BPD. Postnatal risk factors such as mechanical ventilation, high oxygen concentrations and a systemic inflammatory response have been identified to sustain the chronic inflammation in the airways (figure 4) $(17,19,39,95,110-120)$.

Few large studies have correlated chorioamnionitis with lung outcomes. Analysis of outcomes for all infants born before 26 weeks in the United Kingdom and Ireland in 1995 showed that the major cause of death was pulmonary insufficiency and survival was increased with antenatal corticosteroids and when clinical chorioamnionitis was diagnosed (20). In con- trast, histologic chorioamnionitis was not associated with decreased death in a recent trial of cortisol to prevent BPD or in a retrospective analysis $(61,115)$. Remarkably, although chorioamnionitis is frequent, only about $2 \%$ of extremely preterm infants have positive blood cultures at birth (106). Despite the clinical bias that infection should severely compromise the fetus, preterm infants exposed to chorioamnionitis seldom are septic and may have decreased mortality (20). Watterberg et al. correlated histological chorioamnionitis with the incidence of respiratory distress syndrome (RDS) and bronchopulmonary dysplasia (BPD) in ventilated preterm babies (114). They found in patients from the 1990's that preterm infants had a lower incidence of RDS if they were antenatally exposed to chorioamnionitis. However, the incidence of BPD increased in the very same infants (table 4).

Recent clinical studies did not confirm the results that Watterberg et al. obtained a decade before in ventilated preterm babies and what van Marter et al. confirmed in patients with sepsis or mechanical ventilation (111). Chorioamnionitis was not associated with the development of BPD in a large cohort in Australia or in the USA $(2,61$, 115). Several practices in perinatal medicine have changed during the past decade. The venti- 


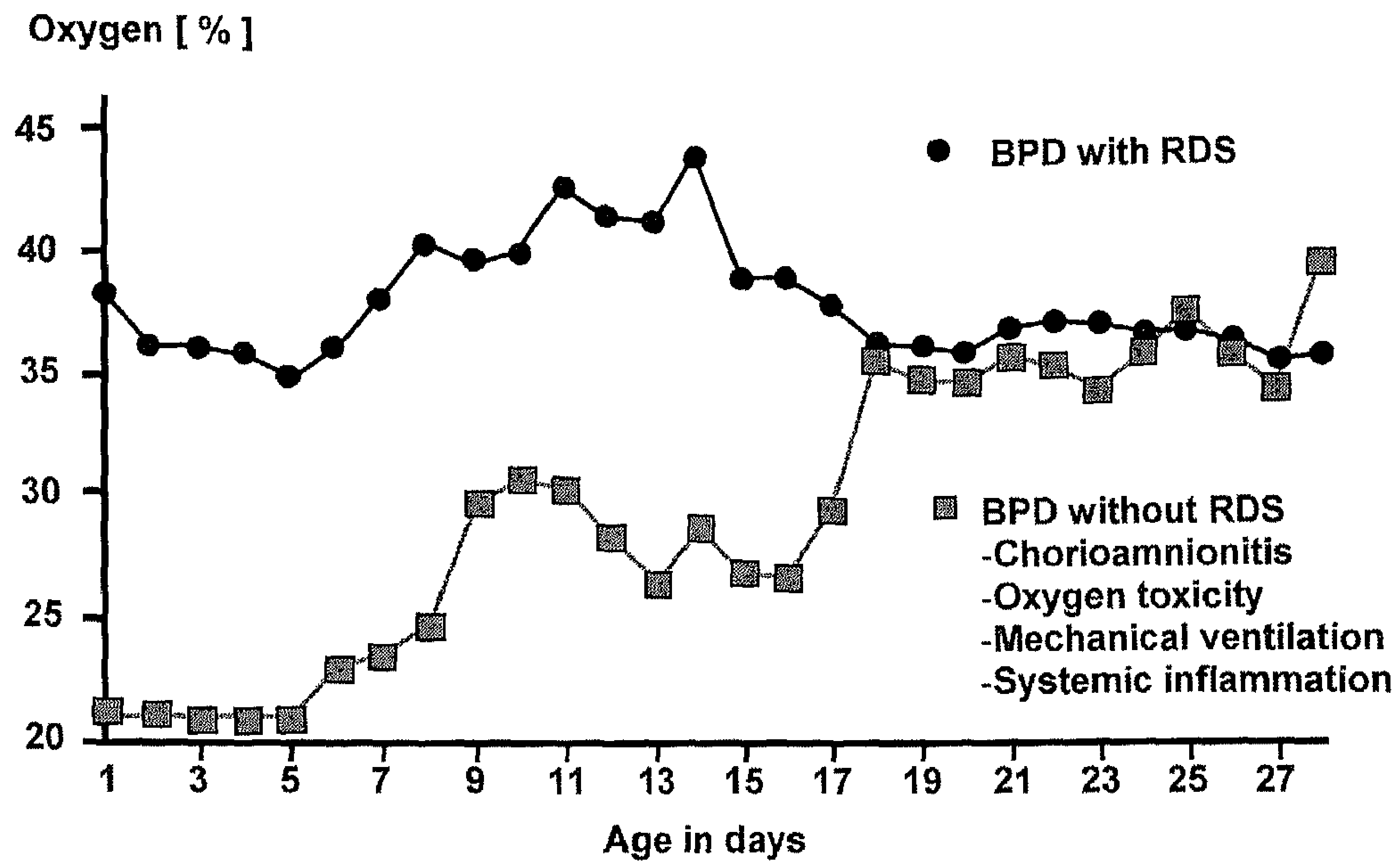

Figure 4: Oxygen needs of infants with BPD in the first three weeks of life. A subpopulation will develop BPD in the context of a very immature lung with RDS after birth and subsequent lung injury and inflammation. However, some babies develop BPD although they were born without RDS but chronic inflammation in the airways is sustained or jnitiated by postnatal events such as mechanical ventilation or systemic inflammation. Modified from Charafeddine et al., Pediatrics, 103: 759-765, 1999

Table 4: Incidence of RDS and BPD in preterm infants exposed to chorioamnionitis

\begin{tabular}{lll}
\hline & Chorioamnionitis & No Chorioamnionitis \\
\hline RDS & $33 \%$ & $67 \%$ \\
BPD & $63 \%$ & $37 \%$ \\
\hline
\end{tabular}

According to Watterberg et al., Pediatrics 97, pp. 210-215, 1996

lation style has moved to favour continous positive airway pressure (CPAP) which is a less invasive way to support ventilation. Experimental models showed that CPAP induced less injury and inflammation in the lung of preterm lambs than state-of-the-art mechanical ventilation (59). Surfactant replacement therapy is nowadays readily available and is given soon after birth to minimize lung injury (102). In vivo and in vitro studies have shown anti-inflammatory properties of surfactant proteins (SP)-B and $-C$ and phospholipids in commercial surfactant preparations $(30,54,109)$. SP-B, SP-C and phospholipids reduced the transcription of tumor necrosis factor alpha in monocytes $(6,101)$. In addition, surfactant preparations of SP-B and phospholipids enhanced the phagocytosis of apoptotic cells as part of the resolution of inflammation (66). Therefore, surfactant therapy not only has effects on the compliance of the lung and subsequent injury but also has anti-inflammatory properties to modulate the pulmonary inflammatory response.
Currently commensal bacteria such as Ureaplasma urealyticumin in the vagina are considered to be the source of the bacterial invasion of the amniotic cavity (38). However, other possible origins have been identified. Periodontal disease has been linked with the onset of preterm labour and preterm birth. The local infection in the gums with bacteria that produce potent endotoxins may result in a systemic exposure to endotoxins which may trigger preterm delivery (80). Intervention trials are currently underway to assess the option of prevention of preterm birth by periodontal treatment $(37,97)$.

\section{Systemic effects of chorioamnionitis}

Hemodynamic disturbances in premature infants have been reported after exposure to chorioamnionitis (117). In addition, the concentration of proinflammatory cytokines in the cord blood have been associated with poor neurodevelopmental outcome (60) but also with a reduction in the incidence of RDS (96). In a large retrospective study the association of systemic inflammation with intraventricular haemorrhage and white matter disease was detected which has been later confirmed by other studies $(24,25,78,79,121)$.

The susceptibility of brain tissue to perinatal injury is considered to be an increased susceptibility to hypoxic-ischemic injury after exposure to pro-in- 
flammatory cytokines $(33,45,47)$. This hypothesis is based on animal experiments in which a cerebral inflammation was induced with subsequent hypoxic injury $(32,34,46)$. Animals previously exposed to inflammation had more cerebral lesions than control animals $(44,73)$. Clinical studies confirmed this association (25). The individual contribution of these factors associated with poor perinatal outcome have not yet been delineated $(29,90)$.

\section{Summary}

Clinical and experimental data suggest that the antenatal exposure to inflammation is a double-edged sword for the fetus. On the one hand, the antenatal inflammation induces changes that improve the postnatal adaptation and increase survival. On the other hand, the later development of organs, namely the lung, are impaired. New therapeutic options should exploit the beneficial effects induced by antenatal inflammation and limit the damage.

\section{References}

1. Albertine $\mathrm{KH}$, Jones GP, Starcher BC, Bohnsack JF, Davis $\mathrm{PL}$, Cho SC, Carlton DP, and Bland RD. Chronic lung injury in preterm lambs. Disordered respiratory tract development. Am J Respir Crit Care Med 159: 945-958, 1999.

2. Andrews WW, Goldenberg RL, Faye-Petersen $O$, Cliver $S$, Goepfert AR, and Hauth JC. The Alabama Preterm Birth study: polymorphonuclear and mononuclear cell placental infiltrations, other markers of inflammation, and outcomes in 23- to 32-week preterm newborn infants. Am J Obstet Gynecol 195: 803-808, 2006.

3. Andrews WW, Goldenberg RL, Hauth JC, Cliver SP, Conner $M$, and Goepfert AR. Endometrial microbial colonization and plasma cell endometritis after spontaneous or indicated preterm versus term delivery. Am J Obstet Gynecol 193: 739-745, 2005.

4. Bakketeig LS and Hoffman HJ. The tendency to repeat gestational age and birth weight in successive births, related to perinatal survival. Acta Obstet Gynecol Scand 62: 385-392, 1983.

5. Bakketeig LS, Hoffman HJ, and Harley EE. The tendency to repeat gestational age and birth weight in successive births. Am J Obstet Gynecol 135: 1086-1103, 1979.
6. Baur FM, Brenner B, Goetze-Speer B, Neu S, and Speer CP. Natural porcine surfactant (Curosurf) down-regulates mRNA of tumor necrosis factor-alpha (TNF-alpha) and TNF-alpha type $\|$ receptor in lipopolysaccharidestimulated monocytes. Pediatr Res 44: 32-36, 1998.

7. Behrman RE and Butler AS. Preterm birth: Causes, consequences, and prevention. Washington D.C.: Institute of medicine of the academies, 2007.

8. Berger R and Garnier $Y$. Pathophysiology of perinatal brain damage. Brain Res Brain Res Rev 30: 107-134, 1999.

9. Berger R, Garnier $Y$, and Jensen A. Perinatal brain damage: underlying mechanisms and neuroprotective strategies. J Soc Gynecol Investig 9: 319-328, 2002.

10. Bhatt AJ, Pryhuber GS, Huyck $H$, Watkins RH, Metlay LA, and Maniscalco WM. Disrupted pulmonary vasculature and decreased vascular endothelial growth factor, FIt-1, and TIE-2 in human infants dying with bronchopulmonary dysplasia. Am J Respir Crit Care Med 164: 1971-1980, 2001.

11. Bibby $E$ and Stewart $A$. The epidemiology of preterm birth. Neuro Endocrinol Lett 25 Suppl 1: 43-47, 2004.

12. Blondel $B$ and Kaminski $M$. Trends in the occurrence, determinants, and consequences of multiple births. Semin Perinatol 26: 239-249, 2002.

13. Burri PH. Structural aspects of postnatal lung development - alveolar formation and growth. Biol Neonate 89: 313-322, 2006.

14. Carr-Hill RA and Hall MH. The repetition of spontaneous preterm labour. $\mathrm{Br} J$ Obstet Gynaecol 92: 921-928, 1985.

15. Cartlidge $\mathrm{PH}$, Jones HP, Stewart JH, Drayton MR, Ferguson DS, Matthes JW, Minchom PE, and Moorcraft J. Confidential enquiry into deaths due to prematurity. Acta Paediatr 88: 220-223, 1999.

16. Cartlidge $\mathrm{PH}$ and Stewart JH. Survival of very low birthweight and very preterm infants in a geographically defined population. Acta Paediatr 86: 105-110, 1997.

17. Charafeddine L, D'Angio CT, and Phelps DL. Atypical chronic lung disease patterns in neonates. Pediatrics 103: 759-765, 1999.

18. Coalson JJ. Pathology of new bronchopulmonary dysplasia. Semin Neonatol 8: 73-81, 2003.

19. Cogo PE, Zimmermann LJ, Pesavento R, Sacchetto E, Burighel $A$, Rosso F, Badon T, Verlato $G$, and Carnielli VP. Surfactant kinetics in preterm infants on mechanical ventilation who did and did not develop bronchopulmonary dysplasia. Crit Care Med 31: 15321538,2003 
20. Costeloe K, Hennessy E, Gibson AT, Marlow N, and Wilkinson AR. The EPICure study: outcomes to discharge from hospital for infants born at the threshold of viability. $\mathrm{Pe}$ diatrics 106: 659-671, 2000.

21. Craig ED, Mantell CD, Ekeroma AJ, Stewart AW, and Mitchell EA. Ethnicity and birth outcome: New Zealand trends 1980-2001. Part 1. Introduction, methods, results and overview. Aust N Z J Obstet Gynaecol 44: 530-536, 2004.

22. Craig ED, Thompson JM, and Mitchell EA. Socioeconomic status and preterm birth: New Zealand trends, 1980 to 1999. Arch Dis Child Fetal Neonatal Ed 86: F142-146, 2002.

23. D'Alquen D, Kramer BW, Seidenspinner S, Marx A, Berg D, Groneck $P$, and Speer CP. Activation of umbilical cord endothelial cells and fetal inflammatory response in preterm infants with chorioamnionitis and funisitis. Pediatr Res 57 : 263-269, 2005

24. Dammann $\mathrm{O}$, Kuban $\mathrm{KC}$, and Leviton $\mathrm{A}$. Perinatal infection, fetal inflammatory response, white matter damage, and cognitive limitations in children born preterm. Ment Retard Dev Disabil Res Rev 8: 46-50, 2002.

25. Dammann $O$ and Leviton A. Biomarker epidemiology of cerebral palsy. Ann Neurol 55: 158-161, 2004.

26. Dammann O, Phillips TM, Allred EN, O'Shea TM, Paneth $N$, Van Marter LJ, Bose C, Ehrenkranz RA, Bednarek FJ, Naples $M$, and Leviton $A$. Mediators of fetal inflammation in extremely low gestational age newborns. Cytokine 13: 234$239,2001$.

27. Defranco $E$, Teramo $K$, and Muglia L. Genetic influences on preterm birth. Semin Reprod Med 25: 40-51, 2007

28. Ehrenkranz RA, Walsh $M C$, Vohr $B R$, Jobe $A H$, Wright $L L$, Fanaroff AA, Wrage LA, and Poole K. Validation of the National Institutes of Health consensus definition of bronchopulmonary dysplasia. Pediatrics 116: 1353-1360, 2005.

29. Elimian A, Verma U, Beneck D, Cipriano R, Visintainer $P$, and Tejani N. Histologic chorioamnionitis, antenatal steroids, and perinatal outcomes. Obstet Gynecol 96: 333-336, 2000.

30. Epaud R, Ikegami M, Whitsett JA, Jobe $A H$, Weaver $T E$, and Akinbi HT. Surfactant protein B inhibits endotoxin-induced lung inflammation. Am J Respir Cell Mol Biol 28: 373-378, 2003.

31. Gardosi $J$ and Francis $A$. Early pregnancy predictors of preterm birth: the role of a prolonged menstruation-conception interval. Bjog 107: 228-237, 2000.
32. Garnier $Y$, Berger R, Alm S, von Duering MU, Coumans $A B$, Michetti $F$, Bruschettini $M$, Lituania $M$, Hasaart $T H$, and Gazzolo D. Systemic endotoxin administration results in increased $\$ 100 \mathrm{~B}$ protein blood levels and periventricular brain white matter injury in the preterm fetal sheep. Eur J Obstet Gynecol Reprod Biol 124: 1522, 2006.

33. Garnier $Y$, Coumans A, Berger $R$, Jensen $A$, and Hasaart TH. Endotoxemia severely affects circulation during normoxia and asphyxia in immature fetal sheep. J Soc Gynecol Investig 8: 134-142, 2001.

34. Garnier $Y$, Pfeiffer $D$, Jensen $A$, and Berger R. Effects of mild hypothermia on metabolic disturbances in fetal hippocampal slices after oxygen/glucose deprivation depend on depth and time delay of cooling. J Soc Gynecol Investig 8: 198-205, 2001.

35. Gerber $S$, Vial $Y$, Hohlfeld $P$, and Witkin SS. Detection of Ureaplasma urealyticum in second-trimester amniotic fluid by polymerase chain reaction correlates with subsequent preterm labor and delivery. $J$ Infect Dis 187: 518-521, 2003.

36. Gibbs RS and Eschenbach DA. Use of antibiotics to prevent preterm birth. Am J Obstet Gynecol 177: 375-380, 1997.

37. Goldenberg RL and Culhane JF. Preterm birth and periodontal disease. $N$ Engl J Med 355: 1925-1927, 2006.

38. Goldenberg RL, Hauth JC, and Andrews WW. Intrauterine infection and preterm delivery. $N$ Engl $J$ Med 342: 1500-1507, 2000.

39. Gomez R, Romero R, Ghezzi F, Yoon BH, Mazor M, and Berry SM. The fetal inflammatory response syndrome. Am J Obstet Gynecol 179: 194-202, 1998.

40. Gortner $L$ and Hilgendorff A. [Surfactant-associated proteins $B$ and $C$ : molecular biology and physiologic properties]. Z Geburtshilfe Neonatol 208: 91-97, 2004.

41. Groneck P, Gotze-Speer B, Oppermann M, Eiffert $H$ and Speer $\mathrm{CP}$. Association of pulmonary inflammation and increased microvascular permeability during the development of bronchopulmonary dysplasia: a sequential analysis of inflammatory mediators in respiratory fluids of high-risk preterm neonates. Pediatrics 93: 712-718, 1994.

42. Groneck P, Schmale J, Soditt V, Stutzer H, Gotze-Speer $B$, and Speer CP. Bronchoalveolar inflammation following airway infection in preterm infants with chronic lung disease. Pediatr Pulmonol 31: 331-338, 2001

43. Groneck $P$ and Speer CP. Inflammatory mediators and bronchopulmonary dysplasia. Arch Dis Child Fetal Neonatal Ed 73: F1-3, 1995 
44. Gustavsson $M$, Anderson MF, Mallard $C$, and Hagberg $H$. Hypoxic preconditioning confers long-term reduction of brain injury and improvement of neurological ability in immature rats. Pediatr Res 57: 305-309, 2005.

45. Hagberg H, Dammann O, Mallard C, and Leviton A. Preconditioning and the developing brain. Semin Perinatol 28: 389395, 2004.

46. Hagberg $\mathrm{H}$, Ichord $\mathrm{R}$, Palmer $\mathrm{C}$, Yager JY, and Vannucci SJ. Animal models of developmental brain injury: relevance to human disease. A summary of the panel discussion from the Third Hershey Conference on Developmental Cerebral Blood Flow and Metabolism. Dev Neurosci 24: 364-366, 2002.

47. Hagberg $\mathrm{H}$, Mallard $\mathrm{C}$, and Jacobsson $\mathrm{B}$. Role of cytokines in preterm labour and brain injury. Bjog 112 Suppl 1: 16-18, 2005.

48. Halliday HL. Evidence-based neonatal care. Best Pract Res Clin Obstet Gynaecol 19: 155-166, 2005.

49. Heaman $\mathrm{MI}$, Sprague $A E_{1}$ and Stewart PJ. Reducing the preterm birth rate: a population health strategy. $J$ Obstet Gynecol Neonatal Nurs 30: 20-29, 2001.

50. Henneke $P$ and Berner R. SIRS and group-B streptococcal sepsis in newborns: pathogenesis and perspectives in adjunctive therapy. Semin Fetal Neonatal Med 11: 333-342, 2006.

51. Hoffman HJ and Bakketeig LS. Risk factors associated with the occurrence of preterm birth. Clin Obstet Gynecol 27: 539-552, 1984.

52. Horbar JD, Badger GJ, Carpenter JH, Fanaroff AA, Kilpatrick S, LaCorte M, Phibbs R, and Soll RF. Trends in mortality and morbidity for very low birth weight infants, 1991-1999. Pediatrics 110: 143-151, 2002.

53. Husain AN, Siddiqui NH, and Stocker JT. Pathology of arrested acinar development in postsurfactant bronchopulmonary dysplasia. Hum Pathol 29: 710-717, 1998.

54. Ikegami M, Whitsett JA, Martis PC, and Weaver TE. Reversibility of lung inflammation caused by SP-B deficiency. Am J Physiol Lung Cell Mol Physiol 289: L962-970, 2005.

55. Ireys HT, Anderson GF, Shaffer TJ, and Neff JM. Expenditures for care of children with chronic illnesses enrolled in the Washington State Medicaid program, fiscal year 1993. Pediatrics 100: 197-204, 1997.

56. Jensen A, Garnier Y, Middelanis J, and Berger R. Perinatal brain damage-from pathophysiology to prevention. Eur $J$ Obstet Gynecol Reprod Biol 110 Suppl 1: S70-79, 2003.

57. Jobe AH. Pathophysiology of RDS. In: Fetal and Neonatal Physiology, edited by Polin and Fox. Philadelphia: Saunders, 1998, p. 1299-1314.
58. Jobe AH and Bancalari E. Bronchopulmonary dysplasia. Am J Respir Crit Care Med 163: 1723-1729, 2001.

59. Jobe AH, Kramer BW, Moss TJ, Newnham JP, and Ikegami M. Decreased indicators of lung injury with continuous positive expiratory pressure in preterm lambs. Pediatr Res 52: 387-392, 2002.

60. Kaukola T, Herva R, Perhomaa M, Paakko E, Kingsmore $S$, Vainionpaa $L$, and Hallman M. Population cohort associating chorioamnionitis, cord inflammatory cytokines and neurologic outcome in very preterm, extremely low birth weight infants. Pediatr Res 59: 478483, 2006

61. Kent A and Dahlstrom JE. Chorioamnionitis/funisitis and the development of bronchopulmonary dysplasia. $J$ Paediatr Child Health 40: 356-359, 2004.

62. Kimberlin DF and Andrews WW. Bacterial vaginosis: association with adverse pregnancy outcome. Semin Perinatol 22: 242-250, 1998.

63. Klein LL and Gibbs RS. Use of microbial cultures and antibiotics in the prevention of infection-associated preterm birth. Am J Obstet Gynecol 190: 1493-1502, 2004.

64. Kramer B and Speer CP. [Lung hypoplasia: an underestimated diagnosis?]. Z Geburtshilfe Neonatol 203: 143151, 1999.

65. Kramer BW and Jobe AH. The clever fetus: responding to inflammation to minimize lung injury. Biol Neonate 88 : 202-207, 2005.

66. Kramer BW, Jobe AH, and Ikegami M. Monocyte function in preterm, term, and adult sheep. Pediatr Res 54: 52-57, 2003.

67. Kramer BW, Kaemmerer U, Kapp M, Herbst D, Marx A, Berg D, Groneck PA, and Speer CP. Decreased expression of angiogenic factors in placentas with chorioamnionitis after preterm birth. Pediatr Res 58: 607-612, 2005

68. Kramer BW and Speer CP. [Surfactant proteins A and D: major factors of the immune response of the lung]. $Z$ Geburtshilfe Neonatol 207: 41-47, 2003.

69. Kubota T, Nojima M, and Itoh S. Vaginal bacterial flora of pregnant women colonized with group $B$ streptococcus. $J$ Infect Chemother 8: 326-330, 2002.

70. Lahra $M M$ and Jeffery $H E$. A fetal response to chorioamnionitis is associated with early survival after preterm birth. Am J Obstet Gynecol 190: 147-151, 2004. 
71. Lassus $P$, Turanlahti $M$, Heikkila $P$, Andersson LC, Nupponen I, Sarnesto A, and Andersson S. Pulmonary vascular endothelial growth factor and Flt-1 in fetuses, in acute and chronic lung disease, and in persistent pulmonary hypertension of the newborn. Am J Respir Crit Care Med 164: 1981-1987, 2001.

72. Leitich $H$, Bodner-Adler $B$, Brunbauer $M$, Kaider $A$, Egarter $C$, and Husslein $P$. Bacterial vaginosis as a risk factor for preterm delivery: a meta-analysis. Am J Obstet Gynecol 189: 139-147, 2003.

73. Lyng $\mathrm{K}$, Munkeby $\mathrm{BH}$, Scheie $\mathrm{D}$, Mallard $\mathrm{C}$, Hagberg $\mathrm{H}_{\text {, }}$ Stray-Pedersen B, Saugstad OD, and Froen JF. Fetal brain injury in experimental intrauterine asphyxia and inflammation in Gottingen minipigs. J Perinat Med 34: 226-234, 2006.

74. Macnaughton M. Perinatal mortality in Scotland. Mabel Liddiard Memorial Lecture. Midwives Chron 105: 46-50, 1992.

75. McCowan $L$ and Stewart AW. Term birthweight centiles for babies from New Zealand's main ethnic groups. Aust NZ J Obstet Gynaecol 44: 432-435, 2004.

76. McDonald $\mathrm{H}$, Brocklehurst $\mathrm{P}$, and Parsons $\mathrm{J}$. Antibiotics for treating bacterial vaginosis in pregnancy. Cochrane Database Syst Rev: CD000262, 2005.

77. Moss TJ. Respiratory consequences of preterm birth. Clin Exp Pharmacol Physiol 33: 280-284, 2006.

78. Nelson KB, Dambrosia JM, Grether JK, and Phillips TM. Neonatal cytokines and coagulation factors in children with cerebral palsy. Ann Neurol 44: 665-675, 1998.

79. Nelson KB, Grether JK, Dambrosia JM, Walsh E, Kohler S, Satyanarayana G, Nelson PG, Dickens BF, and Phillips TM. Neonatal cytokines and cerebral palsy in very preterm infants. Pediatr Res 53: 600-607, 2003.

80. Newnham JP, Shub A, Jobe AH, Bird PS, Ikegami M, Nitsos I, and Moss TJ. The effects of intra-amniotic injection of periodontopathic lipopolysaccharides in sheep. Am J Obstet Gynecol 193: 313-321, 2005.

81. Newton ER. Preterm labor, preterm premature rupture of membranes, and chorioamnionitis. Clin Perinatol 32: 571. $600,2005$.

82. Newton ER and Clark M. Group B streptococcus and preterm rupture of membranes. Obstet Gynecol 71: 198202, 1988.

83. Olsen $P$, Laara E, Rantakallio P, Jarvelin MR, Sarpola A, and Hartikainen AL. Epidemiology of preterm delivery in two birth cohorts with an interval of 20 years. Am J Epidemiol 142: 1184-1193, 1995.
84. Perni SC, Vardhana S, Korneeva I, Tuttle SL, Paraskevas LR, Chasen ST, Kalish RB, and Witkin SS. Mycoplasma hominis and Ureaplasma urealyticum in midtrimester amniotic fluid: association with amniotic fluid cytokine levels and pregnancy outcome. Am $J$ Obstet Gynecol 191: 1382-1386, 2004.

85. Petrou $S$. The economic consequences of preterm birth during the first 10 years of life. Bjog 112 Suppl 1: 10-15, 2005.

86. Petrou S, Henderson J, Bracewell M, Hockley C, Wolke $D$, and Marlow N. Pushing the boundaries of viability: the economic impact of extreme preterm birth. Early Hum Dev 82: 77-84, 2006.

87. Petrou S, Sach T, and Davidson L. The long-term costs of preterm birth and low birth weight: results of a systematic review. Child Care Health Dev 27: 97-115, 2001.

88. Pringle $\mathrm{KC}$. Human fetal lung development and related animal models. Clin Obstet Gynecol 29: 502-513, 1986.

89. Rastogi $S$, Das B, Salhan S, and Mittal A. Effect of treatment for Chlamydia trachomatis during pregnancy. Int $J$ Gynaecol Obstet 80: 129-137, 2003.

90. Richardson BS, Wakim E, daSilva O, and Walton J. Preterm histologic chorioamnionitis: impact on cord gas and $\mathrm{pH}$ values and neonatal outcome. Am $J$ Obstet Gynecol 195: 1357-1365, 2006.

91. Romero $R$, Chaiworapongsa $T$, Kuivaniemi $H$, and Tromp G. Bacterial vaginosis, the inflammatory response and the risk of preterm birth: a role for genetic epidemiology in the prevention of preterm birth. Am J Obstet Gynecol 190: 1509-1519, 2004.

92. Romero R, Espinoza J, Chaiworapongsa $T$, and Kalache K. Infection and prematurity and the role of preventive strategies. Semin Neonatol 7: 259-274, 2002.

93. Schmidt B, Asztalos EV, Roberts RS, Robertson CM, Sauve RS, and Whitfield MF. Impact of bronchopulmonary dysplasia, brain injury, and severe retinopathy on the outcome of extremely low-birthweight infants at 18 months: results from the trial of indomethacin prophylaxis in preterms. Jama 289: 11241129,2003

94. Schmidt $B$, Cao $L$, Mackensen-Haen $S$, Kendziorra $H$, Klingel $K$, and Speer CP. Chorioamnionitis and inflammation of the fetal lung. Am J Obstet Gynecol 185: 173$177,2001$.

95. Shimoya K, Matsuzaki N, Taniguchi T, Jo T, Saji F, Kitajima $H$, Fujimura $M$, Nakayama $M$, and Tanizawa $O$. Interleukin-8 in cord sera: a sensitive and specific marker for the detection of preterm chorioamnionitis. $J$ Infect Dis 165: 957-960, 1992. 
96. Shimoya $K$, Taniguchi $T$, Matsuzaki N, Moriyama A, Murata $Y$, Kitajima $H$, Fujimura $M$, and Nakayama $M$. Chorioamnionitis decreased incidence of respiratory distress syndrome by elevating fetal interleukin- 6 serum concentration. Hum Reprod 15: 2234-2240, 2000.

97. Shub A, Swain JR, and Newnham JP. Periodontal disease and adverse pregnancy outcomes. J Matern Fetal Neonatal Med 19: 521-528, 2006.

98. Smaill F. Antibiotics for asymptomatic bacteriuria in pregnancy. Cochrane Database Syst Rev: CD000490, 2001.

99. Smith VC, Zupancic JA, McCormick MC, Croen LA, Greene $J$, Escobar GJ, and Richardson DK. Rehospitalization in the first year of life among infants with bronchopulmonary dysplasia. J Pediatr 144: 799-803, 2004.

100. Speer $C P$. Inflammation and bronchopulmonary dysplasia: A continuing story. Semin Fetal Neonatal Med 11: 354-362, 2006.

101. Speer CP, Gotze B, Curstedt T, and Robertson B. Phagocytic functions and tumor necrosis factor secretion of human monocytes exposed to natural porcine surfactant (Curosurf). Pediatr Res 30: 69-74, 1991.

102. Speer $C P$, Harms K, Herting E, Neumann N, Curstedt T, and Robertson B. Early versus late surfactant replacement therapy in severe respiratory distress syndrome. Lung 168 Suppl: 870-876, 1990.

103. Speer CP, Ruess D, Harms $K$, Herting $E$, and Gefeller $O$. Neutrophil elastase and acute pulmonary damage in neonates with severe respiratory distress syndrome. Pediatrics 91: 794-799, 1993.

104. Steel JH, Malatos S, Kennea N, Edwards $A D$, Miles $L$, Duggan $P$, Reynolds $P R$, Feldman RG, and Sullivan $M H$. Bacteria and inflammatory cells in fetal membranes do not always cause preterm labor. Pediatr Res 57: 404-411, 2005.

105. Stewart CJ, Tregoning SK, Moller G, and Wainwright $H$. Preterm prelabour rupture of the membranes before 28 weeks: better than feared outcome of expectant management in Africa. Eur J Obstet Gynecol Reprod Biol 126: 186 192, 2006.

106. Stoll BJ, Hansen N, Fanaroff AA, Wright LL, Carlo WA, Ehrenkranz RA, Lemons JA, Donovan EF, Stark AR, Tyson JE, Oh W, Bauer CR, Korones SB, Shankaran S, Laptook $A R$, Stevenson DK, Papile LA, and Poole WK. Changes in pathogens causing early-onset sepsis in very-low-birthweight infants. N Engl J Med 347: 240-247, 2002.

107. Tough SC, Newburn-Cook C, Johnston DW, Svenson LW, Rose $S$, and Belik J. Delayed childbearing and its impact on population rate changes in lower birth weight, multiple birth, and preterm delivery. Pediatrics 109: 399-403, 2002.
108. Tough SC, Svenson LW, Johnston DW, and Schopflocher $D$. Characteristics of preterm delivery and low birthweight among 113,994 infants in Alberta: 19941996. Can J Public Health 92: 276-280, 2001.

109. van Iwaarden JF, Claassen E, Jeurissen SH, Haagsman $H P$, and Kraal G. Alveolar macrophages, surfactant lipids, and surfactant protein $B$ regulate the induction of immune responses via the airways. Am J Respir Cell Mol Biol 24: 452-458, 2001.

110. Van Marter LJ, Allred EN, Pagano M, Sanocka U, Parad $R$, Moore $M$, Susser $M$, Paneth $N$, and Leviton A. Do clinical markers of barotrauma and oxygen toxicity explain interhospital variation in rates of chronic lung disease? The Neonatology Committee for the Developmental Network. Pediatrics 105: 1194-1201, 2000.

111. Van Marter LJ, Dammann O, Allred EN, Leviton A, Pagano $M$, Moore $M$, and Martin C. Chorioamnionitis, mechanical ventilation, and postnatal sepsis as modulators of chronic lung disease in preterm infants. $J$ Pediatr 140: 171-176, 2002.

112. Viscardi RM, Muhumuza $C K$, Rodriguez $A$, Fairchild KD, Sun $C C$, Gross GW, Campbell AB, Wilson PD, Hester $L$, and Hasday JD. Inflammatory markers in intrauterine and fetal blood and cerebrospinal fluid compartments are associated with adverse pulmonary and neurologic outcomes in preterm infants. Pediatr Res 55: 10091017, 2004.

113. Vollmer B, Roth S, Baudin J, Stewart AL, Neville BG, and Wyatt JS. Predictors of long-term outcome in very preterm infants: gestational age versus neonatal cranial ultrasound. Pediatrics 112: 1108-1114, 2003.

114. Watterberg KL, Demers LM, Scott SM, and Murphy S. Chorioamnionitis and early lung inflammation in infants in whom bronchopulmonary dysplasia develops. Pediatrics 97: 210-215, 1996.

115. Watterberg KL, Gerdes JS, Cole CH, Aucatt SW, Thilo EH, Mammel MC, Couser RJ, Garland JS, Rozycki HJ, Leach CL, Backstrom C, and Shaffer ML. Prophylaxis of early adrenal insufficiency to prevent bronchopulmonary dysplasia: a multicenter trial. Pediatrics 114: 1649-1657, 2004.

116. West MA and Heagy W. Endotoxin tolerance: a review. Crit Care Med 30: S64-73, 2002.

117. Yanowitz TD, Jordan JA, Gilmour $\mathrm{CH}$, Towbin R, Bowen $A$, Roberts JM, and Brozanski BS. Hemodynamic disturbances in premature infants born after chorioamnionitis: association with cord blood cytokine concentrations. Pediatr Res 51: 310-316, 2002. 
118. Yoon BH, Romero R, Jun JK, Park KH, Park JD, Ghezzi F, and Kim BI. Amniotic fluid cytokines (interleukin-6, tumor necrosis factor-alpha, interleukin-1 beta, and interleukin-8) and the risk for the development of bronchopulmonary dysplasia. Am J Obstet Gynecol 177: 825-830, 1997.

119. Yoon BH, Romero R, Kim KS, Park JS, Ki SH, Kim BI, and Jun JK. A systemic fetal inflammatory response and the development of bronchopulmonary dysplasia. Am J Obstet Gynecol 181: 773-779, 1999.

120. Yoon BH, Romero R, Kim M, Kim EC, Kim T, Park JS, and Jun JK. Clinical implications of detection of Ureaplasma urealyticum in the amniotic cavity with the polymerase chain reaction. Am J Obstet Gynecol 183: 1130-1137, 2000.

121. Yoon BH, Romero R, Park JS, Kim CJ, Kim SH, Choi JH, and Han TR. Fetal exposure to an intra-amniotic inflammation and the development of cerebral palsy at the age of three years. Am J Obstet Gynecol 182: 675-681, 2000.

122. Zimmermann LJ, Janssen DJ, Tibboel D, Hamvas $A$, and Carnielli VP. Surfactant metabolism in the neonate. Biol Neonate 87: 296-307, 2005. 


\section{CHAPTER 2}

Aim of the Thesis and Animal Model of Chorioamnionitis 
Although the effects of antenatal infection on prematurity have been explored in many animal experiments, the primary outcomes of interest have usually been the pathogenesis of premature labor and adverse effects on the fetal brain (6). The first report of an antenatal inflammatory effect other than pneumonia on the fetal lung was the observation that intraamniotic injection of the pro-inflammatory cytokine $\mathrm{IL}-1 \alpha$ to pregnant rabbits improved lung compliance after preterm delivery (4). The mRNA for the surfactant proteins SP-A and SP-B in the fetal lungs and surfactant lipids also increased as indicators of induced lung maturation. This initial experiment, together with clinical observations linking chorioamnionitis to fetal lung development (1), prompted to explore how inflammation can alter lung development.

\section{Lung development in human and sheep}

The embryonic development of the lung is a well defined sequence of proliferation and differentiation which have been histologically characterized (figure 1) (13). The tracheal bud which forms during the fourth week soon divides into the primary bronchial buds (embryonal phase) (5). Together with the surrounding mesenchyme, the bronchial buds differentiate into the main bronchi and lungs. The main bronchi subdivide into secondary bronchi that form lobar, segmental, and intrasegmental bronchi. By 18 weeks in the human fetus, about 17 orders of airway branches have formed. The developing lung resembles histologically an exocrine gland during the pseudoglandular phase from 6 to 16 weeks. By 16 weeks all major elements of the lung have formed except those involved in gas exchange. Respiration is therefore not possible. The canalicular phase overlaps in the upper parts of the lung with the pseudoglandular phase since cranial segments of the lung develop faster than caudal ones. Respiration is possible at the end of the canalicular phase since thin-walled terminal saccules have developed at the ends of the respiratory bronchioles. The whole lung is well vascularized, making gas exchange via diffusion possible. Although a fetus born at the end of this phase may survive, the incidence of severe respiratory distress syndrome is extremely high and makes sophisticated neonatal intensive care mandatory. During the saccular phase from 26 weeks of gestation till close to term more terminal saccules develop with an increase in the gas exchange surface. Alveoli are not formed until 32 weeks of gestation. Capillaries begin to bulge around these new alveoli and some 4 million orders of airway branches have developed. The intimate contact between epithelial and endothelial cells establishes the blood-air barrier, which permits adequate gas exchange for survival. The alveolar phase starts at approximately 32 weeks and lasts probably until 2 years of age. About $20 \%$ of the alveoli form prenatally. The major mechanism for increasing the number of alveoli is the formation of secondary connective tissue septa that subdivide existing alveoli $(2,3)$. Initially the septa are relatively thick and marked by a concentrated deposition of elastin fibers, but they are soon transformed into mature thin septa that are capable of gas exchange. The exponential growth of alveoli postnatally is opening a window of opportunity for catch-up growth in infants with BPD.

The timing of lung development during gestation and after birth varies from species to species. Rodents for example do not form alveoli until postnatally (13). Among all species sheep and monkeys are closest to the human situation. Much of the pioneering research in neonatal medicine has been done in sheep (figure 2).

\section{Intra-Amniotic Endotoxin as a Model of Chorioamnionitis}

Endotoxin (lipopolysaccharide from gram negative organisms) is used widely as a potent pro-inflammatory agonist to study shock and inflammatory responses. Endotoxin initiates inflammation in many cell types by signaling through toll-like receptor 4 (TLR4) to activate nuclear factor (NF)kappa $B$ and to iniate the inflammatory cascade. Empirically, endotoxin can induce chorioamnionitis and inflammatory responses in human pregnancies and preterm infants and TLR4 is expressed in the human chorioamnion (8). Using ultrasound guidance, intra-amniotic injections of $E$. coli endotoxin in sheep induce chorioamnionitis indicated by increased inflammatory cells in amniotic fluid, histologic inflammation of the chorioamnion, and increased IL-1 $\beta, I L-6$ and IL-8 mRNA in cells from amniotic fluid (7).

All animals were of the same gestational age at delivery and evaluation which allows the comparison of control animals and animals that were exposed to chorioamnionitis. As an example the study design of the first three papers in Chapter 3 , 4 and 5 is shown in figure 4 . 


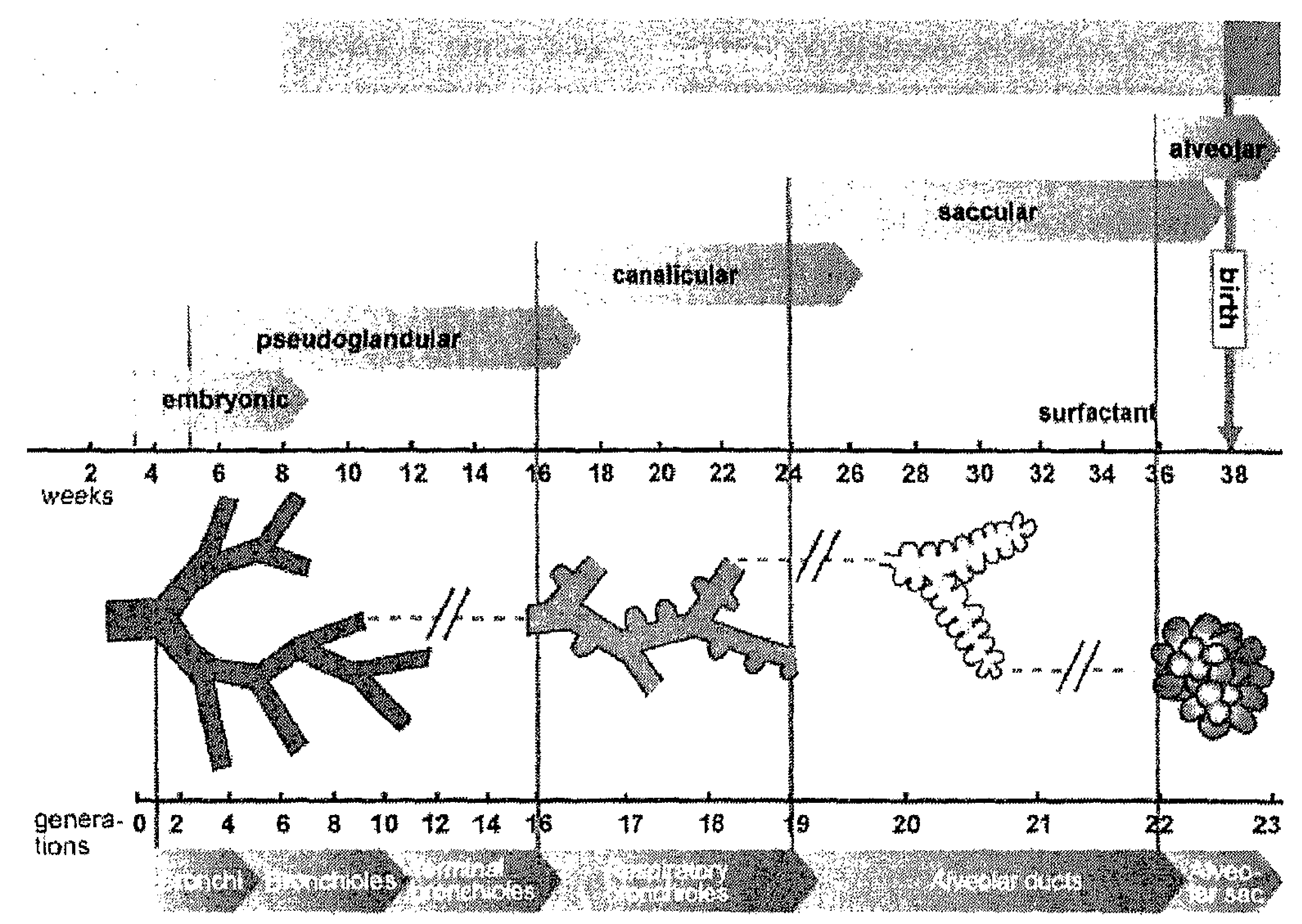

Figure 1: Schematic development of the lung in human. The different phases are depicted over gestational age in the upper part of the figure. Lung structures are depicted on the lower part with the number of airway generations listed beneath and the predominantly formed structures during the individual phase of lung development (modified from www.embryology.ch and 5).
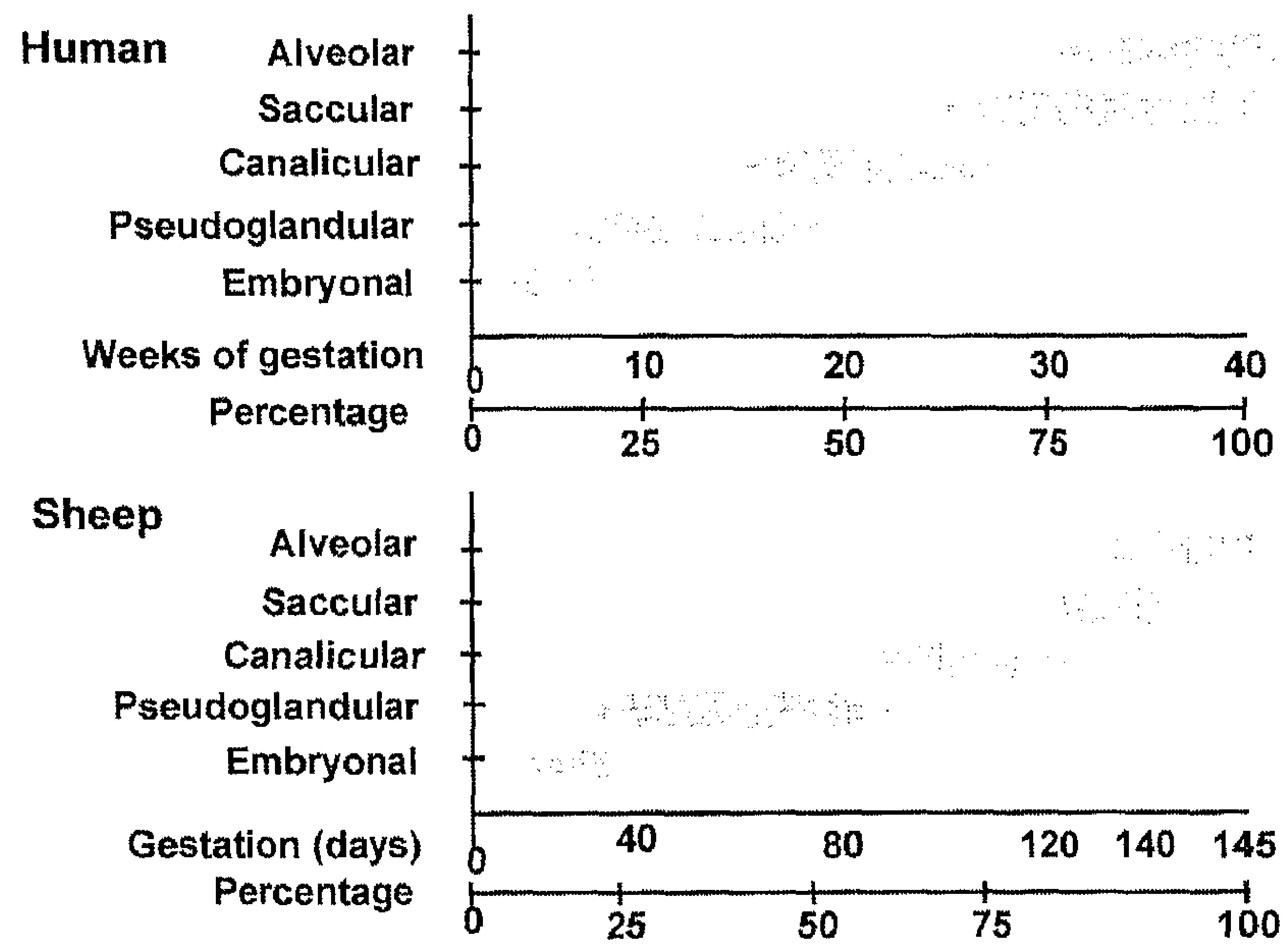

Figure 2: Schematic development of the lung in human and sheep. The correlation of individual histologic lung development phases to gestation are very similar in human and sheep. Modified according to (13). 


\section{IA Endotoxin Dose of $\mathbf{4} \mathbf{~ m g}$}

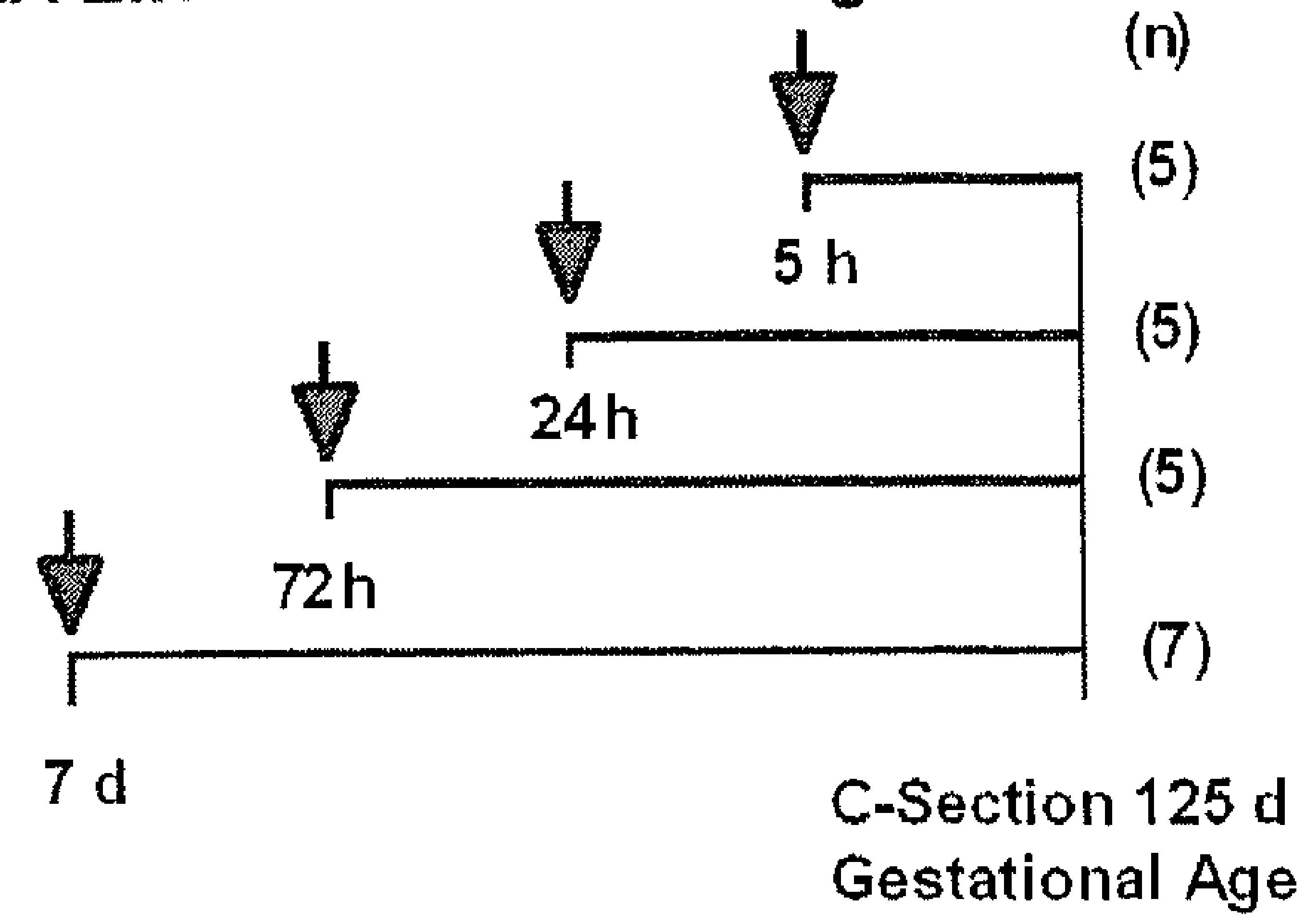

Figure 3: Study design $(9,10,11)$. All fetuses were analyzed after operative delivery (c-section) at the same gestational age of 125 days. Term gestation in the sheep is 150 days. Endotoxin-induced chorioamnionitis was induced by intra-amniotic (IA) injection at $5 \mathrm{~h}, 24 \mathrm{~h}, 72 \mathrm{~h}$ and 7 days before delivery.

\section{Aim and outline of the thesis}

The aim of this thesis was to explore chorioamnionitis in an animal model suitable for the study of lung development with respect to human development. In chapter 3 the minimal dose of endotoxin inducing lung maturation was determined. In addition, the time course of events induced in the chorioamnion and in the fetal lung and airways was studied. The results of chapter 3 suggested that chorioamnionitis caused by intra-amniotic injection of endotoxin induced a cascade of lung injury, pulmonary inflammation and remodelling in the fetal lung, similar to lung injury previously described in adult animal models. This hypothesis was tested and confirmed in chapter 4 . The structural changes in the fetal lung after chorioamnionitis show little to no fibrosis. Cytokine networks and regulators were identified in chapter $\mathbf{5}$ that may explain the absence of fibrosis after intra-uterine inflammation induced alveolar simplification similar to BPD.

The role of fetal immune regulation in the chronicity or resolution of pulmonary inflammation was investigated in chapter 7. Postnatal immune modulation by addition of surfactant protein (SP)-A to standard surfactant preparations was tested in ventilated preterm lambs (chapter 6). In chapter 8 we tested the hypothesis that the ventilated preterm lung may be both the source and the target of systemic inflammation. The immaturity of the preterm lung allowed translocation of endotoxin from the lung into the systemic circulation during ventilation. The function of the monocytes in the developing lung were assessed since they initiate and terminate the inflammatory reaction. In chapter 9 we hypothesized that both pro- and anti-inflammatory functions of monocytes from preterm lambs are impaired. The immaturity of blood-derived monocytes was tested at two different gestational ages. Tests of how the function of monocytes were modulated were explored in chapter 10 where blood derived monocytes after previous maternal corticosteroid therapy were compared to untreated monocytes of the same gestational age. The effects of repetitive endotoxin injections into the amniotic fluid were tested in chapter 11 which resulted in a phenotype of endotoxin tolerance.

The thesis comprises a line of research in an animal model of chorioamnionitis to understand the sites of injury, the time course of cellular responses and the effects on organ and cellular function after intra-uterine exposure to inflammation with respect to the fetal lung and systemic monocytes. The mechanisms of antenatal inflammation in the fetal lung were analysed to identify mediators of inflammation-associated adverse lung development and immune function which may result in potential new targets for therapy.

\section{References}

1. Watterberg $\mathrm{KL}$, Demers $\mathrm{LM}$, Scott $S M$, and Murphy $\mathrm{S}$. Chorioamnionitis and early lung inflammation in infants in whom bronchopulmonary dysplasia develops. Pediatrics 97: 210-215, 1996.

2. Bland RD. Neonatal chronic lung disease in the postsurfactant era. Biol Neonate 88: 181-191, 2005.

3. Bland RD, Albertine KH, Plerce RA, Starcher BC, and Cariton DP. Impaired alveolar development and abnormal lung elastin in preterm lambs with chronic lung injury: potential benefits of retinol treatment. Biol Neonate 84: 101-102, 2003.

4. Bry $K$, Lappalainen $U$, and Hallman $M$. Intraamniotic interleukin-1 accelerates surfactant protein synthesis in fetal rabbits and improves lung stability after premature birth. J Clin Invest 99: 2992-2999, 1997. 
5. Burri PH. Structural aspects of postnatal lung development-alveolar formation and growth. Biol Neonate 89: 313-322, 2006.

6. Hagberg $\mathrm{H}$, lchord R, Paimer $\mathrm{C}$, Yager JY, and Vannucci SJ. Animal models of developmental brain injury: relevance to human disease. A summary of the panel discussion from the Third Hershey Conference on Developmental Cerebral Blood Flow and Metabolism. Dev Neurosci 24: 364-366, 2002.

7. Jobe $A H$, Newnham JP, Willet KE, Moss TJ, Gore Ervin $M$, Padbury JF, Sly $P$, and Ikegami M. Endotoxin-induced lung maturation in preterm lambs is not mediated by cortisol. $A m$ J Respir Crit Care Med 162: 1656-1661, 2000.

8. Kim YM, Romero R, Chaiworapongsa T, Kim GJ, Kim MR, Kuivaniemi $H$, Tromp $G$, Espinaza J, Bujold $E$, Abrahams $V M$, and Mor $G$. Toll-like receptor-2 and -4 in the chorioamniotic membranes in spontaneous labor at term and in preterm parturition that are associated with chorioamnionitis. Am J Obstet Gynecol 191: 1346-1355, 2004.
9. Kramer BW, Kramer S, Ikegami M, and Jobe AH. Injury, inflammation, and remodeling in fetal sheep lung after intra-amniotic endotoxin. Am J Physiol Lung Cell Mol Physiol 283: L452-459, 2002.

10. Kramer BW, Moss TJ, Willet KE, Newnham JP, Sly PD, Kallapur SG, Ikegami M, and Jobe AH. Dose and time response after intraamniotic endotoxin in preterm lambs. Am J Respir Crit Care Med 164: 982-988, 2001.

11. Kunzmann $S$, Speer $C$, Jobe $A H$, and Kramer BW. Antenatal inflammation induced TGF-\{beta\}1 but suppressed CTGF in preterm lungs. Am J Physiol Lung Cell Mol Physiol 292: L223-231, 2007.

12. Perl AK and Whitsett JA. Molecular mechanisms controlling lung morphogenesis. Clin Genet 56: 14-27, 1999.

13. Pringle $\mathrm{KC}$. Human fetal lung development and related animal models. Clin Obstet Gyneca/ 29: 502-513, 1986. 


\section{CHAPTER 3}

\section{Dose and time response after intraamniotic endotoxin in preterm lambs}

Kramer, B.W., Moss, T.J., Willet, K.E., Newnham, J.P., Sly, P.D., Kallapur, S.G., Ikegami, M., Jobe, A.H. 


\title{
: and Time Response after Intraamniotic Endotoxin eterm Lambs
}

\author{
KRAMER, TIMOTHY J. MOSS, KAREN E. WILLET, JOHN P. NEWNHAM, PETER D. SLY, \\ . KALLAPUR, MACHIKO IKEGAMI, and ALAN H. JOBE
}

Pulmonary Biology, Children's Hospital Medical Center, Cincinnati, Ohio; and Department of Obstetrics and Gynecology and Division iciences, Center for Child Health Research at the University of Western Australia, Perth, Australia

\begin{abstract}
tic endotoxin causes chorioamnionitis, which is folmproved fetal lung function after $4 \mathrm{~d}$ in fetal sheep. We $0.1 \mathrm{mg}, 1 \mathrm{mg}, 4 \mathrm{mg}$, and $10 \mathrm{mg}$ endotoxin for inflammang maturation effects after $7 \mathrm{~d}$. Four and $10 \mathrm{mg}$ endotoxin ilar lung maturation and inflammation in the lung and Ion. The number of neutrophils in cord blood and the ory cells in alveolar lavage and fetal lung tissue ina dose-dependent manner. Lower endotoxin doses incators of chorioamnionitis, lung and systemic inflammaut inducing lung maturation. Therefore, some degree of ion can occur without subsequent lung maturation. The ory changes caused by $\mathbf{4} \mathrm{mg}$ endotoxin were assessed af$h, 72 \mathrm{~h}$, and $7 \mathrm{~d}$ to discern local versus systemic inflamer intraamniotic endotoxin. At $5 \mathrm{~h}$ active inflammatory in the airways producing hydrogen peroxide, and interId -8 were increased in the cord blood indicating both systemic responses. Cells recruited into the amniotic uced proinflammatory cytokine mRNA for $7 \mathrm{~d}$ with no JRNA in chorioamnion, lung, or spleen after $72 \mathrm{~h}$. The : amniotic fluid may be a source of prolonged fetal exposinflammatory cytokines.
\end{abstract}

respiratory distress syndrome; bronchopulmonary dysplashil recruitment; surfactant; cytokines

exposure to inflammation/infection has been associnumerous adverse outcomes that include preterm delivery, increased risks of bronchopulmonary dys?D), cerebral palsy, and neonatal sepsis (1-3). Howslogical chorioamnionitis and fetal colonization with s such as Ureaplasma urealyticum also have been asvith a decreased incidence of respiratory distress synDS) $(4,5)$, and in one epidemiological study chorio$s$ predicted increased survival of infants born at $3<26 \mathrm{wk}(6)$. There is very little information about atus responds to intraamniotic infection/inflammation. ve used intraamniotic injections of endotoxin to charhe chorioamniotic and fetal lung responses to an inry stimulus (7-10). Using a dose of $20 \mathrm{mg}$ endotoxin,

\footnotetext{
original form March 13, 2001)

Jas supported by NIH Grant HL-65397, the Women and Infants Redation funding of infrastructural support, and a scholarship from the irschungsgemeinschaft to B. W. K. Commonwealth Scientific and Insarch Organisation, Parkville, Australia, provided recombinant ovine ; and -8. Dr. S. L. Jones, CSL, Park Ville, Australia, kindly provided rejovine interferon gamma. The probe for SP-D was a kind gift of Dr. University of Oulu, Finland.

ence and requests for reprints should be addressed to Alan $\mathrm{H}$. Jobe, - Children's Hospital Medical Center, Division of Pulmonary Biology, [ Avenue, Cincinnati, $\mathrm{OH}$ 45229-3039. E-mail: jobea0@chmcc.org vas an onlline data supplement, which is accessible from this issue's tents online at www.atsjournals.org

Crit Care Med Vol 164. pp 982-988, 2001

dress: www.atsjournals.org
}

we found that inflammatory cells were recruited to the chorioamnion and the chorioamnion produced interleukin (IL)-1 $\beta$, IL-6, and IL-8 mRNA within $5 \mathrm{~h}$ (10). The expression of the mRNAs for the proinflammatory cytokines returned to control values within $2 \mathrm{~d}$ but inflammatory cells were increased in the chorioamnion for $25 \mathrm{~d}$ after the endotoxin exposure (10). The lung tissue expressed the same cytokine mRNAs within $5 \mathrm{~h}$ of the intraamniotic endotoxin injection but expression was higher at later time points and inflammatory cells also persisted in the lungs (10). The mRNAs for the surfactant proteins increased within $24 \mathrm{~h}$ of endotoxin exposure and remained increased for $15 \mathrm{~d}$, although lung mechanics did not improve until 4 to $7 \mathrm{~d}$ after the endotoxin exposure (9). We found a minimal systemic response to the intraamniotic endotoxin. The cord blood granulocytes initially decreased and then increased moderately (10), fetal cortisol levels did not increase (11), and there was no increased cytokine expression in liver, gut, or placental tissue (10). In this study we asked whether systemic or local inflammatory changes are required for subsequent lung maturation by evaluating various endotoxin doses ranging from $0.1 \mathrm{mg}$ to $10 \mathrm{mg}$, and by evaluating both the systemic and local inflammatory changes at different times after intraamniotic endotoxin injection.

\section{METHODS}

\section{Animals, Endotoxin, Delivery, and Postnatal Assessment}

The animal component of the studies was performed in Western Australia, as approved by the animal care and use committees from Children's Hospital Medical Center, Cincinnati, $\mathrm{OH}$, the Ethics Commiltee of the Western Australian Department of Agriculture, and the University of Western Australia. Date bred Merino ewes with a singleton fetus were randomized for the two protocols (Table 1). To evaluate the response to endotoxin dose, animals were randomized to saline, 0.1, 1, 4, or $10 \mathrm{mg}$ Escherichia coli 055:B5 endotoxin (Sigma, St. Louis, MO), given $7 \mathrm{~d}$ before preterm delivery at $125 \mathrm{~d}$ gestation. To evaluate the inflammatory responses by time interval from endotoxin exposure other animals were randomized to receive $4 \mathrm{mg}$ endotoxin at $5 \mathrm{~h}, 24 \mathrm{~h}$, or $72 \mathrm{~h}$ before delivery. The endotoxin was solubilized in saline and filtered. The intraamniotic injection was given into the amniotic cavity with ultrasound guidance $(8,11)$. Preterm lambs were delivered at $125 \mathrm{~d}$ gestational age by cesarean section (12). For evaluating lung function $7 \mathrm{~d}$ after endotoxin exposure, the preterm lambs were ventilated for $40 \mathrm{~min}$ with time-cycled, pressure-limited infant ventilators (11). Peak inspiratory pressures were limited to $40 \mathrm{~cm} \mathrm{H}_{2} \mathrm{O}$. A pressure transducer (model 8507C-2; Endevco, San Juan Capistrano, CA) and pneumotachograph (model 35-597; Hans Rudolph, Kansas City, MO) were placed between the tracheostomy tube and the ventilator to measure tracheal pressure and flow, respectively. Volume was obtained by integrating flow (12).

Measurements on Lungs, Spleen, Plasma, and Cells from Amniotic Fluid and Alveolar Lavage Fluid

Lungs were removed and processed as described (13). The deflation limb of the pressure-volume curve was measured. Saturated phosphatidylcholine (Sat PC) $(14,15)$, total protein $(13,16)$, and surfactant proteins (Western blot) were measured (9). The mRNA for the surfactant proteins and for selected cytokines were quantified using sheep- 
TABLE 1. ENDOTOXIN DOSE AND TIME INTERVAL

\begin{tabular}{lccc} 
Dose & $\begin{array}{c}\text { Number of } \\
\text { Animals }\end{array}$ & $\begin{array}{c}\text { Birth Weight } \\
(\mathrm{kg})\end{array}$ & Cord Blood pH \\
\cline { 1 - 2 } $\begin{array}{l}\text { Endotoxin dose given } 7 \text { d before delivery } \\
\quad \text { Saline }\end{array}$ & 7 & $2.47 \pm 0.09$ & $7.29 \pm 0.02$ \\
$0.7 \mathrm{mg}$ & 7 & $2.55 \pm 0.07$ & $7.33 \pm 0.01$ \\
$1 \mathrm{mg}$ & 7 & $2.76 \pm 0.10$ & $7.28 \pm 0.01$ \\
$4 \mathrm{mg}$ & 7 & $2.62 \pm 0.11$ & $7.30 \pm 0.02$ \\
$10 \mathrm{mg}$ & 7 & $2.73 \pm 0.07$ & $7.27 \pm 0.01$ \\
Time interval after 4 mg endotoxin & & & \\
$5 \mathrm{~h}$ & 5 & $2.53 \pm 0.08$ & $7.28 \pm 0.07$ \\
$24 \mathrm{~h}$ & 5 & $2.60 \pm 0.06$ & $7.31 \pm 0.05$ \\
$72 \mathrm{~h}$ & 5 & $2.55 \pm 0.06$ & $7.29 \pm 0.03$ \\
$7 \mathrm{~d}$ & 7 & $2.73 \pm 0.07$ & $7.27 \pm 0.01$ \\
\hline
\end{tabular}

specific probes $(9,10,17-19)$. To reduce the high viscosity, amniotic fluid was incubated at $37^{\circ} \mathrm{C}$ with $N$-acetyl-L-cysteine, neuraminidase, and hyaluronidase. Cells from amniotic fluid and alveolar lavage fluid were isolated by centrifugation.

The right upper lobe was inflation fixed at $30 \mathrm{~cm} \mathrm{H}_{2} \mathrm{O}$. After hematoxylin and eosin staining the tissue was assessed for inflammatory changes (8). Hydrogen peroxide was measured in cells recovered from alveolar lavage fluid of the left lung. Flow cytometry was used to measure CD11b ( $\alpha$ M subunit of integrin CR3) and CD44 (proteoglycan link protein) and the percentage of apoptotic cells was determined by annexin $\mathrm{V}$ and propium iodide staining (20). Enzyme-linked immunosorbent assays (ELISA) were developed for $\Pi$-6 and IL-8 with antibodies from Chemicon (Temecula, CA) and recombinant proteins as standards from CSIRO (Parkville, Australia). Interferon-gamma (IFN- $\gamma$ ) was measured by ELISA (CSL, Parkville, Australia; recombinant protein was provided by Dr. S. L. Jones, CSL).

\section{Data Analysis}

Results are given as means \pm SEM. Inflammatory scores are given as medians with interquartile, 5th and 95th percentile ranges. Comparisons between endotoxin-treated and untreated lambs were by analysis of variance with Student-Newman-Keuls tests used for post-hoc analyses. Tissue scores were compared using the Mann-Whitney nonparametric tests. Significance was accepted at $p<0.05$.

\section{RESULTS}

\section{Inflammation and Lung Maturation}

There were no differences between the groups in body weights or $\mathrm{pH}$ in cord blood (Table 1). Lung function was improved after intraamniotic injection of $4 \mathrm{mg}$ and $10 \mathrm{mg}$ endotoxin given $7 \mathrm{~d}$ prior to delivery (Figure 1). Lung gas volumes measured by deflation pressure-volume curves were increased for the 4 and $10 \mathrm{mg}$ dose groups. At $40 \mathrm{~cm} \mathrm{H}_{2} \mathrm{O}$ pressure, volumes were increased from a mean value of $11 \mathrm{ml} / \mathrm{kg}$ in control animals to $32-38 \mathrm{ml} / \mathrm{kg}$ after endotoxin exposure of $4 \mathrm{mg}$ and $10 \mathrm{mg}$ (Figure 1A). The compliances also were about 2-fold higher after $4 \mathrm{mg}$ or $10 \mathrm{mg}$ endotoxin than in control lambs (Figure 1B). The alveolar surfactant pool size was significantly increased from $0.5 \mu \mathrm{mol} / \mathrm{kg}$ (control) to values over $4 \mu \mathrm{mol} / \mathrm{kg}$ after $4 \mathrm{mg}$ and $10 \mathrm{mg}$ endotoxin (Figure 1C). The mRNAs for surfactant proteins $\mathrm{A}$ and $\mathrm{C}$ remained elevated $7 \mathrm{~d}$ after injection of $4 \mathrm{mg}$ and $10 \mathrm{mg}$ endotoxin (Figure 1D). The dose of $1 \mathrm{mg}$ endotoxin significantly increased SP-C mRNA but not other surfactant proteins.

\section{Indicators of Inflammation with Endotoxin Doses}

The inflammatory scores in the fetal lung were increased $7 \mathrm{~d}$ after the intraamniotic injection of 1,4 , or $10 \mathrm{mg}$ endotoxin in a dose-dependent manner (Figure 2A). The number of inflammatory cells recovered from the alveolar lavage also increased with dose (Figure 2B). The number of granulocytes and monocytes increased significantly after the $0.1 \mathrm{mg}$ and higher doses of endotoxin. Therefore, inflammatory scores and inflammatory cells in alveolar lavages increased for doses of endotoxin that did not induce lung maturation. The increases were dose dependent. After 1, 4, and $10 \mathrm{mg}$ endotoxin there was an increase in inflammatory cells in chorioamniotic membranes (Figure $3 \mathrm{~A}$ ). In all endotoxin-treated animals there were increased numbers of monocytes and lymphocytes in the amniotic fluid (Figure 3B). After doses of $4 \mathrm{mg}$ and $10 \mathrm{mg}$ there was an influx of neutrophils. The absolute number of cells increased in a dose-dependent fashion.

The white blood cells increased in cord blood $7 \mathrm{~d}$ after the $4 \mathrm{mg}$ and $10 \mathrm{mg}$ endotoxin doses (Figure 4A). The neutrophils were the cell type that accounted for most of the increase in cord blood white cells, and the neutrophils were also increased in the animals treated with a dose of $1 \mathrm{mg}$ after $7 \mathrm{~d}$ (Figure 4B). The increases in white blood cells and neutrophils were dose dependent. The number of platelets increased in all groups after the 7 day exposure interval, including in the animals that received $0.1 \mathrm{mg}$ endotoxin (Figure $4 \mathrm{C}$ ).
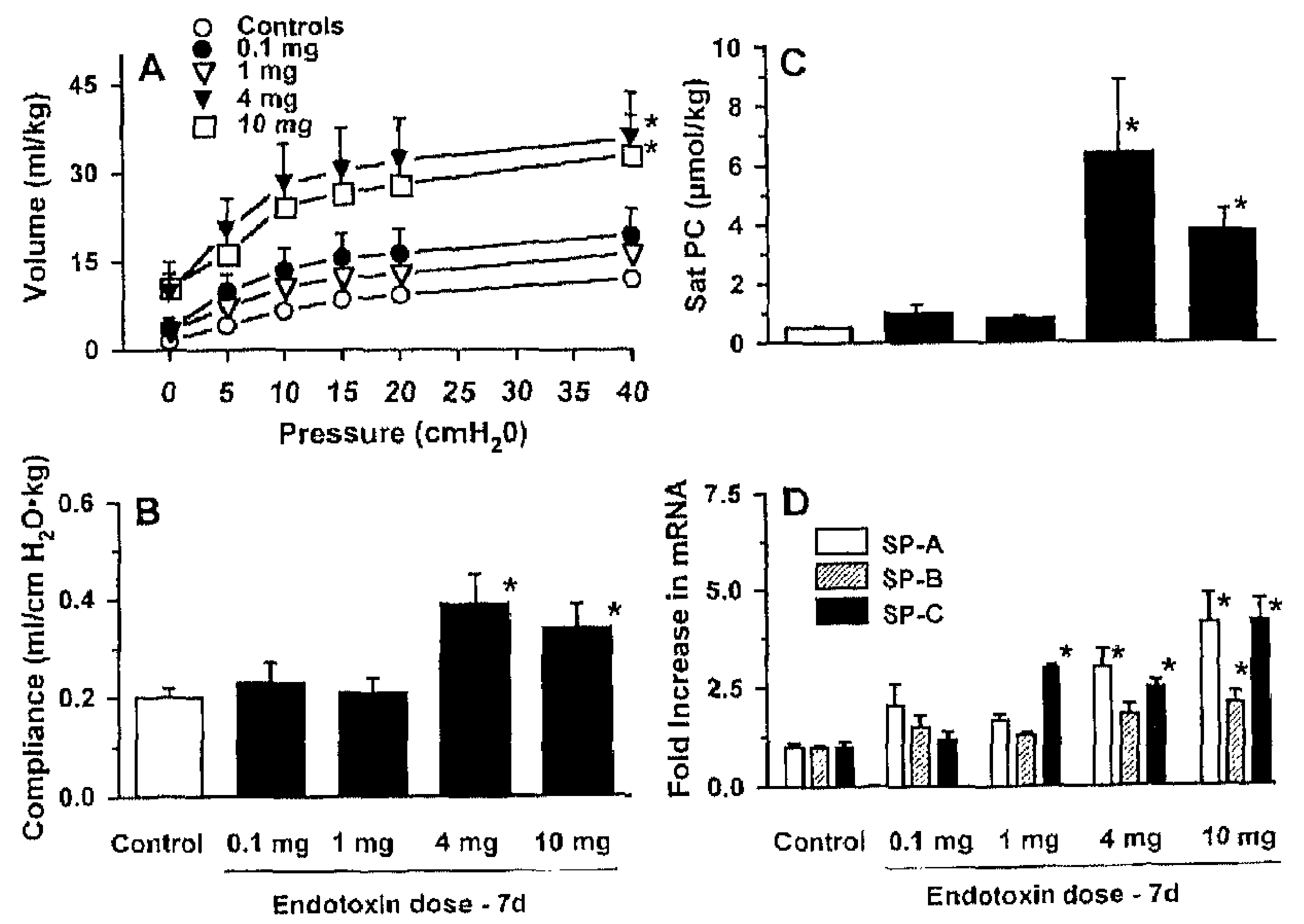

Figure 1. Lung maturation and function. (A) Pressure-volume curves. After $40 \mathrm{~min}$ of ventilation the deflation limbs of the pressure volume curves were improved after 4 and $10 \mathrm{mg}$ endotoxin. (B) Compliance after $\mathbf{4 0} \mathrm{min}$ ventilation. Compliance increased after $4 \mathrm{mg}$ and $10 \mathrm{mg}$ endotoxin by about 2-fold. (C) Sat PC in alveolar lavage fluid increased after $4 \mathrm{mg}$ and $10 \mathrm{mg}$ endotoxin. (D) mRNAs for the surfactant proteins $S P-A, B$, and $C$. The MRNAs were increased $7 d$ after instillation of $10 \mathrm{mg}$ endotoxin, and SP-A and SP-C mRNAs were increased after $4 \mathrm{mg}$ endotoxin, SP-C mRNA was increased after $1 \mathrm{mg}$ endotoxin ( ${ }^{*} \mathrm{p}<0.05$ versus control). 

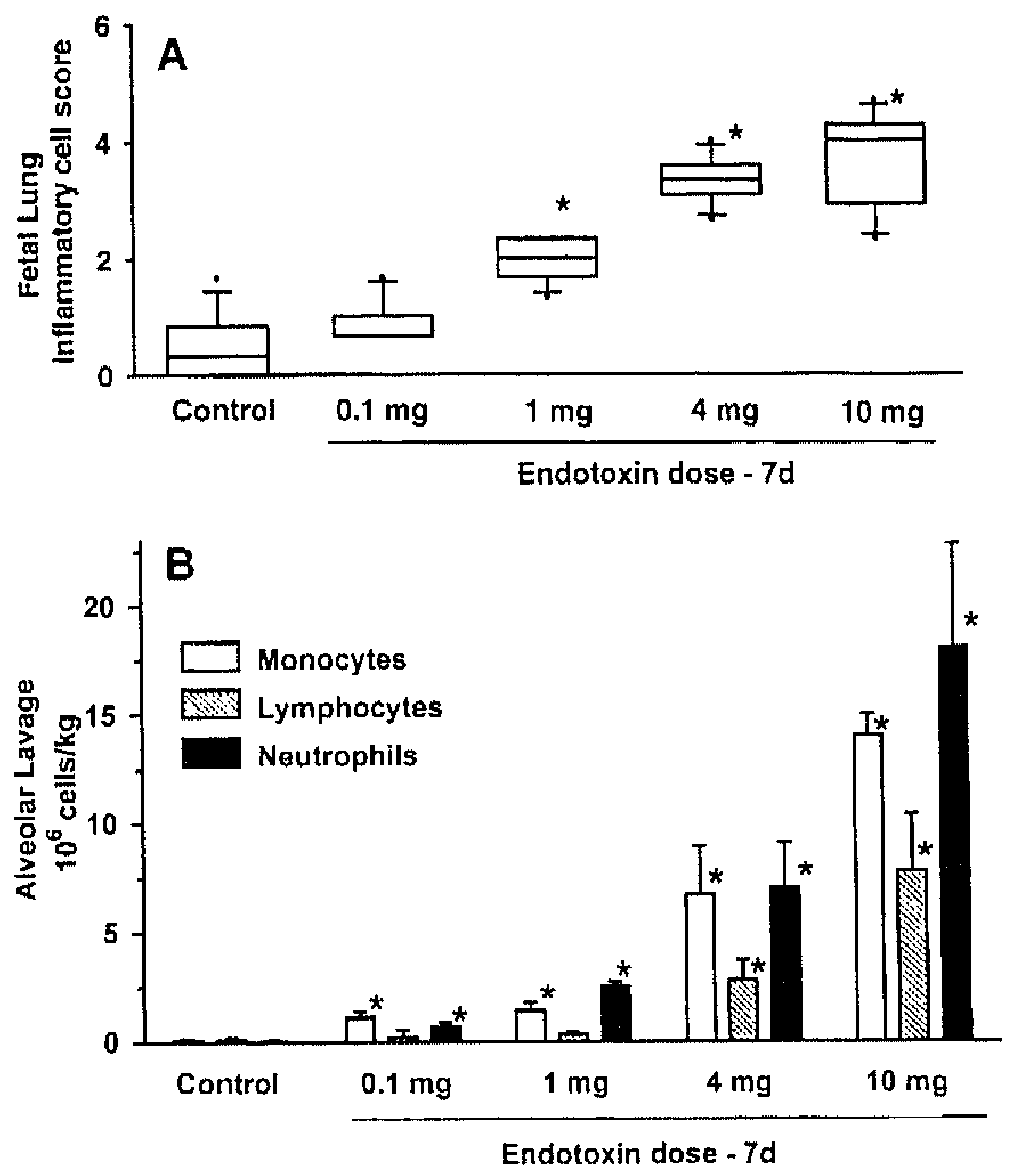

Figure 2. Inflammation in the fetal lungs. $(A)$ Inflammatory scores in the fetal lungs (airspace + tissue). Plots show median, 25th, and 75th percentile ranges as boxes and 5 th to 95 th percentile ranges as error bars. The numbers of inflammatory cells were ranked from few inflammatory cells (score $=1$ ), moderate cell infiltration (score $=2$ ), to extensive influx of cells (score $=3$ ). Endotoxin doses of $1 \mathrm{mg}, 4 \mathrm{mg}$, and $10 \mathrm{mg}$ increased the inflammation scores. $(B)$ Number of cells recovered from alveolar lavage. All doses of endotoxin increased monocytes and neutrophils in alveolar lavage. The number of lymphocytes was increased after doses of $4 \mathrm{mg}$ and $10 \mathrm{mg}\left({ }^{*} \mathrm{p}<0.05\right.$ versus control).

\section{Time Interval for Inflammatory Response}

For the animals studied at different time intervals after $4 \mathrm{mg}$ endotoxin the number of total white blood cells in cord blood decreased at $24 \mathrm{~h}$ because the lymphocytes decreased and subsequently increased at $7 \mathrm{~d}$ due to increased granulocytes (Figure $4 \mathrm{D}$ and $4 \mathrm{E}$ ). The increase in platelets occurred only $7 \mathrm{~d}$ after the $4 \mathrm{mg}$ dose of endotoxin (Figure $4 \mathrm{~F}$ ). The increases in cord blood white cells and platelets were late events after endotoxin exposure.

In contrast, inflammatory cytokine mRNAs for IL-1 $1 \beta, \mathrm{IL}-6$, IL-8, and tumor necrosis factor- $\alpha$ (TNF- $\alpha$ ) increased in the chorioamnion within $5 \mathrm{~h}$ after intraamniotic endotoxin (Figure $5 \mathrm{~A}$ ). The 3- to 7-fold increases were the highest at $5 \mathrm{~h}$. The increase in expression of TNF- $\alpha$ mRNA was not large at any time, and the expression of IL-10 mRNA in chorioamnion did not change at any time. An increase in inflammatory cells in the amniotic fluid occured by $5 \mathrm{~h}$ after the intraamniotic endotoxin and was highest at $72 \mathrm{~h}$ (Figure 5C). The cells recovered from the amniotic fluid had a different time pattern of cytokine mRNA expression than did the chorioamnion (Figure $5 B)$. The expression of IL- $1 \beta$ mRNA increased at $24 \mathrm{~h}$ and remained elevated at $7 \mathrm{~d}$, IL- $8 \mathrm{mRNA}$ was increased at $72 \mathrm{~h}$ and $7 \mathrm{~d}$, and IL-6 mRNA did not increase.

Inflammatory cells were recruited into the alveolar lavage by $5 \mathrm{~h}$, and peaked at $72 \mathrm{~h}$ (Figure 6A). IL-1 $\beta, \mathrm{IL}-8$, and TNF- $\alpha$ mRNAs were increased in lung tissue only $24 \mathrm{~h}$ after endotoxin exposure (Figure 6B). The mRNAs for IL-1 $\beta$ and IL-8 were increased in the alveolar cells recruited to the airways at $24 \mathrm{~h}$ and $72 \mathrm{~h}$ (Figure 6C). Surfactant protein mRNAs for SP-D was increased $5 \mathrm{~h}$ after $4 \mathrm{mg}$ endotoxin and at all later time
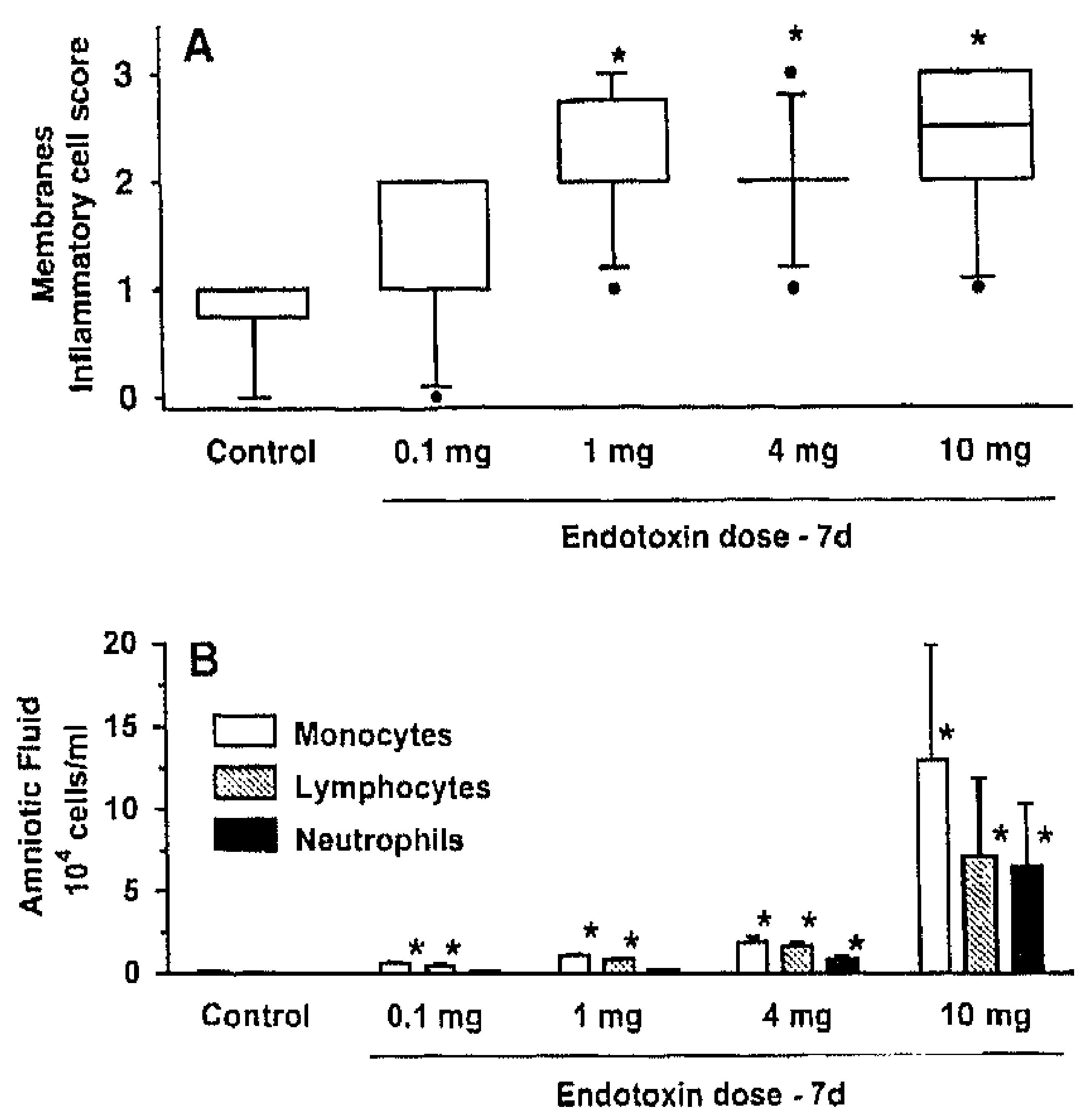

Figure 3. Inflammatory cells in fetal membranes and amniotic fluid. (A) Plots show median, 25th, and 75th percentile ranges as boxes and 5 th to 95 th percentile ranges as error bars. Membranes of control animals had few inflammatory cells and animals treated with $1 \mathrm{mg}$ or higher endotoxin doses had an extensive influx of cells (score $=3$ ). Most of the inflammatory cells were neutrophils. (B) Number and type of inflammatory cells in amniotic fluid. The number of inflammatory cells increased after all doses of endotoxin ( ${ }^{*} p<0.05$ versus control).

points (Figure 6D). SP-A, B, and C mRNA were increased $24 \mathrm{~h}$ after endotoxin exposure. Activation of cells recruited to the airways was assessed by measuring the expression of the adhesion molecules (CD11b and CD44) (Figure 7, A and B). The percentage of positive cells increased at $5 \mathrm{~h}$ and was highest at $72 \mathrm{~h}$ for both cell surface markers. The numbers of apoptotic and necrotic cells per body weight in the alveolar lavage also were the highest at $72 \mathrm{~h}$ after endotoxin (Figure 7, C and D). The cells recruited to the airways at $5 \mathrm{~h}$ were highly active based on the amount of hydrogen peroxide per cell (Figure 7E). However, relative to the number of cells recruited to the airways, the total amount of hydrogen peroxide normalized to body weight was highest at $24 \mathrm{~h}$ (Figure 7F).

\section{Septemic Inflammation}

Several variables were measured to evaluate the systemic inflammation. In cord blood plasma IFN- $\gamma$ was increased 12fold at $24 \mathrm{~h}$ (Figure 8A). IL-6 was increased significantly at $5 \mathrm{~h}$ (Figure 8A). IL-8 was increased from $5 \mathrm{~h}$ to $7 \mathrm{~d}$ by about 3 -fold, and IL-8 was the only cytokine that was elevated at all time points measured. The expression of TNF- $\alpha$ mRNA increased 2 -fold at $24 \mathrm{~h}$ in spleen tissue (Figure 8B). However, the overall cytokine expression pattern indicates minimal cytokine production by the spleen.

\section{DISCUSSION}

We have shown that there was no lung maturation-as indicated by increased lung gas volume, improved compliance, and increased surfactant Sat PC and increased SP mRNAs-without preceding inflammation in chorioamnion and fetal lung using various doses of endotoxin. On the other hand, mild inflammation was not followed by lung maturation. The lower doses of $0.1 \mathrm{mg}$ and $1 \mathrm{mg}$ endotoxin induced an influx of inflammatory cells into the chorioamnion, the amniotic fluid, lung 
Kramer, Moss, Willet, et al.: Endotoxin and Lung Maturation in Lambs

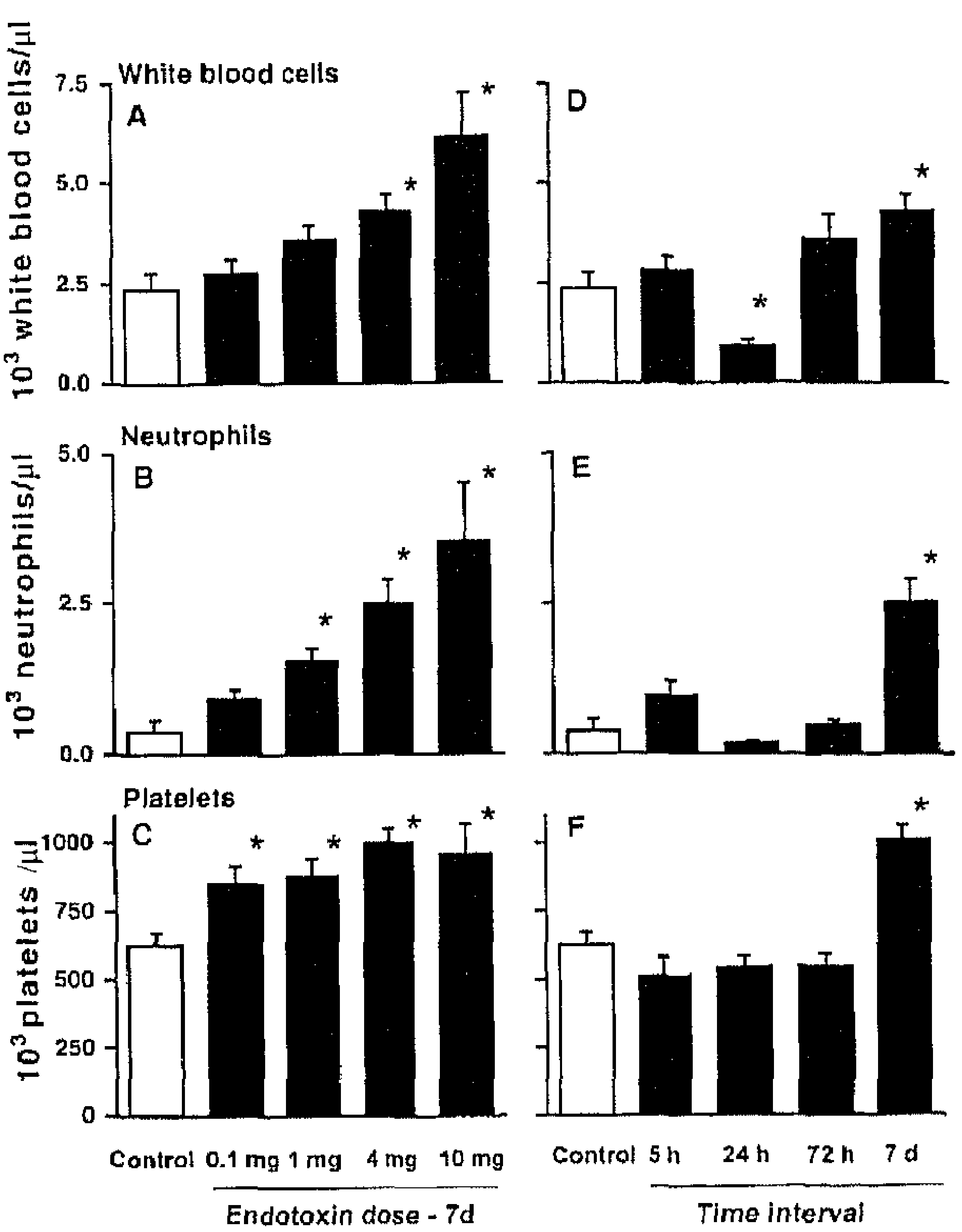

Figure 4. Effect of intraamniotic endotoxin on white blood cells and platelets in cord blood. $(A)$ Doses of $4 \mathrm{mg}$ and $10 \mathrm{mg}$ endotoxin caused an increase in white blood cells after $7 \mathrm{~d}$. (B) The number of circulating neutrophils increased in a dose-dependent manner after $1 \mathrm{mg}$ and higher doses of endotoxin. (C) The number of platelets increased in every group of animals treated with endotoxin. (D) The number of white blood cells decreased after $24 \mathrm{~h}$ and increased at $7 \mathrm{~d}$. (E) The circulating neutrophils increased at $7 \mathrm{~d}$. $(F)$ The number of platelets was elevated only $7 \mathrm{~d}$ after endotoxin ( ${ }^{*} p<0.05$ versus control).

tissue, and alveolar lavages that persisted $7 \mathrm{~d}$ after endotoxin exposure but lung function was not improved. The increases in white blood cells and inflammatory cells in fetal lung and alveolar lavage were dose dependent. Even the lowest dose of cndotoxin induced an increase in cells in amnoitic fluid and in platelets indicating a subtle systemic response to the inflammatory stimulus given into the amniotic fluid.

The inflammatory response in the fetal lungs and cord blood increased with endotoxin dose, suggesting that a threshold amount of inflammation was needed to induce the improved lung function. A distinction between local and systemic inflammatory response could not be made after $7 \mathrm{~d}$. We previously found endotoxin doses of $1,4,20$, or $100 \mathrm{mg}$ caused equivalent maturational exposure without increases in fetal cortisol (11). The variability of response to $1 \mathrm{mg}$ endotoxin may be attributed to the variation in endotoxin preparations. In the fetal sheep model, a dose of 1 or $4 \mathrm{mg}$ given by intraamniotic injection is the minimal stimulus needed to enhance lung function after preterm delivery. There was a clear doseresponse relationship between inflammation and the amount of endotoxin. However there were no clearly graded or partial lung maturation responses.

In a previous study we found that $20 \mathrm{mg}$ endotoxin given by intraamniotic injection increased IL-1 $\beta$, IL-6, and IL-8 mRNA in the chorioamnion at $5 \mathrm{~h}$ with a parallel response in the lungs beginning at $5 \mathrm{~h}$ that increased for about $2 \mathrm{~d}(10)$. For this study we used the minimal effective dose of $4 \mathrm{mg}$ endotoxin for inducing lung maturation and addressed the question whether

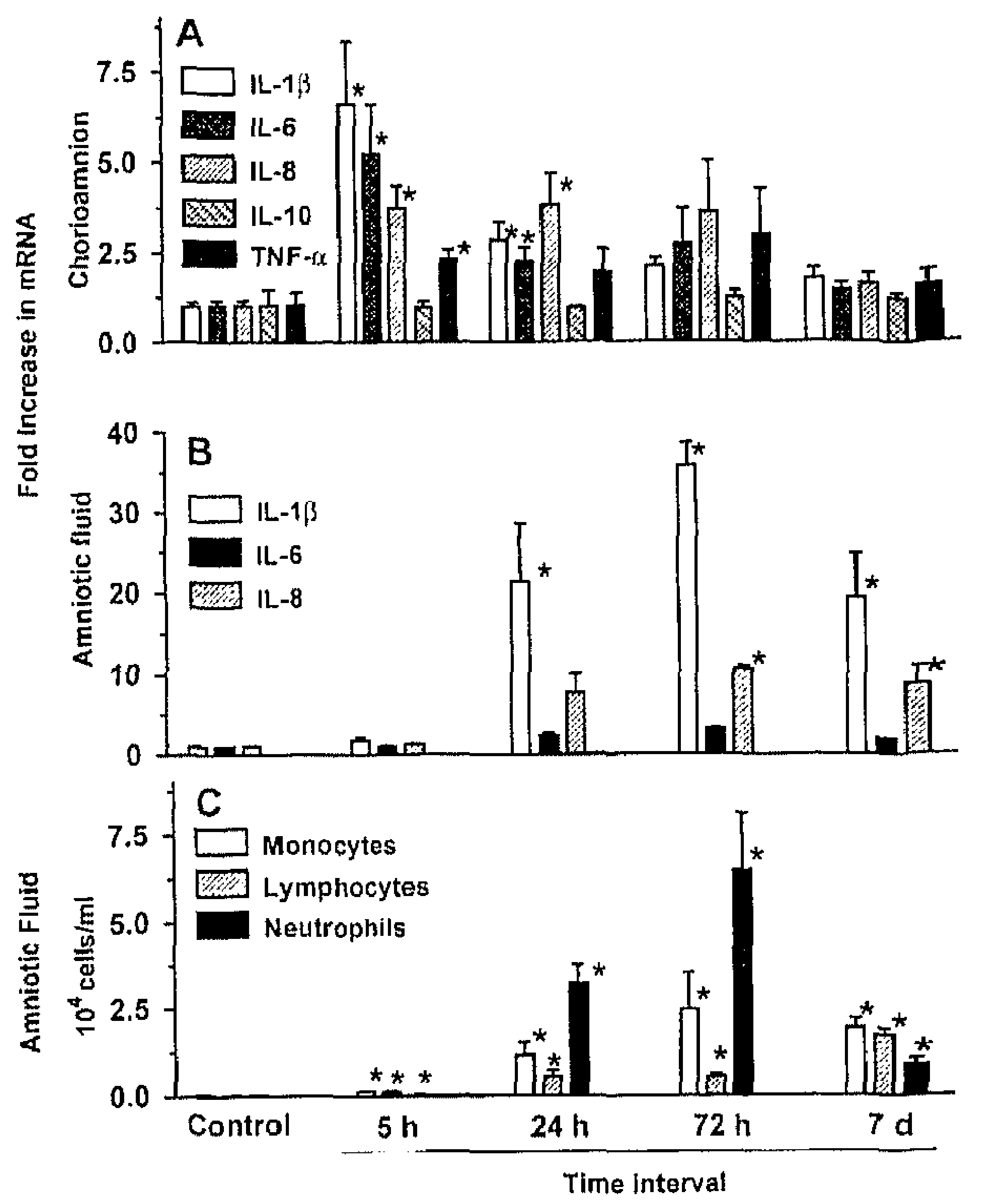

Figure 5 . Cytokine $m R N A$ in fetal membranes and cells from arr fluid. (A) IL-1 $\beta, \mathbb{L}-6, \mathrm{IL}-8$, and TNF- $\alpha$ mRNAs were increased chorioamnion at $5 \mathrm{~h}$ and $24 \mathrm{~h}$. IL-10 mRNA was not increased time. (B) IL-1 $\beta$ and IL-8 mRNA increased at $24 \mathrm{~h}$, and $72 \mathrm{~h}$ and cells from amniotic fluid. (C) The number of monocytes, lymphc and neutrophils in amniotic fluid increased at $5 \mathrm{~h}$ and remain creased at all time points ( ${ }^{*} p<0.05$ versus control).

systemic versus local inflammation in the fetus was ins by intraamniotic endotoxin and which compartment wa ducing proinflammatory cytokines at later time points mRNAs for IL-1 $\beta$, IL- 6 , IL- 8 , and TNF- $\alpha$ were most incr at $5 \mathrm{~h}$ in the chorioamnion. Inflammatory cells in the am fluid were increased at $5 \mathrm{~h}$, but the 40 -fold increase in gr: cytes was at $24-72 \mathrm{~h}$, and the up to 35 -fold increases in and IL-8 mRNA occurred over the $24 \mathrm{~h}$ to 7 day interva no increase in IL-6 mRNA. The distinct differences be chorioamnion and cells in amniotic fluid suggest that $\mathbf{t}$ flammation in amniotic fluid was regulated differently the response of the chorioamnion. The cytokine respons tinued in amniotic fluid after it was extinguished in the $\mathbf{c}$ amnion and fetal lungs.

The mRNAs for the proinflammatory cytokines we creased in lung and alveolar lavage by $24 \mathrm{~h}$, but not at noted previously with the higher endotoxin dose (10 first detectable effect of inflammation in the lungs $w$ large increase in $\mathrm{H}_{2} \mathrm{O}_{2}$ production by the few cells recruj $5 \mathrm{~h}$. At the same time the mRNA for SP-D was increase large number of cells in alveolar lavages at $72 \mathrm{~h}$ express surface adhesion molecules CD11b and CD44, which ox cell recruitment to sites of inflammation. Although $\mathbf{t}$ ? surface antigens indicate that many cells evaluated at 72 . quickly recruited to the airways, they were no longer $\mathbf{p}$ ing $\mathrm{H}_{2} \mathrm{O}_{2}$. We used the measurements of annexin $\mathrm{V}$ anc terstaining with propium iodide to evaluate the percen apoptotic and necrotic cells in the cell population. Beca: total cell numbers increased, we calculated the number crotic and apoptotic cells per kilogram body weight, 

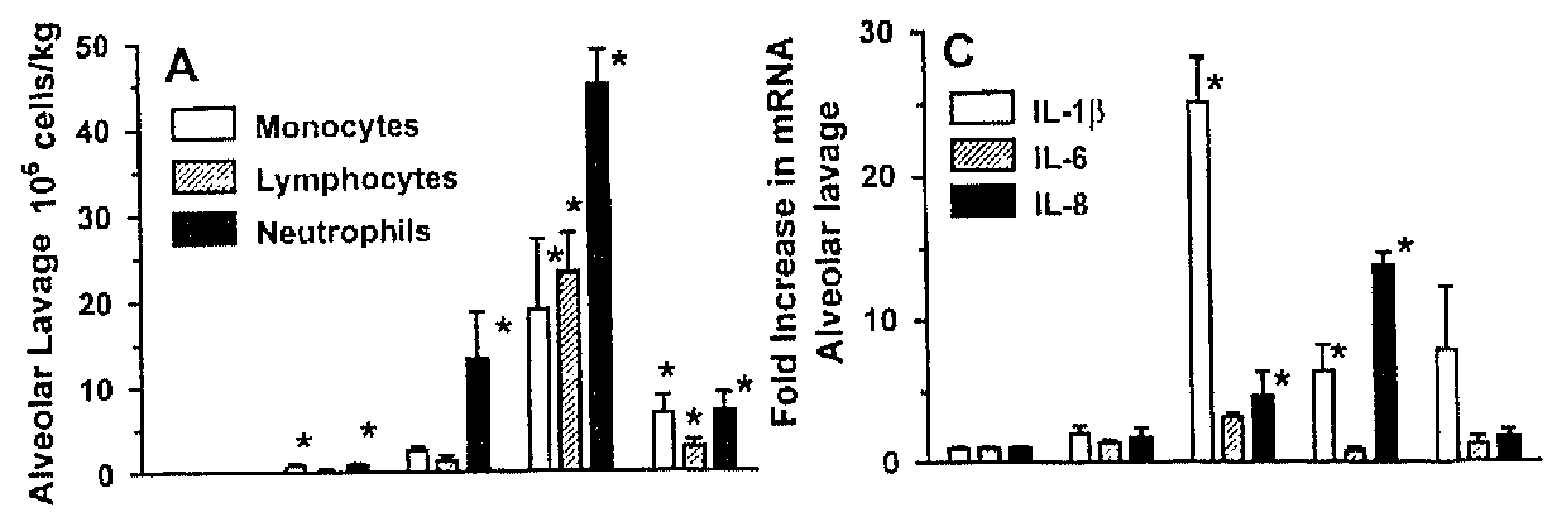

\begin{abstract}
Figure 6. Cells in alveolar lavage, cytokine mRNAs in cells from alveolar lavage and lung, and surfactant protein mRNAs in lung tissues. $(A)$ The number of monocytes and neutrophils in alveolar lavage increased after $5 \mathrm{~h}$ and remained increased to $7 \mathrm{~d}$. (B) At $24 \mathrm{~h} \mathrm{IL-1 \beta ,} \mathrm{IL-8,} \mathrm{and} \mathrm{TNF-} \alpha$ mRNA were elevated in mRNA from lung tissue. (C) The IL$1 \beta$ and IL-8 mRNA from cells recovered from alveolar lavage increased at $24 \mathrm{~h}$ and $72 \mathrm{~h}$. (D) Time course of induction of surfactant protein mRNAs increased after $4 \mathrm{mg}$ endotoxin. The SP-D mRNA was induced after $5 \mathrm{~h}$, the mRNAs of all were increased after $24 h\left(^{*} \mathrm{p}<0.05\right.$ versus control).
\end{abstract}
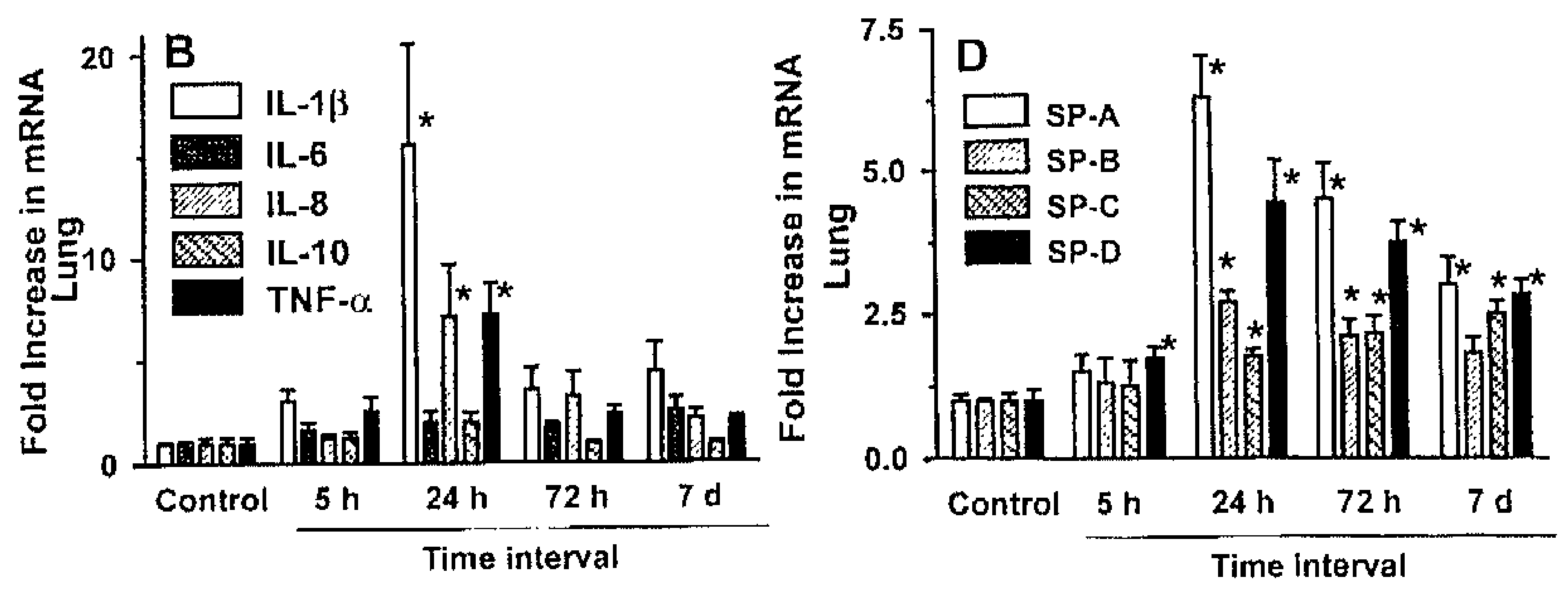

should best reflect the timing of resolution of inflammation in the lungs. The high numbers of apoptotic and necrotic cells at $72 \mathrm{~h}$ indicated resolution of inflammation at $72 \mathrm{~h}(21)$. However, complete resolution had not occurred by $7 \mathrm{~d}$, and we found residual inflammatory cells in alveolar lavage as long as $25 \mathrm{~d}$ after intraamniotic endotoxin (10).

None of the indicators of inflammation that were detected at 7 days correlated very well with the improved lung function
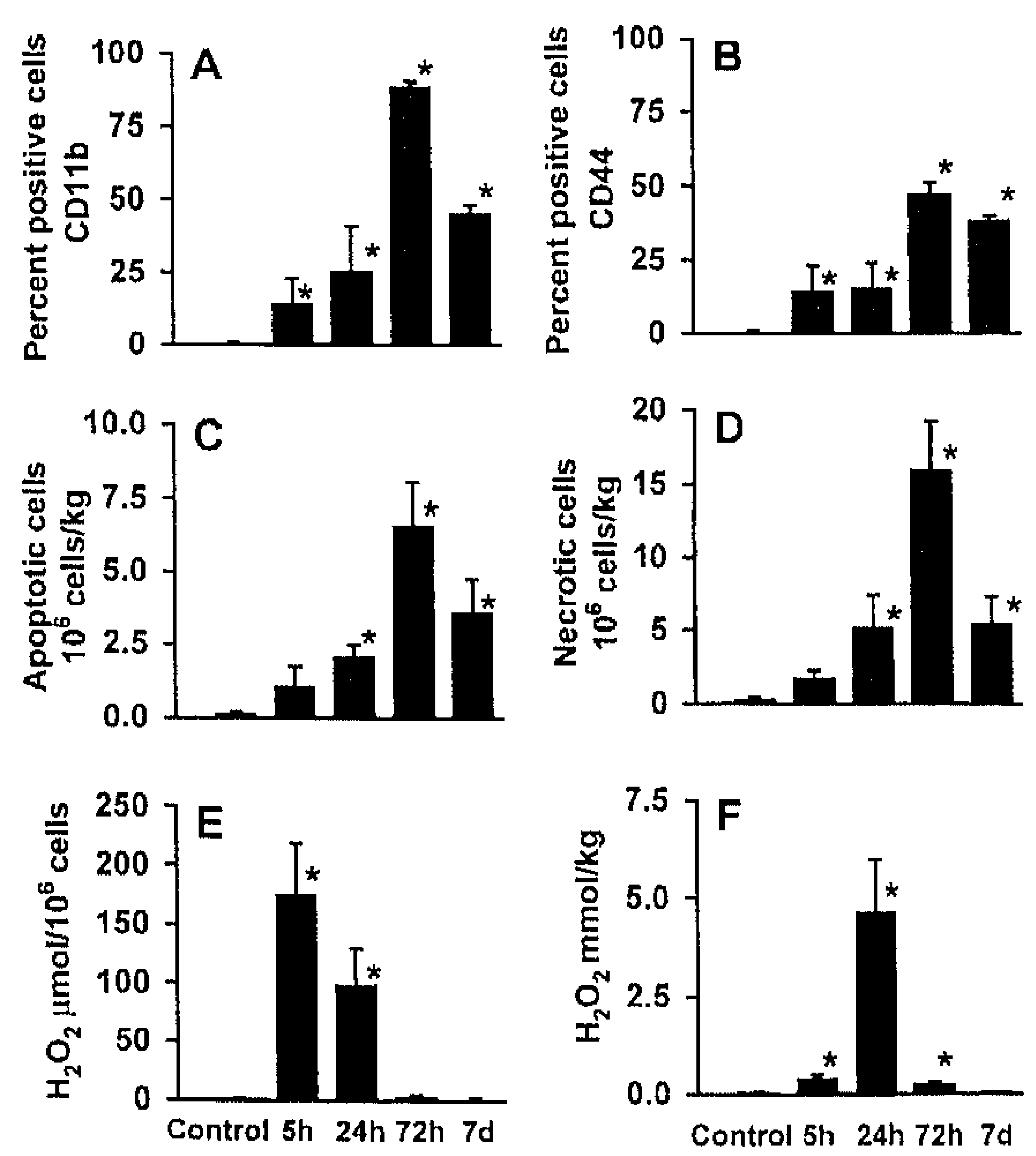

Figure 7. Markers of activation of cells from alveolar lavage. $(A)$ Percent of CD11b ( $\alpha \mathrm{M}$ subunit of integrin CR3) positive cells. The number of CD11b positive cells increased from $5 \mathrm{~h}$ to $72 \mathrm{~h}$. (B) The percentage of CD44 (proteoglycan link protein) positive cells also increased from $5 \mathrm{~h}$ to $72 \mathrm{~h}$. $(C, D)$ The number of apoptoic cells in the alveolar lavage was determined by annexin $V$ staining and counterstaining with propium iodide to detect necrotic cells. The numbers of apoptotic and necrotic cells were highest at $72 \mathrm{~h}$. (E) The production of hydrogen peroxide per $10^{6}$ cells was maximal after $5 \mathrm{~h}$. $(F)$ The production of hydrogen peroxide per kilogram body weight was highest at $24 \mathrm{~h}$ when the total cell number in the alveolar lavage was also most elevated $\left({ }^{\star} p<0.05\right.$ versus control). after preterm delivery. Early indicators such as $\mathrm{H}_{2} \mathrm{O}_{2}$ and cytokine production in the chorioamnion and the lung cannot be evaluated because those indicators have been extinguished before the physiological maturation response occurs. In mature lungs, endotoxin and proinflammatory cytokines initially suppress the mRNAs for surfactant proteins and the surfactant proteins can rebound to higher levels than normal with healing $(17,22)$. Although detectable, the mRNAs for SP-A and SP-B are very low at $125 \mathrm{~d}$ gestation in the fetal sheep lung, and no decreases are seen after intraamniotic endotoxin. SP-C mRNA should be the most sensitive indicator because it is relatively high at $125 \mathrm{~d}$ gestation, and it is unchanged $5 \mathrm{~h}$
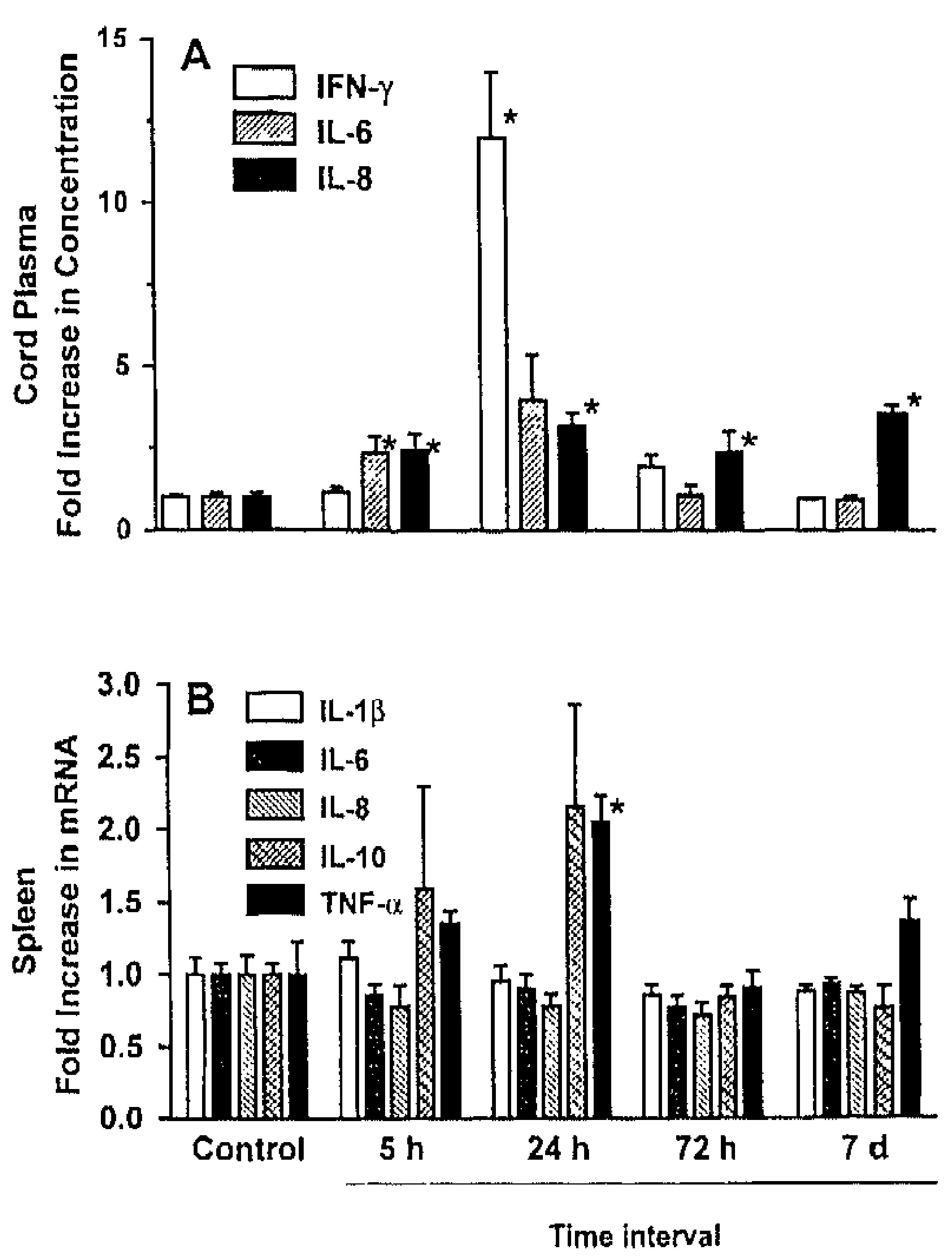

Figure 8. Systemic inflammation. (A) Interferon gamma (IFN- $\gamma$ ) was increased in cord plasma at $24 \mathrm{~h}$. Interleukin- 6 was increased at $5 \mathrm{~h}$ and interleukin-8 was increased from $5 \mathrm{~h}$ to $7 \mathrm{~d}$. (B) The amount of IL$1 \beta, \mathrm{IL}-6, \mathrm{IL}-8$, and IL-10 mRNA in the spleen did not increase. The amount of TNF- $\alpha$ increased by 2 -fold at $24 \mathrm{~h}$ only $\left({ }^{\star} p<0.05\right.$ versus control). 
and increased $24 \mathrm{~h}$ after intraamniotic endotoxin. Inflammatory cells producing $\mathrm{H}_{2} \mathrm{O}_{2}$ and cytokines were accumulating in the lungs over $3 \mathrm{~d}$, providing a source for direct lung injury. The wet-to-dry weights did not change from control values nor did the total protein in the alveolar lavages (data not shown). However, the antioxidant enzymes catalyse, glutathione peroxidase, and superoxide dismutase are induced after endotoxin exposure, indicating activation of oxidant-mediated pathways in the fetal lung (23). SP-A and SP-D may function as antioxidants (24). SP-D mRNA was increased within $5 \mathrm{~h}$. A hypothesis for the events that result in lung maturation after intraamniotic endotoxin is that neutrophils producing oxidants cause a primary injury and that the fetal lung responds with lung maturation as a protective response.

We previously found that $20 \mathrm{mg}$ intraamniotic endotoxin did not increase proinflammatory cytokine mRNA in the placenta, fetal liver, or fetal gut. Wc used the lower dose of $4 \mathrm{mg}$ endotoxin to search for other indicators of a systemic inflammatory response. The TNF- $\alpha$ mRNA increased by about 2 -fold at $24 \mathrm{~h}$ only in the spleen, with no increase in IL-1 $\beta$, IL-6, or IL-8, indicating a very minimal response from the fetal spleen. In preterm lambs that were treated with intratracheal endotoxin the spleen produced high amounts of proinflammatory cytokines within $6 \mathrm{~h}$ demonstrating that the preterm spleen can respond to a proinflammatory stimulus (25). Nevertheless, IL-6 and IL-8 were increased in cord plasma over the extended interval from $24 \mathrm{~h}$ to $7 \mathrm{~d}$. Interferon- $y$ also was increased in plasma $12-$ fold at $24 \mathrm{~h}$. Using IL-8 as a representative proinflammatory cytokine, we found no increases in mRNA at $72 \mathrm{~h}$ or $7 \mathrm{~d}$ in chorioamnion, lung, or spleen. However, the mRNA for IL-8 was elevated in cells in amniotic fluid at $72 \mathrm{~h}$ and $7 \mathrm{~d}$, suggesting that the amniotic fluid is the source of the increased cytokine in the cord plasma. As with the other components of the inflammatory response, we cannot specifically link the increased plasma cytokines at $5 \mathrm{~h}$ and $24 \mathrm{~h}$ to the lung maturation response.

The interpretation of this in vivo model relative to clinical settings is complex. The preterm human fetus at risk of delivering before 30 wk gestational age may be continuously exposed to live organisms, their products, and inflammatory mediators and the exposure may be prolonged (1). The kinetics and dynamics of chorioamniotis caused by live organisms are probably quite different from a single dose of endotoxin from gram-negative bacteria. The most common microorganism associated with chorioamnionitis is Ureaplasma urealyticum, which does not have a cell wall but induces IL- $1 \beta, I L-6$, and TNF- $\alpha$ in amniotic fluid (26). In the clinical literature cord plasma elevations of IL-6 have been used to diagnose systemic inflammation in the fetus $(27,28)$. We found that there were subtle indications of systemic inflammation after intraamniotic injection of endotoxin. The increase of IL-6 in cord plasma within $5 \mathrm{~h}$ after intraamniotic endotoxin showed that the systemic inflammation was present at the same time as the local inflammation in chorioamnion and fetal lung. However, the animals were not injured in any way that was evident by the endotoxin exposure $(8,9,11)$. The antiinflamatory cytokine protein IL-10 was not detectable but sustained increases in IL-8 were in airway samples from infants that developed BPD (29). We found no significant induction of IL-10 mRNA in membranes, in lung, or in spleen. IL-8 was increased in plasma at all time points after intraamniotic endotoxin in the fetal sheep. Increased cytokine proteins in cord blood were reported in clinical studies to be associated with subsequent BPD or cerebral palsy $(3,28)$ and interferons can cause cerebral palsy when given to infants (30). The pattern of cytokine responses in the fetal sheep-elevated IL-8 and IFN- $\gamma$ with no induction of the antiinflamma- tory cytokine IL-10-parallels the clinical observations that have been associated with poor lung and neurodevelopmental outcomes $(2,31)$. In clinical studies oxidative injury has been implicated in the development of BPD after preterm birth (3). In our animal model the response of the fetal lung to intraamniotic endotoxin may be different because the oxidant stress is of short duration.

In summary, we found that intraamniotic doses of $0.1 \mathrm{mg}$ and $1 \mathrm{mg}$ endotoxin induced inflammatory cell recruitment to the chorioamnion and the lungs. However, this inflammation was not accompanied by physiological improvements in lung function. Higher doses of endotoxin sufficient to induce lung maturation were accompanied by systemic inflammation in the fetus within $5 \mathrm{~h}$. Activated cells in the airways producing hydrogen peroxide within $5 \mathrm{~h}$ might cause an initial lung injury. Fetal exposure to sufficient inflammation can therefore induce lung maturation, but the precise link between the components and the intensity of the inflamatory response and lung maturation remains elusive.

\section{References}

1. Goldenberg RL, Hauth JC, Andrews WW. Intrauterine infection and preterm delivery. $N$ Engl I Med 2000;342:1500-1507.

2. Nelson KB, Dambrosia JM, Grether JK, Phillips TM. Neonatal cytokines and coagulation factors in children with ccrebral palsy. Ann Neu rol 1998:44:665-675.

3. Speer CP, Groneck P. Oxygen radicals, cytokines, adhesion molecules and lung injury in neonates. Semin Neonatol 1998;3:219-228.

4. Watterberg KL, Demers LM, Scott SM, Murphy S. Chorioamnionitis and early lung inflammation in infants in whom bronchopulmonary dysplasia develops. Pediatrics 1996;97:210-215.

5. Hannaford K, Todd DA, Jefferey H, John E, Byth K, Gilbert GL. Role of Ureaplasma urealyticum in lung disease of prematurity. Arch Dis Child Fetal Neonatal Ed 1999;81:F162-F167.

6. Costeloe K, Hennessey E, Gibson AT, Marlow N, Wilkinson AR. The EPICure study: outcomes to discharge from hospital for infants born after the threshold of viability. Pediatrics 2000;106:659-671.

7. Willet KE, Jobe AH, Ikegami M, Brennan S, Newnham J, Sly PD. Antenatal cndotoxin and glucocorticoid effects on lung morphometry in preterm lambs. Pediatr Res 2000;48:782-788.

8. Jobe AH, Newnham JP, Willet KE, Sly P, Ervin MG, Bachurski CJ, Possmayer F, Hallman M, Ikegami M, Antenatal endotoxin and glucocorticoid effects on the lungs of preterm lambs. Am J Obstet Gynecol 2000;182:401-408.

9. Bachurski CJ, Ross GF, Ikegami M, Kramer BW, Jobe AH. Intra-amniotic endotoxin increases pulmonary surfactant proteins and induces SP-B processing in fetal sheep. Am J Physiol 2001;280:L279-L285.

10. Kallapur SG, Willet KE, Jobe AH, Ikegami M, Bachurski CJ. Intra-amniotic endotoxin: chorioamnionitis precedes lung maturation in preterm lambs. Am J Physiol 2001;280:L527-L536.

11. Jobe AH, Newnham JP, Willet KE, Moss TJ, Ervin MG, Padbury JF, Sly $\mathrm{P}$, Ikegami $\mathrm{M}$. Endotoxin-induccd lung maturation in preterm lambs is not mediated by cortisol. Am J Respir Crit Care Med 2000;162;16561661 .

12. Ikegami M, Jobe AH, Newnham J, Polk DH, Willet KE, Sly P. Repetitive prenatal glucocorticoids improve lung function and decreasc growth in preterm lambs. Am J Respir Crit Care Med 1997;156:178-184.

13. Wada $\mathrm{K}$, Jobe AH, Ikegami $\mathrm{M}$. Tidal volume effects on surfactant treatment responses with the initiation of ventilation in preterm lambs. $J$ Appl Physiol 1997;83:1054-1061.

14. Mason RJ, Nellenbogen J, Clements JA. Isolation of disaturated phosphatidylcholine with osmium tetroxide. J Lipid Res 1976;17:281-284.

15. Bartlett GR. Phosphorous assay in column chromatography. $J$ Biol Chem 1959;234:466-468.

16. Davis $\mathrm{AJ}$, Jobe $\mathrm{AH}$, Häfner $\mathrm{D}$, Ikegami $\mathrm{M}$. Lung function in premature lambs and rabbits treated with a recombinant SP-C surfactant. Am J Respir Crit Care Med 1998;157:553-559.

17. Bachurski CJ, Pryhuber GS, Glasser SW, Kelly SE, Whitsett JA. Tumor nccrosis factor-alpha inhibits surfactant protcin $\mathrm{C}$ gene transcription. $J$ Biol Chem 1995;270:19402-19407.

18. Young AJ, Hay JB, Chan JYC. Primary structure of ovine tumor necrosis alpha cDNA. Nucleic Acids Res 1990;18:6723-6732. 
19. Martin $\mathrm{H}$, Nash A, Andrews A. Cloning and characterisation of an ovine interleukin-10-encoding cDNA. Gene 1995;159:187-191.

20. Vermes I, Haanen C, Steffens-Nakken H, Reutelingsperger C. A novel assay for apoptosis: flow cytometry detection of phosphatidylserine expression on early apoptotic cells using fluorescin labeled Annexin V. J Immunol Methods 1995;184:39-51.

21. Mann CL, Cidloski JA. Signaling cascades of apoptosis. In: Winkler JD, editor. Apoptosis and inflammation. Basel: Birkhäuser, 1999; p. 7-18.

22. Pryhuber GS, Bachurski C, Hirsch R, Bacon A, Whitsett JA. Tumor necrosis factor-alpha decreases surfactant protcin $B$ mRNA in murine lung. Am J Physiol 1996;270:L714-L721.

23. Sosenko IRS, Jobe AH. Intraamniotic endotoxin: promotion of lung antioxidant enzyme activity in preterm lambs precedes maturation of lung function and surfactant [abstract]. Pediatr Res 2001;49:383A.

24. Bridges JP, Davis HW, Damodarasamy M, Kuroki Y, Howles G, Hui DY, McCormack FX. Pulmonary surfactant proteins $A$ and $D$ are potent endogenous inhibitors of lipid peroxidation and oxidative injury, $J$ Biol Chem 2000;275:38848-38855.

25. Kramer BW, Jobc AH, Ikegami M. Systemic inflammation following intratracheal endotoxin that leaks into the circulation despite gentle ventilation of preterm lambs [abstract]. Am J Respir Crit Care Med 2001;163:A209.
26. Yoon BH, Romero R, Park JS, Chang JW, Kim YA, Kim JC, Kim KS. Microbial invasion of the amniotic cavity with Ureaplasma urealyticum is associated with a robust host in fetal, amniotic, and maternal compartmonts. Am J Obstet Gynecol 1998;179:1254-1260.

27. Yoon BH, Romero R, Kim KS, Park JS, Ki SH, Kim BI, Jun JK. A systemic fetal inflammatory response and the development of bronchopulmonary dysplasia. Am J Obstet Gynecol 1999;179:1254-1260.

28. Gomez R, Romero R, Ghezzi F, Yoon BH, Mazor M, Berry SM. The fetal inflammatory response syndrome. Am J Obstet Gynecol 1998;179: 194-202.

29. Jones CA, Cayabyab RG, Kwong KYC, Stotts C, Wong B, Hamdan H, Minoo $\mathrm{P}$, deLemos RA. Undetectable interleukin (IL)-10 and persistent IL-8 expression early in hyaline membrane disease: a possible development basis for the predisposition to chronic lung inflammation in preterm newborns. Pediatr Res 1996:39:966-975.

30. Barlow CF, Priebe CJ, Mulliken JB, Barnes PD, MacDonald D, Folkman J, Ezckowitz RA. Spastic diplegia as a complication of interferon alpha-2a treatment of hemangiomas in infancy. J Pediatr 1998;132: $527-530$.

31. Grether JK, Nelson KB, Dambrosia JM, Phillips TM. Interferons and cerebral palsy. I Pediatr 1999;134:324-332. 


\section{CHAPTER 4}

Injury, inflammation and remodeling in fetal sheep lung after intraamniotic endotoxin

Kramer, B.W., Kramer, S., Ikegami, M., Jobe, A.H. 


\title{
Injury, inflammation, and remodeling in fetal sheep lung after intra-amniotic endotoxin
}

\author{
BORIS W. KRAMER, SUSANNE KRAMER, MACHIKO IKEGAMI, AND ALAN H. JOBE \\ Division of Pulmonary Biology, Cincinnati Children's Hospital, Cincinnati, Ohio 45229
}

Received 19 October 2001; accepted in final form 14 March 2002

\begin{abstract}
Kramer, Boris W., Susanne Kramer, Machiko Ikegami, and Alan H. Jobe. Injury, inflammation, and remodeling in fetal sheep lung after intra-amniotic endotoxin. Am J Physiol Lung Cell Mol Physiol 283: L452-L459, 2002. First published March 22, 2002; 10.1152/ajplung.00407.2001.Chorioamnionitis is frequent in preterm labor and increases the risk of bronchopulmonary dysplasia. We hypothesized that intra-amniotic endotoxin injures the lung in utero, causing a sequence of inflammation and tissue injury similar to that which occurs in the injured adult lung. Preterm lamb lungs at 125 days gestational age were evaluated for indicators of inflammation, injury, and repair $5 \mathrm{~h}, 24 \mathrm{~h}, 72 \mathrm{~h}$, and 7 days after $4 \mathrm{mg}$ of intra-amniotic endotoxin injection. At $5 \mathrm{~h}$, the epithelial cells in large airways expressed heat shock protein 70, and alveolar interleukin-8 was increased. Surfactant protein B (SP-B) decreased in alveolar type II cells at $5 \mathrm{~h}$, and SP-B in lung tissue and alveolar lavage fluid increased by $72 \mathrm{~h}$. By $24 \mathrm{~h}$, neutrophils were recruited into the large airways, and cell death was the highest. Alveolar type II cells decreased by $25 \%$ at $24 \mathrm{~h}$, and proliferation was highest at $72 \mathrm{~h}$, consistent with tissue remodeling. Intraamniotic endotoxin caused surfactant secretion, inflammation, cell death, and remodeling as indications of lung injury. The recovery phase was accompanied by maturational changes in the fetal lung.
\end{abstract}

surfactant; lung maturation; alveolar type II cells; respiratory distress syndrome; chorioamnionitis

CHORIOAMNIONITIS is frequently associated with preterm birth, with indicators of systemic and pulmonary inflammation in the newborn at birth and with increased risks of bronchopulmonary dysplasia and brain injury (cerebral palsy) $(9,17,20)$. In contrast, histological chorioamnionitis is also associated with a decreased risk of respiratory distress syndrome and may predict increased survival of preterm infants $(6,25)$. With the use of a lamb model to study fetal lung responses to chorioamnionitis induced by intra-amniotic endotoxin, we found that the lung responded by recruiting proinflammatory cells that produced hydrogen peroxide (15, 16). Proinflammatory cytokine mRNAs were expressed in the lung 5 and $24 \mathrm{~h}$ after intra-amniotic endotoxin. Subsequently, there was a striking maturational effect characterized by improved lung mechanics and gas exchange and large increases in surfactant pool sizes

\footnotetext{
Address for reprint requests and other correspondence: A. H. Jobe, Cincinnati Children's Hospital, Division of Pulmonary Biology, 3333 Burnet Ave., Cincinnati, OH 45229-3039 (E-mail: alan.jobe@chmcc.
} org). within 7 days of the intra-amniotic endotoxin $(1,13$, 14). The maturational effects on the fetal lung were accompanied by an arrest in alveolarization (26). Inflammatory cells that were not producing hydrogen peroxide or cytokine mRNA persisted in the lungs for several weeks, indicating ineffective clearing of the inflammatory process $(15,16)$. There was a minimal systemic response to the intra-amniotic endotoxin with no increase in fetal cortisol levels or in cytokine expression in liver, gut, or placental tissue $(13,15)$. Low doses of intra-amniotic endotoxin that did not induce a maturational response also did not increase indicators of inflammation in the fetal lung (16). We hypothesize that intra-amniotic endotoxin initially induces a lung injury response in fetal sheep lung. We evaluated injury responses to endotoxin characteristic of lung injury in the adult. We assessed induction of heat shock protein 70 (HSP70) as an indicator of oxidant injury $(19,28)$, interleukin (IL)-8 as a mediator of neutrophil recruitment (17), and the loss of surfactant protein $B$ (SP-B) from alveolar type II cells as an indicator of injury to alveolar type II cells (29). Apoptosis, proliferation, and alveolar type II cell numbers were evaluated as indicators of remodeling of the fetal lung.

\section{MATERIALS AND METHODS}

Animals, study design, and endotoxin. The animal studies were performed in Western Australia, as approved by the Animal Care and Use Committees from the Cincinnati Children's Hospital and the Western Australian Department of Agriculture. Date-bred Merino ewes were randomized to receive $4 \mathrm{mg}$ of endotoxin at $5 \mathrm{~h}, 24 \mathrm{~h}, 72 \mathrm{~h}$, or 7 days before delivery at 125 days gestational age (Fig. 1 ). The 4 -mg dose was the lowest dose that gave consistent maturational responses (16). Endotoxin (Escherichia coli 055:B5; Sigma Chemical, St. Louis, MO) was solubilized in saline and filtered through a $0.45-\mu \mathrm{m}$ filter. Intra-amniotic saline or endotoxin injections were given with 20-gauge spinal needles with ultrasound guidance $(13,14)$. The inflammatory responses in the chorioamnion, amniotic fluid, and lung tissue were recently reported using samples from the same animals (16).

Delivery and postnatal assessment. Preterm lambs were delivered at 125 days gestational age by cesarean section (7, 12). The thorax was opened, and the top right lobe of the lung was inflation fixed with $10 \%$ formalin at $30 \mathrm{cmH}_{2} \mathrm{O}$ pressure.

The costs of publication of this article were defrayed in part by the payment of page charges. The article must therefore be hereby marked "advertisement" in accordance with 18 U.S.C. Section 1734 solely to indicate this fact. 


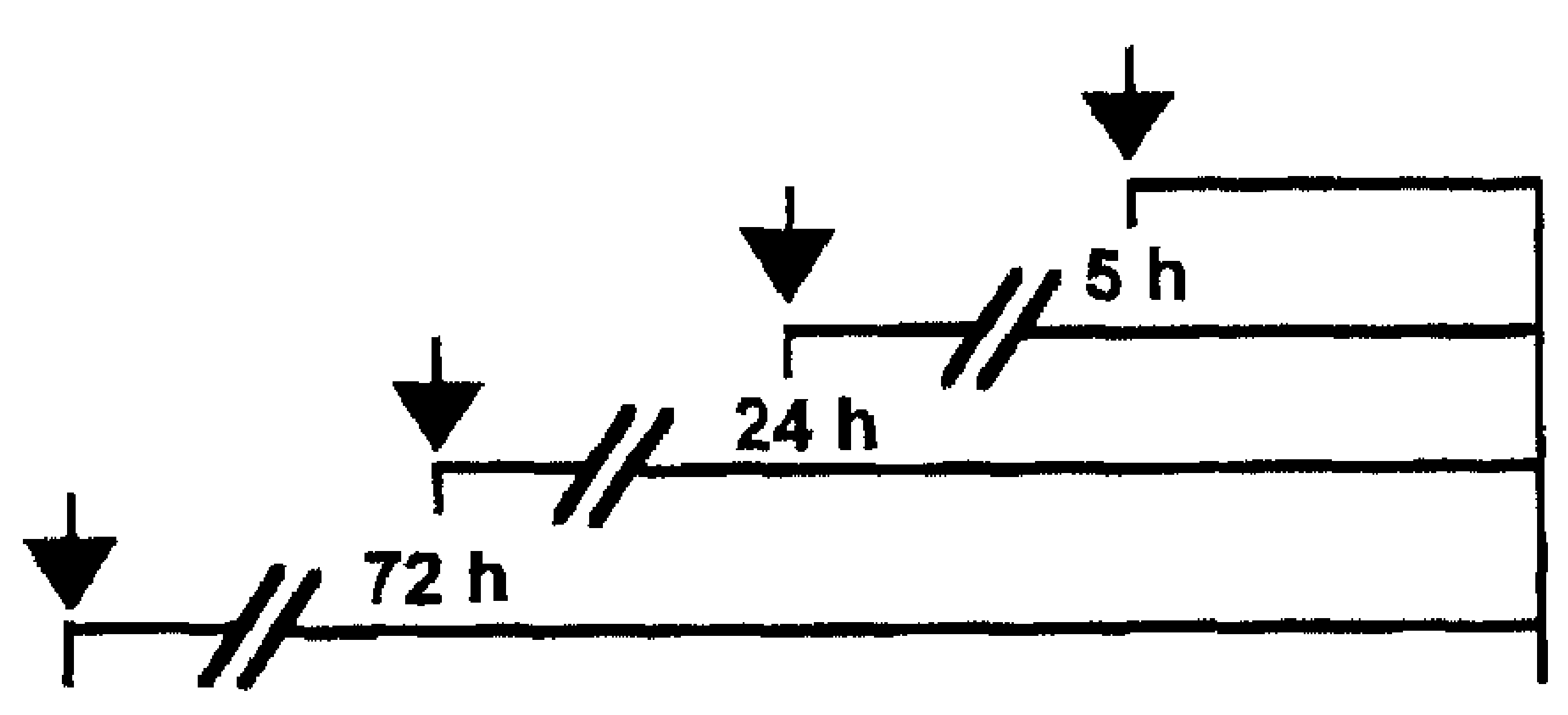

(n)

\section{$7 \mathrm{~d}$}

Deliver 125 d GA

Fig. 1. Study design: intra-amniotic injections of $4 \mathrm{mg}$ of endotoxin were given $5 \mathrm{~h}, 24 \mathrm{~h}, 72 \mathrm{~h}$, and 7 days before delivery at 125 days (d) gestational age (GA). Intra-amniotic injections are marked with arrows. The numbers of animals/group are given in parentheses.

The left lung was lavaged as previously described (24). Five alveolar lavages of the left lung with $0.9 \% \mathrm{NaCl}$ at $4^{\circ} \mathrm{C}$ were pooled, and aliquots were saved for determination of saturated phosphatidylcholine (Sat PC), IL-8, and SP-B $(7,24)$. A piece of the lavaged left lung was frozen.

Immunohistochemistry and histological analyses. Lung tissue was formalin fixed, embedded in paraffin, and cut in $5-\mu \mathrm{m}$ sections. Endogenous peroxidase activity was removed by incubation with hydrogen peroxide. Nonspecific binding sites were blocked with serum. Sections were incubated with a rabbit polyclonal antibody for HSP70 (Santa Cruz Biotechnology, Santa Cruz, CA). After being washed with PBS to remove unbound antibody, the slides were incubated with the secondary biotinylated antibody against rabbit IgG (Vector Laboratories, Burlingame, CA). After adding avidin and horseradish peroxidase (Vector Laboratories), staining of HSP70-positive cells was developed with diaminobenzidine and cobalt with a nuclear fast red counterstain (21).

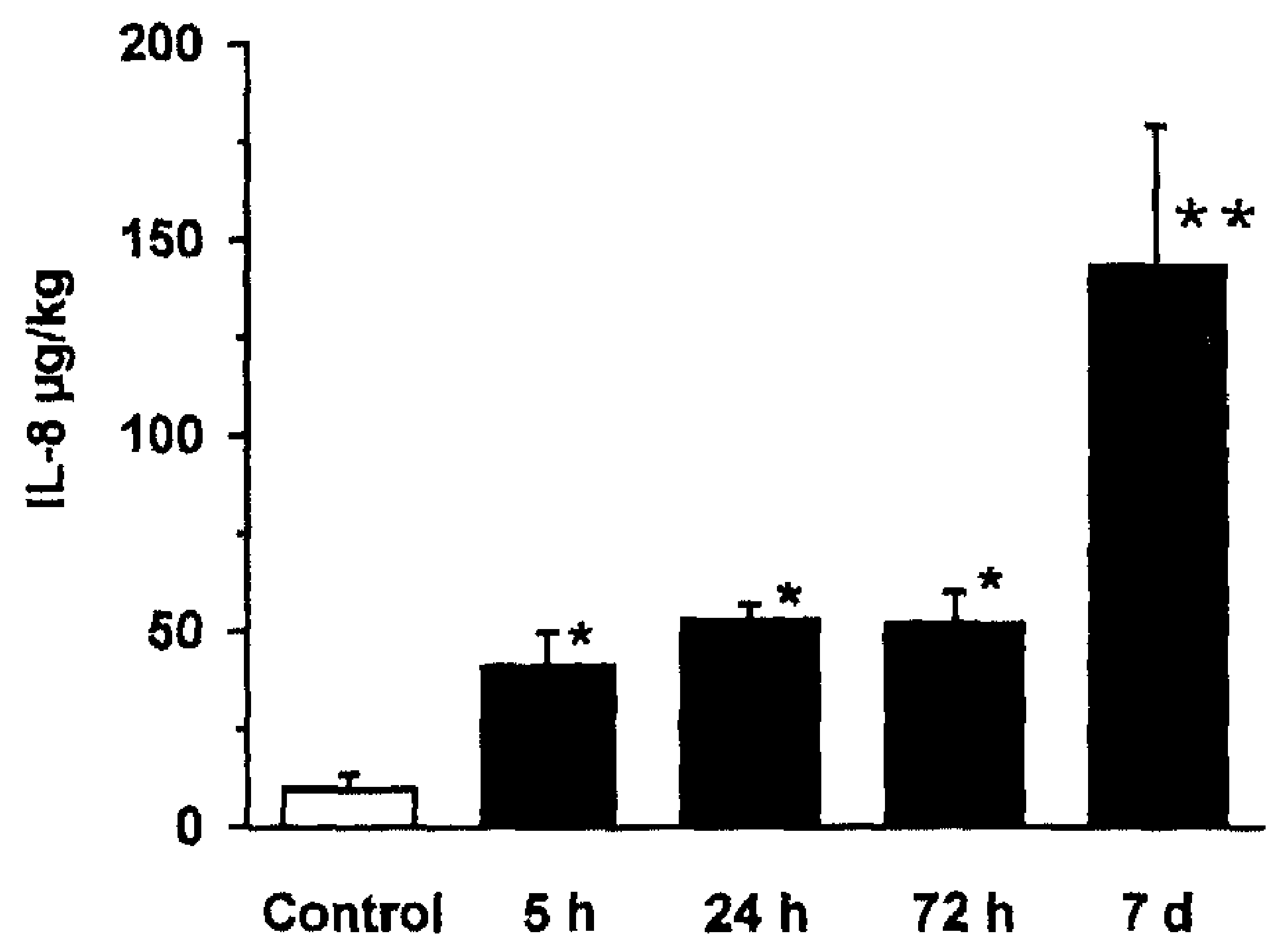

Fig. 3. Interleukin (IL)-8. IL-8 concentration was measured in alveolar lavage fluid by ELISA and standardized per kilogram of body wt. IL- 8 increased at $5 \mathrm{~h}$ and at all later time points vs. control. At 7 days, IL-8 increased further $\left({ }^{*} P<0.05\right.$ vs. control, ${ }^{*} P P<0.05$ vs. $72 \mathrm{~h})$.

Alveolar type II cells were stained after antigen retrieval with a mouse monoclonal antibody specific for thyroid transcription factor-1 (TTF-1) as previously described (11, 21, 22). The antibody was kindly provided by Dr. J. A. Whitsett. The SP-B in the alveolar type II cells was evaluated by immunohistochemistry using a rabbit anti-SP-B that reacts with both completely processed and unprocessed forms of SP-B (1). Sections were graded for the number of SP-B-positive cells using a scale from 0 to 4 . For each triplicate section from each animal, 12 areas were randomly selected and evaluated. Sections stained with hematoxylin and eosin were evaluated
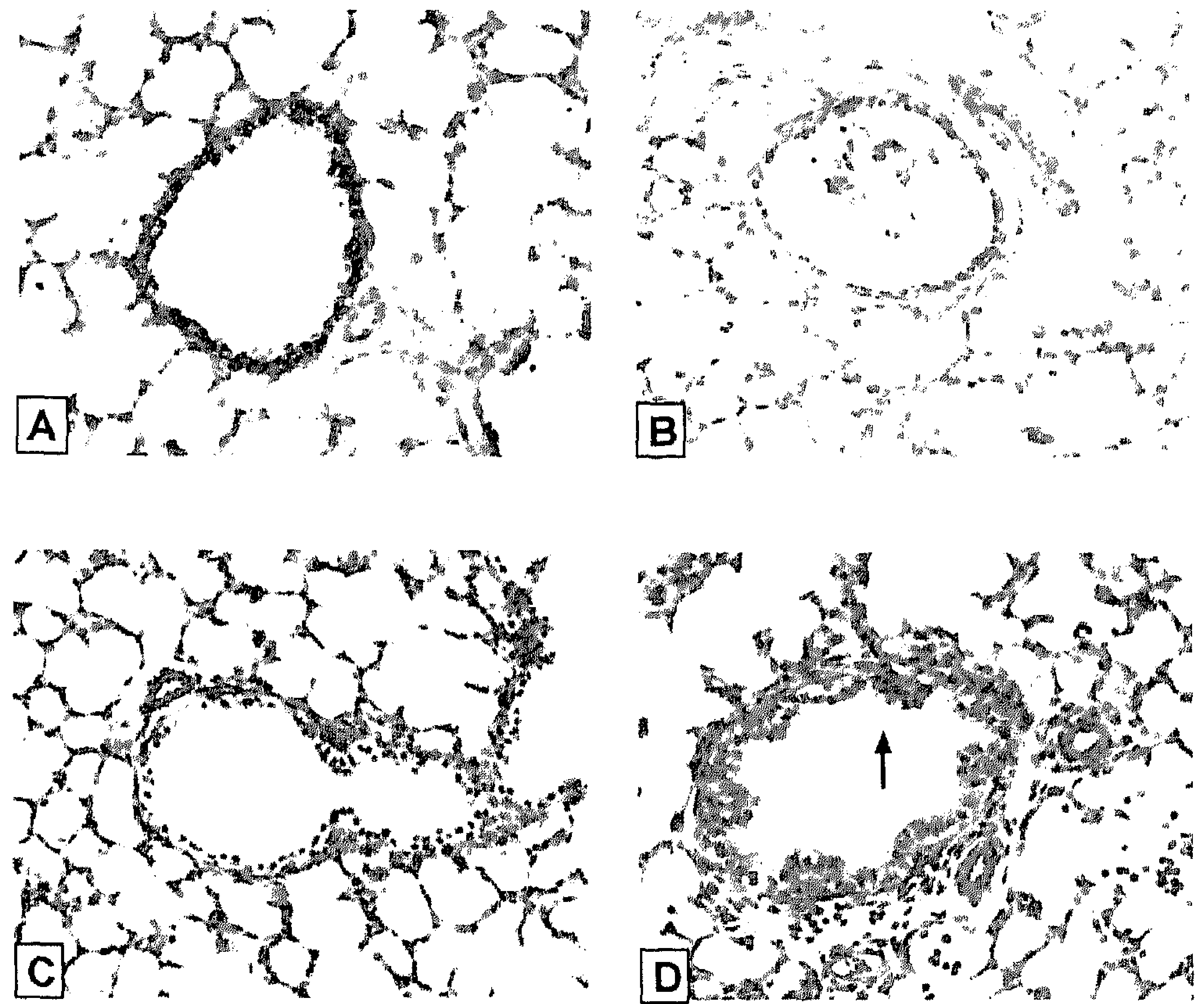

Fig. 2. Heat shock protein 70 (HSP70) and inflammatory cells. A: HSP70 was expressed at $5 \mathrm{~h}$ in the epithelial cells of the fetal airways but not in the parenchyma. $B$ : at $24 \mathrm{~h}$, no HSP70 was detectable. $C$ : hematoxylin and eosin staining of fetal lung after $5 \mathrm{~h}$ of endotoxin exposure. $D$ : inflammatory cells in epithelium of large airways at $24 \mathrm{~h}$ after intra-amniotic endotoxin are indicated by arrow. The cells were predominantly neutrophils. Magnification $\times 320$. 
for inflammatory changes, such as neutrophil influx, in the airways.

IL-8. The potent neutrophil chemoattractant IL-8 was quantified by enzyme-linked immunosorbent assay using antibodies from Chemicon (Temecula, CA) (16). Recombinant protein as a standard was kindly provided by CSIRO (Parkville, Victoria, Australia). The level of detection was 0.5 $\mathrm{ng} / \mathrm{ml}$.

Quantification of SP-B and Sat PC. SP-B was measured in alveolar lavage fluid and in lung tissue after alveolar lavage. Lung tissue was homogenized in $10 \mathrm{mM}$ Tris, $\mathrm{pH} 7.3$, and 2 M sucrose (vol/vol 7:1) to which protease inhibitors were added (Protease Cocktail; Roche Molecular Diagnostics, Indianapolis, IN). Homogenates were centrifuged for $10 \mathrm{~min}$ at $500 \mathrm{~g}$ at $4^{\circ} \mathrm{C}$, and the supernatant was used for SP-B measurement by Western blots as previously described (1). SDSPAGE for SP-B was carried out using 10-20\% gradient tricine gels (Novex, San Diego, CA). Samples containing 3 nmol of Sat PC were electrophoresed along with an ovine SP-B standard under nonreducing conditions (1). Proteins were transferred to polyvinylidene fluoride (PVDF) membranes (Schleicher \& Schuell, Keene, NH) for immunoblot analysis using a rabbit anti-SP-B that reacts with both completely processed and unprocessed forms of SP-B (1). The PVDF membrane was first blocked with 5\% low-fat milk (wt/vol) in Tris-buffered saline, $\mathrm{pH} 7.4$, containing $0.1 \%$ (vol/ vol) Tween 20 . The antibody was diluted and incubated overnight. Horseradish peroxidase-conjugated goat anti-rabbit immunoglobulin (Calbiochem, La Jolla, CA) was used as secondary antibody, and enhanced chemiluminescence substrates (Amersham, Arlington Heights, IL) were used to develop the immunoblots. Separate estimates of the amount of fully processed and partially processed SP-B were made by calculation of the relative band densities using Alpha-Imager 2000 documentation and Analysis software (Alpha Innotech, San Leandro, CA). Mature SP-B was calculated per kilogram
Fig. 4. Surfactant protein B (SP-B) in alveolar type II cells and in the lung. $A$ : sections were stained with an antibody that reacts with processed and unprocessed SP-B. Representative sections for each time point are shown. Magnification $\times 320$. B: immunostaining for SP-B was graded from 0 to 4 . Intra-amniotic endotoxin reduced the SP-B content of type II cells within $5 \mathrm{~h}$. At $72 \mathrm{~h}$ and at 7 days after intra-amniotic injection of endotoxin, the score for SP-B staining was higher than in controls. $C$ : quantification of total (fully processed and partially processed) SP-B in total lung by Western blot expressed relative to a normalized value of 1.0 for the control group. At $72 \mathrm{~h}$ and at 7 days, the amount of total SP-B increased ( $P<$ 0.05 vs. control).
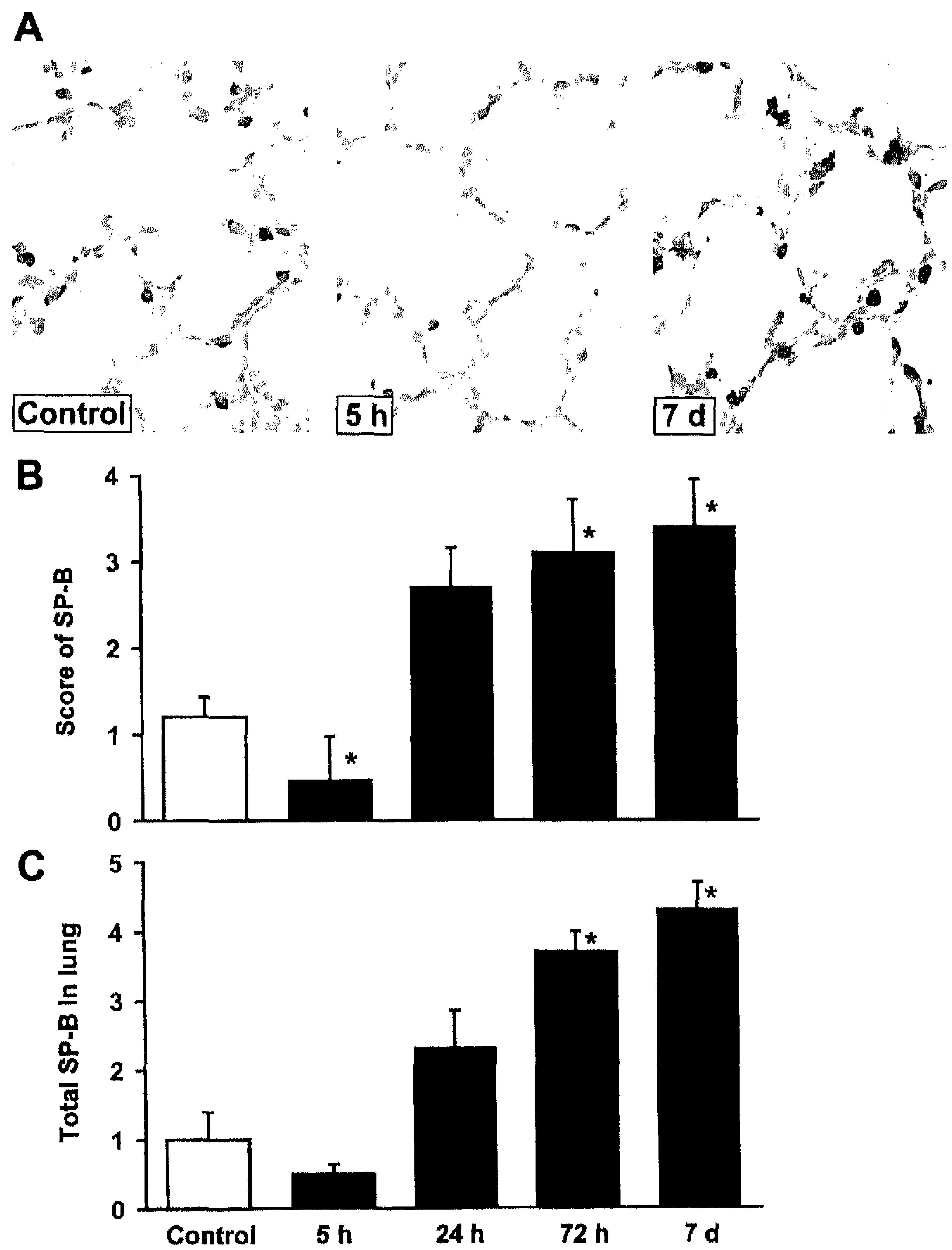
of body wt in the alveolar lavage fluid and in the lung homogenate. Percent secretion of mature SP-B was calculated by dividing the amount in the alveolar lavage fluid by the sum of mature SP-B in alveolar lavage fluid and lung homogenate.

Sat PC was measured in alveolar lavage and lung tissue after lavage. Sat PC was isolated from chloroform-methanol (2:1) extracts by neutral alumina column chromatography after exposure of lipid extracts to osmium tetroxide (18). Sat $\mathrm{PC}$ was quantified by phosphorus assay (3).

Apoptosis and alveolar type II cell quantification. Apoptotic cells were detected by terminal deoxynucleotidyltransferasemediated dUTP nick end labeling using biotin-dUTP (TACS 2 TdT-DAB kit; Trevigen, Gaithersburg, MD). Alveolar type II cells were identified by staining with a monoclonal antibody against TTF-1 (see Immunohistochemistry and histological analyses). The percentages of apoptotic cells and alveolar type II cells were quantified relative to all cells of the lung parenchyma. Intra-amniotic endotoxin injection induced both lung maturation and an arrest of alveolar septation, which reduced the volume of the parenchyma and increased the lung gas volume within 7 days $(14,26)$. The number of alveolar type II cells was not quantified after intra-amniotic endotoxin exposure. The quantification of alveolar type II cells relative to lung volume will be influenced by changes in the parenchyma to air space volume. Therefore, we quanti- fied the apoptotic cells and alveolar type II cells relative to all cells by counting nuclei. Five sections for each animal were quantified.

Proliferation. Proliferating cell nuclear antigen (PCNA) is a nonhistone protein found in nuclei in the S, G2, and $M$ phases of cell mitosis (8). Staining for PCNA was performed with a biotinylated monoclonal antibody (Zymed Laboratories, San Francisco, CA) and was developed with diaminobenzidine and cobalt with a nuclear fast red counterstain. The percentage of proliferating cells was quantified relative to all cells of the lung parenchyma.

Data analysis. Results are given as means $\pm \mathrm{SE}$. Comparisons between endotoxin-treated and untreated lambs were by analyses of variance with Student-Newman-Keuls tests used for post hoc analyses. Significance was accepted at $P<$ 0.05 .

\section{RESULTS}

HSP70, inflammatory cells, and IL-8 as indicators of lung injury. HSP70, an indicator of oxidant-stress mediated lung injury, was not expressed in control animals. In endotoxin-treated animals, HSP70 stained intensely in the epithelium of the conducting airways but not in the alveolar or vascular structures at $5 \mathrm{~h}$
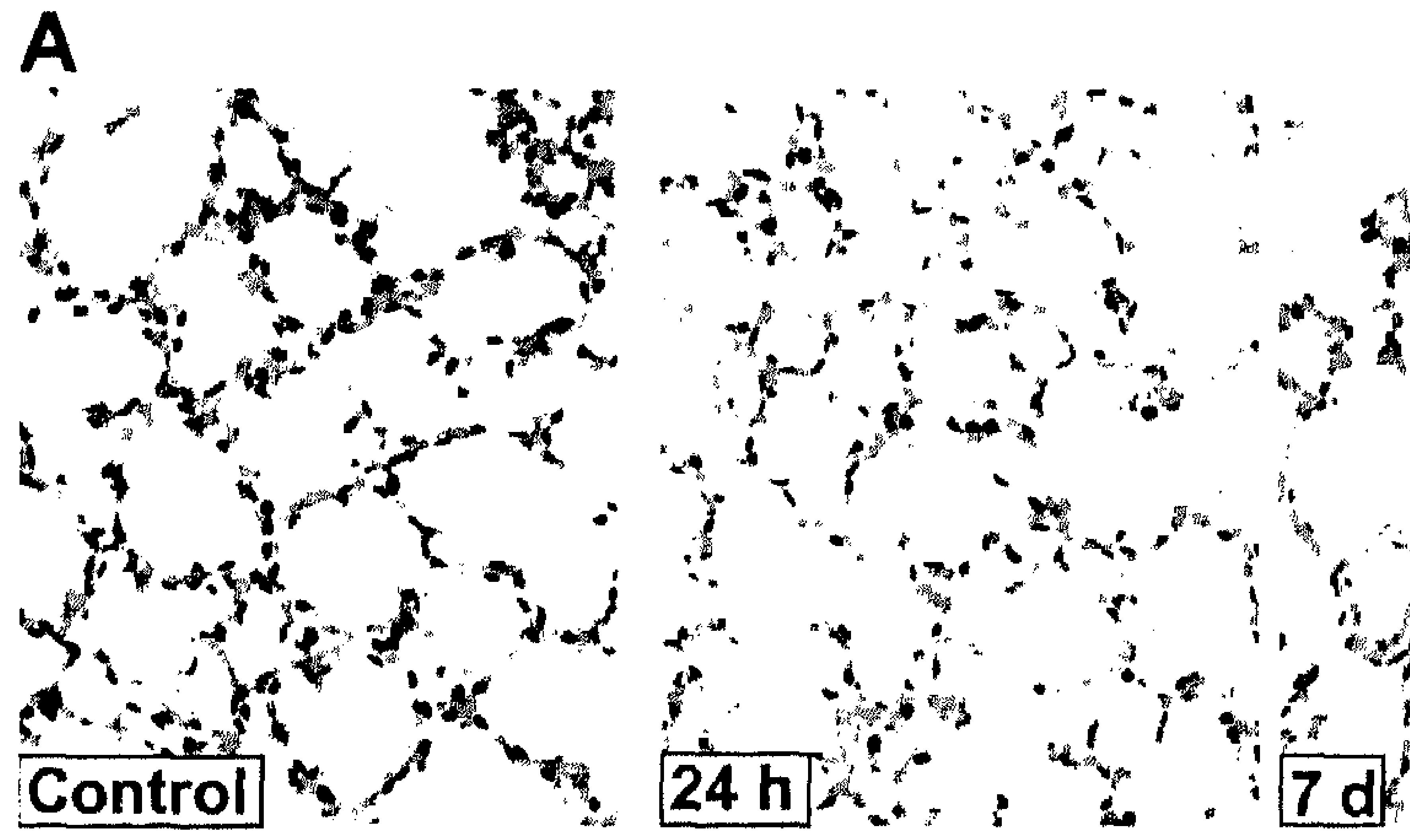<smiles>CCCCC</smiles><smiles>CC(C)(C)C(C)(C)C(C)(C)C</smiles>

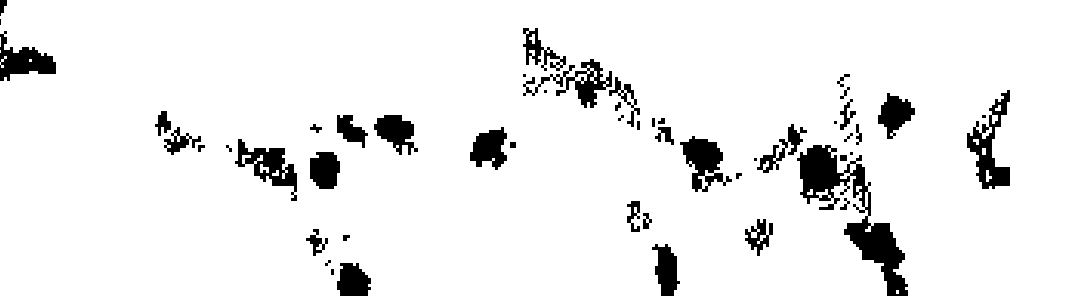

B

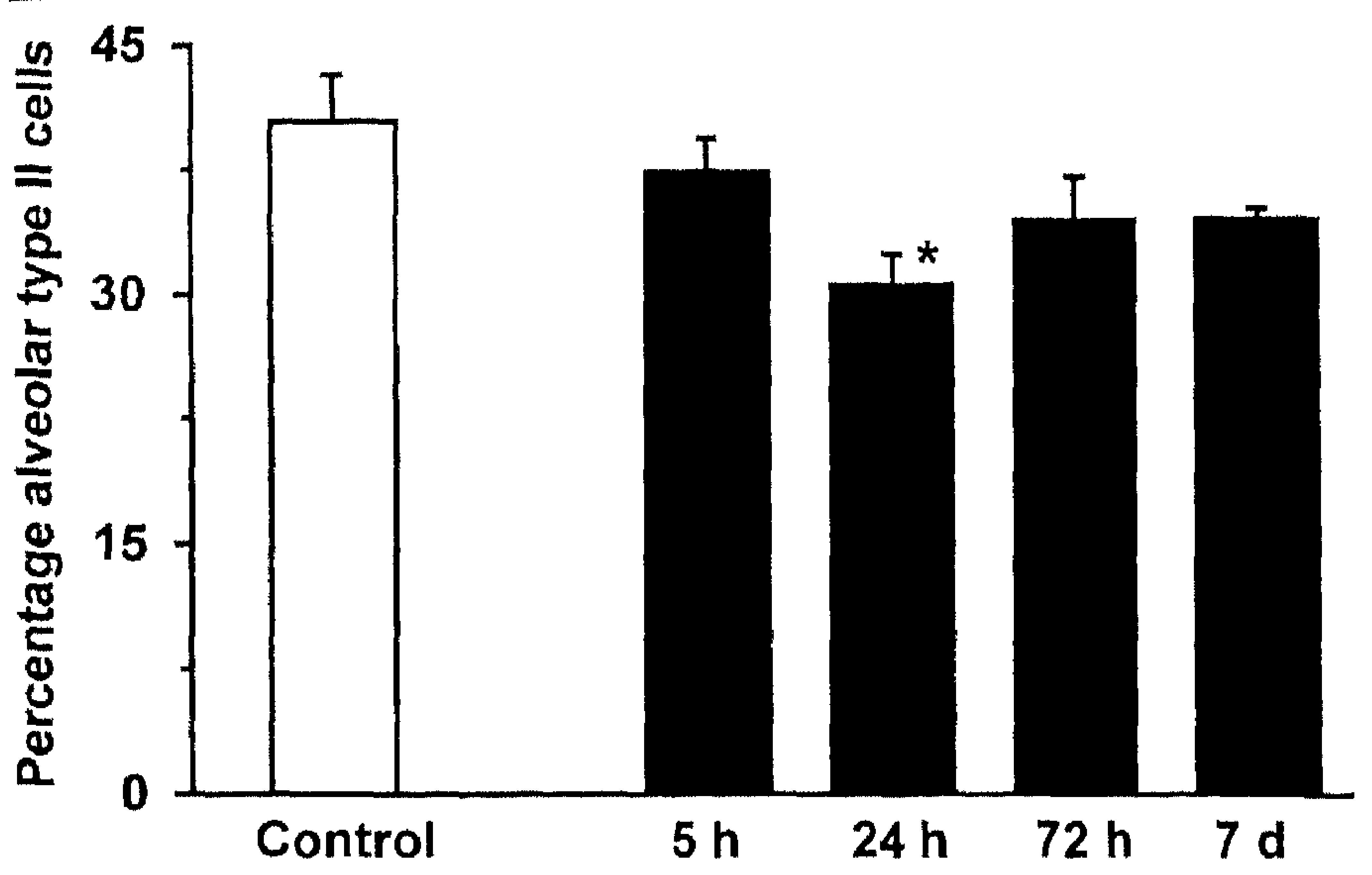

Fig. 5. Alveolar type II cells. A: alveolar type II cells were stained for thyroid transcription factor-1. Representative sections are shown for controls and lungs $24 \mathrm{~h}$ and 7 days after endotoxin exposure. Magnification $\times 320$. B: num. ber of alveolar type II cells was determined relative to all cells in the lung parenchyma by counting nuclei. The percentage of alveolar type II cells was reduced at $24 \mathrm{~h}$. At other time points, the numbers were not different $(* P<$ 0.05 vs. control). 


\section{INJURY AFTER INTRA-AMNIOTIC ENDOTOXIN}

A). By $24 \mathrm{~h}$, there was no expression of HSP70 ble in epithelial cells lining the large airways or distal lung parenchyma (Fig. 2B), and no HSP70 sion was detectable at $72 \mathrm{~h}$ and at 7 days. At $5 \mathrm{~h}$, vere no inflammatory changes in the large air$\mathfrak{f}$ in the distal lung parenchyma (Fig. $2 C$ ). By - he large airways were infiltrated with inflamcells, most of which were neutrophils based on ppearance at high magnification (Fig. 2D). Neuis were also present in the alveoli. The inflam$r$ cells persisted at $72 \mathrm{~h}$ and at 7 days. There were ammatory cells in the lungs of control animals. potent neutrophil chemoattractant, was increased imately threefold in alveolar washes from endoxposed lambs at $5 \mathrm{~h}$ and remained increased 7 fter endotoxin exposure (Fig. 3).

3 and alveolar type II cell numbers. Immunohisiistry demonstrated that SP-B was lost from ar type II cells $5 \mathrm{~h}$ after intra-amniotic endotoxin ire (Fig. $4, A$ and $B$ ). This depletion was no present at $24 \mathrm{~h}$, and more SP-B containing type 3 was identified at $72 \mathrm{~h}$ and at 7 days. The total it of SP-B in the alveolar wash and lung tissue sed qualitatively at $5 \mathrm{~h}$ and then increased 4.6$\checkmark 7$ days (Fig. $4 C$ ). The ratio of secreted mature in the airspace to total SP-B increased from $2.0 \%$ in controls to $26.1 \pm 5.2 \%$ at $5 \mathrm{~h}(P<0.05)$. ercent of SP-B in the air spaces increased to
$62.7 \pm 8.5 \%$ at 7 days $(P<0.05$ vs. control and $5 \mathrm{~h})$. The loss of SP-B from the tissue is consistent with the decreased immunostaining for SP-B.

The number of alveolar type II cells identified by TTF-1 staining as a proportion of total cells was not changed $5 \mathrm{~h}$ after intra-amniotic endotoxin exposure (Fig. 5). At $24 \mathrm{~h}$, the percent of alveolar type II cells was reduced by $-25 \%$, and at $72 \mathrm{~h}$ and at 7 days, the number of type II cells was not different from control animals.

Tissue repair by apoptosis and proliferation. The percent of apoptotic cells and the cell populations undergoing apoptosis changed over time. In controls and at $5 \mathrm{~h}$, few cells were apoptotic (Fig. 6A). At $24 \mathrm{~h}$, the highest percent of apoptotic cells was identified (Fig. $6 B)$. Inflammatory cells in both the air spaces and epithelial cells were apoptotic. By $72 \mathrm{~h}$ and 7 days, fewer parenchymal cells were apoptotic, and the apoptotic cells were primarily inflammatory cells.

To assess proliferation, lung sections were stained for PCNA, a nonhistone protein elevated in the $\mathrm{S}$, G2, and $M$ phases of mitosis, and the cells were quantified (Fig. 7). There was no increase in proliferating cells as indicated by PCNA staining 5 or $24 \mathrm{~h}$ after intra-amniotic endotoxin exposure. At $72 \mathrm{~h}$ and at 7 days, the number of proliferating epithelial cells was increased.
Apoptotic cells. A: at $5 \mathrm{~h}$, few apoptotic tre detected. $B$ : at $24 \mathrm{~h}$, parenchymal d inflammatory cells in the air spaces sitive. Arrows indicate apoptotic cells cation $\times 640$ in $A$ and $B$. $C$ : quantifiJf apoptotic cells per high power field zent of total cells $(* P<0.05$ vs. \$).

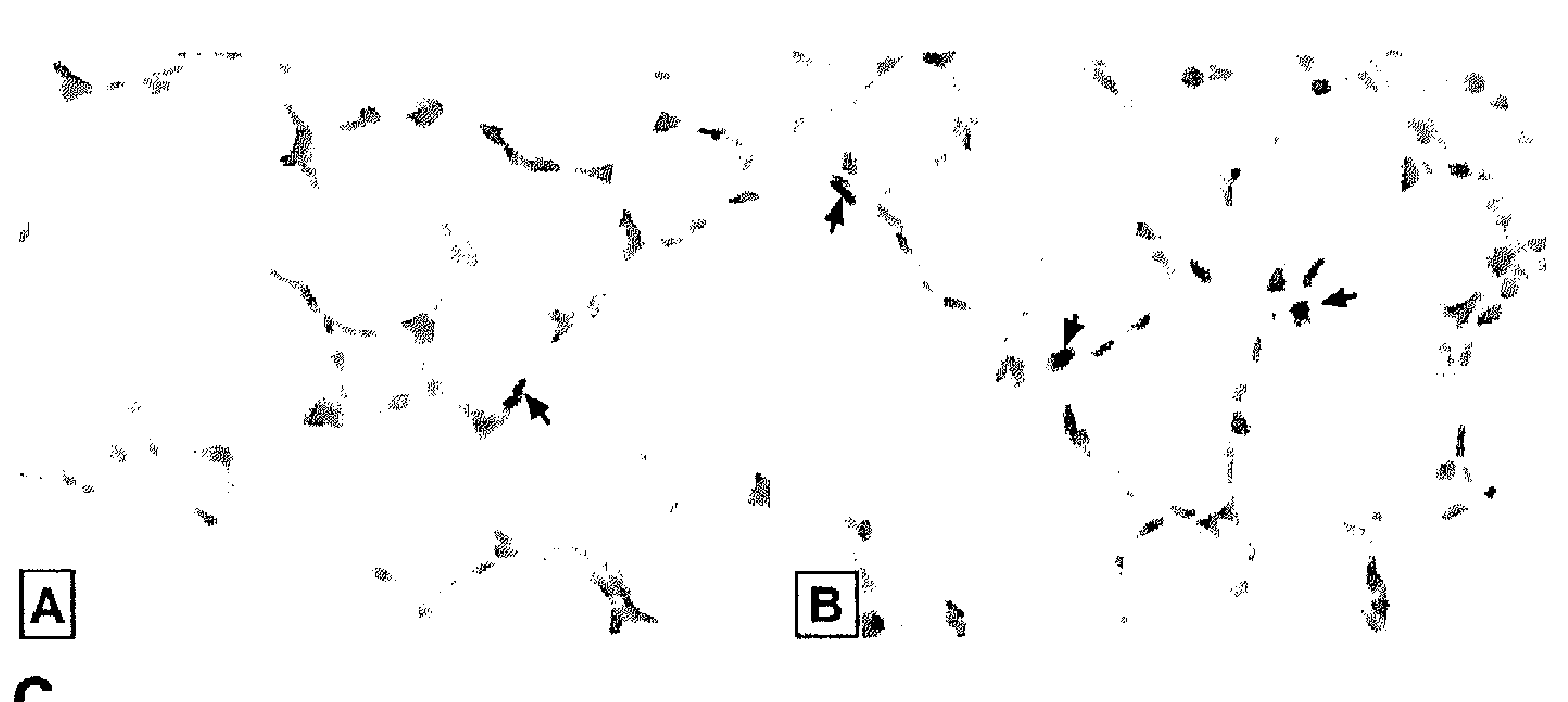

C

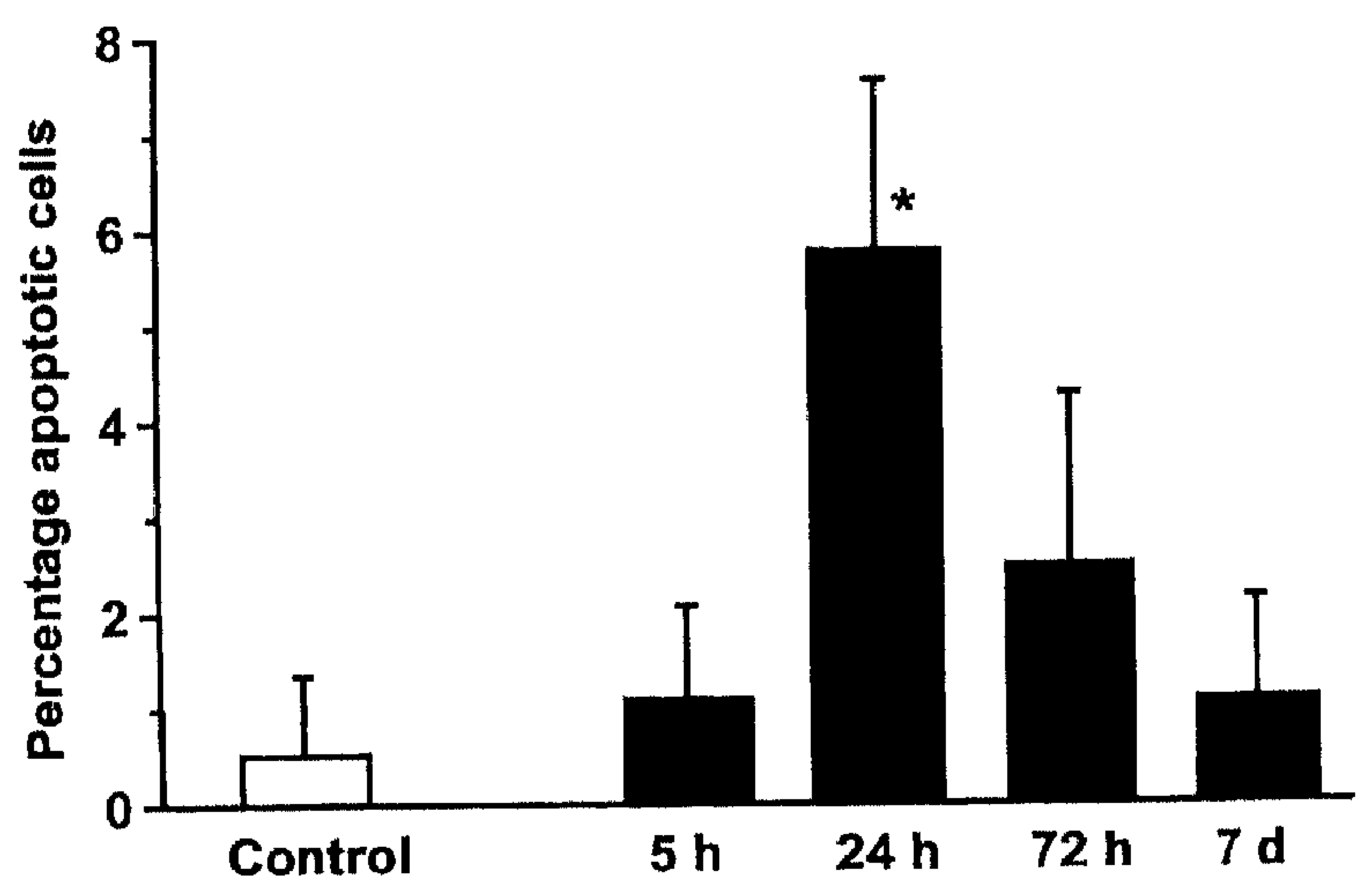




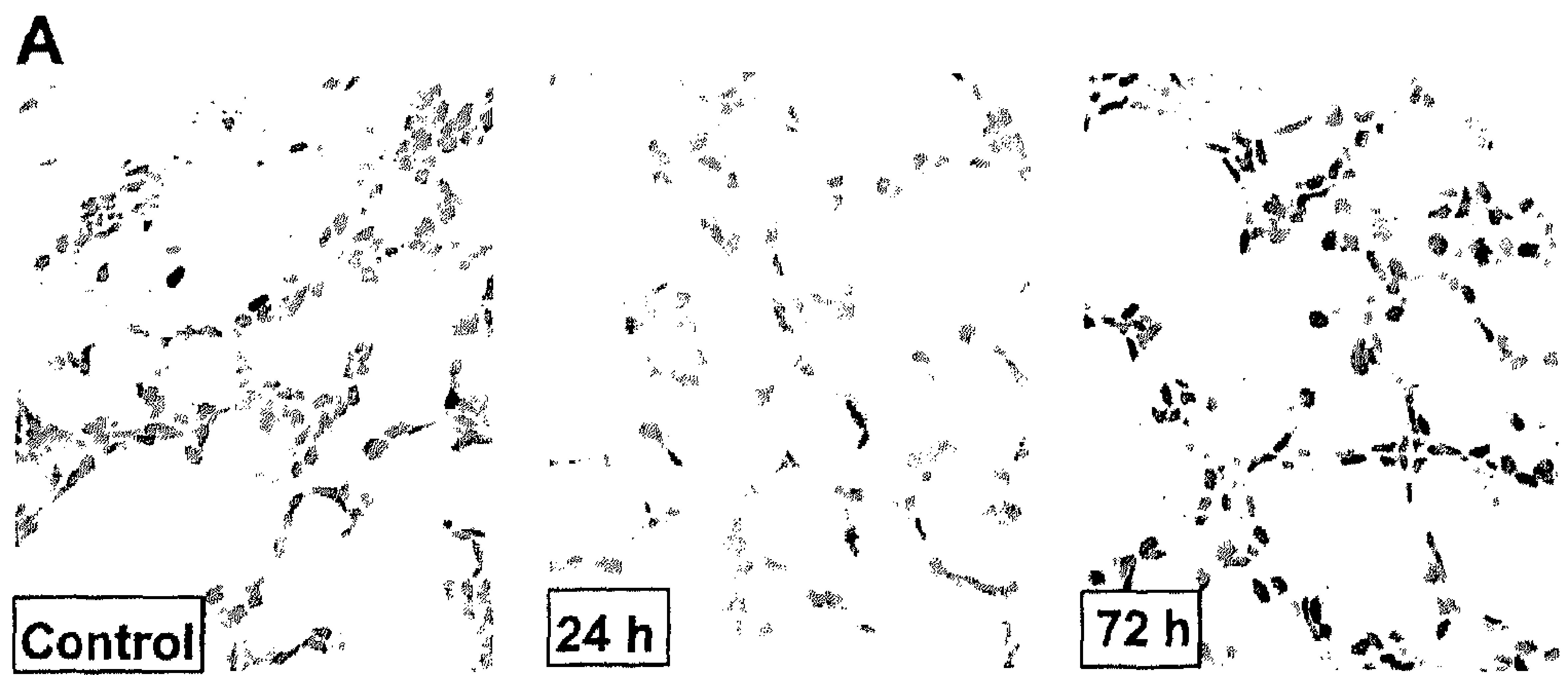

B

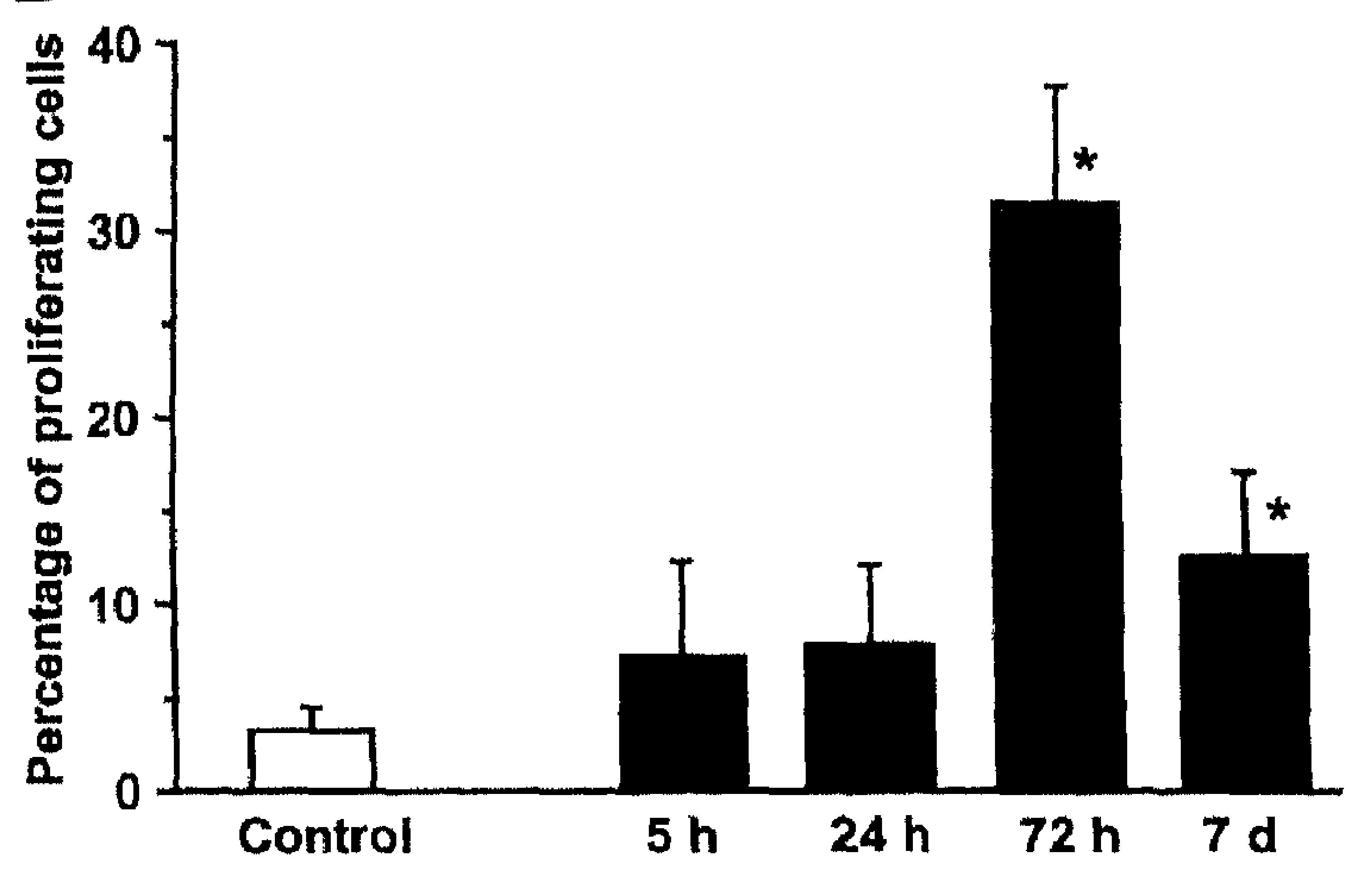

Fig. 7. Cell proliferation in fetal lung. $A$ : lung sections were stained for proliferating cell nuclear antigen (PCNA), a nonhistone protein elevated in the $\mathrm{S}$, G2, and $M$ phases of cell mitosis. Magnification $\times 320, B$ : percentage of proliferating cells. At 5 and $24 \mathrm{~h}$ after intra-amniotic injection of endotoxin, the number of proliferating cells did not change. At $72 \mathrm{~h}$ and at 7 days, more cells were positive for PCNA ( $* P<0.05$ vs. controls),

\section{DISCUSSION}

We found that intra-amniotic endotoxin induces injury, inflammation, apoptosis, and remodeling of the fetal lung. A lung injury response was indicated by the expression of HSP70 in the epithelial cells of the large airways and depletion of SP-B from alveolar type II cells at $5 \mathrm{~h}$. The percent of alveolar type II cells decreased at $24 \mathrm{~h}$ but was not different from controls at 7 days. Apoptotic cell death was maximal at $24 \mathrm{~h}$, and cell proliferation was maximal at $72 \mathrm{~h}$. We previously reported that intra-amniotic endotoxin caused recruitment of hydrogen peroxide-producing neutrophils to the fetal lungs and proinflammatory cytokine expression by cells recovered by alveolar lavage $(15,16)$. The identification of HSP70 in the large airway lining cells at $5 \mathrm{~h}$ indicates an oxidant injury response of the tissue $(19,28)$. Although hydrogen peroxide production was maximal at $24 \mathrm{~h}$ (16), the HSP70 response occurred at $5 \mathrm{~h}$ and was localized to the airways. Cells in the amniotic fluid contained increased IL-8 mRNA within $5 \mathrm{~h}$ of endotoxin exposure, and IL-8 protein was elevated in amniotic fluid at $72 \mathrm{~h}$ and at 7 days (16). The inflammatory cells recruited to the lungs were activated based on hydrogen peroxide production only at 5 and $24 \mathrm{~h}$, and cell numbers were decreasing by 7 days.
The acute inflammatory responses in the fetal lung resolved quickly, and the remodeling and maturation effects then became evident. However, IL-8 remained elevated in alveolar washes and was increased at 7 days, and inflammatory cells persisted. We previously found that cells in amniotic fluid continued to express proinflammatory cytokines for 7 days after a single dose of intra-amniotic endotoxin, and repeated doses of endotoxin did not cause increased inflammation (13, 16). Therefore, the brief inflammatory response of the fetal lung may result from a downregulation of the response of the fetal lung to the inflammatory stimulus rather than disappearance of the stimulus.

In the fetal lung, the alveolar type II cells are not fully developed, and SP-B is only partially processed (1, 10). In these animals, more cells stained for TTF-1 than for SP-B, indicating that some of the immature type II cells were not making enough SP-B to immunostain. We found that the immature alveolar type II cells that contained SP-B responded to intra-amniotic endotoxin with loss of SP-B. In adult mice, the secretion of SP-B after intratracheal adenovirus instillation was a marker of alveolar type II cell injury (29). Two events related to SP-B occurred after intra-amniotic endotoxin. At $5 \mathrm{~h}$, the lung injury caused a loss of 
mature SP-B from alveolar type II cells, followed by a lung maturation response with large increases in SP-B in the tissue and the alveoli at 7 days. Therefore, the initial injury response of the immature alveolar type II cells was followed by a maturation of the alveolar type II cells.

The transient decrease of alveolar type II cells at $24 \mathrm{~h}$ coincided with the maximal percent of apoptotic cells. Alveolar type II cells can undergo apoptosis in vivo after injury (2). Because the lung parenchyma-toair space volume ratio changes after intra-amniotic endotoxin exposure, lung structure and cell numbers also change at each time point. The quantification of alveolar type II cells relative to all cells is independent of the thinning of the parenchyma and should give a reasonable estimate of alveolar type II cell numbers. The general conclusion was that alveolar type II cells did not change much because of a balance between cell loss and proliferation.

We have better characterized the early phase of lung injury that occurs in our model of endotoxin-induced chorioamnionitis. The chorioamnion and the fetal lung are inflamed very soon after exposure to intra-amniotic endotoxin, and the inflammation persists for several days. Elements characteristic of lung injury in adult animals occurred in the preterm lung soon after endotoxin exposure. There was a sequence of injury and inflammatory changes in the fetal lung within hours of endotoxin exposure that was followed by apoptotic cell death and remodeling within days. The injury resolves with thinning of the mesenchyme, increases in surfactant lipids and proteins, and an arrest of septation (14-16, 26). These changes appear physiologically to be maturation because lung mechanics and gas exchange improve (13). However, the resolution of injury resulted in altered alveolar development, also characteristic of oxidant- or ventilation-induced lung injury in the preterm $(4,5,23)$. We recently reported that IL-1 given by intra-amniotic injection can also induce the same alterations in lung development that result from endotoxin exposure (27). A question that remains to be resolved is whether injury to the fetal lung invariably triggers alterations in subsequent lung development.

We thank Dr. S. E. Wert for help with the immunohistochemical studies.

This study was supported by National Heart, Lung, and Blood Institute Grant HL-65397 and the histopathological core (HL-61646).

\section{REFERENCES}

1. Bachurski CJ, Ross GF, Ikegami M, Kramer BW, and Jobe AH. Intra-amniotic endotoxin increases pulmonary surfactant proteins and induces SP-B processing in fetal sheep. Am J Physiol Lung Cell Mol Physiol 280: L279-L285, 2001.

2. Bardales RH, Xie SS, Schafer RF, and Hsu SM. Apoptosis is a major pathway responsible for the resolution of type II pneumocytes in acute lung injury. Am J Pathol 149: 845-852, 1996.

3. Bartlett GR. Phosphorous assay in column chromatography. $J$ Biol Chem 234: 466-468, 1959.

4. Coalson JJ, Winter V, and deLemos RA. Decreased alveolarization in baboon survivors with bronchopulmonary dysplasia. Am J Respir Crit Care Med 152: 640-646, 1995.
5. Coalson JJ, Winter VT, Siler-Khodr T, and Yoder BA. Neonatal chronic lung disease in extremely immature baboons. Am J Respir Crit Care Med 160: 1333-1346, 1999.

6. Costeloe K, Hennessey E, Gibson AT, Marlow N, and Wilkinson AR. The EPICure study: outcomes to discharge from hospital for infants born after the threshold of viability. Pediat. rics 106: 659-671, 2000.

7. Davis AJ, Jobe AH, Häfner D, and Ikegami M. Lung function in premature lambs and rabbits treated with a recombinant SP-C surfactant. Am J Respir Crit Care Med 157: 553-559, 1998

8. Deckert M, Reifenberger $G$, and Wechsler W. Determination of the proliferative potential of human brain tumors using the monoclonal antibody Ki-67. J Cancer Res Clin Oncol 115: 179$188,1989$.

9. Goldenberg RL, Hauth JC, and Andrews WW. Intrauterine infection and preterm delivery. $N$ Engl J Med 342: 1500-1507, 2000.

10. Guttentag SH, Beers MF, Bieler BM, and Ballard PL Surfactant protein B processing in the human fetal lung. Am $J$ Physiol Lung Cell Mol Physiol 275: L559-L566, 1998.

11. Holzinger A, Dingle S, Bejarano PA, Miller MA, Weaver TE, Dihaurs R, and Whitsett JA. Monoclonal antibody to TTF-1: production, characterization and usefulness in tumor diagnosis. Hybridoma 15: 49-53, 1996.

12. Ikegami M, Jobe AH, Newnham J, Polk DH, Willet KE, and Sly $\mathbf{P}$. Repetitive prenatal glucocorticoids improve lung function and decrease growth in preterm lambs. Am J Respir Crit Care Med 156: 178-184, 1997 .

13. Jobe AH, Newnham JP, Willet KE, Moss TJ, Ervin MG, Padbury JF, Sly P, and Ikegami M. Endotoxin-induced lung maturation in preterm lambs is not mediated by cortisol. $A m J$ Respir Crit Care Med 162: 1656-1661, 2000.

14. Jobe AH, Newnham JP, Willet KE, Sly P, Ervin MG, Bachurski CJ, Possmayer F, Hallman M, and Ikegami M. Antenatal endotoxin and glucocorticoid effects on the lungs of preterm lambs. Am J Obstet Gynecol 182: 401-408, 2000.

15. Kallapur SG, Willet KE, Jobe AH, Ikegami M, and Bachurski CJ. Intra-amniotic endotoxin: chorioamnionitis precedes lung maturation in preterm lambs. Am J Physiol Lung Cell Mol Physiol 280: L527-L536, 2001.

16. Kramer BW, Moss TJ, Willet KE, Newnham JP, Sly PD, Kallapur SG, Ikegami M, and Jobe AH. Dose and time response after intraamniotic endotoxin in preterm lambs. Am J Respir Crit Care Med 164: 982-988, 2001.

17. Kwonz KY, Jones CA, Cayabysb R, Lecart C, Khuu H, Randhawa I, Hanley JM, Ramanathan R, deLemos RA, and Minso $P$. The effects of IL-10 on proinflammatory cytokine expression (IL-1b and IL-8) in hyaline membrane disease. Clin Immunol Immunopathol 88: 105-113, 1998.

18. Mason RJ, Nellenbogen J, and Clements JA. Isolation of disaturated phosphatidylcholine with osmium tetroxide. $J$ Lipid Res 17: 281-284, 1976.

19. Morimoto RI, Kroeger PE, and Cotto JJ. The transcriptional regulation of heat shock genes: a plethora of heat shock factors and regulatory conditions. In: Stress-Inducible Cellular Responses, edited by Feige U, Morimoto RI, Yahara I, and Polla B. Basel: Birkhäuser, 1996.

20. Nelson KB, Dambrosia JM, Grether JK, and Phillips TM. Neonatal cytokines and coagulation factors in children with cerebral palsy. Ann Neurol 44: 665-675, 1998.

21. Nogee LM, Wert SE, Proffit SA, Hull WM, and Whitsett JA. Allelic heterogeneity in hereditary surfactant protein B (SP-B) deficiency. Am J Respir Crit Care Med 161: 973-981, 2000.

22. Perl AK and Whitsett JA. Molecular mechanisms controlling lung morphogenesis. Clin Genet 56: 14-27, 1999.

23. Turrentine MA, Wilson PD, and Wilkins IA. A retrospective analysis of the effect of antenatal steroid administration on the incidence of respiratory distress syndrome in preterm twin pregnancies. Am J Perinatol 13: 351-354, 1996.

24. Wada K, Jobe AH, and Ikegami M. Tidal volume effects on surfactant treatment responses with the initiation of ventilation in preterm lambs. $J$ Appl Physiol 83: 1054-1061, 1997.

25. Watterberg KL, Demers LM, Scott SM, and Murphy S. Chorioamnionitis and early lung inflammation in infants in 


\section{INJURY AFTER INTRA-AMNIOTIC ENDOTOXIN}

whom bronchopulmonary dysplasia develops. Pediatrics 97: $210-215,1996$.

26. Willet KE, Jobe AH, Ikegami M, Brennan S, Newnham J, and Sly PD. Antenatal endotoxin and glucocorticoid effects on lung morphometry in preterm lambs. Pediatr Res 48: 782-788, 2000 .

27. Willet KE, Kramer BW, Kallapur SG, Moss TJ, Newnham JP, Sly PD, Ikegami M, and Jobe AH. Intra-amniotic injection of
IL-1 induces inflammation and maturation in Am J Physiol Lung Cell Mol Physiol 282: L41128. Wong HR and Wispe JR. The stress respon Am J Physiol Lung Cell Mol Physiol 273: L1-

29. Zsengeller Z, Wert SE, Bachurski CJ, Kirw BC, and Whitsett JA. Recombinant adenovir: surfactant homeostasis in mouse lung. Hum Ge 1344, 1997.

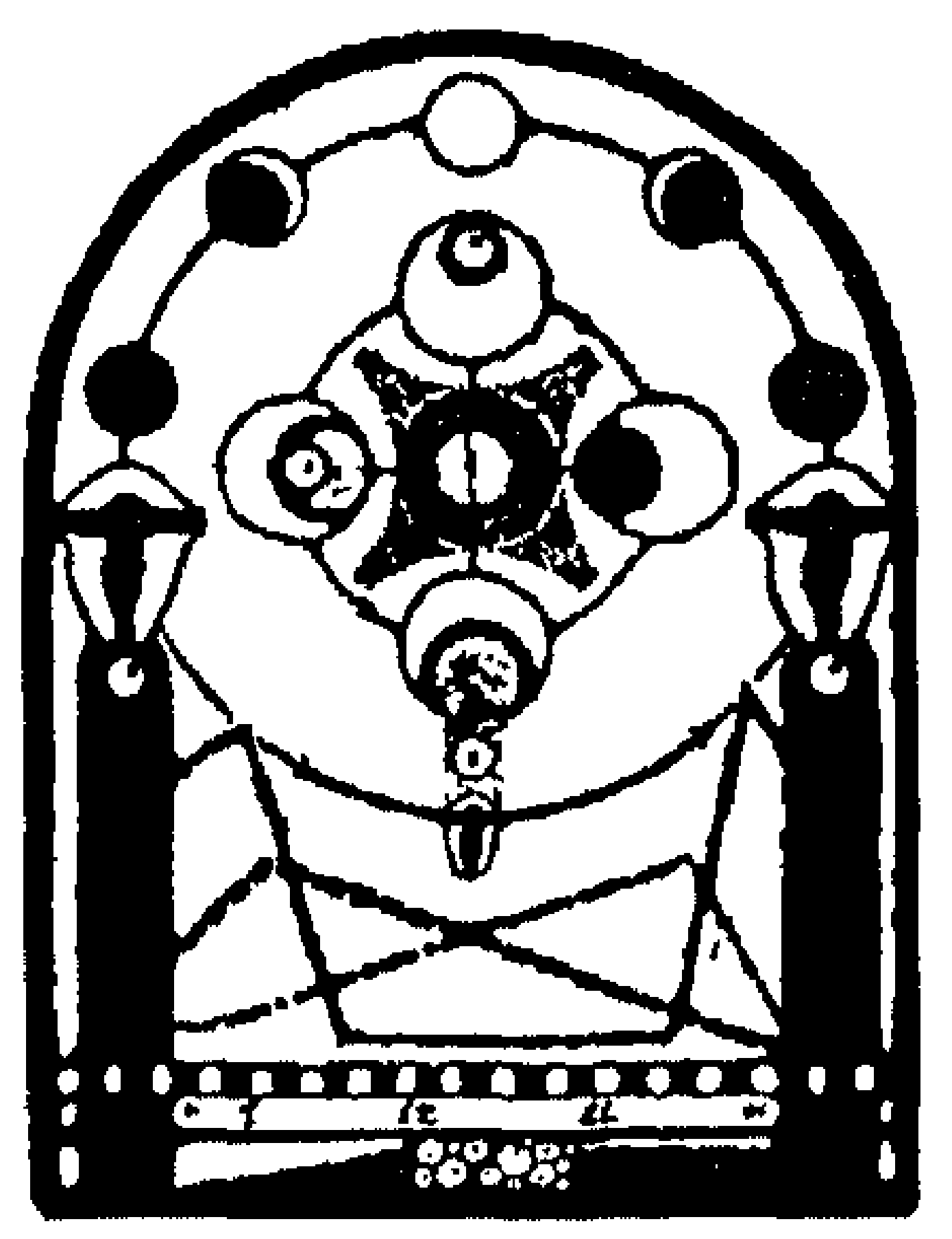




\section{CHAPTER 5}

\section{Antenatal inflammation induced TGF-beta1 but suppressed CTGF in preterm lungs}

Kunzmann S., Speer C.P., Jobe A.H., Kramer B.W. 


\title{
Antenatal inflammation induced TGF- $\beta 1$ but suppressed
}

\section{CTGF in preterm lungs}

\author{
Steffen Kunzmann, ${ }^{1}$ Christian P. Speer, ${ }^{1}$ Alan H. Jobe, ${ }^{2}$ and Boris W. Kramer ${ }^{1,3}$ \\ ${ }^{1}$ University Children's Hospital, Würzburg, Germany; ${ }^{2}$ Children's Hospital Medical Center, \\ Cincinnati, Ohio; and ${ }^{3}$ University Hospital, Maastricht, The Netherlands
}

Submitted 25 April 2006; accepted in final form 4 August 2006

Kunzmann, Steffen, Christian P. Speer, Alan H. Jobe, and Boris W. Kramer. Antenatal inflammation induced TGF- $\beta 1$ but suppressed CTGF in preterm lungs. Am J Physiol Lung Cell Mol Physiol 292: L223-L231, 2007. First published August 26, 2006; doi:10.1152/ajplung.00159.2006.-Chorioamnionitis is frequently associated with preterm birth and increases the risk of adverse outcomes such as bronchopulmonary dysplasia (BPD). Transforming growth factor (TGF) $-\beta 1$ is a key regulator of lung development, airway remodeling, lung fibrosis, and regulation of inflammation, and all these processes contribute to the development of BPD. Connective tissue growth factor (CTGF) is a downstream mediator of some of the profibrotic effects of TGF- $\beta 1$, vascular remodeling, and angiogenesis. TGF- $\beta 1$-induced CTGF expression can be blocked by TNF- $\alpha$. We asked whether chorioamnionitis-associated antenatal inflammation would regulate TGF- $\beta 1$, the TGF- $\beta 1$ signaling pathway, and CTGF in preterm lamb lungs. Fetal sheep were exposed to $4 \mathrm{mg}$ of intraamniotic endotoxin or saline for $5 \mathrm{~h}, 24 \mathrm{~h}, 72 \mathrm{~h}$, or 7 days before preterm delivery at 125 days gestation (full term $=150$ days). Intra-amniotic endotoxin increased lung TGF- $\beta 1 \mathrm{mRNA}$ and protein expression. Elevated TGF- $\beta 1$ levels were associated with TGF- $\beta 1$ induced phosphorylation of Smad2. CTGF was selectively expressed in lung endothelial cells in control lungs, and intra-amniotic endotoxin caused CTGF expression to decrease to $30 \%$ of control values and TNF- $\alpha$ protein to increase. The antenatal inflammation-induced TGF- $\beta 1$ expression and Smad signaling in the fetal lamb lung may contribute to impaired lung alveolarization and reduced lung inflammation. Decreased CTGF expression may inhibit vascular development or remodeling and limit lung fibrosis during remodeling. These effects may contribute to the impaired alveolar and pulmonary vascular development that is the hallmark of the new form of BPD.

chorioamnionitis; bronchopulmonary dysplasia; Smad signaling; fibrosis

LUNG INJURY IN THE MATURE lung often resolves with fibrosis, which is prominent in larger infants who developed bronchopulmonary dysplasia (BPD) after prolonged exposure to oxygen and mechanical ventilation $(1,22,25,27)$. In contrast, the lungs of preterm infants who most frequently develop BPD have less fibrosis but striking inhibition of alveolar septation and microvascular development $(14,22)$. This altered lung development occurs in preterm ventilated baboons and sheep in association with persistent inflammation.

The alterations in lung development resulting in BPD also have been associated with chorioamnionitis in very low-birthweight infants (48). Chorioamnionitis results in increased concentrations of proinflammatory cytokines in human amniotic fluid and fetal cord blood, presumably in response to bacterial

\footnotetext{
Address for reprint requests and other correspondence: B. W. Kramer, Dept. of Pediatrics, Academisch ziekenhuis Mastricht, Postbus 5800, 6202 AZ Maastricht, The Netherlands (e-mail: bkra@paed.azm.nl).
}

products and injury $(18,55)$. These proinflammatory cytokines may be important mediators in the early inflammatory response that recruits activated inflammatory cells to the fetal lung (12). Inflammation-induced tissue injury is normally followed by a phase of repair $(39,40,44)$. The endotoxin-induced chorioamnionitis in preterm lambs initiated a sequence of lung injury, inflammation, apoptosis, and remodeling that resulted in a phenotype of clinical lung maturation with increased surfactant and improved gas exchange, but with microvascular injury and decreased alveolar septation $(27,30,36)$. Within 7 days of intra-amniotic endotoxin exposure, the histological changes were similar to those in fetal sheep with mild BPD (52). The fetal lungs did not develop fibrosis, even with prolonged exposure to intra-amniotic endotoxin (30).

Lung injury in adult animals induces transforming growth factor (TGF)- $\beta 1$ as part of the tissue repair-and-healing process ("airway remodeling"). TGF- $\beta 1$ is present in an latent state, which prevents interaction with its receptor (32). The biological effects of TGF- $\beta 1$ may be controlled at the level of conversion of latent TGF- $\beta 1$ to active TGF- $\beta 1$ (33). If the repair processes are repeatedly triggered and not adequately controlled, fibrosis will ensue (4). TGF- $\beta 1$ also contributes to normal lung development. Overexpression of TGF- $\beta 1$ during the critical period of lung alveolarization in mice caused morphological changes similar to those in human BPD $(16,50)$. Downstream of TGF- $\beta 1$, connective tissue growth factor (CTGF) and other proteins modulate the cellular response to TGF- $\beta 1$ and can prolong wound healing and promote the fibrotic response. CTGF mediates the profibrotic effects of TGF- $\beta 1$ by stimulating fibroblast growth and extracellular matrix synthesis (20). In addition, CTGF increases the affinity of TGF- $\beta 1$ for its receptors (3) and influences the regulation of endothelial cell function, angiogenesis, and vascular remodeling $(7,41)$. TGF- $\beta 1$ normally induces CTGF expression in fibroblasts and endothelial cells (6), and CTGF expression can be inhibited by proinflammatory cytokines such as TNF- $\alpha$ (2). Because of its involvement in airway and vascular remodeling processes, CTGF might have a role in mediating the pathogenesis of BPD. However, there is no information about CTGF in BPD or in preterm animals. Therefore, we used lung tissue from preterm fetal sheep exposed to endotoxin-induced chorioamnionitis to measure TGF- $\beta 1$ signaling and CTGF expression. Our hypothesis was that chorioamnionitis induced by endotoxin would increase TGF- $\beta 1$ in the fetal lung but that CTGF might not be induced.

The costs of publication of this article were defrayed in part by the payment of page charges. The article must therefore be hereby marked "advertisement" in accordance with 18 U.S.C. Section 1734 solely to indicate this fact. 


\section{MATERIALS AND METHODS}

Tissue for study. The animal studies were performed in Western Australia, as approved by the Animal Care and Use Committees of the Cincinnati Children's Hospital and the Western Australian Department of Agriculture. Date-bred Merino ewes were randomized to receive $4 \mathrm{mg}$ of endotoxin (Escherichia coli, serotype 055:B5; Sigma Chemical, St. Louis, MO) at $5 \mathrm{~h}, 24 \mathrm{~h}, 72 \mathrm{~h}$, or 7 days before delivery at 125 days gestational age. Control animals received an intraamniotic saline injection under ultrasound guidance at the same time points. Preterm lambs were delivered by cesarean section, and the lungs were taken for multiple assessments. The tissues used for the measurements reported here were from previous studies $(35,36)$.

RNA extraction and RT-PCR. Total RNA was isolated from tissue pieces from the right lower lung lobe by guanidinium thiocyanatephenol-chloroform extraction, as described elsewhere (31). RT-PCR were performed with Taq polymerase (TaqPCR Master Mix Kit, Qiagen, Hilden, Germany). Primers and optimized PCR conditions for all the molecules have been reported previously (Table 1) $(17,31,54)$. A negative control of non-reverse-transcribed total RNA did not yield a PCR product for any of the primers, indicating there was no detectable genomic DNA contamination. The PCR product for CTGF was confirmed by sequencing. PCR products were loaded to a standard and analyzed on $1 \%$ agarose gels. Image analysis was performed using a fluorescence image analyzer (model FLA 3000, Fuji, Dielsdorf, Switzerland) and quantified using AIDA software (Raytest, Urdorf, Switzerland).

Immunohistochemistry and histological analyses. The immunostaining methods were performed as previously described (35). Lung tissue was fixed in formalin, embedded in paraffin, and cut into 5- $\mu \mathrm{m}$ sections. Endogenous peroxidase activity was removed by incubation with hydrogen peroxide. Nonspecific binding sites were blocked with serum. Sections were incubated at $4^{\circ} \mathrm{C}$ overnight with a rabbit polyclonal antibody for bioactive TGF- $\beta 1$ (catalog no. sc-146, Santa Cruz Biotechnology, Santa Cruz, CA), a goat polyclonal antibody for CTGF (catalog no. sc-14939, Santa Cruz Biotechnology), or a rabbit anti-phosphorylated Smad2 (generous gift from Dr. C.-H. Heldin, Ludwig Institute for Cancer Research, Uppsala, Sweden). Unbound antibody was removed with PBS, and the slides were incubated with the secondary biotinylated antibody against rabbit or goat IgG (Vector Laboratories, Burlingame, $\mathrm{CA}$ ) for $1 \mathrm{~h}$ at room temperature. Immunostaining was visualized by the Vectastain $\mathrm{ABC}$ peroxidase Elite kit for detection of the antigen-antibody complexes (Vector Laboratories). For analysis of immunohistochemistry, we used a previously described five-step semiquantitative scale (15). Two independent observers who were unaware of the identity of the samples performed the analysis at $\times 20$ and $\times 40$ magnification. Four to five tissue sections of each lung from different regions were analyzed. The average count of all results was calculated for each lung.

Western blot. Frozen lung samples were homogenized in ice-cold buffer containing $50 \mathrm{mM}$ Tris $\cdot \mathrm{HCl}, \mathrm{pH} 7.5,1 \mathrm{mM}$ EGTA, $1 \mathrm{mM}$
EDTA, and protease inhibitor cocktail (complete minitablets; Roche, Mannheim, Germany) supplemented with $1 \mathrm{mM}$ phenylmethylsulfonyl fluoride (Sigma Chemical). The samples were sonicated and then centrifuged at $500 \mathrm{~g}$ for $20 \mathrm{~min}$ at $4^{\circ} \mathrm{C}$ for removal of cellular debris. Protein content in the supernatant was determined by the bicinchoninic acid method, with BSA as the standard. Protein samples (50 $\mu \mathrm{g} / \mathrm{lane}$ ) were boiled and loaded onto a molecular weight marker (Invitrogen, Karlsruhe, Germany) on NuPAGE 4-12\% Bis $\cdot$ Tris gel (Invitrogen) under nonreducing conditions. The proteins were electroblotted onto a Hybond-P polyvinylidene difluoride membrane (Amersham Life Science, Freiburg, Germany), and the blots were blocked for $1 \mathrm{~h}$ in $5 \%$ nonfat dry milk in TBS with $0.1 \%$ Tween 20 . Activated TGF- $\beta 1$ was detected with an anti-TGF- $\beta 1$ antibody (catalog no. TS05, BD PharMingen, Heidelberg, Germany) and with a secondary antibody (goat anti-mouse IgGl horseradish peroxidaseconjugated antibody; Amersham Life Science). The reaction was visualized on X-ray medical film (Konica Minolta, Unterföhring, Germany) after incubation of membranes with luminol-based chemiluminescence reagent (Pierce Biotechnology, Rockford, IL) for $1 \mathrm{~min}$. For normalization of the experiments, membranes were stripped, as recommended by the manufacturer (Pierce Biotechnology), and reprobed with an antibody against $\beta$-actin (Santa Cruz Biotechnology). The autoradiographs were scanned at high resolution, and the images were acquired using Adobe Photoshop software. The densitometric quantitation was performed using AIDA software.

Measurement of TGF- $\beta 1$ and TNF- $\alpha$ protein in lung tissue by ELISA. Pieces of the right lower lobe were sonicated as described above. Supernatants were diluted 1:10. Levels of bioactive TGF- $\beta 1$ were determined using a specific TGF- $\beta 1$ enzyme-liked immunosorbent assay (ELISA) kit ( $\mathrm{R} \& \mathrm{D}$ Systems, Minneapolis, $\mathrm{MN}$ ) that cross-reacts with porcine, rodent, and sheep TGF- $\beta 1$, but not with TGF- $\beta 2$ or TGF- $\beta 3$. Total active TGF- $\beta 1$ levels were measured using acid-activating samples, as recommended by the manufacturer (32). TNF- $\alpha$ levels were measured with an ELISA kit to detect ovine TNF- $\alpha$ (ENDOGEN, Rockford, IL). TGF- $\beta 1$ and TNF- $\alpha$ protein concentrations were calculated per kilogram of body weight.

Statistical analysis. Values are means $\pm S E$. Analysis of variance was used for comparisons between endotoxin groups at each gesta. tional age; Student-Newman-Keuls tests were used for post hoc analyses. Significance was accepted at $P<0.05$.

\section{RESULTS}

$T G F-\beta 1$ expression in response to endotoxin-induced chorioamnionitis. We evaluated the expression of TGF- $\beta 1 \mathrm{mRNA}$ in fetal lung tissue by RT-PCR. Signal intensity of TGF- $\beta 1$ mRNA was expressed relative to that of the ribosomal gene L32. The ratio of TGF- $\beta 1$ mRNA to L32 mRNA increased with time in the endotoxin-exposed groups compared with the control group (Fig. 1). To confirm that increased TGF- $\beta 1$

Table 1. Primer sequences and PCR conditions

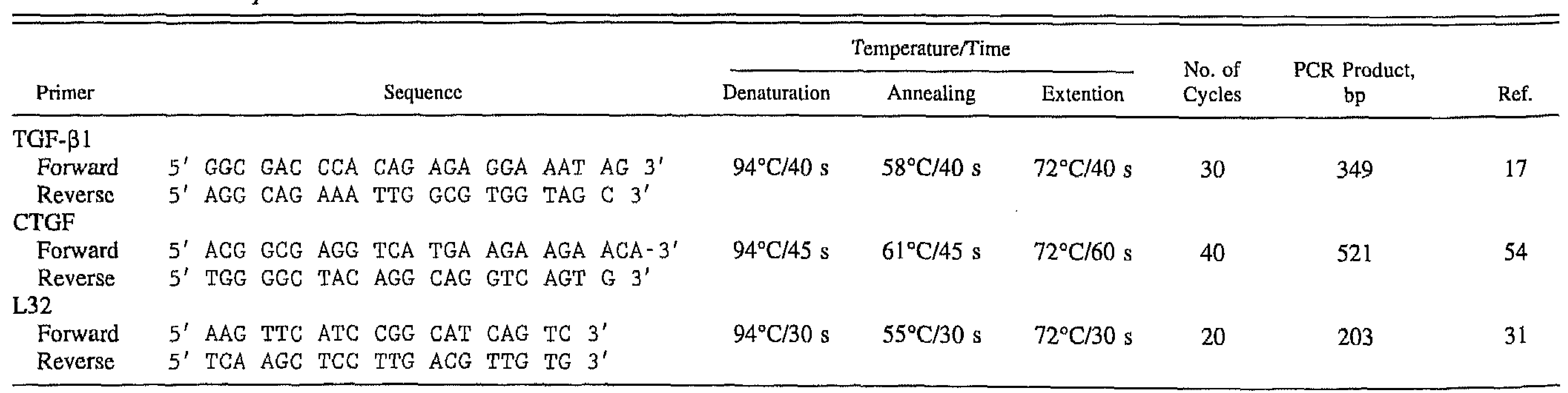

TGF- $\beta 1$, transforming growth factor- $\beta 1$; CTGF, connective tissue growth factor. 
A

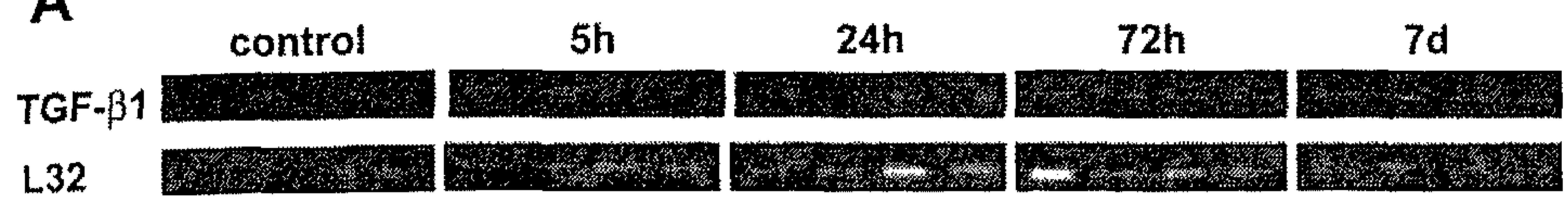

B

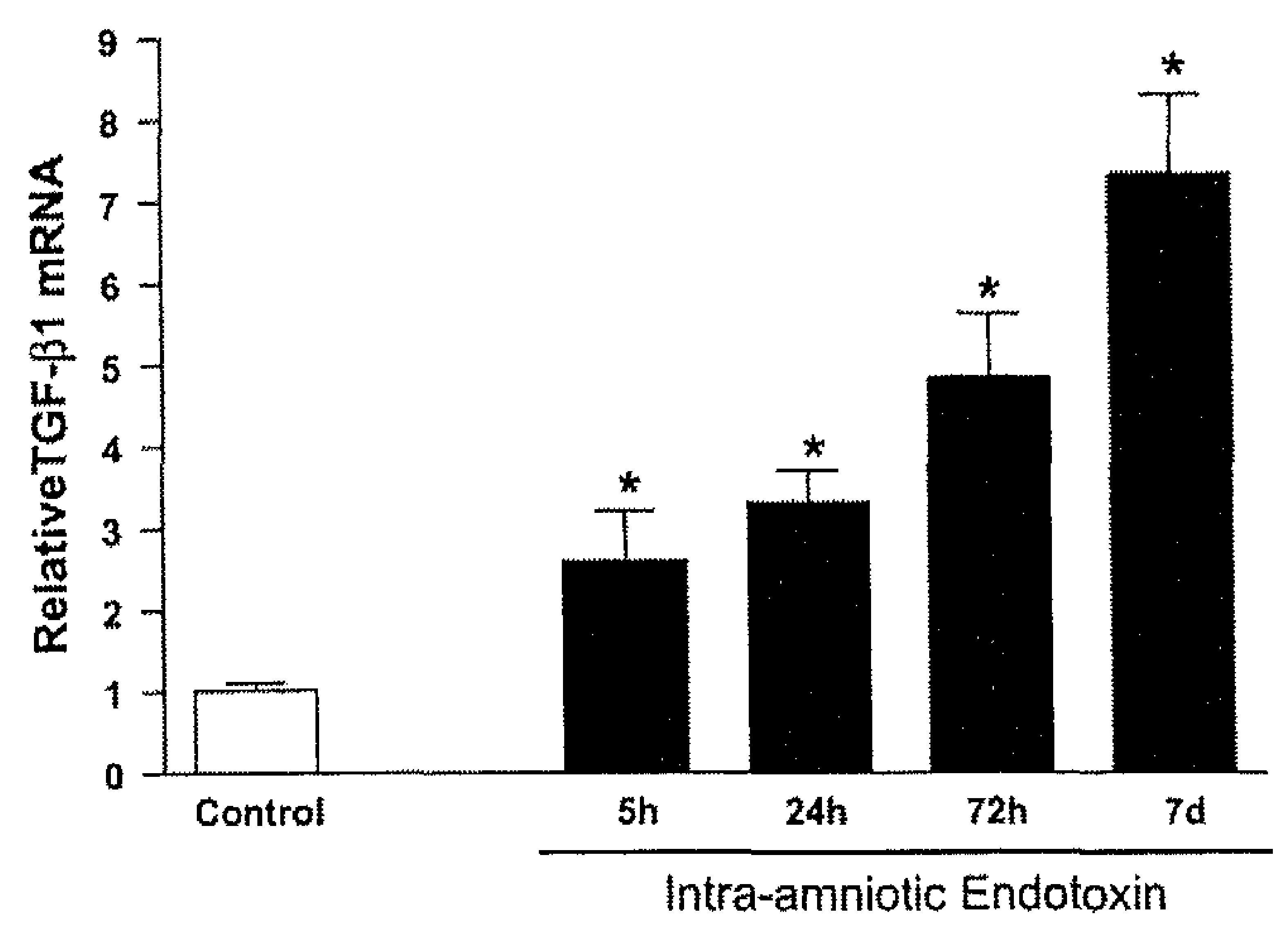

Fig. 1. Intra-amniotic endotoxin increases steady-state levels of transforming growth factor (TGF)- $\beta 1 \mathrm{mRNA}$ in the lung. $A$ : representative RT-PCR for TGF- $\beta 1$ and L32 from lung of control animals and animals exposed to endotoxin for $5 \mathrm{~h}, 24 \mathrm{~h}, 72 \mathrm{~h}$, and 7 days. $B$ : densitometric analysis of PCR results. TGF- $\beta 1$ was quantitated at $5 \mathrm{~h}, 24 \mathrm{~h}, 72 \mathrm{~h}$, and 7 days after normalization to L32 (ribosomal protein mRNA). Mean RNA value in control animals was set to 1 , and levels at each time point are expressed relative to the mean control value. Values are means \pm SE; $n=4$ animals in each group at each time point. ${ }^{*} P<0.05$ vs. control.
mRNA corresponded with increased protein levels, bioactive TGF- $\beta 1$ was quantified by Western blot and ELISA analysis of whole lung homogenates and by immunohistochemistry in lung tissue. Bioactive TGF- $\beta 1$ protein in lung tissue increased by $300 \%$ in Western blot analysis (Fig. $2 A$ ) and by $350 \%$ in ELISA analysis (Fig. $2 B$ ). TGF- $\beta 1$ immunostaining was weakly detected in the control lungs. Staining for TGF- $\beta 1$ was more apparent in lung stroma of the endotoxin-exposed group (Fig. 3). Immunostaining for bioactive TGF- $\beta 1$ was increased about twofold at all times after endotoxin exposure.

Induction of the Smad signaling pathway. TGF- $\beta 1$ signaling from the cell membrane to the nucleus is mediated through Smad proteins (47). Early events for TGF- $\beta 1$ signal transduction are the phosphorylation of TGF- $\beta$ type I and type II receptors and the subsequent phosphorylation and translocation of the intracellular effectors Smad2 and Smad3 to the nucleus, where they regulate gene transcription. Therefore, the effect of intra-amniotic endotoxin on the subcellular distribution of phosphorylated Smad2 was evaluated in the lung of preterm lambs. Smad2 phosphorylation was detected by immunostaining with anti-phosphorylated Smad2-specific antibodies. Cytoplasmic staining for phosphorylated Smad 2 was weak in bronchial epithelial cells in the control lungs (Fig. 4A). In contrast, endotoxin exposure resulted in intense staining of phosphorylated Smad2 in almost all bronchial epithelial cells and some staining in vascular endothelial and fibroblast-like cells (Fig. 4B). The Smad2 staining increased $5 \mathrm{~h}$ after intra-amniotic exposure to endotoxin (Fig. 4C). The majority of the cells had nuclear staining, consistent with TGF- $\beta 1$ signaling and translocation of phosphorylated Smad2 to the nucleus.

CTGF expression in response to endotoxin-induced chorioamnionitis. We evaluated the steady-state levels of mRNA of CTGF mRNA in sheep lung homogenates by RT-PCR. The ratio of CTGF mRNA to L32 mRNA decreased to $<33 \%$ of control levels in the endotoxin-exposed groups (Fig. 5). Expression of CTGF protein was evaluated by immunohisto- chemistry (Fig. 6). CTGF was exclusively detected in lung endothelial cells in control lungs, with decreased immunostaining in endotoxin-exposed animals (Fig. 6, $A$ and $B$ ). A semiquantitative analysis of the immunohistochemistry demonstrated that CTGF protein was reduced to $<50 \%$ of control values by $5 \mathrm{~h}$ of endotoxin exposure and remained low at later times (Fig. 6).

Intra-amniotic endotoxin induced TNF- $\alpha$ expression in the lung. We measured the TNF- $\alpha$ concentration in whole lung homogenates by ELISA, because TNF- $\alpha$ is a known inhibitor of TGF- $\beta 1$-induced CTGF expression (2). TNF $\alpha$ protein increased in lung tissue of the endotoxin-exposed groups $>20$ fold relative to the control group (Fig. 7).

\section{DISCUSSION}

Chorioamnionitis is a complex disease that has multiple and contrasting effects on preterm babies. Although the incidence of respiratory distress syndrome may be decreased, the incidence of BPD is increased (51). We and others have developed models to study this disease, which occurs in the context of a developing fetus (8). Bry and colleagues (10) were the first to describe an increase in surfactant pool size and compliance after intrauterine exposure to the proinflammatory cytokine L-1 in the preterm rabbit lung. This phenotypic lung maturation, however, was different from lung maturation induced by maternal corticosteroid treatment, since the systemic cortisol levels were unchanged (26). The phenotypic lung maturation was induced in fetal sheep within 7 days of intrauterine exposure to inflammation; however, an injury response resulting in interference with alveolar and microvascular development also occurred (52). Moreover, the response of the fetal lung to a secondary inflammatory stimulus, such as mechanical ventilation, also was increased by intrauterine exposure to inflammation (23).

Pulmonary inflammation could be induced in utero with $\mathbb{L}-1 \alpha, \Pi-1 \beta$, endotoxin from periodontal organisms, or endo- 
A
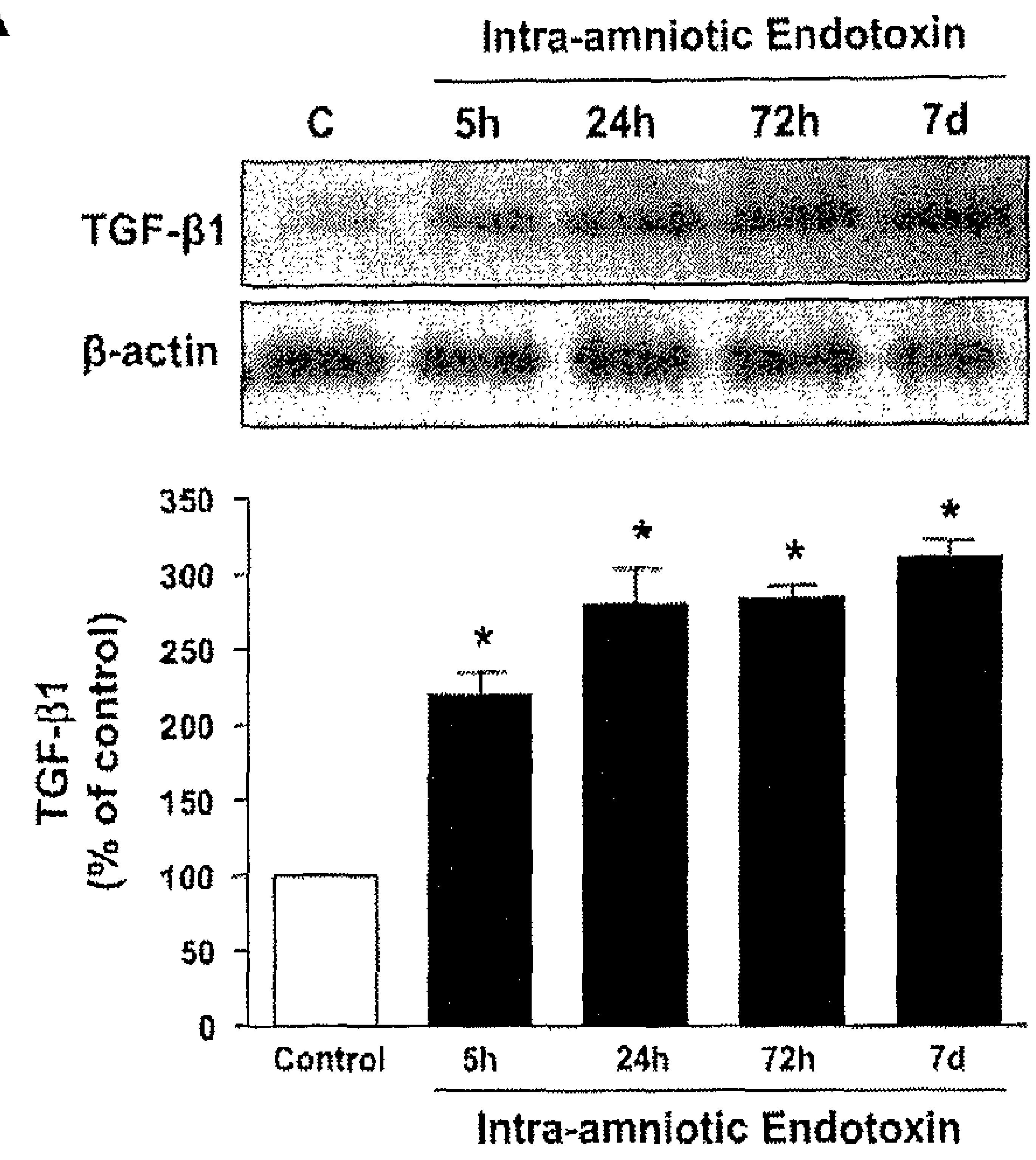

B

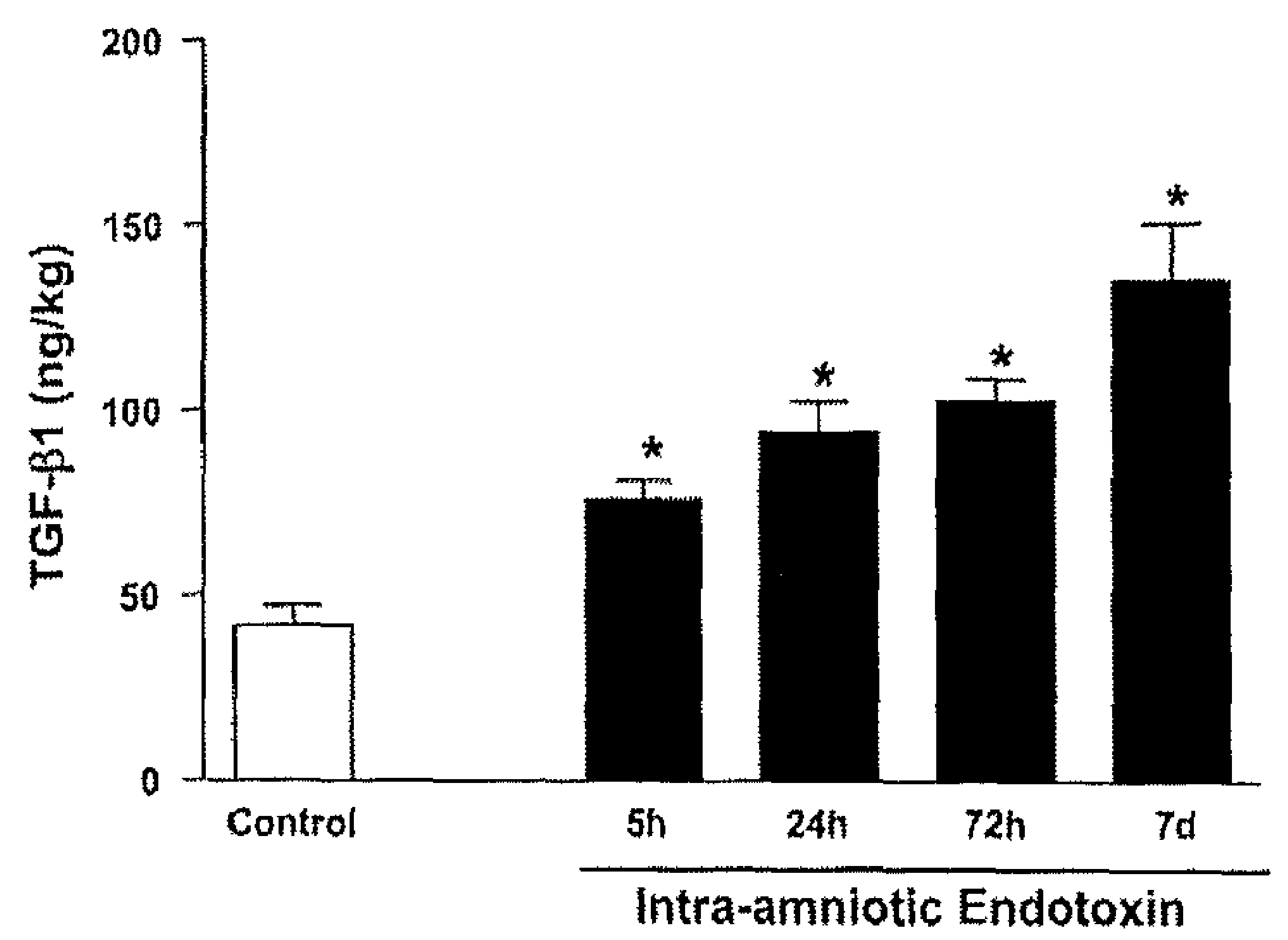

Fig. 2. Intra-amniotic endotoxin exposure increases TGF- $\beta 1$ protein concentration in the lung. $A$ : Western blot measurement of TGF- $\beta 1$ protein concentration in whole lung homogenates. Total bioactive TGF- $\beta 1$ protein was analyzed by Westem blotting with an anti-TGF- $\beta 1$ antibody. The same membrane was analyzed with anti- $\beta$-actin antibody. TGF- $\beta 1$ and $\beta$-actin protein levels were quantified by densitometry. Optical density of the TGF- $\beta 1$ protein band was corrected for $\beta$-actin, and results are expressed as ratio (\%) of endotoxin-exposed to control animals. $B$ : ELISA measurement of TGF- $\beta 1$ protein concentration in whole lung homogenates. TGF- $\beta 1$ protein concentration was standardized per kilogram of body weight. Values are means $\pm S E$; $n=4$ animals in each group at each time point. $* P<0.05$ vs, control.

toxin from $E$. coli, all of which resulted in a phenotype of maturation of the fetal lung with increased surfactant pool sizes in sheep $(26,42,53)$. The injury and developmental responses of the fetal lung seem to be generalizable. Perinatal expression of $\mathrm{IL}-1 \beta$ in a transgenic mouse model resulted in a phenotype similar to BPD, with alveolar simplification and impaired microvascular development (9).

We have identified increased expression of TGF- $\beta 1$ and decreased expression of CTGF in fetal sheep exposed to endotoxin-induced chorioamnionitis. The BPD phenotype of alveolar simplification and microvascular injury resulting from intra-amniotic endotoxin exposure is not mediated by mechanical ventilation and oxygen exposure, which are the traditional causes of BPD, but by inflammatory responses of the fetal lung $(26,52)$. The increase in TGF- $\beta 1$ was accompanied by an activation of the Smad signaling pathway. Generally, CTGF expression increases if TGF- $\beta 1$ expression increases (6). However, the elevated TGF- $\beta 1$ expression was associated with reduced CTGF expression in endotoxin-exposed lungs in association with increased $\mathrm{TNF}-\alpha$ protein concentration. We speculate that the CTGF downregulation may be mediated by an endotoxin-induced induction of TNF- $\alpha$ expression (Fig. 8),

In 1967, Northway and colleagues (43) described BPD as severe lung injury resulting from the mechanical ventilation and oxygen exposure of preterm infants. The oxidant injury and mechanical ventilation resulted in inflammation, fibrosis, and hypertrophy of airway smooth muscle. With progress in neonatal care, which includes antenatal glucocorticoids, surfactant treatment, and more gentle ventilation strategies, larger preterm infants now seldom develop BPD. However, the disease remains the most common lung complication for extremely immature babies with gestations $<28$ wk (46), a patient group that generally did not survive when BPD was first described. BPD is defined as supplemental oxygen dependency of preterm babies at a postmenstrual age of $36 \mathrm{wk}$ (25). The "new" BPD is frequently diagnosed in very preterm infants who did not initially have severe respiratory distress syndrome $(13,27)$. In clinical series and animal models, chorioamnionitis resulted in a lung maturation response, because surfactant increased and the volume of the potential gas space in the fetal lung increased. However, prenatal exposure to chorioamnionitis was associated with the development of BPD in these very preterm infants $(19,49,51)$. The inflammation already present in the lungs may be sustained or aggravated by therapeutic interventions, such as resuscitation, oxygen, mechanical ventilation, or postnatal infection (45). Angiogenesis occurs with alveolarization during normal lung development, and injury to the developing pulmonary circulation during a critical period of growth can also contribute to development of BPD (1). Decreased concentrations of vascular endothelial growth factor and its receptors were measured in lung tissue of preterm babies who died of BPD and in the lungs of preterm lambs exposed to chorioamnionitis $(5,29,37)$.

The activation of latent TGF- $\beta 1$ to active TGF- $\beta 1$ has been proposed to contribute to the pathogenesis of acute respiratory distress syndrome, causing a disruption of the alveolar epithelial barrier function (21). However, the role of TGF- $\beta 1$ in the normal development and injury response of the lung in preterm infants remains unclear. The TGF- $\beta$ family has been associated with the pathophysiology of BPD, because the levels of TGF- $\beta 1$ protein increased in airway samples from preterm infants developing BPD $(28,34,38)$. However, it is not known whether an elevated TGF- $\beta 1$ concentration in the fetal lung induced activation of the Smad signaling pathway in vivo. In fetal sheep exposed to chorioamnionitis, the Smad signaling pathway was activated during the inflammation-triggered lung injury and remodeling processes.

TGF- $\beta 1$ is important for wound healing and in the pathogenesis of fibrosis, but it is also involved in other critical biological activities, including suppression of immune reactions. Because of its multifunctional role, inhibition of TGF- $\beta 1$ 
A

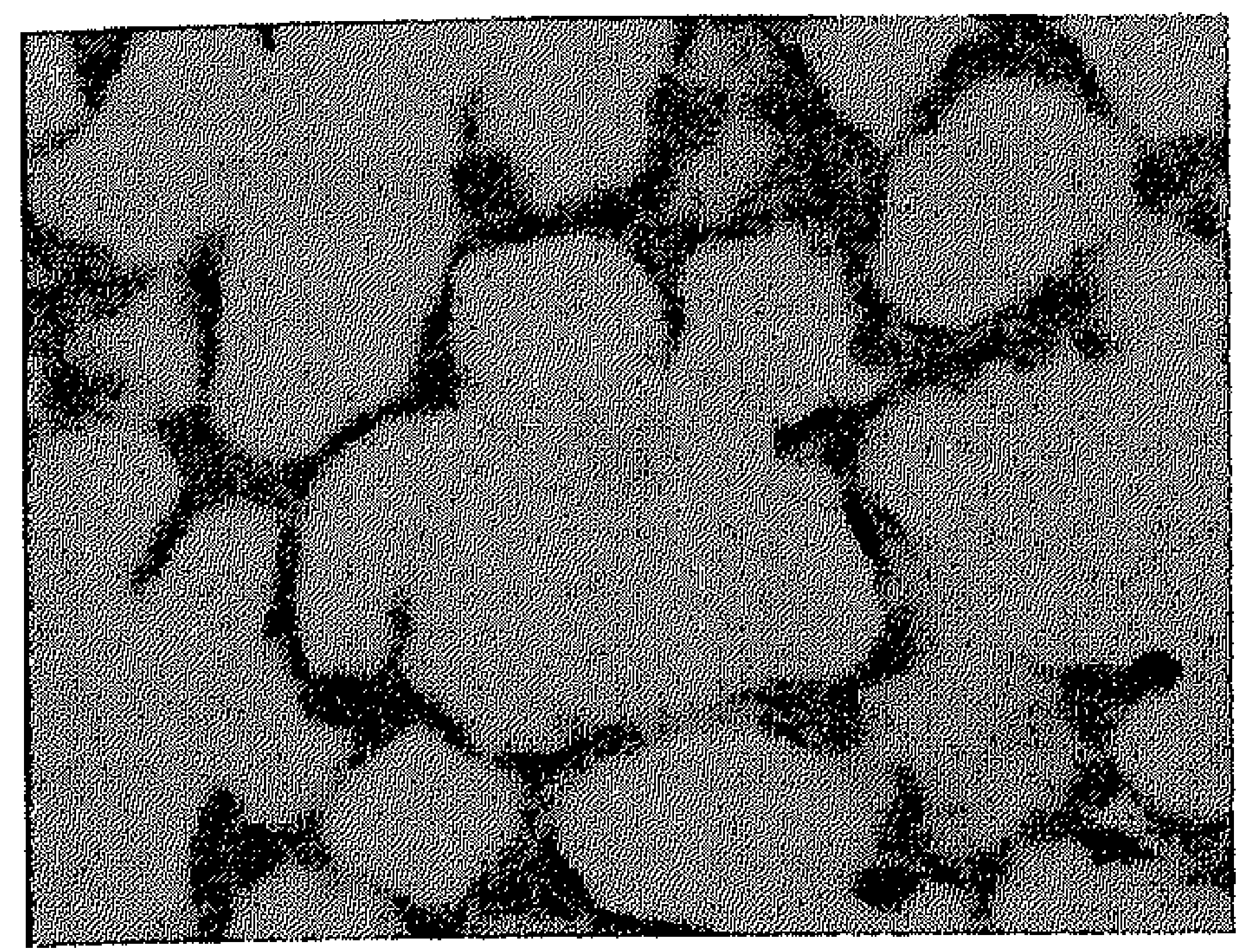

B

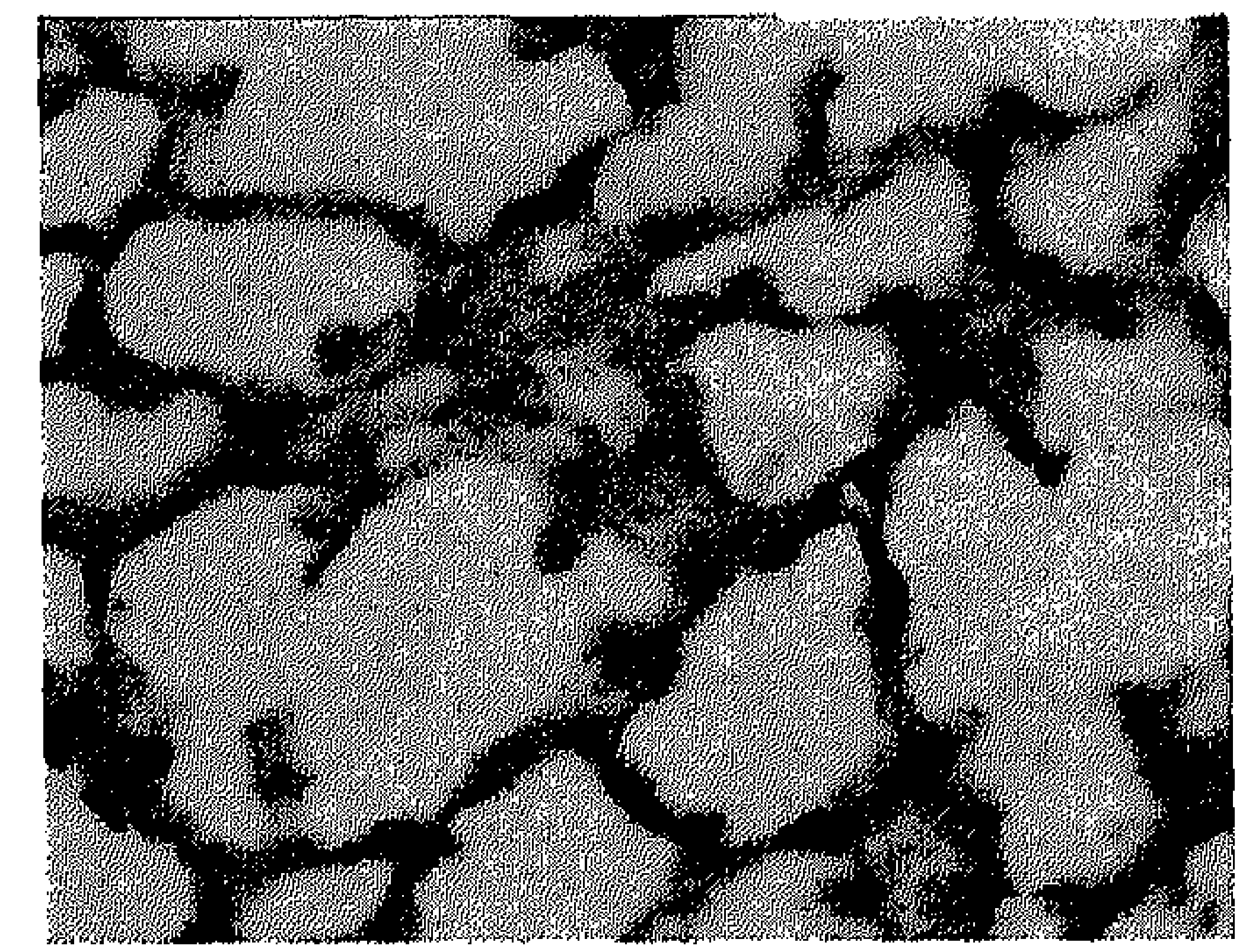

C

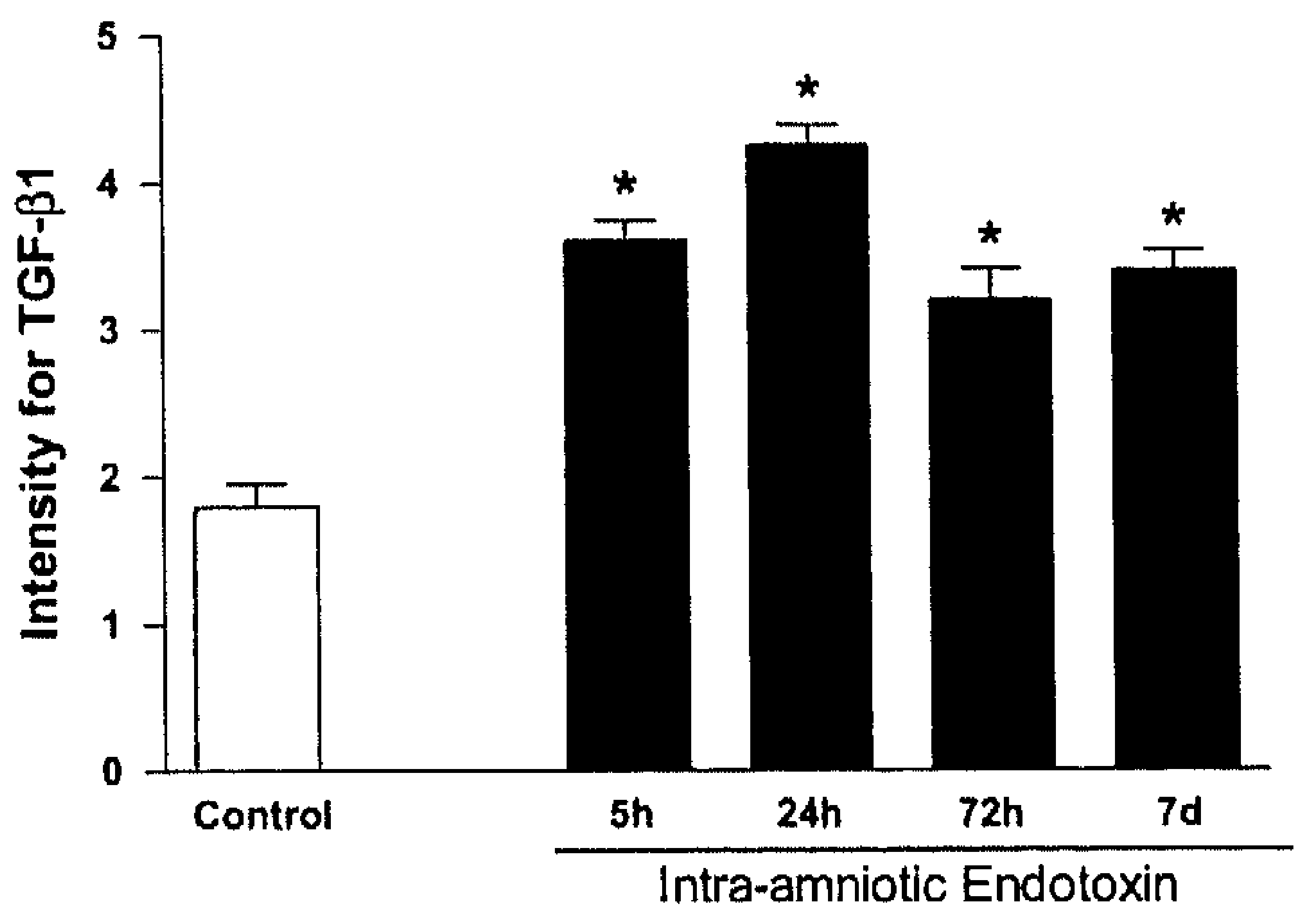

Fig. 3. Immunohistochemical evaluation of TGF- $\beta 1$ protein in lung tissue. $A$ : representative sections from a control animal and an animal exposed to endotoxin-induced chorioamnionitis for 7 days stained with an antibody that detects TGF- $\beta$ l. Magnification $\times 320 . B$ : immunohistochemical quantification of TGF- $\beta 1$ in lung sections. Immunostaining for TGF- $\beta 1$ was graded on a scale from 0 to 5 . Values are means $\pm \mathrm{SE} ; n=4$ animals in each group at each time point. ${ }^{*} P<0.05$ vs. control.

Fig. 4. Intra-amniotic endotoxin exposure induces the Smad signaling pathway in lungs of preterm lambs. Smad2 phosphorylation was evaluated in lung tissue by immunohistochemistry, $A$ : representative sections from a control animal and an animal exposed to endotoxin-induced chorioamnionitis for 7 days stained with an antibody that reacts specifically with phosphorylated Smad2. Magnification $\times 320$. B: immunohistochemical quantification of phosphorylated Smad2 in lung sections. Immunostaining for phosphorylated Smad2 was graded on a scale from 0 to 5 . Values are means $\pm \mathrm{SE} ; n=4$ animals in each group at each time point.

A

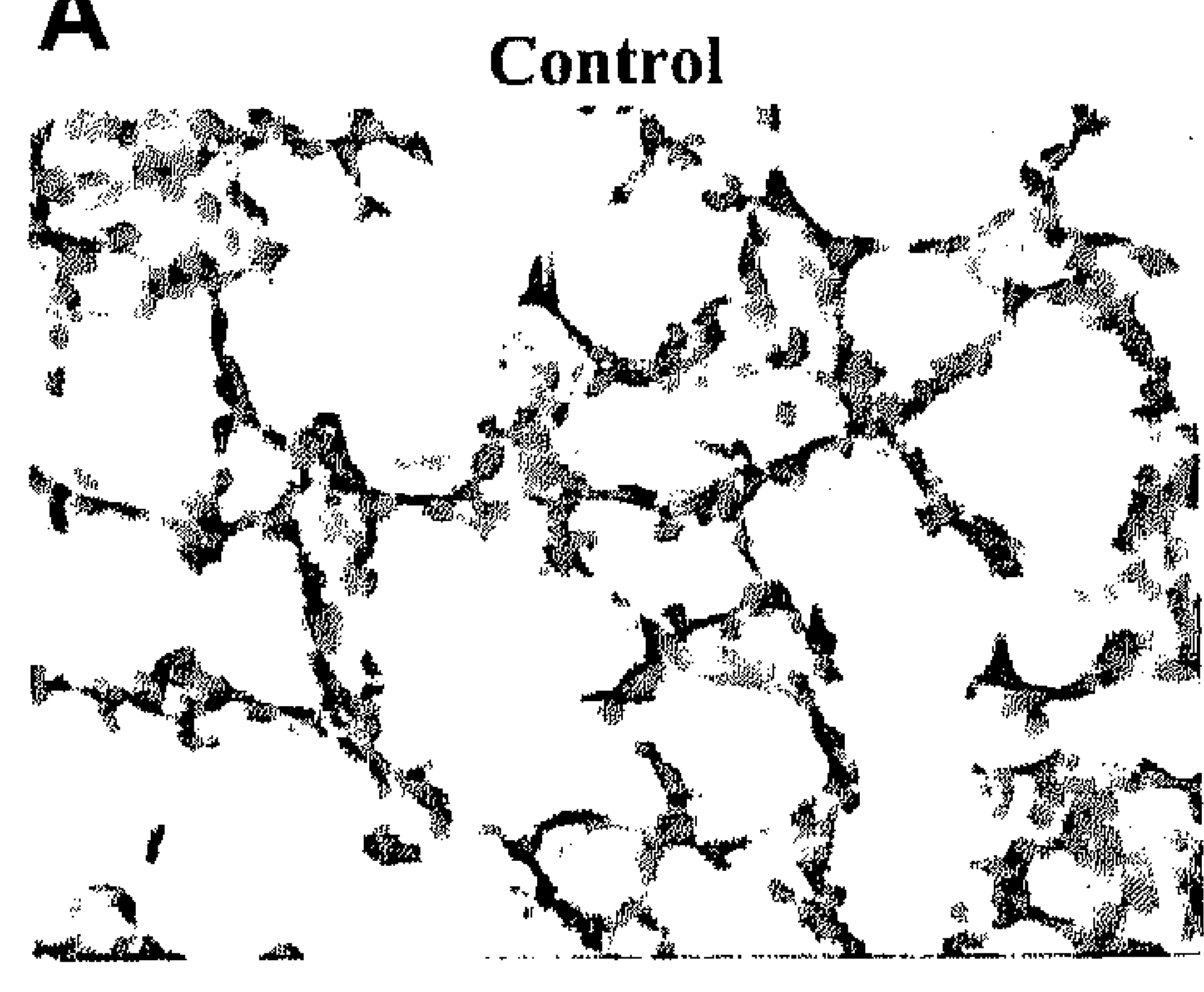

B

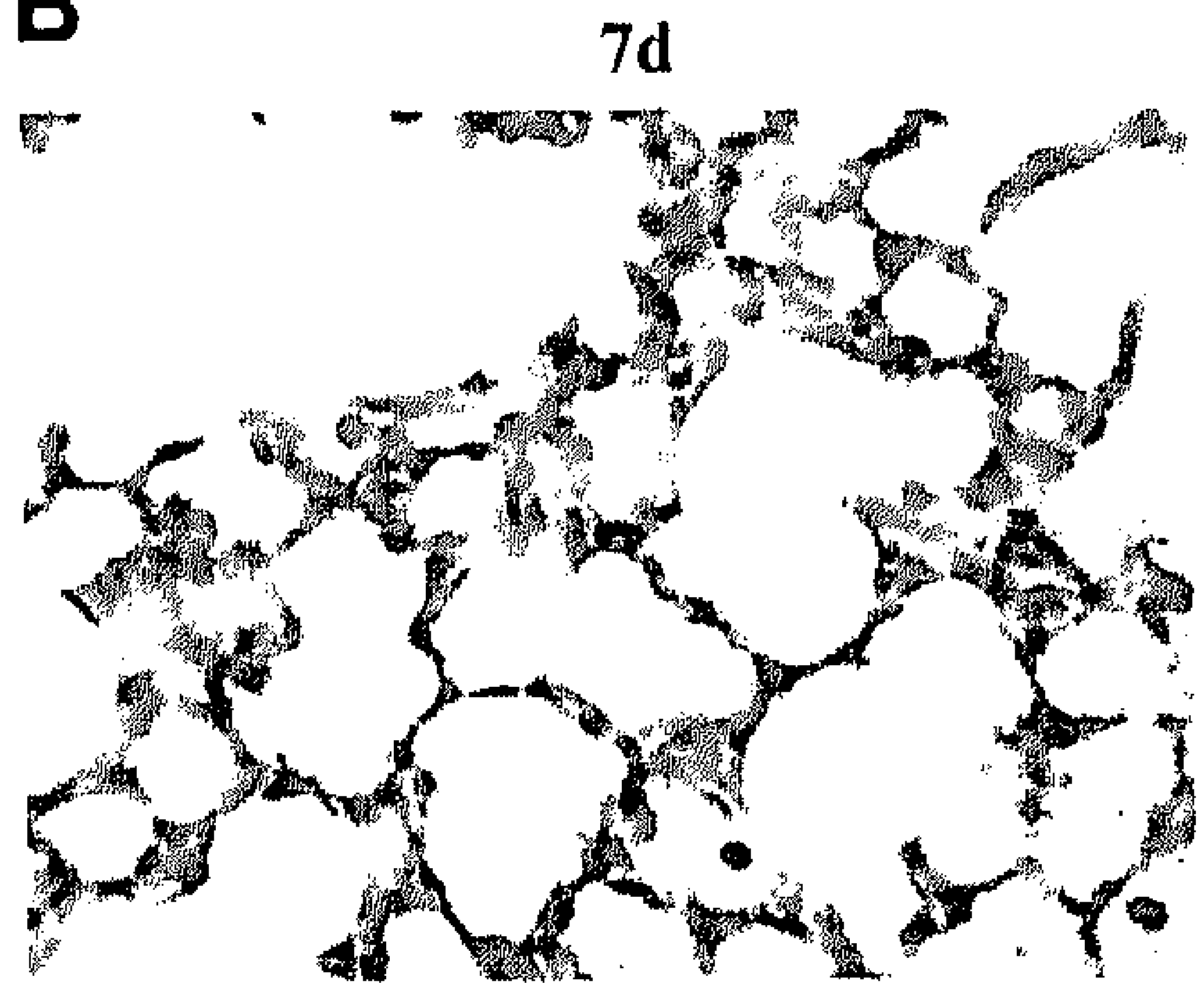

C

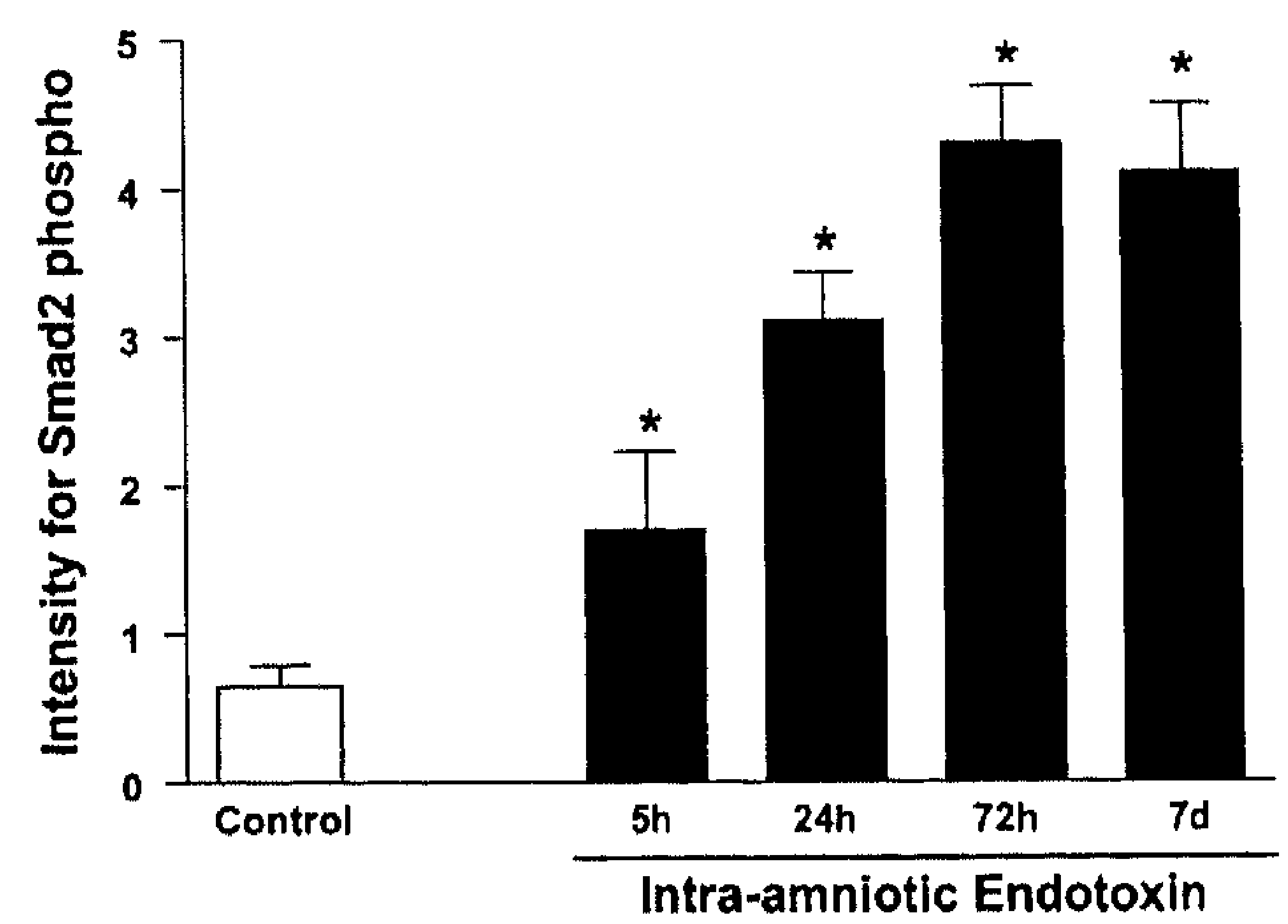


A

control

$5 h$

$24 h$

$72 \mathrm{~h}$

$7 d$

CTGF

क.
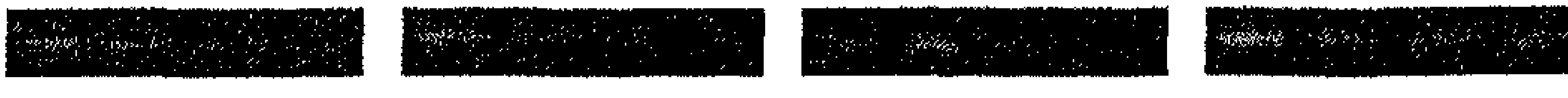

L32
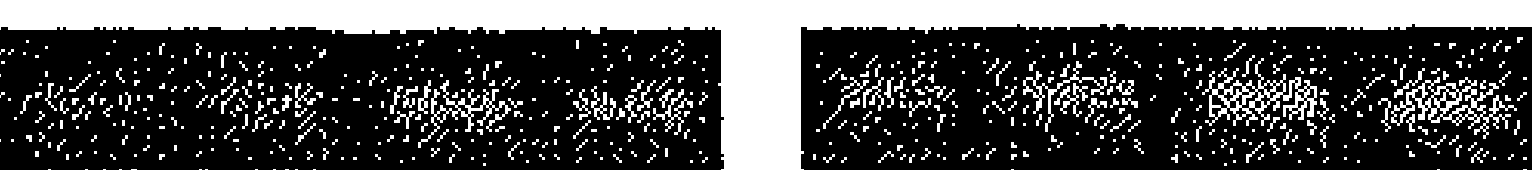

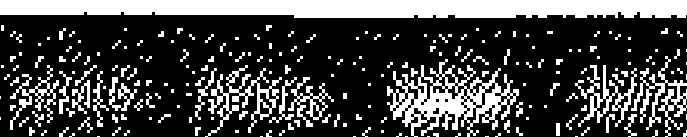

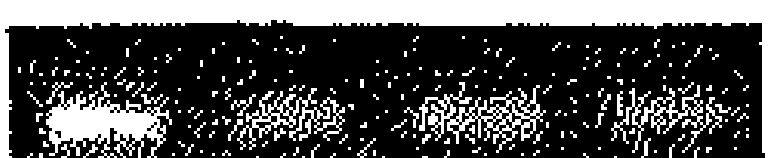

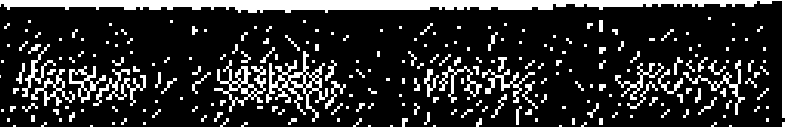

Fig. 5. Intra-amniotic endotoxin exposure decreased steady-state levels of connective tissue growth factor (CTGF) mRNA in the lung. $A$ : representative RT-PCR for CTGF and L,32 from lung of control animal and animals exposed to endotoxin for $5 \mathrm{~h}, 24 \mathrm{~h}, 72 \mathrm{~h}$, and 7 days. $B$ : densitometric analysis of PCR results. CTGF was quantified at $5 \mathrm{~h}, 24 \mathrm{~h}, 72 \mathrm{~h}$, and 7 days after normalization to L32 (ribosomal protein mRNA). Mean RNA value in control animals was given a value of 1 , and levels at each time point are expressed relative to the mean control value. Values are means $\pm S E ; n=4$ animals in each group at each time point. ${ }^{*} P<0.05$ vs. control.

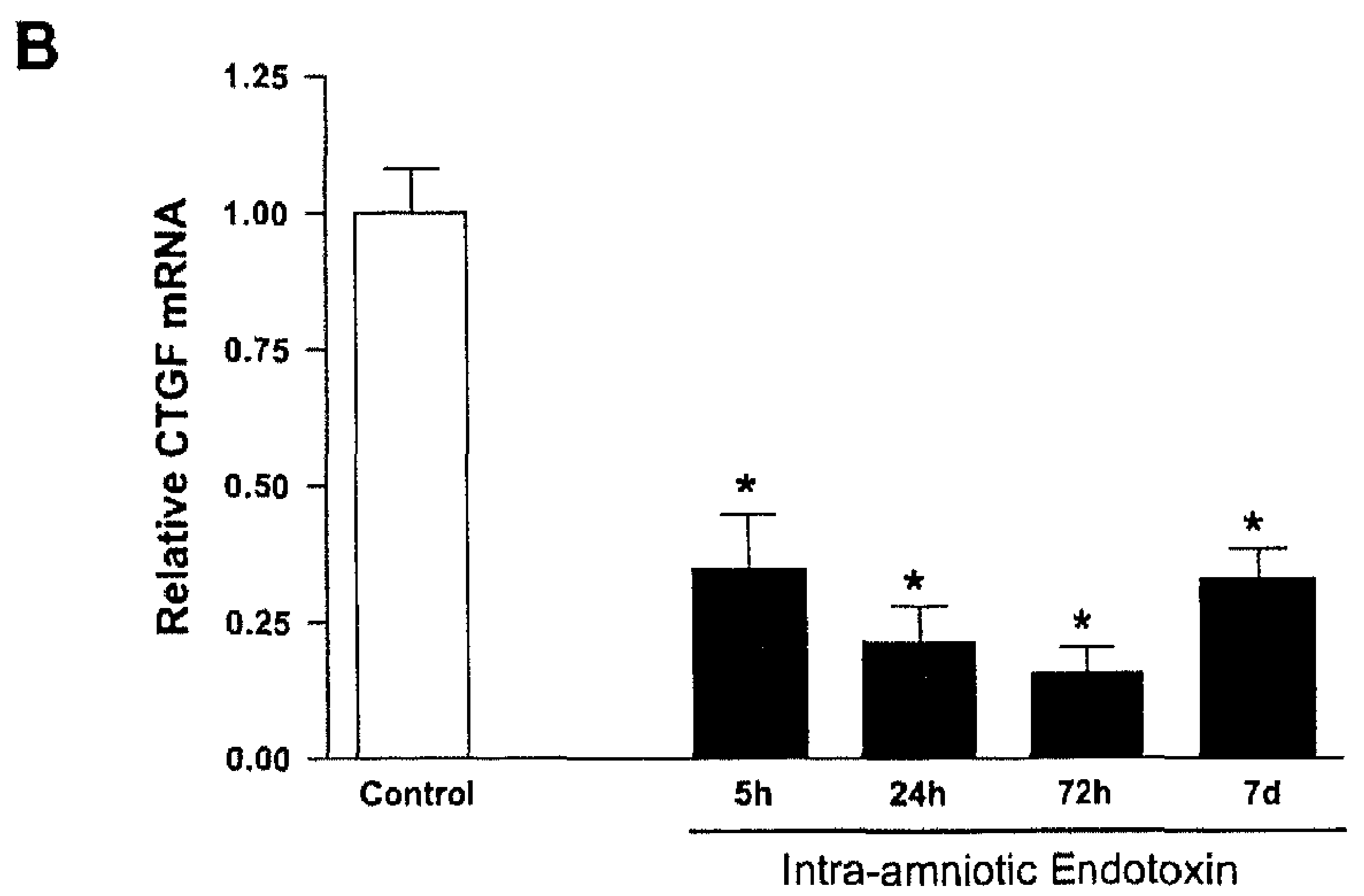

would be expected to impact numerous other important functions, many in an adverse way. CTGF might play a role in targeting fibrotic processes. The exposure of fibroblasts and endothelial cells to TGF- $\beta 1$ is sufficient to induce CTGF expression, which mediated some of the profibrotic effect of TGF- $\beta 1$ (6). Recent reports suggest that CTGF may anchor vascular endothelial growth factor to the extracellular matrix to promote angiogenesis (11). We found that the CTGF production was reduced in endotoxin-exposed animals. Furthermore, CTGF expression was limited to endothelial cells of blood vessels in the lung. The limited expression of CTGF in endothelial lung cells and the downregulation of CTGF in these cells in the endotoxin-exposed animals support the vascular hypothesis of BPD. The selective expression of
Fig. 6. Immunohistochemical evaluation of CTGF protein in lung tissue. Intra-amniotic endotoxin exposure decreased CTGF protein in the lung. A: representative sections from a control animal and an animal exposed to endotoxin-induced chorioamnionitis for 7 days stained with an antibody that reacts with CTGF. Arrow, brownish-stained endothelial cell layer. Magnification $\times 320, B$ : immunohistochemical quantification of CTGF in lung sections. Immunostaining for CTGF was graded on a scale from 0 to 5 . Values are means $\pm \mathrm{SE} ; n=4$ animals in each group at each time point. ${ }^{*} P<0.05$ vs. control.
A

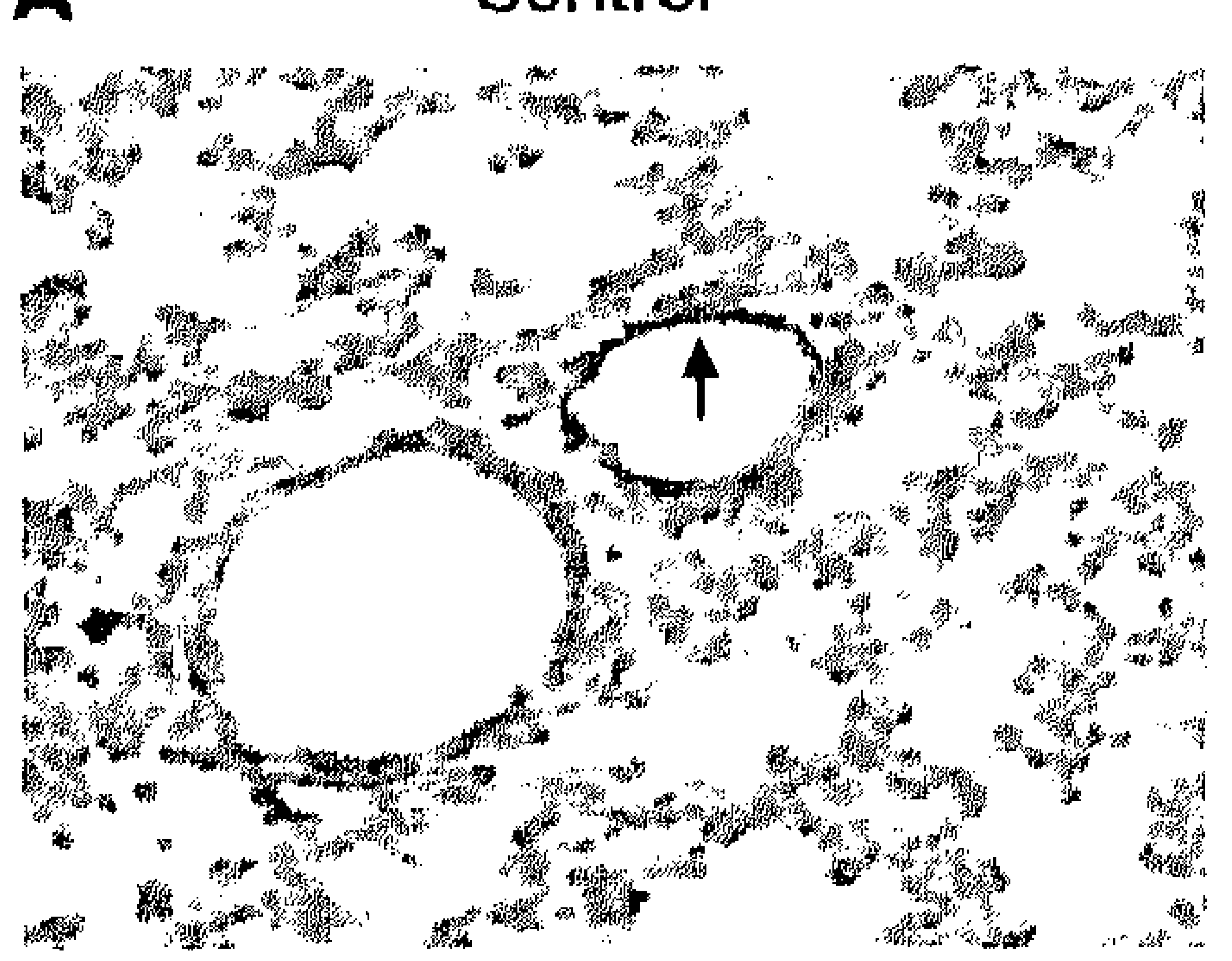

C.

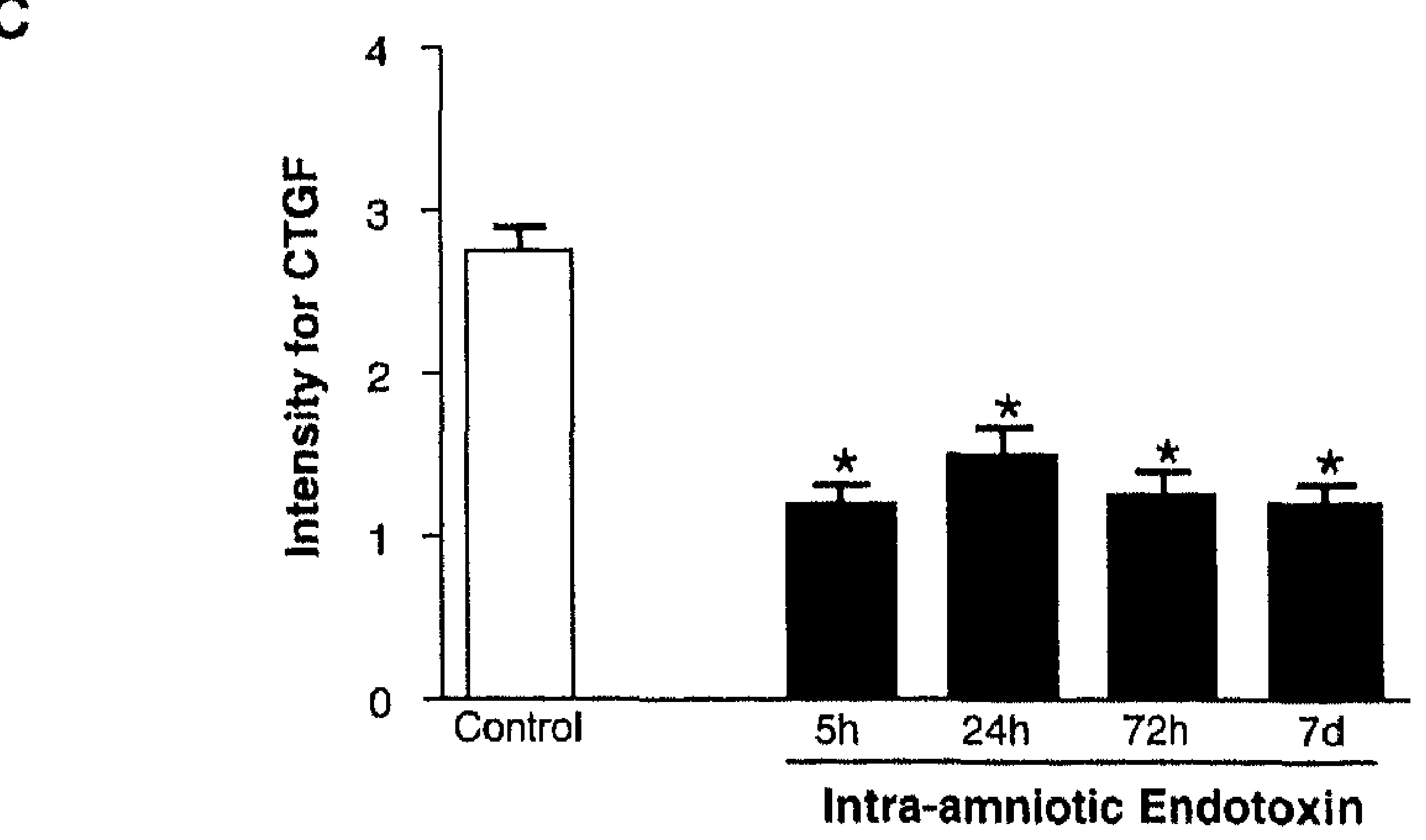

$7 d$

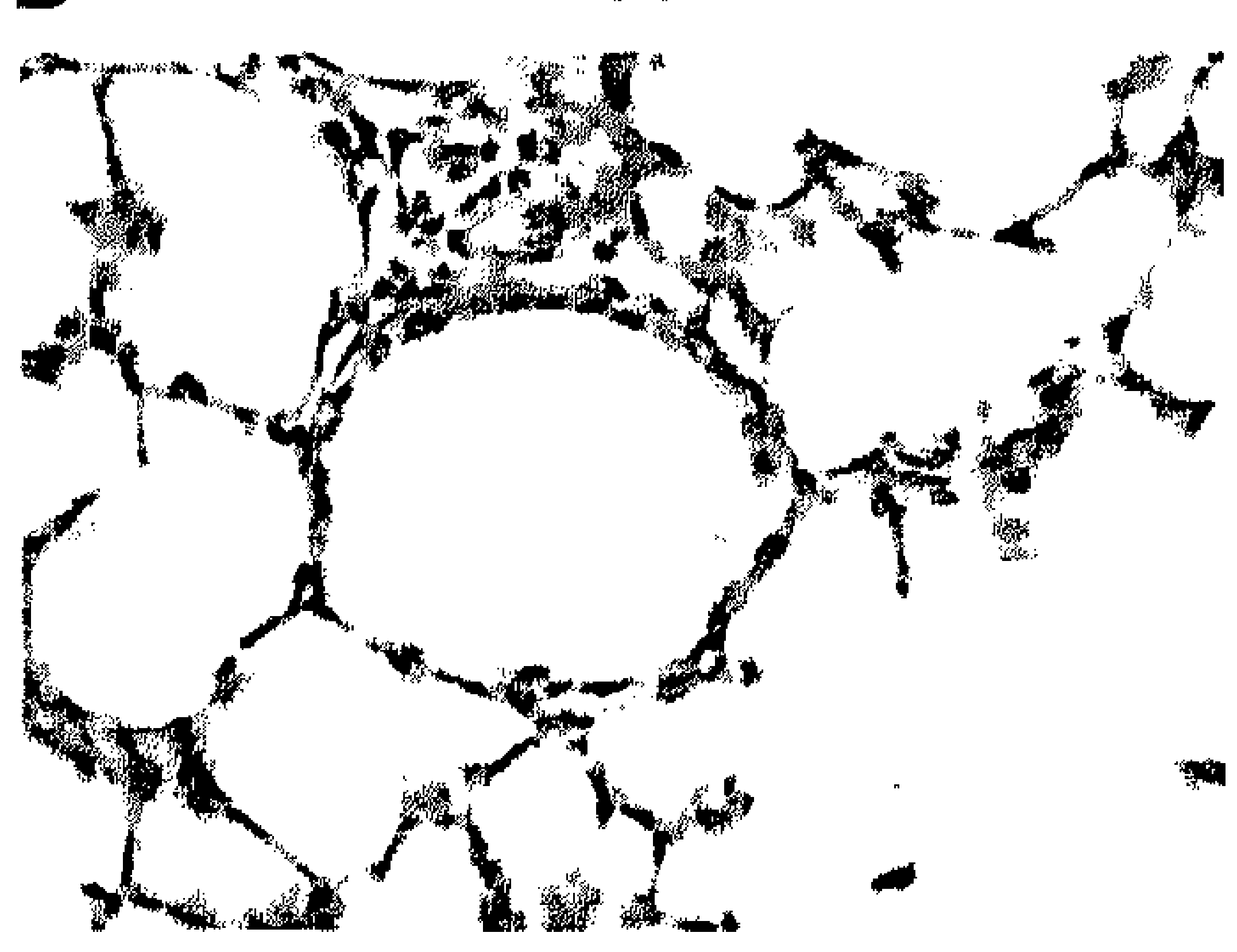




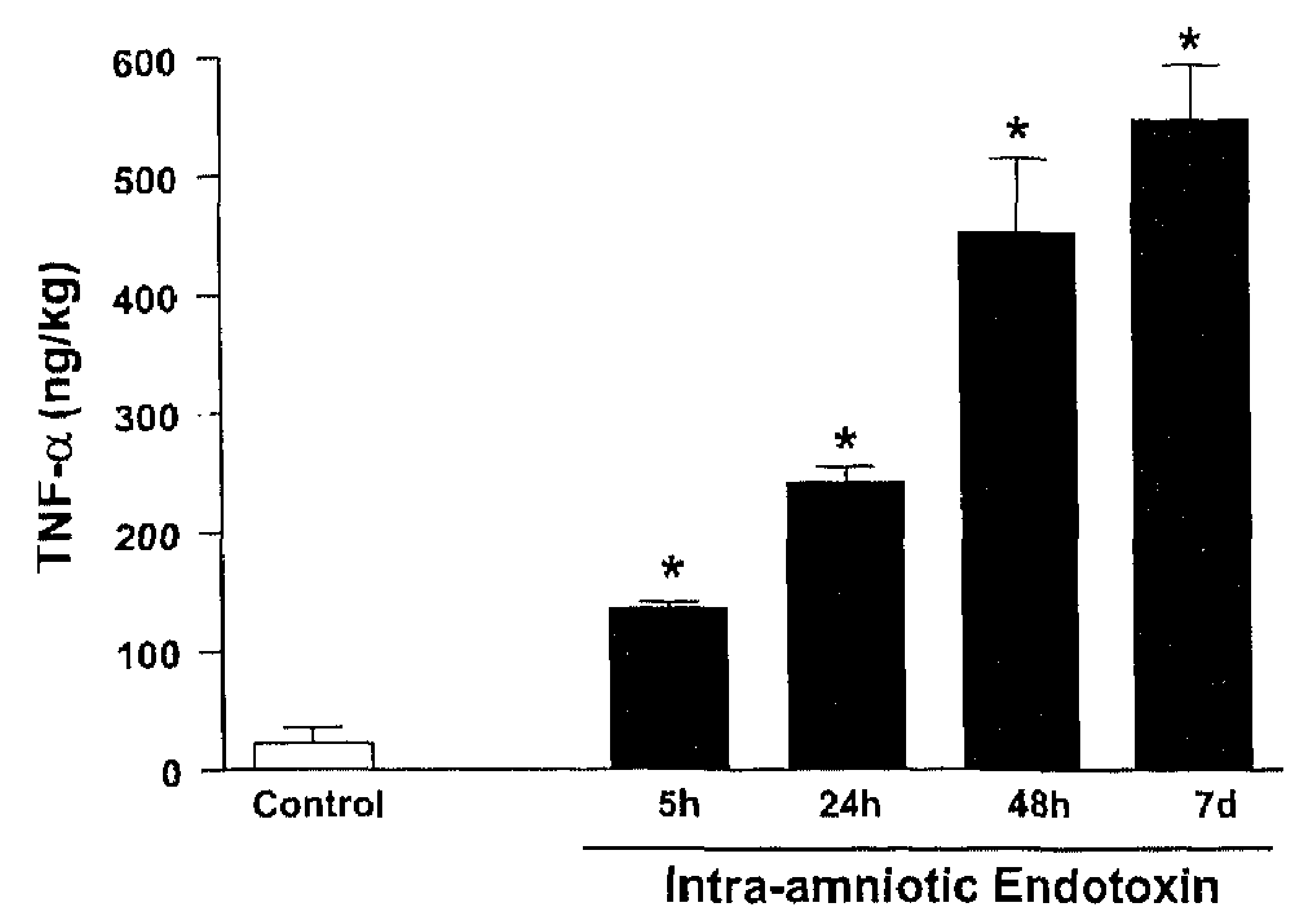

;. 7. Intra-amniotic endotoxin exposure increased TNF- $\alpha$ protein in the fetal g. TNF- $\alpha$ concentration was measured in whole lung homogenates by ISA and standardized per kilogram of body weight. Values are means $\pm S E$; $=4$ animals in each group at each time point. $* P<0.05$ vs. control.

rGF in endothelial cells could play an important role rring normal lung development and for the homeostasis of dothelial cells (7).

The regulation of the CTGF promoter is well understood. $\sqrt{ } \mathrm{F}-\alpha$ was found to suppress the TGF- $\beta 1$-induced expression CTGF protein in cultured normal fibroblasts at the transcripnal level (2). Interestingly, the sequences between -244 and 166 of the CTGF promoter were necessary for TGF- $\beta 1$ and VF- $\alpha$ modulation of CTGF expression. Taken together, $\sqrt{ } \mathrm{F}-\alpha$ could influence two steps in the pathogenesis of BPD: TNF- $\alpha$ initiates the inflammatory responses, and 2) TNF- $\alpha$ ems to inhibit the generation of fibrosis by suppressing TGF synthesis (2). Increased TNF- $\alpha$ concentrations in pre$\mathrm{rm}$ babies have been associated with the development of BPD 5). Surprisingly, fetal sheep do not respond to bioactive combinant ovine TNF- $\alpha$, irrespective of the route of admin- istration (24). Intra-amniotic or intratracheal administration did not result in an inflammatory response by the pulmonary immune system. However, mechanical ventilation and chorioamnionitis induced some TNF- $\alpha$ mRNA (24). Although TNF- $\alpha$ may not be an important mediator of inflammation in the sheep fetus, it may modulate other signaling pathways.

Increased TGF- $\beta 1$ concentration did not result in increased CTGF concentration in the fetal lung that was exposed to inflammation. The changed ratio of TGF- $\beta 1$ to CTGF may explain, in part, the lack of prominent fibrosis in the new BPD. We summarized our results and interpretations with respect to the clinical findings in new BPD in Fig. 8. The first aspect is the physiological role of TGF- $\beta 1$ in lung development. Increased concentrations of TGF- $\beta 1$ reduce alveolarization (50). Furthermore, the anti-inflammatory effects of TGF- $\beta 1$ reduce lung inflammation (4). TGF- $\beta 1$ is also essential for the "wound remodeling or healing" after lung injury. These effects are mediated in part by TGF- $\beta 1$ itself, but the fibrosis is particularly mediated by CTGF. We found that endotoxin-mediated chorioamnionitis induced TGF- $\beta 1$ and TNF- $\alpha$ but decreased CTGF. The downregulation of CTGF could be mediated by TNF- $\alpha$. Therefore, fibrosis was not initiated, which is typical for the new BPD. The reduced concentrations of CTGF might increase the impaired development of the microvasculature, since CTGF is involved in normal vascular development (7). Our findings support the notion that increased TGF- $\beta 1$ and decreased CTGF concentrations in the fetal lung impaired alveologenesis (50). In addition, in this sheep model, chronic chorioamnionitis induced by 28 days of exposure to endotoxin did not induce lung fibrosis (30), demonstrating the resistance of the fetal lung to the development of fibrosis, despite the prolonged presence of proinflammatory agonists.

\section{ACKNOWLEDGMENTS}

We thank T. Tambuse, B. Ottensmeyer, M. Kapp, and D. Herbst for excellent technical assistance.

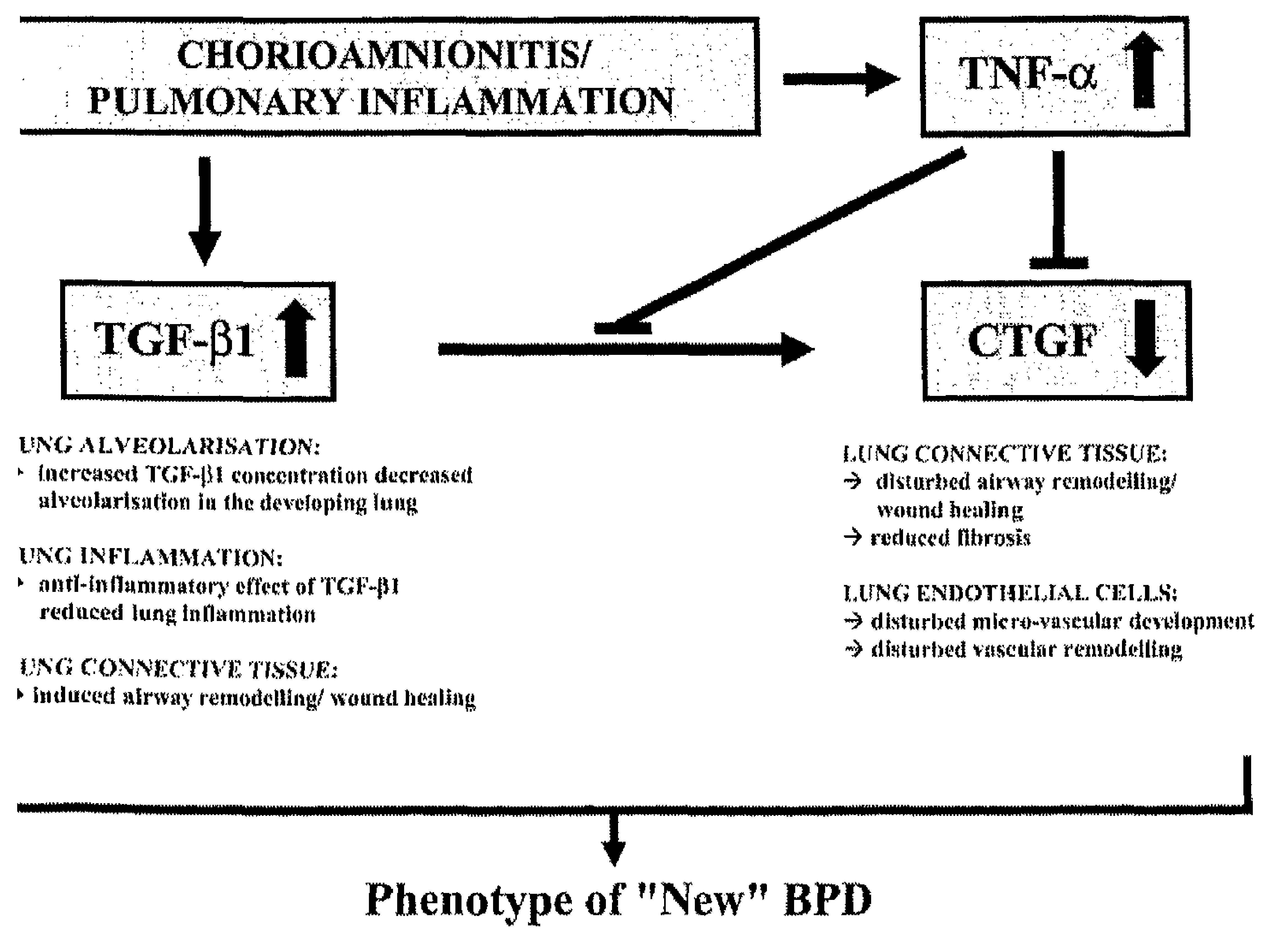

Fig. 8. Model of interaction between endotoxin, TNF $\alpha$, TGF- $\beta 1$, and CTGF in the pathophysiology of "new" BPD. Some of the hallmarks of the new BPD may be explained by the cytokine profiles. TGF- $\beta 1$ is essential for the "wound remodeling or healing" after lung injury, but increased TGF- $\beta 1$ concentration impairs alveologenesis. These effects are mediated in part by TGF- $\beta 1$ itself, but the fibrosis is primarily mediated by CTGF. Furthermore, TGF- $\beta 1$ reduces lung inflammation. $\mathrm{TGF}_{-} \beta 1$ and TNF- $\alpha$ were induced, but CTGF was decreased, in this model of endotoxininduced chorioamnionitis. Downregulation of CTGF might be mediated by TNF- $\alpha$. Therefore, the reduced concentrations of CTGF might have limited fibrosis but also impaired microvascular development, since CTGF is involved in normal vascular development. Taken together, the cytokine profile may explain, in an overly simplified way, the findings of new BPD. 


\section{GRANTS}

This work was supported by Deutsche Forschungsgemeinschaft Grant KU 1403/2-1, Interdisciplinary Center for Clinical Research, University of Würzburg, Grant IZKF Z 08, and National Heart, Lung, and Blood Institute Grant HL-65397.

\section{REFERENCES}

1. Abman SH. Bronchopulmonary dysplasia: "a vascular hypothesis." Am J Respir Crit Care Med 164: 1755-1756, 2001.

2. Abraham DJ, Shiwen X, Black CM, Sa S, Xu Y, and Leask A. Tumor necrosis factor- $\alpha$ suppresses the induction of connective tissue growth factor by transforming growth factor- $\beta$ in normal and scleroderma fibroblasts. J Biol Chem 275: 15220-15225, 2000.

3. Abreu JG, Ketpura NI, Reversade B, and De Robertis EM. Connective-tissue growth factor (CTGF) modulates cell signalling by BMP and TGF-B. Nat Cell Biol 4: 599-604, 2002.

4. Bartram $U$ and Speer CP. The role of transforming growth factor- $\beta$ in lung development and disease. Chest 125: 754-765, 2004.

5. Bhatt AJ, Pryhuber GS, Huyck H, Watkins RH, Metlay LA, and Maniscalco WM. Disrupted pulmonary vasculature and decreased vascular endothelial growth factor, Flt-1, and TIE-2 in human infants dying with bronchopulmonary dysplasia. Am I Respir Crit Care Med 164: 19711980, 2001.

6. Blom IE, Goldschmeding $\mathbf{R}$, and Leask A. Gene regulation of connective tissue growth factor: new targets for antifibrotic therapy? Matrix Biol 21: 473-482, 2002.

7. Brigstock DR. Regulation of angiogenesis and endothelial cell function by connective tissue growth factor (CTGF) and cysteine-rich 61 (CYR61). Angiogenesis 5: 153-165, 2002.

8. Bry $\mathbf{K}$ and Lappalainen $\mathrm{U}$. Intra-amniotic endotoxin accelerates lung maturation in fetal rabbits. Acta Paediatr 90: 74-80, 2001.

9. Bry K and Lappalainen U. Pathogenesis of bronchopulmonary dysplasia: the role of interleukin $1 \beta$ in the regulation of inflammation-mediated pulmonary retinoic acid pathways in transgenic mice. Semin Perinatol 30 : $121-128,2006$.

10. Bry $\mathbf{K}$, Lappalainen $\mathbf{U}$, and Hallman $\mathbf{M}$. Intra-amniotic interleukin-1 accelerates surfactant protein synthesis in fetal rabbits and improves lung stability after premature birth. J Clin Invest 99: 2992-2999, 1997.

11. Burgess JK, Ge Q, Poniris MH, Boustany S, Twigg SM, Black JL, and Johnson PR. Connective tissue growth factor and vascular endothelial growth factor from airway smooth muscle interact with the extracellular matrix. Am J Physiol Lung Cell Mol Physiol 290: L153-L161, 2006.

12. Cao L, Liu C, Cai B, Jia X, Kang L, Speer CP, and Sun B. Nuclear factor-kB expression in alveolar macrophages of mechanically ventilated neonates with respiratory distress syndrome. Biol Neonate 86: 116-123, 2004.

13. Charafeddine L, D'Angio CT, and Phelps DL. Alypical chronic lung disease patterns in neonates. Pediatrics 103: 759-765, 1999.

14. Coalson JJ. Pathology of new bronchopulmonary dysplasia. Semin Neonatol 8: 73-81, 2003.

15. D'Alquen D, Kramer BW, Seidenspinner S, Marx A, Berg D, Groneck P, and Speer CP. Activation of umbilical cord endothelial cells and fetal inflammatory response in preterm infants with chorioamnionitis and funisitis. Pediatr Res 57: 263-269, 2005.

16. Gauldie J, Galt T, Bonniaud P, Robbins C, Kelly M, and Warburton D. Transfer of the active form of transforming growth factor- $\beta 1$ gene to newborn rat lung induces changes consistent with bronchopulmonary dysplasia. Am J Pathol 163: 2575-2584, 2003.

17. Gobet R, Park JM, Nguyen HT, Chang B, Cisek LJ, and Peters CA. Renal renin-angiotensin system dysregulation caused by partial bladder outlet obstruction in fetal sheep. Kidney Int 56: 1654-1661, 1999.

18. Gomez R, Romero R, Ghezzi F, Yoon BH, Mazor M, and Berry SM. The fetal inflammatory response syndrome. Am J Obstet Gynecol 179: $194-202,1998$

19. Groneck P, Gotze-Speer B, Oppermann M, Eiffert H, and Speer CP. Association of pulmonary inflammation and increased microvascular permeability during the development of bronchopulmonary dysplasia: a sequential analysis of inflammatory mediators in respiratory fluids of high-risk preterm neonates. Pediatrics 93: 712-718, 1994

20. Grotendorst GR, Okochi $\mathbf{H}$, and Hayashi $\mathbf{N}$. A novel transforming growth factor $\beta$ response element controls the expression of the connective tissue growth factor gene. Cell Growth Differ 7: 469-480, 1996.
21. Guidot DM, Folkesson HG, Jain L, Sznajder JI, Pittet JF, and Matthay MA. Integrating acute lung injury and regulation of alveolar fluid clearance. Am J Physiol Lung Cell Mol Physiol 291: L301-L306, 2006.

22. Husain AN, Siddiqui NH, and Stocker JT. Pathology of arrested acinar development in postsurfactant bronchopulmonary dysplasia. Hum Pathol 29: $710-717,1998$.

23. Ikegami M, Kallapur SG, and Jobe AH. Initial responses to ventilation of premature lambs exposed to intra-amniotic endotoxin 4 days before delivery. Am J Physiol Lung Cell Mol Physiol 286: L573-L579, 2004.

24. Ikegami M, Moss TJ, Kallapur SG, Mulrooney N, Kramer BW, Nitsos I, Bachurski CJ, Newnham JP, and Jobe AH. Minimal lung and systemic responses to TNF- $\alpha$ in preterm sheep. Am J Physiol Lung Cell Mol Physiol 285: L121-L129, 2003.

25. Jobe AH and Bancalari E. Bronchopulmonary dysplasia. Am $J$ Respir Crit Care Med 163: 1723-1729, 2001.

26. Jobe AH, Newnham JP, Willet KE, Moss TJ, Gore Ervin M, Padbury JF, Sly P, and Ikegami M. Endotoxin-induced lung maturation in preterm lambs is not mediated by cortisol. Am J Respir Crit Care Med 162: $1656-1661,2000$.

27. Jobe AJ. The new BPD: an arrest of lung development. Pediatr Res 46: 641-643, 1999.

28. Jonsson B, Li YH, Noack G, Brauner A, and Tullus K. Downregulatory cytokines in tracheobronchial aspirate fluid from infants with chronic lung disease of prematurity. Acta Paediatr 89: 1375-1380, 2000.

29. Kallapur SG, Bachurski CJ, Le Cras TD, Joshi SN, Ikegami M, and Jobe AH. Vascular changes after intra-amniotic endotoxin in preterm lamb lungs. Am J Physiol Lung Cell Mol Physiol 287: L1178-L1185, 2004.

30. Kallapur SG, Nitsos I, Moss TJ, Kramer BW, Newnham JP, Ikegami $\mathbf{M}$, and Jobe AH. Chronic endotoxin exposure does not cause sustained structural abnormalities in the fetal sheep lungs. Am J Physiol Lung Cell Mol Physiol 288: L966-L974, 2005.

31. Kallapur SG, Willet KE, Jobe AH, Ikegami M, and Bachurski C.J. Intra-amniotic endotoxin: chorioamnionitis precedes lung maturation in preterm lambs. Am J Physiol Lung Cell Mol Physiol 280: L527-L536, 2001.

32. Khalil N. Posttranslational activation of latent transforming growth factor- $\beta$ (L-TGF- $\beta$ ): clinical implications. Histol Histopathol 16: 541-551, 2001.

33. Khalil N. TGF- $\beta$ : from latent to active. Microbes Infect 1: 1255-1263, 1999.

34. Kotecha S, Wangoo A, Silverman M, and Shaw RJ. Increase in the concentration of transforming growth factor- $\beta 1$ in bronchoalveolar lavage fluid before development of chronic lung disease of prematurity. $J$ Pediatr 128: 464-469, 1996.

35. Kramer BW, Kramer S, Ikegami M, and Jobe AH. Injury, inflammation, and remodeling in fetal sheep lung after intra-amniotic endotoxin. Am J Physiol Lung Cell Mol Physiol 283: L452-L459, 2002.

36. Kramer BW, Moss TJ, Willet KE, Newnham JP, Sly PD, Kallapur SG, Ikegami $\mathbf{M}$, and Jobe AH. Dose and time response after intraamniotic endotoxin in preterm lambs. Am I Respir Crit Care Med 164: 982-988, 2001

37. Lassus P, Turanlahti M, Heikkila P, Andersson LC, Nupponen I, Sarnesto A, and Andersson S. Pulmonary vascular endothelial growth factor and Flt-1 in fetuses, in acute and chronic lung disease, and in persistent pulmonary hypertension of the newborn. Am J Respir Crit Care Med 164: 1981-1987, 2001.

38. Lecart C, Cayabyab R, Buckley S, Morrison J, Kwong KY, Warburton D, Ramanathan R, Jones CA, and Minoo P. Bioactive transforming growth factor- $\beta$ in the lungs of extremely low birth weight neonates predicts the need for home oxygen supplementation. Biol Neonate 77 217-223, 2000.

39. May M, Marx A, Seidenspinner S, and Speer CP. Apoptosis and proliferation in lungs of human fetuses exposed to chorioamnionitis. Histopathology 45: 283-290, 2004.

40. May M, Strobel P, Preisshofen T, Seidenspinner S, Marx A, and Speer CP. Apoptosis and proliferation in lungs of ventilated and oxygen-treated preterm infants. Eur Respir J 23: 113-121, 2004.

41. Moussad EE and Brigstock DR. Connective tissue growth factor: what's in a name? Mol Genet Metab 71: 276-292, 2000

42. Newnham JP, Shub A, Jobe AH, Bird PS, Ikegami M, Nitsos I, and Moss TJ. The effects of intra-amniotic injection of periodontopathic lipopolysaccharides in sheep. Am J Obstet Gynecol 193: 313-321, 2005. 
43. Northway WH Jr, Rosan RC, and Porter DY. Pulmonary disease following respirator therapy of hyaline-membrane disease. Bronchopulmonary dysplasia. $N$ Engl J Med 276: 357-368, 1967.

44. Speer CP. Inflammation and bronchopulmonary dysplasia. Semin Neonatol 8: 29-38, 2003

45. Speer CP. Pre- and postnatal inflammatory mechanisms in chronic lung disease of preterm infants. Paediatr Respir Rev 5 Suppl A: S241-S244, 2004.

46. Stevenson DK, Wright LL, Lemons JA, Oh W, Korones SB, Papile LA, Bauer CR, Stoll BJ, Tyson JE, Shankaran S, Fanaroff AA, Donoyan EF, Ehrenkranz RA, and Verter J. Very low birth weight outcomes of the National Institute of Child Health and Human Development Neonatal Research Network, January 1993 through December 1994. Am J Obstet Gynecol 179: 1632-1639, 1998.

47. Ten Dijke $P$ and Hill CS. New insights into TGF- $\beta$-Smad signalling. Trends Biochem Sci 29: 265-273, 2004.

48. Thomas W and Speer CP. Management of infants with bronchopulmonary dysplasia in Germany. Early Hum Dev 81: 155-163, 2005.

49. Van Marter LJ, Allred EN, Pagano M, Sanocka U, Parad R, Moore M, Susser M, Paneth N, and Leviton A. Do clinical markers of barotrauma and oxygen toxicity explain interhospital variation in rates of chronic lung disease? The Neonatology Committee for the Developmental Network. Pediatrics 105: 1194-1201, 2000.
50. Vicencio AG, Lee CG, Cho SJ, Fickelberg O, Chuu Y, Haddad GG, and Elias JA. Conditional overexpression of bioactive transforming growth factor- $\beta 1$ in neonatal mouse lung: a new model for bronchopulmonary dysplasia? Am J Respir Cell Mol Biol 31: 650-656, 2004.

51. Watterberg KL, Demers LM, Scott SM, and Murphy S. Chorioamnionitis and early lung inflammation in infants in whom bronchopulmonary dysplasia develops. Pediatrics 97: 210-215, 1996.

52. Willet KE, Jobe AH, Ikegami M, Newnham J, Brennan S, and Sly PD. Antenatal endotoxin and glucocorticoid effects on lung morphometry in preterm lambs, Pediatr Res 48: 782-788, 2000.

53. Willet KE, Kramer BW, Kallapur SG, Ikegami M, Newnham JP, Moss TJ, Sly PD, and Jobe AH. Intra-amniotic injection of IL-1 induces inflammation and maturation in fetal sheep lung. Am J Physiol Lung Cell Mol Physiol 282: L411-L_420, 2002.

54. Workalemahu G, Foerster M, Kroegel C, and Braun RK. Human $\gamma \delta$-T lymphocytes express and synthesize connective tissue growth factor: effect of $I L-15$ and TGF- $\beta 1$ and comparison with $\alpha \beta-T$ lymphocytes. $J$ Immunol 170: 153-157, 2003.

55. Yoon BH, Romero R, Jun JK, Park KH, Park JD, Ghezzi F, and Kim BI. Amniotic fuid cytokines (interleukin-6, tumor necrosis factor- $\alpha$, interleukin-1 $\beta$, and interleukin-8) and the risk for the development of bronchopulmonary dysplasia. Am J Obstet Gynecol 177: 825-830, 1997.

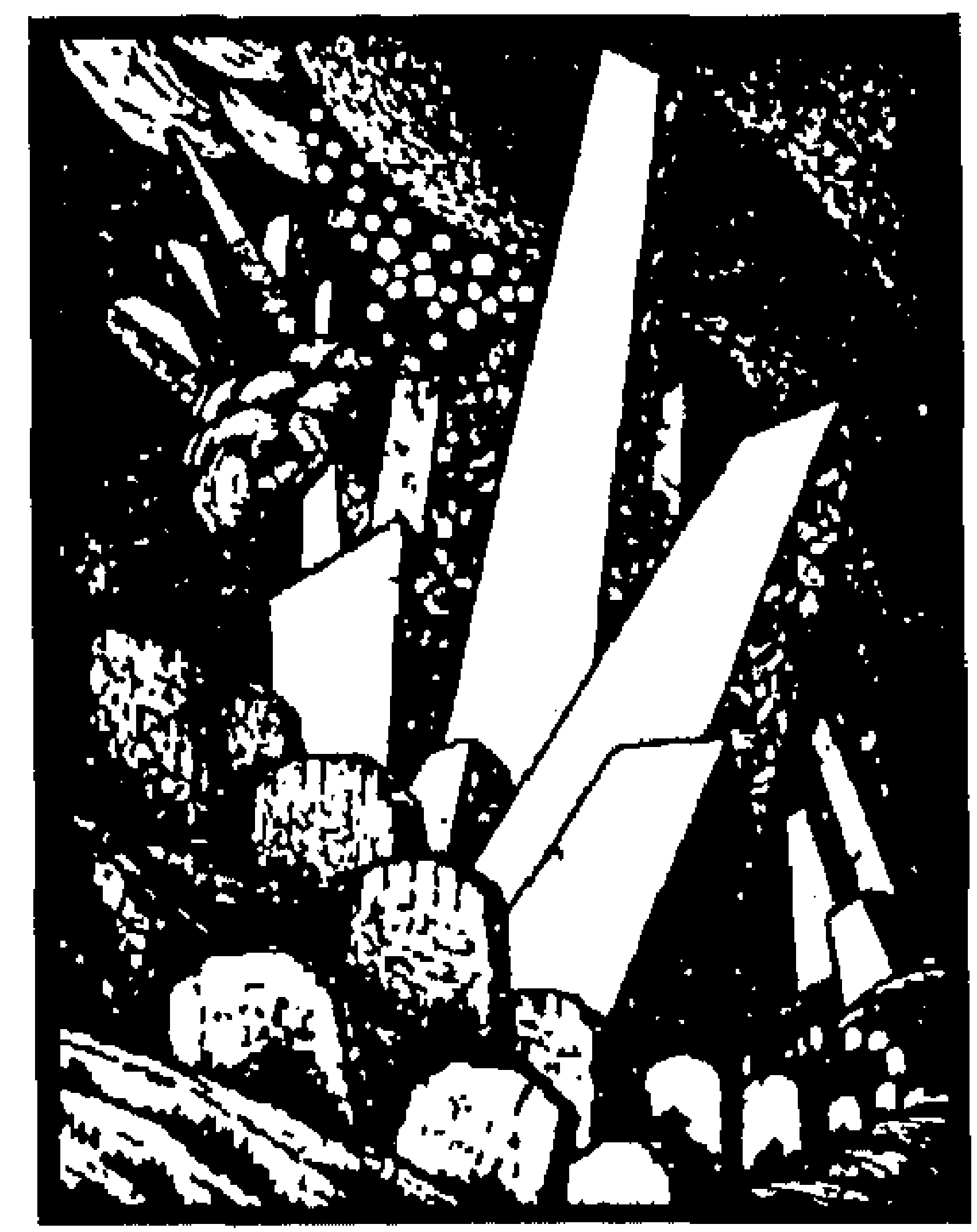




\section{CHAPTER 6}

Surfactant protein A recruits neutrophil granulocytes into the lungs of ventilated preterm sheep

Kramer, B.W., Jobe, A.H., Bachurski, C.J., Ikegami, M. 


\title{
Surfactant Protein A Recruits Neutrophils into the Lungs of Ventilated Preterm Lambs
}

\author{
BORIS W. KRAMER, ALAN H. JOBE, CINDY J. BACHURSKI, and MACHIKO IKEGAMI \\ Department of Pulmonary Biology, Children's Hospital Medical Center, Cincinnati, Ohio
}

\begin{abstract}
We tested the effects of surfactant protein A (SP-A) on inflammation and surfactant function in ventilated preterm lungs. Preterm lambs of $131 \mathrm{~d}$ gestation were ventilated for $15 \mathrm{~min}$ to initiate a mild inflammatory response, and were then treated with $100 \mathrm{mg} /$ $\mathrm{kg}$ recombinant human SP-C surfactant or with the same surfactant supplemented with $3 \mathrm{mg} / \mathrm{kg}$ ovine SP-A. Addition of SP-A to the SP-C surfactant did not change lung function. After $6 \mathrm{~h}$ of ventilation, cell numbers in the alveolar wash were 4.9 times higher in SP-A + SP-C-surfactant-treated animals. Cellular infiltrates consisted of neutrophils that produced less hydrogen peroxide than did cells from SP-C-surfactant-treated animals. Expression of adhesion molecules CD11b and CD44 was significantly greater after SP-A treatment, whereas the expression of CD14 was unchanged. Messenger RNAs (mRNAs) for the proinflammatory cytokines interleukin (IL)-1 $\beta$, IL-6, and IL-8, but not tumor necrosis factor- $\alpha$, were increased in SP-A-treated lungs. Surfactant protein mRNAs and protein leakage into alveolar washes were not altered by SP-A, indicating that SP-A treatment produces no evidence of lung injury. The present study identifies an unanticipated role of SP-A in neutrophil recruitment in the lungs of preterm lambs.
\end{abstract}

Surfactant treatment of infants with respiratory distress syndrome (RDS) decreases morbidity and mortality and is now the standard of care. Nevertheless, many infants of very low birth weight progress to having bronchopulmonary dysplasia (BPD), and airway samples from infants destined to have BPD have increased numbers of proinflammatory cells and cytokines within the first days after birth and initiation of ventilation (1). The surfactants used to treat preterm infants with RDS are isolated from animal lungs, and the organic solvent extraction and purification steps used in their isolation remove the innate host-defense protein surfactant protein $A$ (SP-A) while leaving variable amounts of SP-B and SP-C. SP-A is a member of the collectin family of proteins that bind carbohydrates and lipopolysaccharides (2). Although SP-A binds to phospholipids and is essential for tubular myelin formation, SP-A-ablated mice have normal surfactant function, metabolism, and tolerance to exercise and hyperoxia (3-5). However, SP-A-deficient mice are more susceptible to bacterial and viral infections $(6,7)$. SP-A enhances the efficiency of clearance and killing of bacteria, fungi, and viruses in vitro and in SP-Adeficient mice that are treated with SP-A $(7,8)$. Immunomodulatory functions of SP-A in the airways include binding and

(Received in original form on May 19, 2000 and in revised form August 30, 2000) Supported by grant HD-12714 from the National Institutes of Child Health and Development. Dr. Kramer was supported by a scholarship from the Deutsche Forschungsgemeinschaft.

Correspondence and requests for reprints should be addressed to Machiko Ikegami, M.D., Ph.D., Children's Hospital Medical Center, Division of Pulmonary Biology, 3333 Burnet Avenue, Cincinnati, OH 45229-3039. E-mail: machiko.ikegami@ chmcc.org

Am J Respir Crit Care Med Vol 163. pp 158-165, 2001

Internet address: www.atsjournals.org modulation of processing of endotoxin, modulation of cytokine production by alveolar macrophages (AM) $(9,10)$, and interaction with the endotoxin receptor CD14 (11).

SP-A has been proposed as being either pro- or antiinflammatory on the basis of its properties in vitro (12-14). There is no information about host-defense effects of exogenous SP-A in the preterm lung, in which SP-A is normally present in very small amounts. The initiation of ventilation with mechanical ventilation induces transcription of proinflammatory cytokines in preterm lamb lungs $(15,16)$. This cytokine induction is presumed to be injurious, because preterm fetuses exposed to chorioamnionitis and increased levels of tumor necrosis factor (TNF)- $\alpha$, interleukin (IL)-1 $\beta$, IL-6, and IL- 8 have an increased risk of developing BPD, as do infants with increased levels of the same cytokines in samples of bronchoalveolar lavage fluid (BALF) taken within the first days of life $(1,17)$. In preterm infants, low concentrations of SP-A in the airways correlated with increased mortality and with a higher rate of BPD (18). In the preterm baboon model of BPD, SP-A was present in lung tissue, but was present at very low levels in BALF, demonstrating an abnormality of secretion of SP-A (19).

The host-defense functions of the preterm fetal lung differ from those of the adult lung because the fetal lung contains virtually no granulocytes or mature macrophages (1). Multiple immune defects have been described for white blood cells from infants, and levels of innate host-defense molecules such as lysozyme and defensins also are low (20). We hypothesized that SP-A would alter the proinflammatory response of the preterm lung to mechanical ventilation. To test this hypothesis, we treated preterm lambs with an effective synthetic surfactant that contained human recombinant SP-C, or with the same surfactant supplemented with $3 \%$ sheep SP-A, and evaluated lung function, surfactant components, and multiple local and systemic indicators of inflammation.

\section{METHODS}

\section{SP-A and SP-C Surfactant}

SP-A was isolated from alveolar washes of healthy adult sheep by butanol extraction (21). After extraction of whole surfactant with butanol, insoluble proteins were resuspended in octylglucopyranoside, and SP-A was solubilized in $5 \mathrm{mM}$ Tris-HCl in water (pH 7.4). SP-A was dialyzed for $48 \mathrm{~h}$ against the same buffer to remove residual octylglucopyranoside, and the purification was verified by sodium dodecylsulfate-polyacrylamide gel (SDS-PAGE) analysis. The SP-A used to treat the lambs was tested for bacterial endotoxin contamination with the Limulus amebocyte lysate assay (Sigma Chemical Co., St. Louis, $\mathrm{MO}$ ), and no endotoxin was detected. The treatment dose of $3 \mathrm{mg} / \mathrm{kg}$ SP-A in $100 \mathrm{mg} / \mathrm{kg}$ of recombinant human SP-C surfactant (Byk Gulden, Konstanz, Germany) was similar to the amount of SP-A and surfactant recovered from alveolar lavage of full-term animals. The SP-C surfactant contained $2 \%$ recombinant human SP-C in phospholipids (dipalmitoylphosphatidylcholine and palmitoyloleoylphosphatidylglycerol in a 70:30 [wt/wt] ratio) and 5\% palmitic acid (22). This SP-C surfactant was very effective when tested in preterm lambs and in models 
of lung injury $(22,23)$. Currently, SP-C surfactant is being tested in clinical trials for the treatment of acute respiratory distress syndrome (ARDS) (24). The recombinant SP-C consists of the 34-amino-acid human SP-C peptide, altered by the replacement of cysteine in positions 4 and 5 with phenylalanine, and of methionine in position 32 by isoleucine. The aitered sequence of recombinant SP-C improves solubility and prevents the aggregation of native SP-C, but maintains the functions of the dipalmitoylated form of SP-C (25). This recombinant protein has clearance kinetics from the airways and lungs of rabbits and preterm lambs that are similar to those of native SP-C (22). The SP-C surfactant was resuspended in $0.9 \% \mathrm{NaCl}$ to a final concentration of $25 \mathrm{mg} / \mathrm{ml}$.

\section{Delivery and Ventilation of Preterm Lambs}

Preterm lambs were delivered at $130 \mathrm{~d}$ to $132 \mathrm{~d}$ gestational age by cesarean section, as previously described (term is $150 \mathrm{~d})(22,26)$. Each pregnant ewe was preanesthetized with ketamine $(20 \mathrm{mg} / \mathrm{kg}$ intramuscularly) and acepromazine $(0.3 \mathrm{mg} / \mathrm{kg})$, and then given spinal-epidural anesthesia $(10 \mathrm{ml}$ of $2 \%$ lidocaine and $0.5 \%$ bupivacaine $[1: 1, \mathrm{vol} /$ vol]). After exposure of the head, the preterm lamb was given ketamine $(10 \mathrm{mg} / \mathrm{kg}$ intramuscularly) and acepromazine $(0.1 \mathrm{mg} / \mathrm{kg}$ intramuscularly). A tracheal tube of $4.5-\mathrm{mm}$ I.D. was inserted and tied into the trachea after local anesthesia of the anterior neck with $2 \%$ lidocaine. Fluid from fetal airways was removed with a syringe. After the umbilical cord was cut, the newborn lamb was delivered and weighed. Ventilation was started with the following settings: fraction of inspired oxygen $\left(\mathrm{FI}_{\mathrm{O}_{2}}\right)=1.0$, respiratory rate $(\mathrm{RR})=60$ breaths $/ \mathrm{min}$, inspiratory time $(\mathrm{TI})=0.4 \mathrm{~s}$, positive end-expiratory pressure (PEEP) $=4 \mathrm{~cm}$ $\mathrm{H}_{2} \mathrm{O}$, and a peak inspiratory pressure $\left(\mathrm{P}_{\mathrm{max}}\right)$ sufficient to yield a tida volume (VT) of 6 to $8 \mathrm{ml} / \mathrm{kg}$, but with $\mathrm{PI}_{\max }$ limited to $40 \mathrm{~cm} \mathrm{H}_{2} \mathrm{O}$. VT was monitored continuously (CP-100; Bicore Monitoring Systems, Anaheim, CA). A size 5 French catheter was advanced into the aorta via an umbilical artery, and a $10 \mathrm{ml} / \mathrm{kg}$ transfusion of filtered fetal blood collected from the placenta was administered within $10 \mathrm{~min}$ of delivery. After 15 min of ventilation, each preterm lamb was randomly assigned to treatment with $100 \mathrm{mg} / \mathrm{kg}$ SP-C surfactant $(\mathrm{n}=7$; SP-C surfactant group) or $100 \mathrm{mg} / \mathrm{kg} \mathrm{SP-C} \mathrm{surfactant} \mathrm{plus} 3 \mathrm{mg} / \mathrm{kg} \mathrm{SP-A}$ ( $\mathrm{n}=7$; SP-A + SP-C-surfactant group). The surfactant treatment was given in two equal aliquots, with the lamb in the left lateral and right lateral positions, respectively (26). The initial ventilation for $15 \mathrm{~min}$ without surfactant treatment was used to initiate the injury process in the preterm lungs, and to mimic the clinical sequence for resuscitation followed by surfactant treatment of preterm infants. After surfactant treatment, the ventilation pressure was adjusted to achieve an arterial carbon dioxide tension $\left(\mathrm{Pa}_{\mathrm{CO}_{2}}\right)$ of 45 to $60 \mathrm{~mm} \mathrm{Hg}$ and an arterial oxygen tension of 150 to $200 \mathrm{~mm} \mathrm{Hg}$ with a $V_{T}$ of 6 to $8 \mathrm{ml} / \mathrm{kg}$. VT was measured at $15 \mathrm{~min}, 45 \mathrm{~min}, 2 \mathrm{~h}, 4 \mathrm{~h}$, and $6 \mathrm{~h}$ with a pneumotachometer, and dynamic compliance (Cdyn) was calculated as VT normalized to body weight and divided by the ventilatory pressure ( $\mathrm{P}_{\max }$ PEEP) $(22,26)$. The ventilatory efficiency index (VEI) was calculated as VEI $=3,800 /$ (respiratory rate $\left.\times\left[\mathrm{P}_{\max }-\mathrm{PEEP}\right] \times \mathrm{Pa}_{\mathrm{CO}_{2}}\right]$, where 3,800 is a $\mathrm{CO}_{2}$ production constant $([\mathrm{ml} \times \mathrm{mm} \mathrm{Hg}] /[\mathrm{kg} \times$ min] $)(25)$. Complete blood counts and differentials were done on from cord blood and on peripheral blood at $6 \mathrm{~h}$. The arterial catheter was used for blood gas analysis, $\mathrm{pH}$ measurement, and blood pressure recording, and to infuse $10 \%$ dextrose $(100 \mathrm{ml} / \mathrm{kg} / \mathrm{d})$. Rectal temperature was monitored and kept at $38^{\circ}$ to $39^{\circ} \mathrm{C}$ with heating pads and radiant heat. Supplemental ketamine $(10 \mathrm{mg} / \mathrm{kg}$ intramuscularly) and acepromazine $(0.1 \mathrm{mg} / \mathrm{kg}$ intramuscularly) were administered to suppress spontaneous breathing. At $2 \mathrm{~h}$ of afterbirth, a sample of BALF was obtained by wedging a feeding tube in an airway and infusing $1 \mathrm{ml}$ of saline, followed by aspiration. After $6 \mathrm{~h}$, each animal was deeply anesthetized with $25 \mathrm{mg} / \mathrm{kg}$ pentobarbital given intravenously, and was ventilated briefly with $100 \%$ oxygen. The endotracheal tube was clamped for $3 \mathrm{~min}$ to permit oxygen absorption. The animal was exsanguinated by cutting the abdominal aorta.

\section{Pressure-Volume Curve and Lung Processing}

The thorax of the lamb was opened, the lungs were inflated with $40 \mathrm{~cm}$ $\mathrm{H}_{2} \mathrm{O}$ pressure for $1 \mathrm{~min}$, and maximal lung volume was recorded (26). The pressure was sequentially lowered to $20,15,10,5$, and $0 \mathrm{~cm} \mathrm{H}_{2} \mathrm{O}$, and lung volumes were recorded $30 \mathrm{~s}$ after each pressure was reached.
Volumes were corrected for the compliance of the system. Lungs were then removed from the thorax. Pieces of the right lower lobe were immediately frozen in liquid nitrogen for RNA isolation. Alveolar washing was done on the left lung by filling the lung with $0.9 \%$ $\mathrm{NaCl}$ at $4^{\circ} \mathrm{C}$ until it was visually distended, and was repeated five times $(22,26)$. The washes were pooled and aliquots were saved for measurement of saturated phosphatidylcholine (SatPC), total protein, cell number and differential count, surfactant protein quantification, and flow cytometric analysis. Cell pellets were used for hydrogen peroxide assay and RNA isolation. The lung was homogenized in $0.9 \%$ $\mathrm{NaCl}$ and SatPC was measured in aliquots of homogenate.

\section{Measurement of SatPC and Total Protein}

SatPC was isolated from chloroform-methanol (2:1) extracts by neutral alumina column chromotography after exposure to osmium tetroxide, and was quantified by phosphorus assay (25). Total protein in alveolar washes was measured as previously described (26).

\section{Alveolar Cells}

Collected alveolar washings were centrifuged at $500 \times g$ for $10 \mathrm{~min}$ and the pellet was resuspended in phosphate-buffered saline (PBS). Total cells were stained with tryptan blue and counted. Differential cell counts were performed on cytospin preparations after staining with Diff-Quik (American Scientific Products, San Diego, CA). In order to assess the activation state of the cells recruited to the airways, hydrogen peroxide was measured with an assay based on the oxidation of ferrous iron $\left(\mathrm{Fe}^{2+}\right)$ to ferric iron $\left(\mathrm{Fe}^{3+}\right)$ by hydrogen peroxide under acidic conditions (Bioxytech $\mathrm{H}_{2} \mathrm{O}_{2}-560$ Assay; OXIS International, Portland, OR).

Aliquots of alveolar cells were incubated on ice with monoclonal antibodies (primary antibody) against ovine CD11b ( $\alpha \mathrm{M}$ subunit of integrin CR3), CD14 (receptor for complex of lipopolysaccharide and lipopolysaccharide binding protein), and CD44 (proteoglycan link protein). The cell pellet was washed twice with PBS to remove unbound antibody, and was incubated with phycoerythrin (PE)-labeled $\mathrm{F}\left(\mathrm{ab}^{\prime}\right)_{2}$ anti-IgG fragments (secondary antibody) in the dark on ice. Control staining was performed with isotype antibodies and with secondary antibody alone to obtain background fluorescence. Cells were washed twice, resuspended in PBS, kept on ice, and immediately analyzed on a fluorescence-activated cell sorter (FACS) (Calibur; Becton-Dickinson, Inc., Mountain View, CA). All antibodies were purchased from Serotec (Raleigh, NC).

\section{Western Blots for SP-B and SP-D}

SDS-PAGE electrophoresis was done with 8 to $16 \%$ gradient Tris/ glycine gels (Novex, San Diego, CA). Samples containing $3 \mathrm{nmol}$ of SatPC were electrophoresed along with ovine SP-B or murine SP-D standards. Proteins were transferred to nitrocellulose paper (Schleicher \& Schuell, Keene, NH) for immunoblot analysis with rabbit antiSP-B or anti-SP-D serum. The nitrocellulose membrane was first blocked with $5 \%$ bovine serum albumin (wt/vol) (Sigma Chemicals)

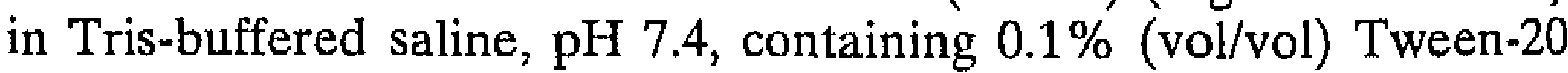
(5). The antibody was diluted and incubated overnight. Horseradish peroxidase-conjugated goat antirabbit immunoglobulin (Calbiochem, La Jolla, CA) was used as secondary antibody, and enhanced chemiluminescence substrates (Amersham, Arlington Heights, IL) were used to develop the immunoblots. Estimates of the amount of SP-B and SP-D were made by calculation of the relative band densities, using Alpha-Imager 2000 Documentation and Analysis Software (Alpha Innotech, San Leandro, CA).

\section{Cytokine Messenger RNA}

Total RNA was isolated from a portion of the right lower lobe and from cell pellets of the tracheal aspirate and alveolar washings by guanidium thiocyanate-phenol-chloroform extraction (27). Ribonuclease (RNAse) protection assays were performed with total RNA from lung tissue and cell pellets (28). Briefly, RNA transcripts of ovine interleukin (IL)-1 $\beta$, IL-6, IL-8, IL-10, tumor necrosis factor (TNF)- $\alpha$, and ovine ribosomal protein L32 as a reference RNA were synthesized with $\left.{ }^{32} \mathrm{P}\right]$ uridine triphosphate (Life Sciences Products, Boston, MA), using SP6 or T7 polymerase (Ribonuclease Protection Assay III; Ambion, Austin, TX). Aliquots of $10 \mu \mathrm{g}$ RNA were incu- 
bated with excess radiolabeled probes for cytokines and $\mathrm{L} 32$ at $55^{\circ} \mathrm{C}$ for $18 \mathrm{~h}$. Remaining single-stranded RNA was digested with RNAse A/RNAse T1 (Ambion). After inactivation and precipitation, protected fragments were electrophoresed on a $6 \%$ polyacrylamide-urea $(8 \mathrm{~mol} / \mathrm{L})$ sequencing gel and visualized by autoradiography. Densities of the protected bands were quantified on a Phosphorimager (Molecular Dynamics Inc., Sunnyvale, CA), using ImageQuant software (Molecular Dynamics).

\section{Surfactant Protein mRNA}

The relative abundance of surfactant protein mRNA was measured with the S1 nuclease protection assay as previously described (27). Briefly, an excess of linearized probes for SP-A, SP-B, SP-C, and L32, all $5^{\prime}$ end -labeled with $\left[^{32} \mathrm{P}\right.$ ], were hybridized at $56^{\circ} \mathrm{C}$ with $3 \mu \mathrm{g}$ of total RNA from lung tissue. SP-D was detected in a separate hybridization using $10 \mu \mathrm{g}$ RNA. The SP-D probe was a kind gift of Dr. M. Hallman of the University of Oulu, Finland. After incubation with S1 nuclease, the protected fragments were resolved on a $6 \%$ polyacrylamide-urea $(8 \mathrm{~mol} / \mathrm{L})$ sequencing gel, visualized by autoradiography, and quantified on a Phosphorimager with ImageQuant software.

\section{Lung Morphology/Inflammation Score}

The right upper lobe was inflation fixed with $10 \%$ formalin at $30 \mathrm{~cm}$ $\mathrm{H}_{2} \mathrm{O}$ pressure. Paraffin tissue sections of $5 \mu \mathrm{m}$ thickness, stained with hematoxylin and eosin, were graded for the degree of inflammation in a blinded fashion by scoring three sections from each animal as zero if they had no inflammatory cells in tissue or airspaces, 1 if they had a few cells, 2 if they exhibited moderate cell infiltration, and 3 if they had a large number of inflammatory cells in airspaces and tissue (27). Airspaces and tissue were assessed separately. Average scores were calculated for each animal.

\section{Data Analysis}

Results are given as mean \pm SEM. Comparisons between SP-Atreated lambs and SP-C-surfactant-treated animals were made with two-tailed $t$ tests. Significance was accepted at $\mathrm{p}<0.05$.

\section{RESULTS}

\section{Lung Function}

The seven lambs randomized to SP-C surfactant treatment weighed $3.4 \pm 0.2$ (mean $\pm S E M$ ) $\mathrm{kg}$, and the seven lambs randomized to SP-A + SP-C-surfactant treatment weighed $3.3 \pm 0.3 \mathrm{~kg}$. There were no differences between the groups in cord blood gas or $\mathrm{pH}$ values. Values of Cdyn were similar for the two groups of lambs at $15 \mathrm{~min}$ of age (Figure 1A). After surfactant treatment, Cdyn increased in both groups. A VT of $7.8 \pm 0.2 \mathrm{ml} / \mathrm{kg}$ were used to maintain target $\mathrm{PCO}_{2}$ values of 45 to $60 \mathrm{~mm} \mathrm{Hg}$ for both groups. Over the 6-h period of ventilation, there were no significant differences in ventilation between the SP-A + SP-C-surfactant-treated group and the SP-Csurfactant-treated group, as evaluated with the ventilation efficiency index, a measure of the efficiency of gas exchange (Figure 1B). Sequential blood gas and $\mathrm{pH}$ values also were not different. Lung volumes for the deflation limbs of the pressurevolume curves of the two groups of animals were similar after $6 \mathrm{~h}$ of ventilation (Figure 1C). Therefore, the presence of SPA had no effect on lung function.

\section{Surfactant Measurements}

The amounts of SatPC in alveolar washes and in homogenized total lungs, measured after $6 \mathrm{~h}$ of ventilation, were not different in the SP-A + SP-C-surfactant and the SP-C-surfactanttreated groups (Table 1 ). The relative amounts of SP-B and SP-D were measured by Western blotting. There was no difference between SP-A + SP-C-surfactant-treated and SP-Csurfactant-treated animals after $6 \mathrm{~h}$. The steady-state levels of mRNAs for SP-A, SP-B, SP-C, and SP-D were not affected by treatment with SP-A (Figure 2), although the increase in
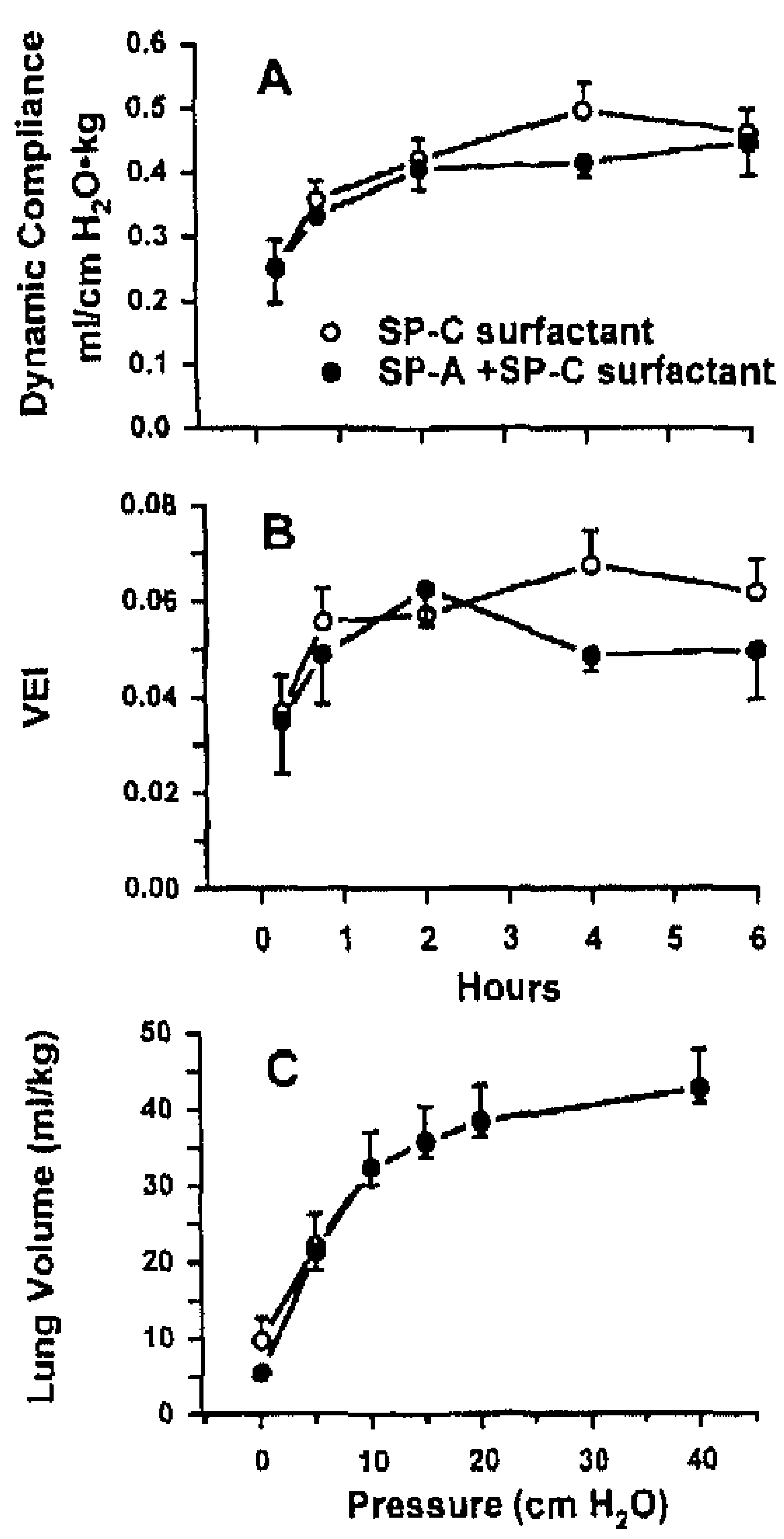

Figure 1. Sequential measurements of lung function in premature lambs treated with SP-C surfactant alone or with ovine SP-A (SP-A + SP-C surfactant). (A) Cdyn. Initial Cdyn was similar for both groups. After surfactant treatment, Cdyn increased in both groups. (B) The ventilation efficiency index (VEI) was similar in the two study groups over the ventilation period of $6 \mathrm{~h}$. ( $($ ) Deflation limbs of pressure-volume curves. After $6 \mathrm{~h}$ of ventilation there were no significant differences in the maximal lung volumes of the SP-A + SP-C-surfactant-treated and the SP-C-surfactant-treated animals.

mRNA for SP-D in SP-A-treated animals approached significance $(p=0.07)$.

\section{Indicators of Inflammation}

The total protein in alveolar washes was low in both study groups, and was not typical of lung injury (26) (Table 1). The total cell number in alveolar washes of the SP-A + SP-C-surfactant-treated group was increased by 4.9 -fold above the cell numbers for SP-C-surfactant-treated animals (Figure 3A). The recruited cells consisted predominantly of neutrophils and macrophages/monocytes (Figure 3B). Hydrogen peroxide was measured in aliquots of $1 \times 10^{6}$ cells, to evaluate metabolic activation. In cells from SP-A + SP-C-surfactant-treated

TABLE 1

SATURATED PHOSPHATIDYLCHOLINE, SURFACTANT PROTEIN B, SURFACTANT PROTEIN D, AND TOTAL PROTEIN IN ALVEOLAR WASHES AND WHOLE LUNGS OF VENTILATED PRETERM SHEEP

\begin{tabular}{lcc}
\hline & SP-C Surfactant & SP-A + SP-C Surfactant \\
\hline Sat PC, $\mu \mathrm{mol} / \mathrm{kg}$ & & \\
$\quad$ Alveolar & $19.5 \pm 1.4$ & $19.6 \pm 2.4$ \\
$\quad$ Total lung & $82.0 \pm 5.4$ & $78.6 \pm 6.1$ \\
Surfactant proteins (intensity relative to control) & \\
$\quad$ SP-B & $1.0 \pm 0.2$ & $1.0 \pm 0.2$ \\
SP-D & $1.0 \pm 0.2$ & $1.1 \pm 0.1$ \\
Protein, $\mathrm{mg} / \mathrm{kg}$ & & \\
Alveolar & $41.2 \pm 8.3$ & $49.4 \pm 7.5$ \\
\hline
\end{tabular}

Definition of abbreviations: SatPC = saturated phosphatidylcholine; $S P=$ surfactant protein. 


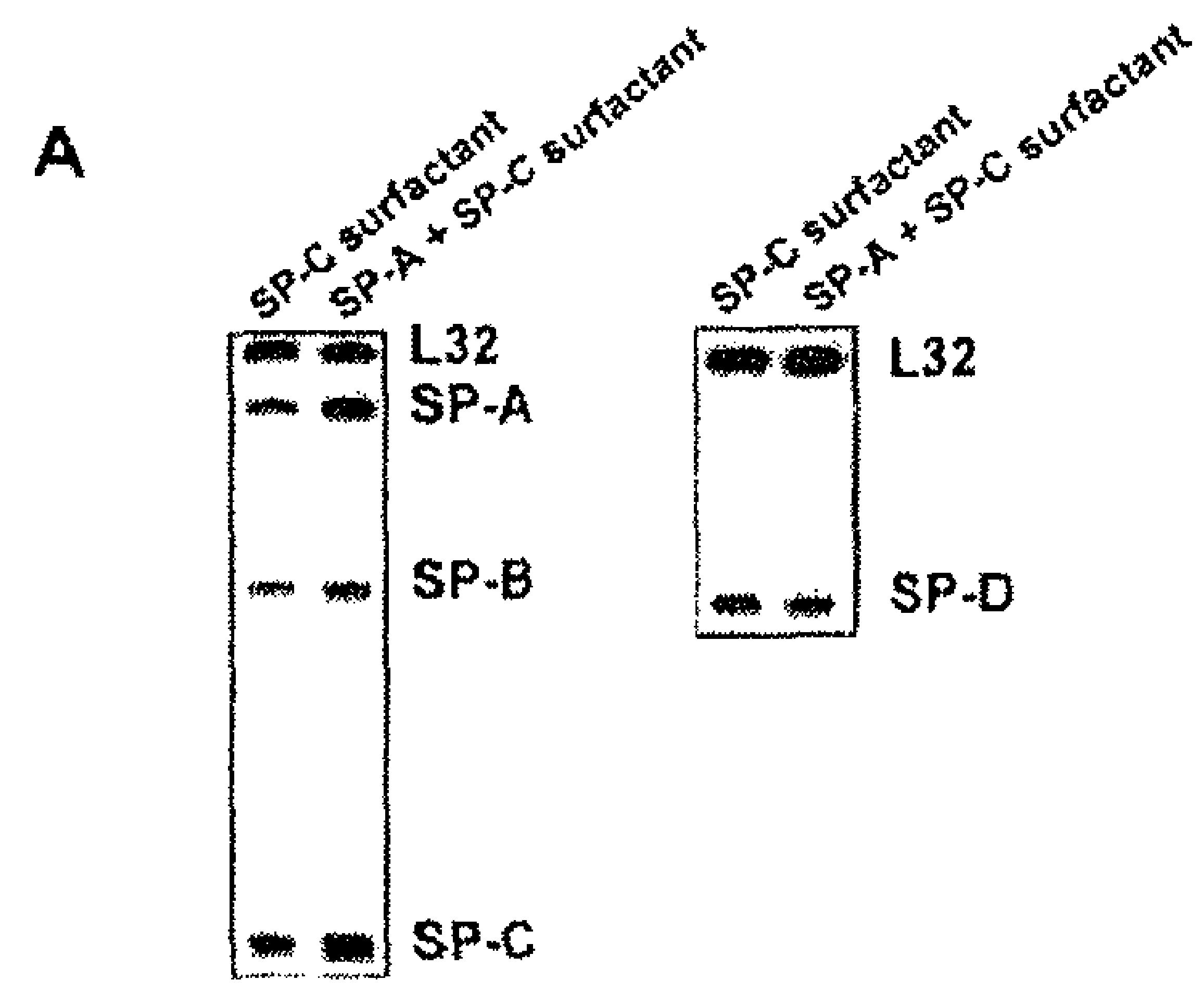

B

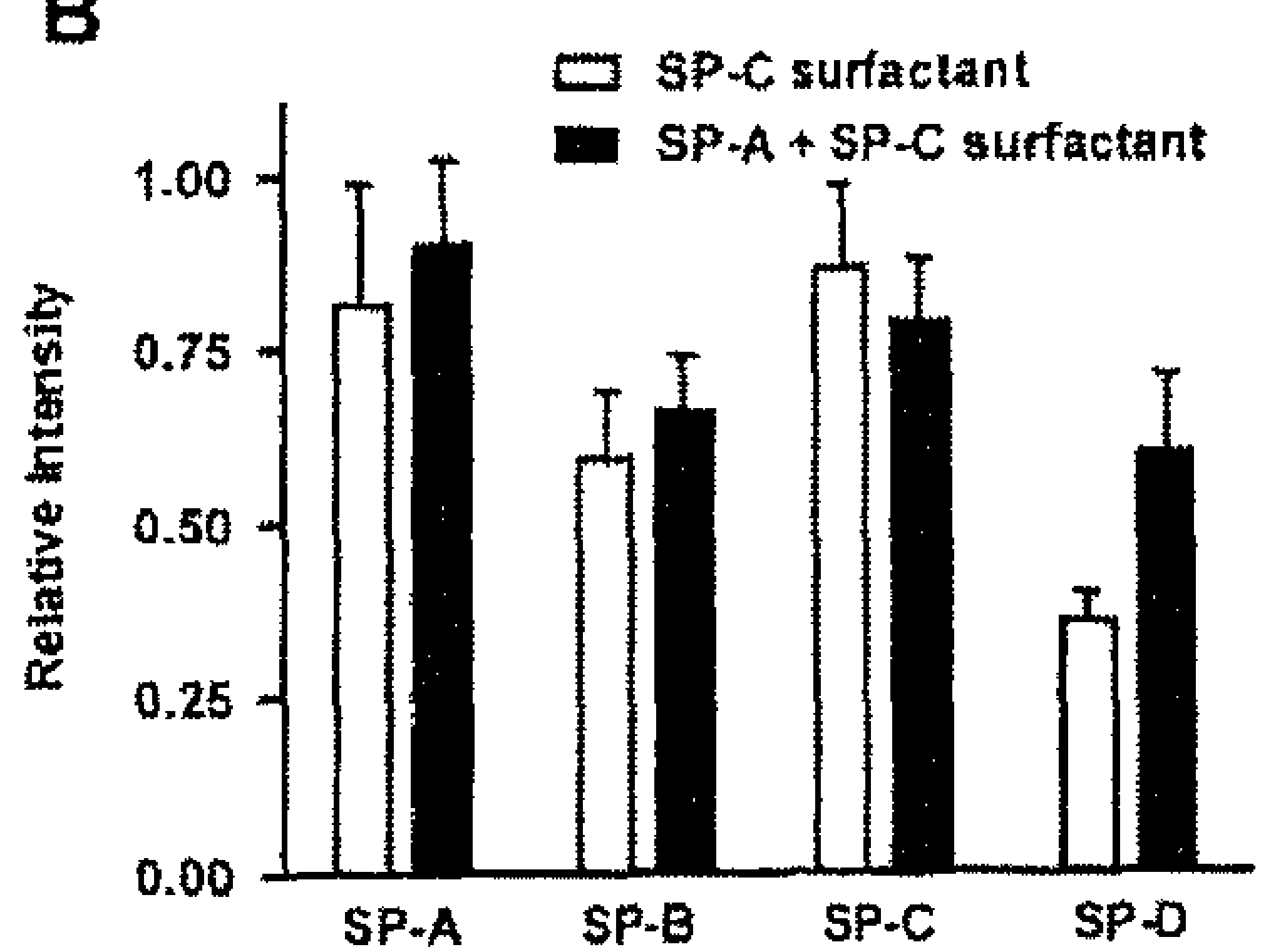

Figure 2. (A) Representive 51 nuclease protection assays for SP-A, SP-B, $S P-C$, and SP-D mRNAs and ribosomal protein L32 mRNA. (B) Quantification for surfactant protein mRNA. Intensity of hybridization of mRNA was related to that of $L 32$ mRNA a ribosomal protein mRNA for each reaction. SP-A treatment did not significantly change mRNAs of surfactant proteins.

lambs, the average hydrogen peroxide production was $15 \mu \mathrm{M}$ per $10^{6}$ cells, as compared with $42 \mu \mathrm{M}$ per $10^{6}$ cells in SP-Csurfactant-treated animals (Figure $3 C$ ). Stimulation with phorbol myristate acetate did not significantly increase hydrogen peroxide production. Therefore, cells from the alveolar washes of SP-A + SP-C-surfactant-treated animals produced significantly less hydrogen peroxide than did those from SP-C-surfactant-treated animals.

Cells from alveolar washes were analyzed for the expression of intercellular adhesion molecule-1 receptor (CD11b) and proteoglycan link protein (CD44), both of which molecules are involved in the vascular-to-tissue migration of neutrophils and monocytes to sites of inflammation (29). The cells from SP-A-treated animals expressed significantly higher levels of both proteins as measured by the percentages of CD11b- and CD44-positive cells (representive samples are shown in Figure 4A) and by mean fluorescence intensity (Figure 4B). The expression of endotoxin receptor CD14 was low and not different between the two study groups.

The mRNAs for IL-1 $\beta$, IL-6, IL- 8 , TNF- $\alpha$, and IL-10 were measured in total RNA from cells recovered from BALF at $2 \mathrm{~h}$, from cells recovered from alveolar washes, and from total lung homogenates after $6 \mathrm{~h}$ of ventilation. These mRNAs were virtually undetectable in fetal lungs at this gestational age (16). Low levels of proinflammatory cytokine mRNAs were detected in cell pellets from BALF samples after $2 \mathrm{~h}$ of ventilation, and no differences were observed between the two study groups of animals (Figure 5A). After $6 \mathrm{~h}$ of ventilation, there were significant differences between SP-A + SP-C-surfactant-treated and SP-C-surfactant-treated lambs in terms of cytokine expression in cells from alveolar washes (Figure 5B).
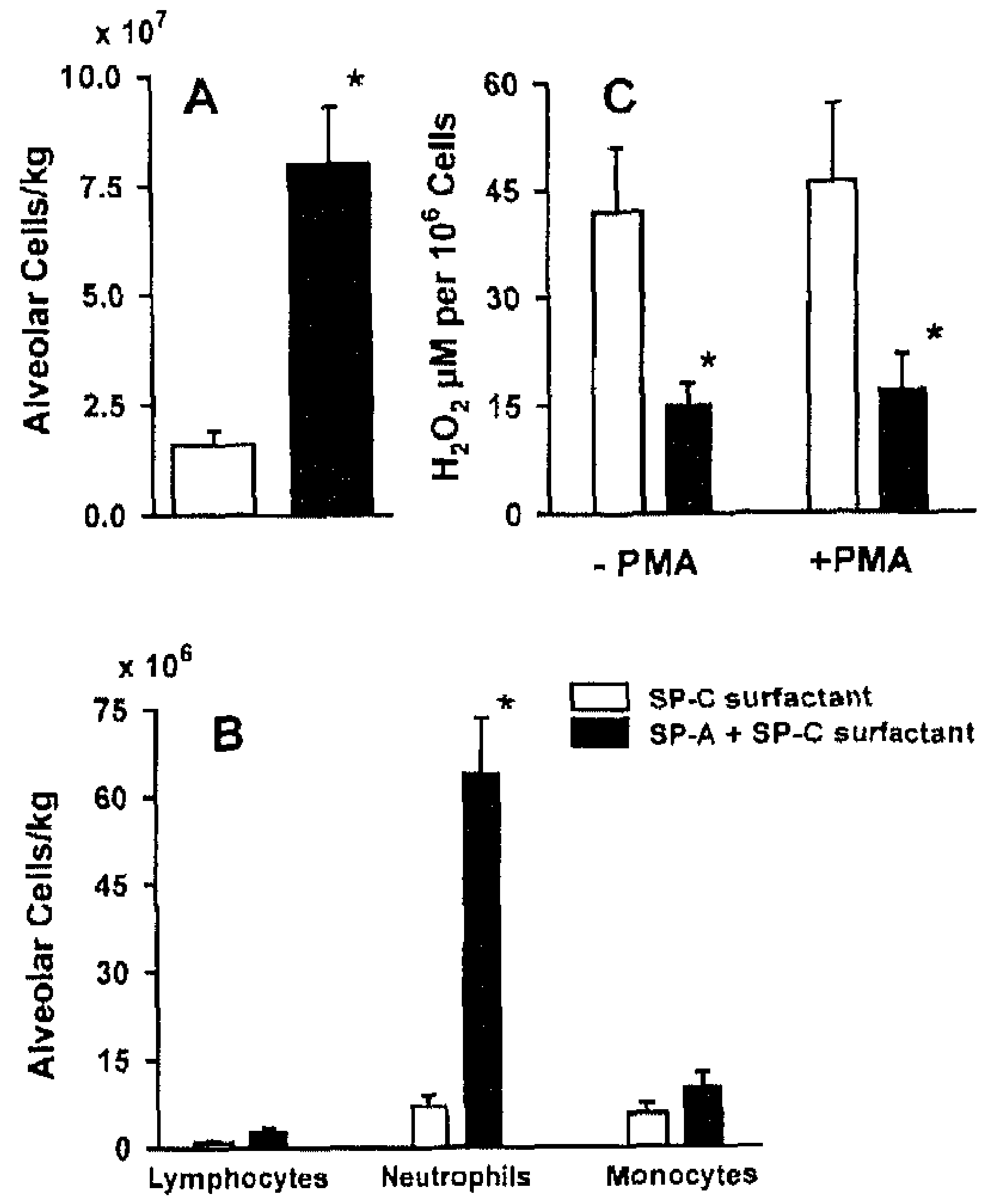

Figure 3. Cell numbers in alveolar washes, differential counts, and hydrogen peroxide production. (A) The total number of nucleated cells recovered from alveolar washes per unit body weight was 4.9-fold greater in SP-A + SP-C-surfactant-treated than in SP-C-surfactanttreated animals. (B) Absolute number of lymphocytes, neutrophils, and monocytes in alveolar washes. The recruited cells in SP-A + SP-C-surfactant-treated animals consisted mainly of neutrophil granulocytes. The numbers of lymphocytes and monocytes recruited to the airway of SP-A + SP-C-surfactant-treated animals were slightly higher than for SP-C-surfactant-treated animals. (C) Quantification of hydrogen peroxide in alveolar washes. Hydrogen peroxide was measured in aliquots of $1 \times 10^{6}$ cells with and without stimulation with phorbol myristate acetate (PMA, $5 \mathrm{nM}$ ). Cells of SP-A-treated animals produced significantly less hydrogen peroxide both before and after stimulation with PMA than did cells of SP-C-treated animals. ${ }^{*} \mathrm{p}<0.05$ versus $\mathrm{SP}-\mathrm{C}$ surfactant.

Levels of IL-1 $\beta$ and IL- 8 mRNAs were significantly higher in SP-A + SP-C-surfactant-treated animals than in SP-C-surfactant-treated animals. In lung tissue, the staining intensities of IL- $1 \beta$, IL -6 , and IL- $8 \mathrm{mRNA}$ relative to that of ribosomal protein L32 mRNA were higher in SP-A + SP-C-surfactanttreated animals than in the SP-C-surfactant-treated group (Figure 5C). The level of IL-10 mRNA did not differ in the groups, and TNF- $\alpha$ mRNA was not detected in either group. The pattern of mRNA levels for IL-1 $\beta$, IL-6, and IL- 8 in alveolar cells at $6 \mathrm{~h}$ differed from the pattern found in lung tissue at $6 \mathrm{~h}$. The ratio of IL- $1 \beta$ mRNA in SP-A + SP-C-surfactanttreated animals to that in SP-C-surfactant-treated animals increased from 3.2 in tissue to about 6.0 in the cells from alveolar washes (Figures 5B and 5C). For IL-8, the ratio of tissue mRNA of SP-A + SP-C-surfactant-treated to that of SP-Csurfactant-treated animals was about 3.2 , and this ratio rose to 8.5 for cells from the respective two groups' alveolar washes. The level of IL-6 mRNA was approximately 2.6-fold greater in the lung tissue of SP-A + SP-C-surfactant-treated animals than in that of SP-C-surfactant-treated animals. In contrast, in cells from alveolar washes the level of IL-6 mRNA was lower in SP-A + SP-C-surfactant-treated than in SP-C-surfactanttreated animals (ratio 0.5 ).

Lung pathology. Representative sections of lung tissue illustrate the increased numbers of inflammatory cells in SP-A + SP-C-surfactant-treated animals but show no other signs of 

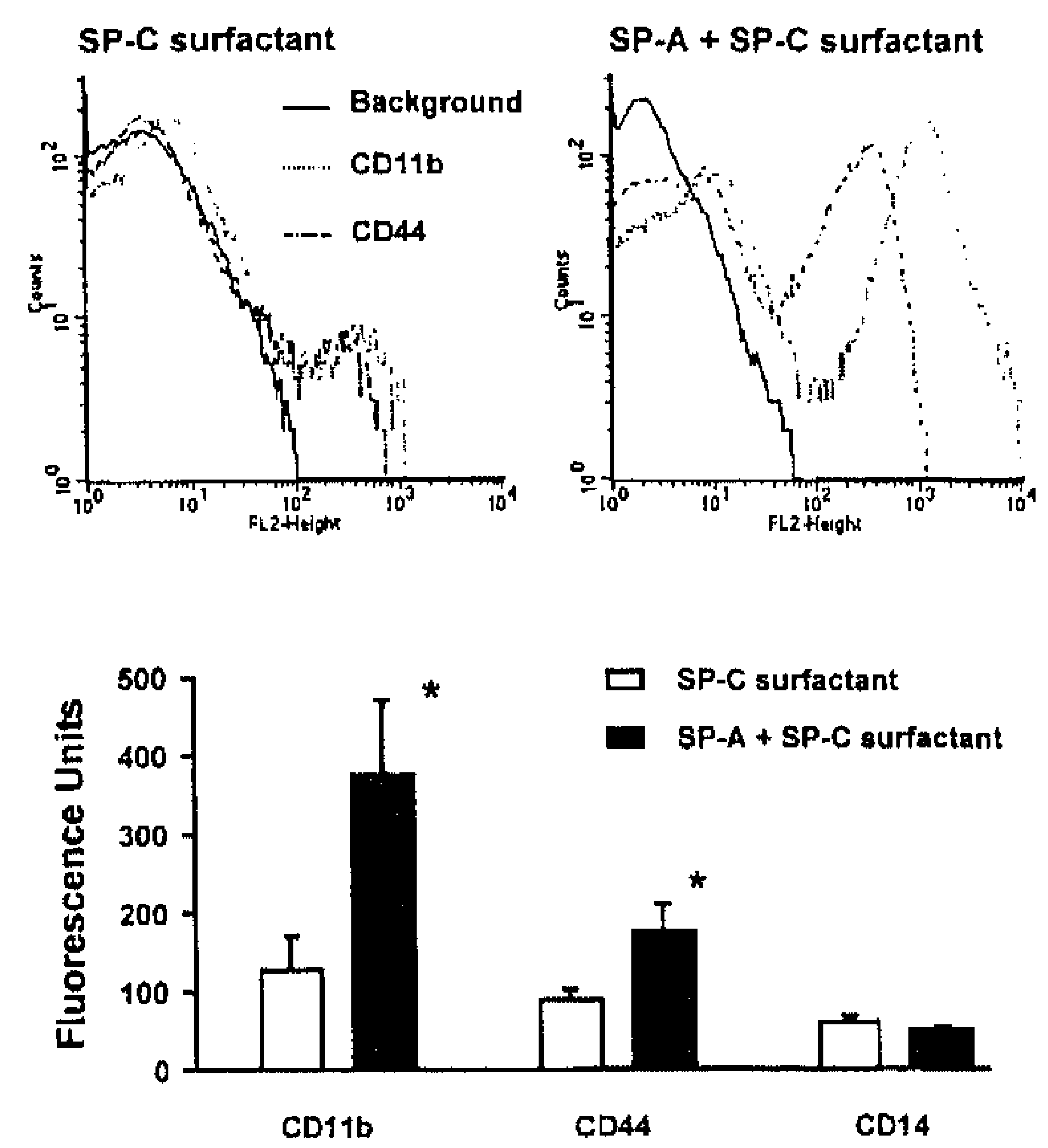

Figure 4. Flow-cytometric analysis of cells from alveolar washes. Cells from SP-A + SP-C-surfactant-treated animals expressed greater amounts of $C D 11 b$ and CD44. The expression of CD14 was low in both groups and unchanged after SP-A + SP-C surfactant treatment ${ }^{*} p<0.05$ versus SP-C surfactant.

injury (Figure 6). Inflammatory cells were scored in lung tissue and airspaces (Figure 7). There were significantly higher scores in SP-A + SP-C-surfactant-treated animals.

White blood cell count. Systemic effects of SP-A treatment were evaluated by white blood cell and differential counting of cells from cord blood and after $6 \mathrm{~h}$ of ventilation (Table 2). The cord blood had the typical lymphocytosis of fetal blood for both study groups. After $6 \mathrm{~h}$ of ventilation the number of leukocytes changed in both groups, without significant differences between the groups.

\section{DISCUSSION}

We treated preterm lambs with recombinant SP-C surfactant containing $3 \%$ ovine SP-A in order to evaluate the responses of the immature lung to SP-A treatment. This experiment was designed to initiate a proinflammatory response through a 15min period of ventilation before surfactant treatment, so as to test whether SP-A would modulate the proinflammatory injury response of the preterm lung to ventilation. The presence of SP-A resulted in a 4.9 -fold increase in cells in alveolar washes after $6 \mathrm{~h}$ of ventilation. The increased cells were predominantly granulocytes, expressing CD 44 and CD11b adhesion molecules, that were recruited to the lungs. However, these granulocytes and the monocytes that accompanied them were not activated, because expression of the endotoxin receptor CD14 was not increased, and because hydrogen peroxide production was 3-fold lower for alveolar cells from SP-A + SP-C-surfactant-treated than for alveolar cells from SP-C-surfactant-treated lambs. Nevertheless, SP-A treatment was associated with increased mRNA levels for the proinflammatory cytokines IL-1 $\beta$, IL-6, and IL-8 in total lung, with no change in IL-10 or TNF- $\alpha$ mRNA levels. SP-A treatment had no effect on lung function or measured concentrations of selected surfactant proteins, or on mRNA levels for the surfactant proteins. These results demonstrate unanticipated responses of the preterm lung to SP-A.

In our experiment, we used species-specific SP-A from healthy sheep. Butanol extraction was used for purification of

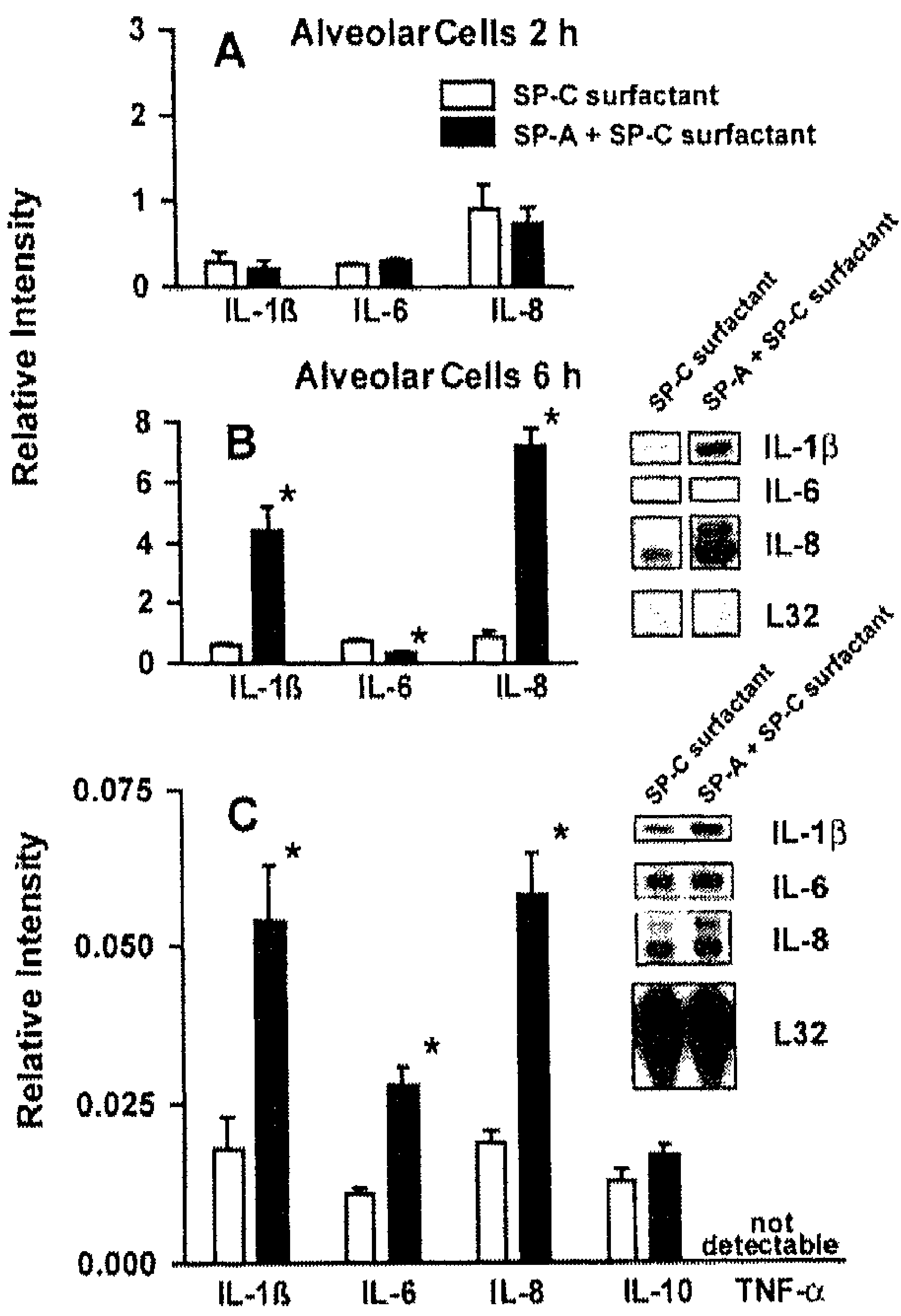

Figure 5. Quantification of cytokine mRNAs. (A) Proinflammatory cytokine mRNA in cells recovered at $2 \mathrm{~h}$ from BALF. After $2 \mathrm{~h}$ of ventilation, there was only moderate expression of proinflammatory cytokine mRNAs, with no differences between the SP-A + SP-C-surfactanttreated and SP-C-surfactant-treated groups. (B) Proinflammatory cytokine mRNA levels in cells from alveolar washes after $6 \mathrm{~h}$ of ventilation. After $6 \mathrm{~h}$ there was a much higher level of proinflammatory cytokine mRNA in cells from the airways. In SP-A + SP-C-surfactant-treated animals, levels of IL-1 $\beta$ and IL-6 were significantly higher than in SP-Csurfactant-treated animals. In SP-C-surfactant-treated animals the level of IL-6 mRNA was significantly higher than in SP-A + SP-C-surfactant-treated animals. (C) Expression of mRNA for IL-1 $\beta, I L-6, I L-8$, IL-10, and TNF- $\alpha$ in $10 \mu \mathrm{g}$ of total lung RNA relative to mRNA for ribosomal protein L32. In SP-A + SP-C-surfactant-treated animals the level of proinflammatory cytokines $\mathrm{L}-1 \beta, \mathrm{LL}-6$, and IL-8 was significantly higher than in SP-C-surfactant-treated animals. The level of IL-10 mRNA did not differ in the SP-A + SP-C-surfactant-treated and SP-Csurfactant-treated groups. TNF- $\alpha$ was not detectable in either group ${ }^{*} p<0.05$ versus SP.C surfactant.

the SP-A to maintain its protein function (21). On the basis of in vitro studies, SP-A has been labeled as either proinflammatory or antiinflammatory (11-13). Disparity in results with the protein may be partly explained by the use of SP-A from different sources and different purification methods. In some experiments, proinflammatory effects of SP-A were attributed to possible endotoxin contamination because SP-A binds endotoxin. Because the response of the immature lung to SP-A was predominantly proinflammatory, we carefully evaluated the possibility of endotoxin contamination of the SP-A used in our study. The SP-A tested negatively for endotoxin in the sensitive Limulus lysate assay, and we verified the earlier report that SP-A did not mask endotoxin in the assay (10). We treated three other lambs with the highest amount of Escherichia coli O55/B5 endotoxin that could be present in SP-A with- 

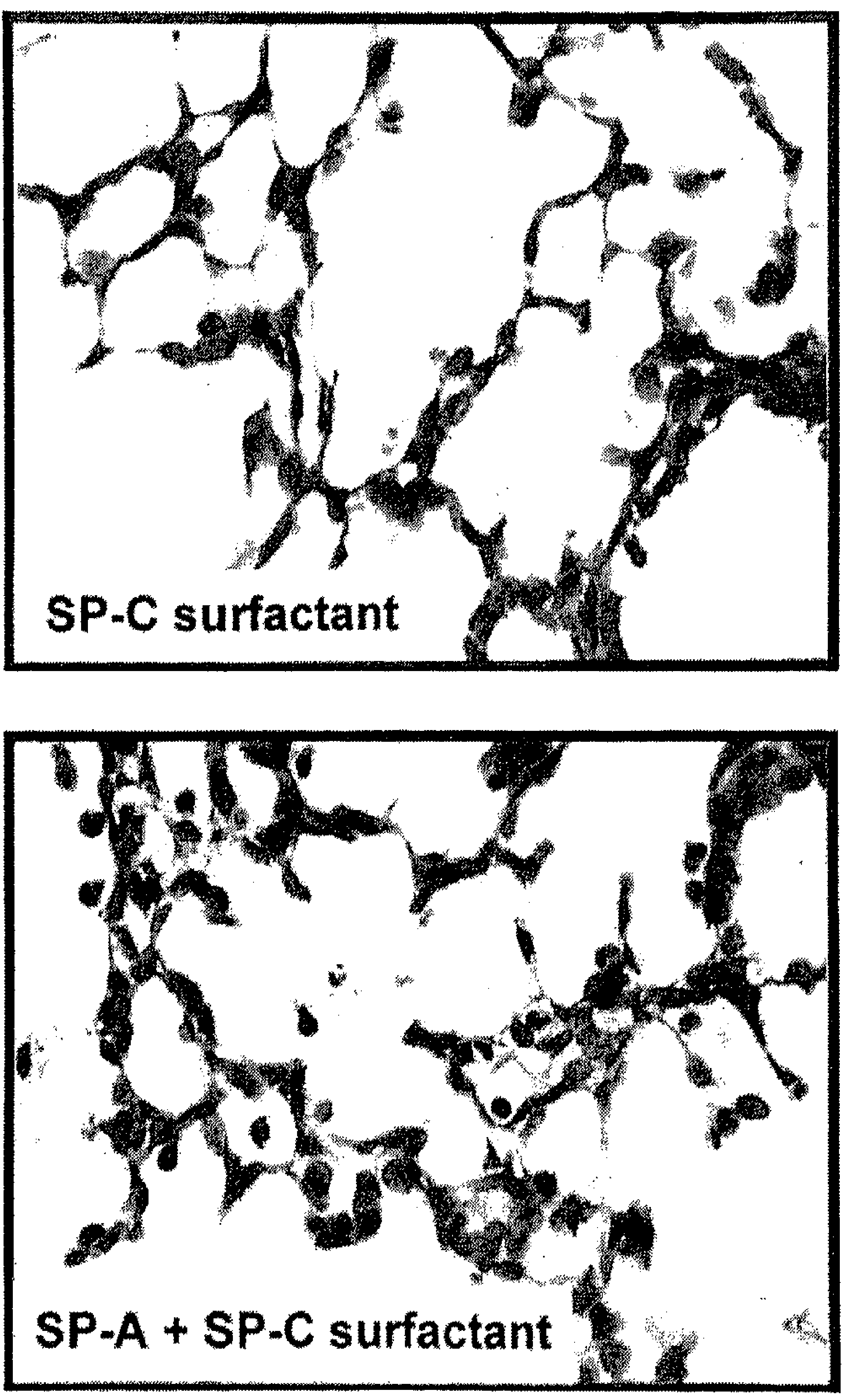

Figure 6. Histology of lungs. Upper panel shows a representive section from SP-C-surfactant-treated group. Lower panel shows a section from SP-A + SP-C-surfactant-treated group. The difference was the presence of more inflammatory cells in lung tissue and airspace.

out being detected by the Limulus lysate assay. Lambs were also treated with the same SP-C surfactant as used in our study and which contained $0.1 \mathrm{ng} / \mathrm{kg} E$. coli O55/B5 endotoxin. After $6 \mathrm{~h}$ of ventilation, results for most variables were similar to those for SP-C-surfactant-treated animals: the total number of cells per unit weight in alveolar washes was $1.4 \pm$ $0.4 \times 10^{7}$ cells $/ \mathrm{kg}$ after endotoxin treatment, in comparison to $1.6 \pm 0.3 \times 10^{7}$ cells $/ \mathrm{kg}$ in SP-C-surfactant-treated animals. The numbers of granulocytes were similar, at $6.5 \pm 1.0 \times 10^{6} / \mathrm{kg}$ after endotoxin treatment versus $6.8 \pm 2.0 \times 10^{6} / \mathrm{kg}$ in SP-Csurfactant-treated animals. The level of CD11b was $187 \pm 33$ mean fluorescence units (FU) in endotoxin-treated animals, versus $128 \pm 43 \mathrm{FU}$ in SP-C-surfactant-treated animals, and that of CD44 was $112 \pm 21 \mathrm{FU}$ in endotoxin-treated animals, versus $89 \pm 16$ FU in SP-C-surfactant-treated animals. Hydrogen peroxide production was similar, at $45 \pm 4 \mu \mathrm{M}$ per $1 \times 10^{6}$ cells for endotoxin-treated animals, versus $42 \pm 9 \mu \mathrm{M}$ per $1 \times$ $10^{6}$ cells for SP-C-surfactant-treated animals. However, the endotoxin receptor CD14 was increased on cells in the alveolar washes of endotoxin-treated animals, at $92 \pm 11 \mathrm{FU}$, versus $59 \pm 7$ FU in SP-C-surfactant-treated animals $(\mathrm{p}<0.05)$, and

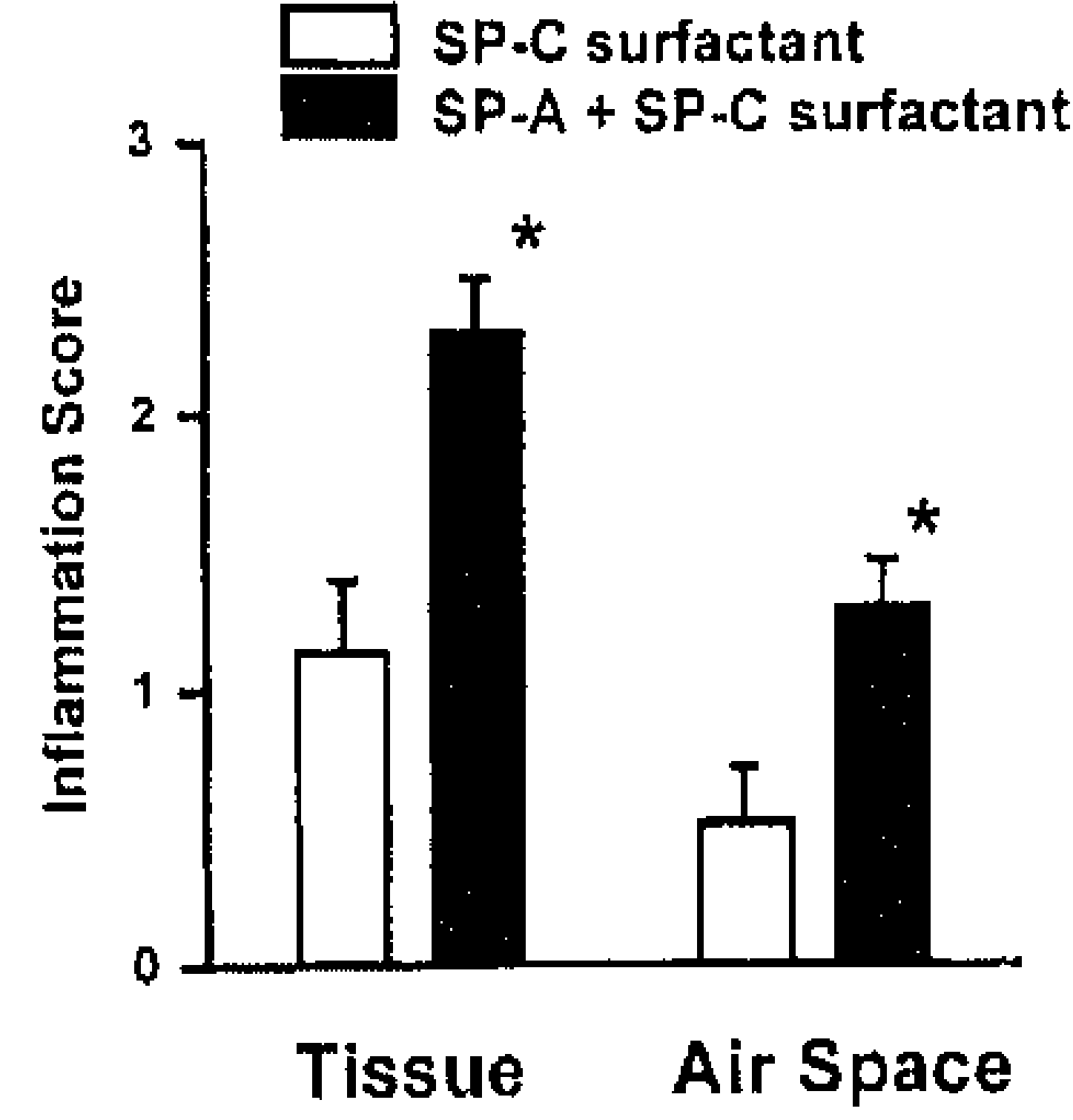

Figure 7. Inflammatory scores in airspace and lung tissue. Treatment with SP-A + SP-C surfactant increased the inflammatory score in both lung tissue and airspace ${ }^{*} p<0.05$ versus control.

the mRNA level for prinflammatory cytokines was 10 -fold higher in the total lung homogenates of endotoxin treated animals than in those of SP-C-surfactant-treated animals. The responses of the preterm lung to treatment with SP-A were distinct from the responses to endotoxin.

In adult animals, SP-A functions as a potent host-defense molecule and modulator of the inflammatory responses to pathogens. Mice that are SP-A deficient are unable to successfully phagocytose and kill bacteria and viruses $(6,7)$. The lungs become more inflamed in response to group B steptococcus, with greater recruitment of activated granulocytes that produce higher levels of proinflammatory cytokines, including TNF- $\alpha$, than is the case for the lungs of normal SP-A-sufficient mice (6). Treatment of adult SP-A-deficient mice with SP-A corrects the phagocytosis and killing defects and modulates the proinflammatory cytokine response (7).

In vitro studies have given conflicting results for the proand antiinflammatory properties of SP-A. Kremlev and colleagues found proinflammatory cytokine production after incubation of a monocytic cell line with SP-A $(13,30)$. Blau and coworkers reported that both SP-A and endotoxin stimulated the production of nitrite by AM (12). On the other hand, McIntosh and associates reported a downregulation of production of the proinflammatory cytokine TNF- $\alpha$ by SP-A (14), and Borron and colleagues reported that SP-A had antiinflammatory effects on lymphocytes (31). In all of these experiments, mature AM and monocytic and lymphotic cell lines were used. There is no information about interactions of SP-A in-vitro with immature cells from animals.

On the basis of the effects of SP-A on mature macrophages and granulocytes, and the in vivo results with SP-A-deficient mice, we anticipated that SP-A treatment would suppress the

TABLE 2

WHITE BLOOD CELL COUNT AND DIFFERENTIAL COUNT AT BIRTH AND AFTER $6 \mathrm{~h}$ OF VENTILATION OF PRETERM SHEEP

\begin{tabular}{lcc}
\hline & SP-C Surfactant & SP-A + SP-C Surfactant \\
\hline $\begin{array}{l}\text { Cord blood at birth, } 10^{3} / \mu \text { l } \\
\text { Leukocytes }\end{array}$ & $2.8 \pm 0.5$ & $2.9 \pm 0.3$ \\
Lymphocytes & $2.4 \pm 0.2$ & $2.3 \pm 0.3$ \\
Monocytes & $0.1 \pm 0.1$ & $0.2 \pm 0.1$ \\
$\quad$ Neutrophils & $0.3 \pm 0.1$ & $0.4 \pm 0.2$ \\
At 6 h, 10 $/ \mu$ l & & \\
Leukocytes & $2.4 \pm 0.4$ & $1.7 \pm 0.3$ \\
Lymphocytes & $1.4 \pm 0.1$ & $0.7 \pm 0.1$ \\
Monocytes & $0.4 \pm 0.1$ & $0.3 \pm 0.1$ \\
Neutrophils & $0.6 \pm 0.2$ & $0.7 \pm 0.1$ \\
\hline
\end{tabular}

Definition of abbreviation: $S P=$ surfactant protein 
granulocyte recruitment and decrease the proinflammatory cytokine transcription that accompanies mechanical ventilation after preterm birth. We chose to measure the cytokines IL-1 $\beta$, IL-6, IL-8, IL-10, and TNF- $\alpha$ because these cytokines increase in SP-A-deficient mice (7), increase in the airways of infants developing bronchopulmonary dysplasia (BPD) (1), are increased in the amniotic fluid with chorioamnionitis (17), and contribute to lung injury in adult-lung models of lung injury (32). We found that SP-A induced granulocyte recruitment and increased the mRNAs of IL-1 $\beta$, IL- 6 , and IL-8, but did not increase the mRNA of IL-10 or TNF- $\alpha$. The hydrogen peroxide assay indicated that the granulocytes in alveolar washes were not activated. This unusual pattern of response is probably explained by the immaturity of the host-defense response of the preterm newborn (33). Granulocytes in term and preterm newborns have deficiencies in adherence, deformability, and locomotion in comparison with mature granulocytes (33), and chemotaxis of granulocytes from preterm infants to sites of inflammation is impaired irrespective of gestational age (34). Phagocytosis of opsonized particles is normal in term newborns, but the respiratory burst may be impaired (33). In most types of immunologic cell the second-messenger responses to exogenous stimuli are different from the responses measured in adult cells, partly explaining the immaturity of the host-defense response $(20,33)$. The present study suggests that SP-A is a potent neutrophil chemoattractant in the preterm lung. In our study a high dose of SP-A was locally administered to an immature lung with an immature immune system, in which other immunomodulatory molecules are present in low concentrations (33). SP-A functioned in the immature immune system as a potent neutrophil chemoattractant, with upregulation of the cell-surface molecules CD11b and CD44, which are involved in the recruitment of cells to sites of inflammation. The chemoatraction of neutrophils (35) and AM (36) by SP-A has previously been described in vitro. The present study shows that in vivo, SP-A is a potent neutrophil chemoattractant that efficiently recruits immature neutrophils and partially overcomes deficiencies of immature granulocytes. Our study evaluated a unique situation: the initiation of ventilation in a preterm, surfactant-deficient lung, and there is no comparable information for full-term or adult lungs.

The simplest interpretation of the findings in our study is that SP-A treatment of the preterm lung is predominantly proinflammatory and therefore harmful. However, this interpretation may be incorrect. The preterm lung has major defects in both immune and innate host defenses $(1,18)$. SP-A may promote host defenses as a chemoattractant by recruiting unactivated granulocytes to an alveolar environment without significant numbers of mature macrophages. Although low levels of SP-A were correlated with subsequent lung injury in preterm infants (18), there is no information about whether or how exogenous SP-A alters host defenses in the preterm newborn, or how SP-A might improve outcomes. Although supplementation of surfactant with SP-A can improve the lung function of preterm animals to a greater extent than can surfactant that lacks SP-A, these effects are modest and are not apparent in animals ventilated with sufficient PEEP (25). SP-A also can minimize inhibition of surfactant by proteinaceous pulmonary edema, but this effect will be of benefit only after severe lung injury has occurred, and injury in general suppresses SP-A synthesis $(18,37)$. Treatment with SP-A in our study was not associated with decreased mRNA levels for any of the surfactant proteins investigated, and TNF- $\alpha$ mRNA did not increase.

The function of SP-A as a neutrophil chemoattractant in a preterm human ventilated lung is of particular interest with regard to ventilation of preterm human newborns. In these patients bacterial infections of the airways have been associated with BPD (38). Therefore, adding SP-A to surfactant treatment may overcome deficiencies in recruitment and adhesion of neutrophil granulocytes in clearing bacteria from the airways in preterm infants. SP-A treatment of the preterm lung may be beneficial because of induction of protective responses.

Acknowledgment: Dr. M. Hallman, University of Oulu, Finland, kindly supplied a probe for ovine surfactant protein D. The authors thank Dr. Suhas Kallapur and Dr. Gary Ross for advice and help with the RNAse protection assays and Western blots, respectively. Byk Gulden, Konstanz, Germany, provided recombinant SP-C surfactant.

\section{References}

1. Speer CP, Groneck P. Oxygen radicals, cytokines, adhcsion molecules and lung injury in nconates. Semin Neonatol 1998;3:219-228.

2. Wright JR. Immunomodulatory functions of surfactant. Physiol Rev 1997; 77:931-962.

3. Ikegami M, Korfhagen TR, Bruno MD, Whitsett JA, Jobe AH. Surfactant metabolism in surfactant protein A-deficient mice. Am J Physiol 1997;272:L479-L485.

4. Ikcgami M, Jobe AH, Whitsett J, Korfhagen T. Tolerance of SP-A deficient mice to hyperoxia or excrcise. I Appl Physiol 2000;89:644-648.

5. Korfhagen TR, Bruno MD, Ross GF, Huelsman KM, Ikegami M, Jobe AH, Wert SE, Stripp BR, Morris RE, Glasser SW, et al. Altered surfactant function and structure in SP-A gene targeted mice. Proc Nall Acad Sci USA 1996;93:9594-9599.

6. LeVine AM, Bruno MD, Huelsman KM, Ross GF, Whitsett JA, Korfhagen TR. Surfactant protein A-deficient mice are susceptible to group B streptococcal infcction. $J$ Immunol 1997;158:4336-4340.

7. LcVinc AM, Kurak KE, Wright JR, Watford WT, Bruno MD, Ross GF, Whitsett JA, Korfhagen TR. Surfactant protein-A (SP-A) binds group $B$ streptococcus enhancing phagocytosis and clearance from lungs of surfactant protein-A deficient mice. Am J Respir Mol Cell Biol 1999; 20:279-286.

8. Rosseau S, Hammerl P, Maus U, Gunther A, Seeger W, Grimminger F, Lohmeyer J. Surfactant protein A downregulates proinflammatory cytokine production evoked by Candida albicans in human alveolar macrophages and monocytes. J Immunol 1999;163:4495-4502.

9. Stamme C, Wright JR. Surfactant protein A enhances the binding and deacylation of $E$. coli LPS by alveolar macrophages. Am J Physiol 1999; 276:L540-L547.

10. Wright JR, Zlogar DF, Taylor JC, Zlogar TM, Restrepo CI. Effects of cndotoxin on surfactant protein $\mathrm{A}$ and $\mathrm{D}$ stimulation of NO production by alveolar macrophages. Am J Physiol 1999;276:L650-L658.

11. Sano H, Sohma H, Muta T, Nomura S, Voelker DR, Kuroki Y. Pulmonary surfactant protein $\mathrm{A}$ modulates the cellular response to smooth and rough lipopolysaccharides by interaction with CD14. $J$ Immunol 1999;163:387-395.

12. Blau H, Riklis S, VanIwaarden JF, McCormack FX, Kalina M. Nitric oxide production by rat alveolar macrophages can be modulated in vitro by surfactant protein A. Am J Physiol 1997;272:L1198-L1204.

13. Kremlev SG, Phclps DS. Surfactant protein A stimulation of inflammatory cytokine and immunoglobulin production. Am J Physiol 1994; 267:L712-L719.

14. McIntosh JC, Mervin-Blake S, Conner E, Wright JR. Surfactant protein A protects growing cells and reduces TNF-alpha activity from LPS stimulated macrophages. Am J Physiol 1996;271:L310-L319.

15. Ikegami M, Kallapur S, Michna J, Jobe AH. Lung injury and surfactant metabolism after hyperventilation of premature lambs. Pediatr Res 2000; 47:398-404.

16. Naik A, Kallapur SG, Bachurski CJ, Michna J, Jobe AH, Ikegami M. Effects of different styles of ventilation on cytokine expression in the preterm lamb lung [abstract], Pediatr Res 2000;47:A370.

17. Yoon BH, Romero R, Jun JK, Park KH, Park JD, Ghezzi F, Kim BI. Amniotic fluid cytokines (interleukin-6, tumor necrosis factor-alpha interleukin-1 $\beta$, and interleukin-8) and the risk for the development of bronchopulmonary dysplasia. Am J Obstet Gynecol 1997;177:825-830.

18. Hallman M, Merritt TA, Akino T, Bry K. Surfactant protein-A, phosphatidylcholine, and surfactant inhibitors in epithelial lining fluidcorrelation with surface activity, severity of respiratory distress syndromc, and outcome in small premature infants. Am Rev Respir Dis 1991;144:1376-1384.

19. Awasthi S, Coalson JJ, Crouch E, Yang F, King RJ. Surfactant proteins A 
and $D$ in premature baboons with chronic lung injury: evidence for an inhibition of secretion. Am J Respir Crit Care Med 1999;160:942-949.

20. Marshall Clarke S, Reen D, Tasker L, Hassan J. Neonatal immunity: how well has it grown up? Immunol Today 2000;21:35-41.

21. Hawgood S, Benson BJ, Hamilton RLJ. Effects of a surfactant-associated protein and calcium ions on the structure and surface activity of lung surfactant lipids. Biochemistry 1985;24:184-190.

22. Davis AJ, Jobe AH, Häfner D, Ikegami M. Lung function in premature lambs and rabbits treated with a recombinant SP-C surfactant. $A m J$ Respir Crit Care Med 1998;157:553-559.

23. Lcwis J, McCaig L, Häfner D, Spragg R, Veldhuizen R, Kerr C. Dosing and delivery of a recombinant surfactant in lung-injury adult sheep. Am J Respir Crit Care Med 1999;159:741-747.

24. Spragg R, Lewis J, Wurst W, Rathgeb F. Treatment of ARDS with rSP-C surfactant [abstract]. Am J Respir Crit Care Med 2000;161:A47.

25. Michna J, Jobe AH, Ikegami M. Positive end expiratory pressure preserves surfactant function in preterm lambs. Am J Respir Crit Care Med 1999;160:634-639.

26. Wada $\mathrm{K}$, Jobe AH, Ikegami M. Tidal volume effects on surfactant treatment responses with the initiation of ventilation in preterm lambs. $J$ Appl Physiol 1997;83:1054-1061.

27. Jobe AH, Newnham JP, Willet KE, Sly P, Ervin MG, Bachurski C, Possmayer F, Hallman M, Ikegami M. Antenatal endotoxin and glucocorticoid effects on the lungs of preterm lambs. Am J Obstet Gynecol 2000; 182:401-408.

28. Kallapur S, Jobe AH, Ikegami M, Naik A, Bachurski C. Amnion chorion and lung tissuc cytokine response to intra amniotic endotoxin in fetal sheep [abstract]. Pediatr Res 2000;47:363A.

29. Weirich E, Rabin RL, Maldonado Y, Benitz W, Modler S, Herzenberg LA. Neutrophil CD11b expression as a diagnostic marker for early onset neonatal infection. $J$ Pediatr 1998;132:445-451.
30. Kremlev SG, Umstead TM, Phelps DS. Surfactant protein A regulates cytokine production in the monocytic cell line THP-1. Am J Physio 1997;272:L996-L1004.

31. Borron P, Veldhuizen RAW, Lewis JE, Possmayer F, Caveney A, Inchley K, Mcfadden RG, Fraher LJ. Surfactant associated protein-A inhibits human lymphocyte proliferation and IL-2 production. Am J Respir Cell Mol Biol 1996;15:115-121.

32. Tremblay L, Valenza F, Ribeiro SP, Li J, Slutsky AS. Injurious ventilatory strategics increase cytokines and c-fos m RNA expression in an isolated rat lung mode. $J$ Clin Invest 1997;99:944-952.

33. Speer CP, Johnston RB. Neutrophil function in newborn infants. In: Polin RA, Fox WW, editors. Fetal and neonatal physiology. Philadelphia: W. B. Saunders; 1998. p. 1954-1960.

34. Bektas S, Goetze B, Speer CP. Decreased adherence, chemotaxis and phagocytic activitics of neutrophils from preterm neonates. Acta Paediatr Scand 1990;79:1031-1038.

35. Madan T, Egglcton P, Kishore U, Strong P, Aggrawal SS, Sarma PU, Reid KBM. Binding of pulmonary proteins A and D to Aspergillus fumigatus conidia enhances phagocytosis and killing by human neutrophils and alveolar macrophages. Infect Immun 1997;65:3171-3179.

36. Wright JR, Youmans DC. Pulmonary surfactant protein-A stimulates chemotaxis of alvcolar macrophagc. Am J Physiol 1993;264:L338-L344.

37. Baughman RP, Sternberg RI, Hull W, Buchsbaum JA, Whitsett J. Decreased surfactant protein-A in patients with bacterial pneumonia. Am Rev Respir Dis 1993;147:653-657.

38. Groneck P, Goctze-Speer B, Spccr CP. Inflammatory bronchopulmonary response of preterm infants with microbial colonisation of the airways at birth. Arch Dis Child 1996;74:F51-F55. 
CHAPTER T

The clever fetus: responding to inflammation to minimize lung injury

Kramer B.W., Jobe A.H. 


\title{
Review
}

Biology of the

Neonate
Biol Neonate 2005;88:202-207

DOI: $10.1159 / 000087583$

\section{The Clever Fetus: Responding to Inflammation to Minimize Lung Injury}

\author{
Boris W. Kramer ${ }^{a}$ Alan H. Jobe ${ }^{b}$ \\ a Universitäts-Kinderklinik, Würzburg, Germany; ${ }^{b}$ Division of Pulmonary Biology, Cincinnati Children's Hospital, \\ Cincinnati, Ohio, USA
}

\section{Key Words}

Innate immunity - Respiratory distress syndrome •

Bronchopulmonary dysplasia · Chorioamnionitis

\begin{abstract}
Clinical and experimental information indicate that fetal exposure to inflammation can induce lung maturation. This inflammation may be chronic and indolent. We present clinical and experimental information that challenge assumptions about chorioamnionitis associated infection/inflammatory exposures to the fetus. We question the assumption that the fetal compartment is sterile, and that delivery is inevitable if chronic infection/inflammation is present. We demonstrate that the preterm fetus can develop a brisk and adequate inflammatory response, and the fetus also can quickly modulate and downregulate inflammation to prevent injury. The fetus at risk of early preterm delivery may be exposed to both chorioamnionitis and glucocorticoids. Both exposures can either increase or decrease fetal inflammatory responses depending on the timing of the exposures. The immunomodulatory ability of the fetus to fetal exposures remains an unexplored research field.
\end{abstract}

Copyright (ㄷ) 2005 S. Karger AG, Basel

Presented at the International Symposium 'Recent Advances in Neonatal Mediciner', Würzburg, 2005.

\section{KARGER}

Fax +41613061234

E-Mail karger@karger.ch

www.karger.com
C 2005 S. Karger AG, Basel

Accessible online at: www.karger.com/bon
Our goals are to challenge four assumptions about how the fetus and fetal lung cope with infection/inflammation during development. Perhaps the most central assumption is that the fetal compartment (fetus, amniotic fluid, membranes) is sterile in the normal fetus. A second assumption is that if infection/inflammation occurs, then preterm labor and delivery is inevitable. A third assumption is that the fetal inflammatory response may be poor or inadequate because of immaturity, and a fourth assumption is that inflammation, once initiated, is likely to be progressive and to injure the fetus. The field of fetal immunology is dominated by the general concepts that the fetus is immunologically immature and will respond poorly to an immune challenge [1]. The fetus is in a protected and unique environment because the mother is 'tolerant' to the fetus as foreign and there is some maternal immune suppression (e.g. increased susceptibility to varicella infection). Fetuses in general do not make antibodies either because they are not exposed to foreign antigen or because acquired immune response mechanisms are immature or suppressed. The innate immune system also is very immature based on the levels of many modulators of innate immunity (table 1). Although quantitative levels are not available for all these factors and many others that are not listed, the levels are undetectable earlier in gestation and very low during late fetal life. Therefore, the concept that the fetus should be extremely susceptible to infection is reasonable. 
Table 1. Components of innate immune defenses in the lung: fetus relative to adult

\begin{tabular}{ll}
\hline Component of innate immunity & Preterm vs. adult \\
\hline Cellular & \\
Alveolar macrophages & immature and decreased \\
Lung tissue neutrophils & decreased \\
Dendritic cells & probably decreased \\
Molecular & decreased \\
Complement & decreased \\
Fibronectin & decreased \\
SP-A, SP-D & decreased \\
Surfactant lipids & decreased \\
Defensins & decreased \\
Lysozyme & decreased \\
Iron binding proteins & decreased \\
Mechanical & decreased \\
Mucocilliary function & \\
Cough/forced expiration & \\
\hline
\end{tabular}

\section{Assumption 1: The Fetal Compartment Is Sterile}

The uterine cavity is directly connected to the vagina and is unlikely to be truly sterile at the time of conception. There must be very effective innate host defenses that protect the mother from ascending infection with differential expression of Toll-like receptors in the female reproductive tract [2]. Few organisms other than Neisseria gonorrhea frequently cause an ascending infection. After conception a mucus plug isolates the fetal compartment from the lower urogenital track, but is it really sterile and if not, how is overt infection suppressed? There is information to suggest that 'silent' colonization of amniotic fluid can occur. Two reports using PCR techniques indicate that about $10 \%$ of fluids collected from normal pregnancies at about 18 weeks of gestation for genetic amniocentesis are positive for Ureaplasma and other low-pathogenicity organisms $[3,4]$. Using a fluorescently labeled probe for bacterial 16s ribosomal RNA, Steel et al. [5] recently reported that 25 of 29 fetuses that delivered prematurely had bacteria deep within intact fetal membranes and in some cases there was no associated inflammation. The majority of infants delivered without preterm labor or ruptured membranes had evidence of colonized membranes using this bacterial probe. Bacteria in membranes also were identified in the majority of term infants delivered by C-section without ruptured membranes. This report suggests that fetal coexistence with commensal organisms may be the rule and not the exception. More research is needed to define if organisms are present and if they influence pregnancy outcomes. An interesting hypothesis is that the fetus may contribute to suppressing colonization/infection. One fact is for certain - the majority of infants delivering before 30 weeks gestational age have been exposed to low pathogenicity organisms and histologic chorioamnionitis $[6,7]$. There presently is no way to evaluate the duration or intensity of fetal exposure to inflammation prior to preterm birth.

\section{Assumption 2: If Infection/Inflammation of the Fetal Compartment Occurs, then Delivery Is Inevitable}

When highly pathogenic organisms such as Escherichia coli and Listeria monocytogenes cause infection, rapid delivery generally occurs. However, colonization/infection of the fetal compartment with organisms of low pathogenicity may not uniformly cause preterm labor. Women that were culture positive at the time of genetic amniocentesis (and were not treated with antibiotics) did not deliver for weeks [3, 4]. It is not known for how long the organisms identified using the bacterial ribosomal RNA probe had been in the membranes or even if the inflammation was in response to the organisms identified by the probe [5]. We injected live Ureaplasma parvum into the amniotic fluid of fetal sheep as early as 60 days of gestation (term $=150$ days) and demonstrated inflammation and culture positivity in the amniotic fluid and fetal lungs 65 days later [8]. Low-dose $U$, parvum given to fetal sheep at 80 days gestation colonized the amniotic fluid and fetal lungs and caused inflammation at term. There was no associated preterm labor or signs of fetal injury. While the sheep may tolerate infection/inflammation better than the human, these results demonstrate in principle that chronic colonization of the fetus with organisms of low pathogenicity is possible.

\section{Assumption 3: The Fetus Will Have an Inadequate Initial Inflammatory Response to Infection}

An inflammatory response depends on the fetus recognizing something as foreign. Innate immune signaling results from a family of receptors recognizing antigenetic motifs common to gram-positive, gram-negative, viral and fungal organisms - the toll like receptors or TLRs [9]. TLR signaling to initiate an inflammatory response is 
Fig. 1. Responses of monocytes recovered from adult ewe and preterm fetal blood to challenge in culture with different TLR receptor agonists. The amount of hydrogen peroxide produced by $10^{6}$ monocytes from adult sheep blood was similar for all TLR agonists. The monocytes from the preterm fetus produced less hydrogen peroxide $\left({ }^{*} p<0.05\right.$ preterm vs. adult $)$.

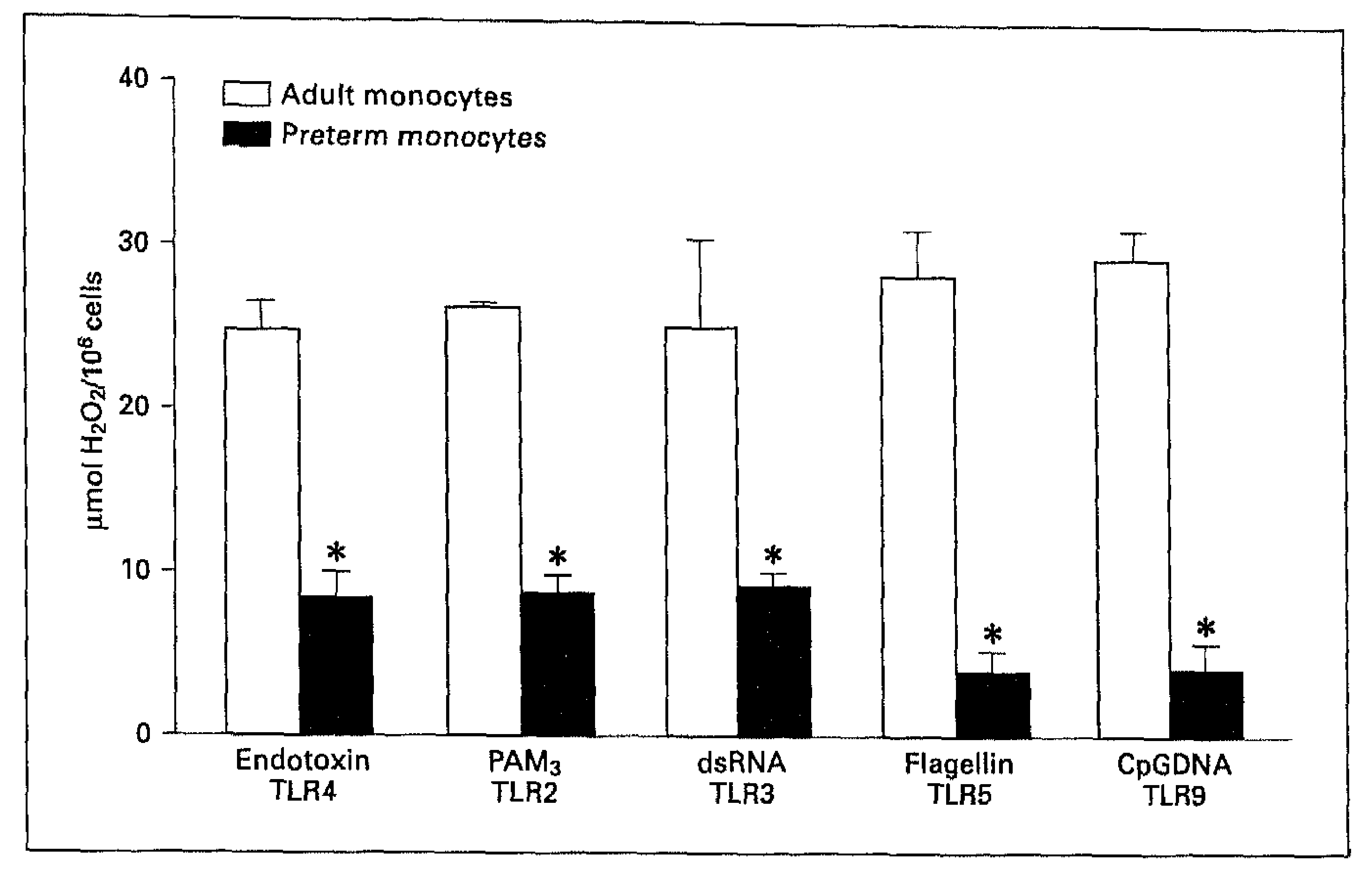

modulated by other components of the innate immune system that promote clearance or inactivation of organisms (table 1) and which are quantitatively deficient in the fetus. We tested the TLR signaling responses of fetal blood monocytes (fig. 1). In comparison to blood monocytes from adult sheep, the fetal monocytes produced much less peroxide when stimulated with the TLR agonists. Fetal sheep also do not respond to ovine recombinant TNF- $\alpha$, which is another demonstration of a decreased inflammatory response [10]. These results are consistent with a depressed inflammatory potential.

In contrast, intra-amniotic injections of the TLR 4 agonist $E$. coli endotoxin (lipopolysaccharide) induce chorioamnionitis (increased granulocytes and IL-8 in amniotic fluid and inflammatory cell accumulation in the chorioamnion) [11]. Within hours of intra-amniotic injection granulocytes appear in the lung tissue and fetal lung fluid and pro-inflammatory cytokine expression increases to high levels for about 2 days. The intra-amniotic endotoxin initiates the lung inflammation by direct contact with the airway epithelium, which propagates an injury sequence (inflammation and apoptosis followed by cell proliferation) that evolves in 5-7 days to striking lung maturation [12-14]. The fetus responds similarly to intra-amniotic IL-1, a prototypic pro-inflammatory cytokine that shares receptor homology and signaling pathways with TLR4 [15]. Therefore, the fetus can develop a prompt inflammatory response.

The severity/intensity of the inflammatory response of the preterm fetus relative to the response of the term or adult sheep has not been formally studied. However, fetal sheep given only $10 \mu \mathrm{g}$ LPS have a high mortality which is similar to the lethal dose in adult seep [16]. Following delivery, preterm and term lambs, given intratracheal endotoxin, recruited similar numbers of neutrophils and expressed similar amounts of pro-inflammatory cytokines in the lungs [17]. Therefore, the preterm certainly can mount a prompt and potentially lethal inflammatory response if endotoxin enters the systemic circulation.

The dose-response relationship for the effects of intraamniotic endotoxin on the fetal lung tells a different story. Low intra-amniotic doses of $0.1 \mathrm{mg}$ endotoxin cause some lung inflammation, increase blood platelet counts but do not induce lung maturation [18]. Doses from 1 to $10 \mathrm{mg}$ endotoxin cause much more inflammation, but the amount of inflammation does not increase further with doses up to $100 \mathrm{mg}$ [14]. Endotoxin has a biological halflife in amniotic fluid of about $35 \mathrm{~h} \mathrm{[19].} \mathrm{Therefore,} \mathrm{despite}$ very high doses and prolonged exposures, lung inflammation does not increase with time beyond about 2 days or with dose. Very large exposures of $100 \mathrm{mg}$ that are 1,000 times higher than the amount needed to cause some lung inflammation do not cause enough inflammation to interfere with the lung maturation response [14]. Chronic colonization or infection of the fetal lung with $U$. parvum for many weeks also causes inflammation and lung maturation [8]. To date, fetal responses to other TLR agonists have not been evaluated. These results demonstrate that the fetus can quickly develop an inflammatory response to intra-amniotic inflammation that is not very dose sensitive. The lung inflammatory response to intra-amniotic endotoxin is not severe. 
Fig. 2. Effects of chronic intra-amniotic endotoxin on fetal sheep lungs at late gestational age. Fetal sheep were exposed to $1 \mathrm{mg}$ intra-amniotic endotoxin infused each day for 28 days from 80 to 108 days of gestation using an osmotic pump. The fetal lungs were assessed at 138 days (term is 150 days). The measurements are expressed relative to a normalized value of 1 for controls implanted with saline filled pumps. The lungs had increased inflammation and surfactant but no changes in lung gas volumes or alveolar numbers. Data redrawn from Kallapur et al. [22].

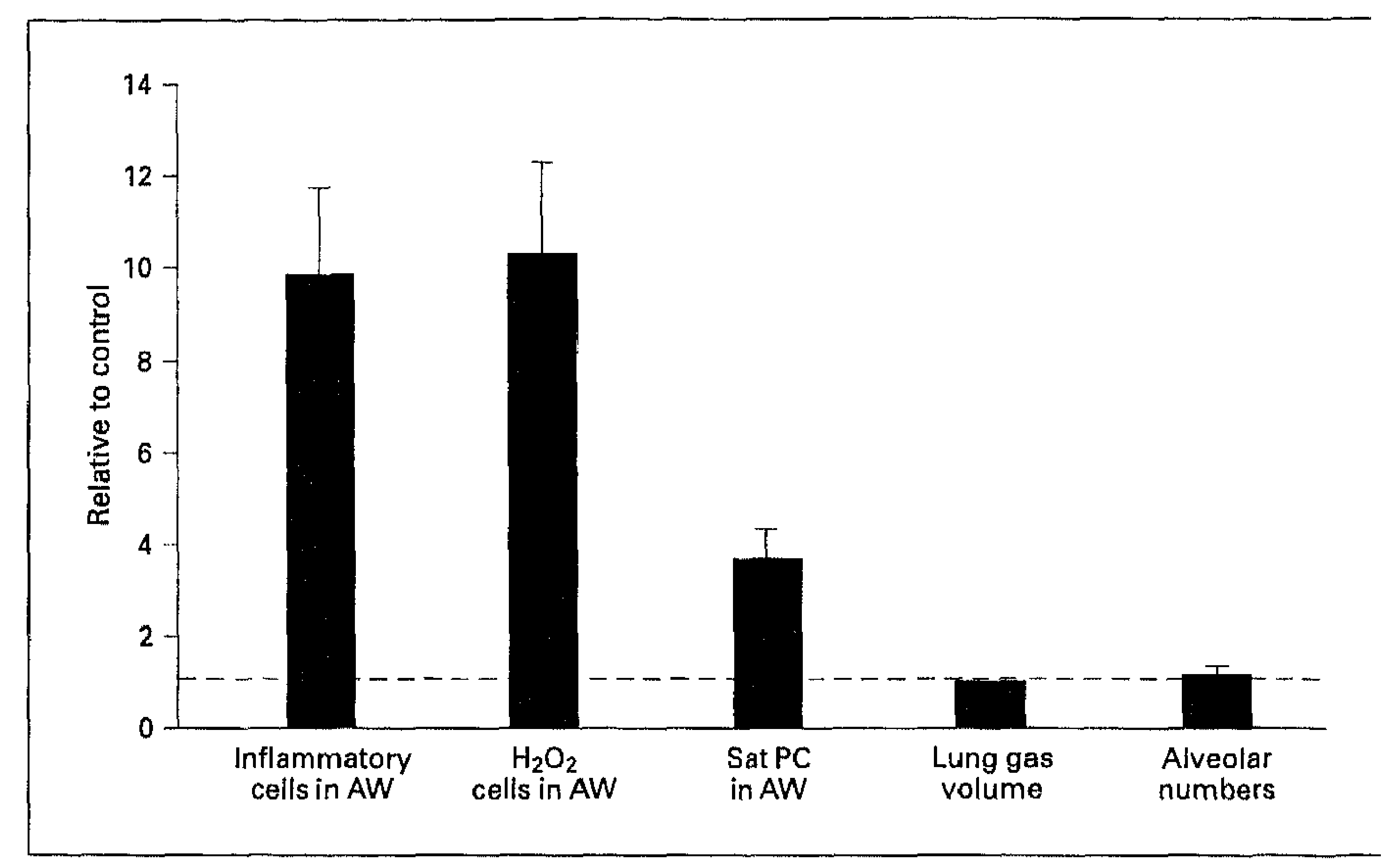

\section{Assumption 4: Once Fetal Inflammation Has Begun It Will Progress and Injure the Fetus}

A single dose of intra-amniotic endotoxin causes acute inflammation that resolves over several weeks. The residual effects on the fetal lung are microvascular injury, decreased alveolar septation and functional lung maturation [20]. The anatomic abnormalities are not progressive because alveolar number is normal at term or at 2 months postnatal age [21]. However, a prolonged exposure to chronic indolent chorioamnionitis is probably the more common clinical situation [6]. Therefore, we modeled prolonged fetal endotoxin exposure using either Alzet osmotic pumps to deliver $1 \mathrm{mg}$ /day of endotoxin into the amniotic fluid for 28 days (gestational age 80-108 days) or 4 intra-amniotic injections of $10 \mathrm{mg}$ LPS given at 100 , 107,114 and 121 days [22]. Fetal lungs were assessed between 130 and 145 days of gestation. Our primary question was if chronic exposure to endotoxin injured the fetus or caused progressive lung injury. We found no effects on cord blood gas values, birth weights or plasma cortisol values, indicating no obvious effects on the fetus. Although a single dose of endotoxin or a 28-day intra-amniotic exposure inhibit alveolar septation following preterm delivery [23], the fetal lungs had healed and had no significant decreases in alveolar numbers and no markers of vascular injury when delivery occurred close to term [22]. The surfactant pool sizes were greatly increased and low-grade lung inflammation (increased inflammatory cells, IL-8 mRNA and IL $1 \beta$ mRNA) was present until term (fig. 2). These experiments demon- strate that the fetus did not develop progressive inflam mation/injury in response to chronic exposures to larg amounts of endotoxin. Similarly, chronic colonizatios of the fetal sheep lung with $U$. parvum for periods as lon: as 65 days did not cause much injury [8]. If the fetus wer. truly immune naïve and immune deficient, then thes exposures would be anticipated to cause progressive in jury. Clinical experience is consistent with the response we find in sheep. Tracheal aspirates collected soon afte: birth from many preterm infants contain multiple indi cators of inflammation, presumably in response to chron ic indolent chorioamnionitis [24]. However, these pre term infants seldom have pneumonia. More commonly they have less RDS and lung maturation despite the in flammation. These experiments demonstrate that the fe tus can 'control' or 'downregulate' inflammation. Tht fourth assumption that fetal inflammation will be pro gressive and injure the fetus may not be true in many cases - except for the small number of preterm babie: with sepsis [25].

\section{How Does a Fetus Control Inflammation?}

There is very little information about how a fetus responds to infection/inflammation other than clinical pathologic descriptions, which focus on invasive organ. isms known to cause fetal injury and death (e.g. cytomeg. alovirus, Treponema pallidum, Listeria moncytogenes) The much more common occurrence of preterm delivery after chronic, indolent chorioamnionitis caused by low 
Fig. 3. Hydrogen peroxide production by blood monocytes challenged in vitro with endotoxin. The amount of hydrogen peroxide production by $10^{6}$ blood monocytes from preterm fetal sheep was less than for adult sheep. Maternal treatment with betamethasone initially suppressed and then stimulated the response to endotoxin. Intraamniotic endotoxin also suppressed and then stimulated monocyte responses to a second challenge to endotoxin in vitro response to endotoxin. *p $<0.05$. Data redrawn from Kramer et al. [29] and Kramer et al. [27].

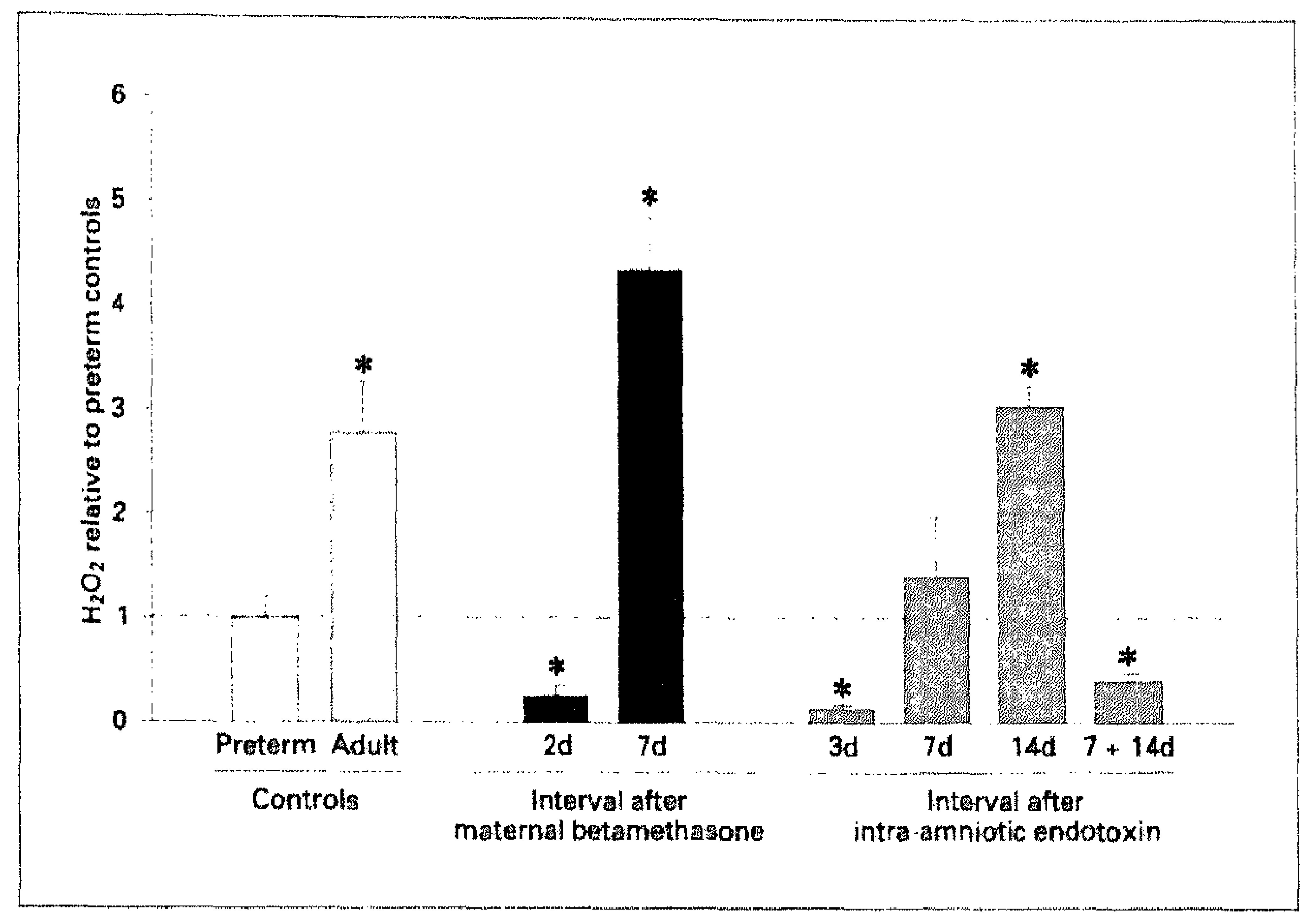

pathogenic organisms, remains to be studied. The clinical context for adaptation to inflammation is the concept of innate immune tolerance, often referred to as endotoxin tolerance. Mice and man exposed to an agonist such as endotoxin have brisk inflammatory responses, but second or subsequent exposures soon after the first exposure cause less or no systemic responses (fever, cytokine expression, granulocyte responses) by mechanisms that are not well understood [26]. Duncan et al. [16] demonstrated that fetal sheep become tolerant to an intravascular dose of $1 \mu \mathrm{g}$ endotoxin. We asked if chorioamnionitis caused by intra-amniotic injections induced an endotoxin tolerance-type response in blood monocytes of fetal sheep. After intra-amniotic injections of endotoxin, we recovered blood monocytes 3,7 and 14 days later [27]. One group of fetal sheep received intra-amniotic endotoxin injections 14 and 7 days before blood monocytes were isolated, placed in culture and challenged again with endotoxin. A single exposure to intra-amniotic L.PS suppressed monocyte production of peroxide and II -6 at 3 days, demonstrating an endotoxin tolerance response. However, by 14 days, the blood monocyte had increased responsiveness to a second endotoxin challenge in vitro. The immature preterm monocyte seems to have matured to function more like an adult monocyte (fig. 3). However, a second fetal exposure 7 days after the first exposure again caused an endotoxin tolerance-type response. These results demonstrate that the fetus has the capacity to down regulate inflammation.
In clinical practice, the fetus at risk of preterm delivery is likely to be exposed to inflammation and to maternal corticosteroids. Maternal corticosteroids suppressed the initial inflammatory responses in fetal sheep lungs to intra-ammiotic endotoxin [28]. However, 5 or 15 days after the simultaneous exposure to maternal corticosteroids and intra-amniotic endotoxin, the lung inflammatory response was increased. We interpret this increased response to the maturation of inflammatory cell function by 7 days [29]. There is no information about how corticosteroids might modulate inflammatory responses in chronic chorioamnionitis.

New clinical observations about fetal exposure to infection and inflammation together with our initial studies of fetal lung and blood monocyte responses to acute and chronic chorioamnionitis indicate that common assumptions about fetal responses to inflammation may be wrong. Far more needs to be learned about how the fetus copes with a chronically inflamed environment.

\section{Acknowledgements}

This work was supported in part by grants HL-65397 and HD12714 from the National Institute of Health and Human Services - US and grant A-27, Interdisciplinary Centre for Clinical Research, University of Würzburg, Germany. 


\section{References}

1 Marshall-Clarke S, Reen D, Tasker L, Hassan J: Neonatal immunity: how well has it grown up? Immunol Today 2000;21:35-41.

2 Fazeli A, Bruce C, Anumba DO: Characterization of Toll-like receptors in the female reproductive tract in humans. Hum Reprod 2005: Complete reference pending.

3 Gerber S, Vial Y, Hohlfeld P, Witkin SS: Detection of Ureaplasma trealyticum in secondtrimester amniotic fluid by polymerase chain reaction correlates with subsequent preterm labor and delivery. J Infect Dis 2003;187:518521.

4 Gray DJ, Robinson HB, Malone J, Thomson $\mathrm{RB} \mathrm{Jr}$ : Adverse outcome in pregnancy following amniotic fluid isolation of Ureaplasma urealyticum. Prenat Diagn 1992;12:111-117.

5 Steel JH, Malatos S, Kennea N, Edwards AD, Miles L, Duggan P, Reynolds PR, Feldman RG, Sullivan MH: Bacteria and inflammatory cells in fetal membranes do not always cause preterm labor. Pediatr Res 2005;57:404-411.

6 Goldenberg RL, Hauth JC, Andrews WW: Intrauterine infection and preterm delivery. $\mathrm{N}$ Engl J Med 2000;342:1500-1507.

7 Lahra MM, Jeffery HE: A fetal response to chorioamnionitis is associated with early survival after preterm birth. Am J Obstet Gynecol 2004;190:147-151.

8 Moss TJM, Nitsos I, Ikegami M, Jobe AH, Newnham JP: Experimental intra-uterine Ureaplasma infection in sheep. Am J Obstet Gynecol 2005; 192:1179-1 186.

9 Takeda K, Kaisho T, Akira S: Toll-like receptors. Annu Rev Immunol 2003;21:335-376.

10 Ikegami M, Moss TJM, Kallapur SG, Mulrooney N, Kramer BW, Nitsos I, Bachurski C, Newnham JP, Jobe AH: Minimal lung and systemic responses to TNFa in preterm sheep. Am J Physiol 2003;285:L121-L129.

11 Kallapur SG, Willet KE, Jobe AH, Ikegami M, Bachurski C: Intra-amniotic endotoxin: Chorioamnionitis precedes lung maturation in preterm lambs. Am J Physiol 2001;280:L527L536.
12 Kramer BW, Kramer S, Ikegami M, Jobe A: Injury, inflammation and remodeling in fetal sheep lung after intra-amniotic endotoxin. Am J Physiol 2002;283:L452-L459.

13 Moss TJ, Nitsos I, Kramer BW, Ikegami M, Newnham J, Jobe A: Intra-amniotic endotoxin induces lung maturation by direct effects on the developing respiratory tract in preterm sheep. Am J Obstet Gynecol 2002;187:10591065.

14 Jobe AH, Newnham JP, Willet KE, Moss TJ, Ervin MG, Padbury JF, Sly PD, Ikegami M: Endotoxin induced lung maturation in preterm lambs is not mediated by cortisol. Am J Resp Crit Care Med 2000;162:1656-1661.

15 Willet K, Kramer BW, Kallapur SG, Ikegam M, Newnham J, Moss T, Sly P, Jobe A: Intraanniotic injection of IL-1 induces inflammation and maturation in fetal sheep lung. Am J Physiol 2002;282:L411-L420.

16 Duncan JR, Cock ML, Scheerlinck JP, Westcott KT, McLean C, Harding R, Rees SM: White matter injury after repeated endotoxin exposure in the preterm ovine fetus. Pediatr Res 2002;52:941-949.

17 Kramer BW, Jobe AH, Ikegami M: Systemic inflammation following intratracheal endotoxin that leaks into the circulation despite gentle ventilation of preterm lambs. Am J Respir Crit Care Med 2001;163:A209.

18 Kramer BW, Moss TJ, Willet K, Newnham J, Sly P, Kallapur SG, Ikegami M, Jobe A: Dose and time response after intra-amniotic endotoxin in preterm lambs. Am J Respir Crit Care Med 2001;164:982-988.

19 Newnham J, Kallapur SG, Kramer BW, Moss TJM, Nitsos I, Ikegami M, Jobe AH: Betamethasone effects on chorioamnionitis induced by intra-amniotic endotoxin in sheep. Am J Obstet Gynecol 2003; 189:1458-1466.

20 Kallapur SG, Bachurski CJ, Le Cras TD, Joshi $\mathrm{SN}$, Ikegami M, Jobe AH: Vascular changes following intra-amniotic endotoxin in preterm lamb lungs. Am J Physiol 2004;287:L1178L1 185 .
21 Moss TJ, Harding R, Newnham JP: Lung function, arterial pressure and growth in sheep during early postnatal life following single and repeated prenatal corticosteroid treatments. Early Hum Dev 2002;66:11-24.

22 Kallapur SG, Nitsos I, Moss TJM, Kramer BW, Newnham J, Ikegami M, Jobe AH: Chronic endotoxin exposure does not cause sustained structural abnormalities in the fetal sheep lungs. Am J Physiol [L] 2005; in press.

23 Willet $\mathrm{K}$, Jobe A, Ikegami M, Brennan S, Newnham J, Sly P: Antenatal endotoxin and glucocorticoid effects on lung morphometry in preterm lambs. Pediatr Res 2000;48:782788.

24 Speer CP: Inflammation and bronchopulmonary dysplasia. Semin Neonatol 2003;8:2938.

25 Stoll BJ, Hansen N, Fanaroff AA, Wright LL, Carlo WA, Ehrenkranz RA, Lemons JA, Donovan EF, Stark AR, Tyson JE, Oh W, Bauer CR, Korones SB, Shankaran S, Laptook AR, Stevenson DK, Papile LA, Poole WK: Changes in pathogens causing early-onset sepsis in verylow-birth-weight infants. N Engl J Med 2002; 347:240-247.

26 West MA, Heagy W: Endotoxin tolerance: a review. Am J Respir Crit Care Med 2002;30: S64-73.

27 Kramer BW, Ikegami M, Moss TJ, Nitsos I, Newnham JP, Jobe AH: Endotoxin-induced chorioamnionitis modulates innate immunity of monocytes in preterm sheep. Am J Respir Crit Care Med 2005;171:73-77.

28 Kallapur SG, Kramer BW, Moss TJ, Newnham JP, Jobe AH, Ikegami M, Bachurski CJ: Maternal glucocorticoids increase endotoxininduced lung inflammation in preterm lambs. Am J Physiol 2003;284:L633-642.

29 Kramer BW, Ikegami M, Moss TJ, Nitsos I, Newnham JP, Jobe AH: Antenatal betamethasone changes cord blood monocyte responses to endotoxin in preterm lambs. Pediatr Res 2004;55:764-768. 


\section{CHAPTER 8}

\section{Intratracheal endotoxin induces systemic inflammation in ventilated preterm lambs}

Kramer, B.W., Ikegami, M., Jobe, A.H. 


\title{
Intratracheal Endotoxin Causes Systemic Inflammation in Ventilated Preterm Lambs
}

\author{
BORIS W. KRAMER, MACHIKO IKEGAMI, and ALAN H. JOBE \\ Children's Hospital Medical Center, Division of Pulmonary Biology, Cincinnati, Ohio
}

Intratracheal endotoxin causes acute inflammation in the adult lung, and injurious styles of mechanical ventilation can result in systemic inflammation derived from the lungs. We asked how ventilated premature and near-term lungs responded to intratracheal endotoxin and if systemic inflammation occurred. Lambs delivered at $130 \mathrm{~d}$ gestational age (GA) were treated with surfactant or surfactant plus endotoxin $(0.1 \mathrm{mg} / \mathrm{kg}$ or $10 \mathrm{mg} / \mathrm{kg}$ ) (Escherichia coli, serotype 055:B5) and were ventilated for $6 \mathrm{~h}$. Both endotoxin doses resulted in impaired gas exchange and systemic inflammation in the preterm lambs. Lambs at $141 \mathrm{~d}$ GA (term $146 \mathrm{~d}$ ) were given either $10 \mathrm{mg} / \mathrm{kg}$ intratracheal endotoxin, $10 \mathrm{mg} / \mathrm{kg}$ endotoxin plus high tidal volume ventilation for the first $30 \mathrm{~min}$ of life, or $5 \mu \mathrm{g} / \mathrm{kg}$ endotoxin given intravenously. Endotoxin alone (10 $\mathrm{mg} / \mathrm{kg}$ ) caused lung inflammation but no systemic effects after $6 \mathrm{~h}$ of ventilation. Lambs given $10 \mathrm{mg} / \mathrm{kg}$ endotoxin plus high tidal volume ventilation or $5 \mu \mathrm{g} / \mathrm{kg}$ endotoxin intravenously had decreased gas exchange and systemic inflammation. Endotoxin was detected in the plasma of lambs at $130 \mathrm{~d}$ GA but not at $141 \mathrm{~d} \mathrm{GA}$. Inflammation in the lungs was more severe in preterm animals. Mechanical ventilation of the endotoxin-exposed preterm lung resulted in systemic effects at a low endotoxin dose and without high tidal volume ventilation.

Keywords: lung injury; bronchopulmonary dysplasia; neutrophils; cytokines

Endotoxin administered intratracheally causes an inflammatory lung injury in adult animals. Intratracheal endotoxin results in the rapid recruitment of activated white cells to the lungs and the production of tumor necrosis factor- $\alpha$ (TNF- $\alpha$ ) and other proinflammatory cytokines (1). In adult animals responses to intratracheal endotoxin are localized to the lungs unless the lungs are ventilated with injurious ventilation styles (2). A leak of endotoxin from the airspaces to the systemic circulation and increased plasma cytokines were demonstrated in adult rabbits ventilated with high tidal volumes and no positive end-expiratory pressure (PEEP) (3).

Little is known of the responses of newborn lungs to intratracheal endotoxin. The term or preterm newborn lung may be exposed to endotoxin or other proinflammatory products as a result of chorioamnionitis and microorganisms in amniotic fluid (4). The term lung differs from the adult lung because it is structurally immature and has very few resident macrophages (5). The preterm lung has more structural immaturity and surfactant deficiency and is more easily injured by mechanical ventilation (6-8). The preterm fetal lung does not have increased

(Received in original form December 7, 2000; accepted in final form November 9, 2001) This study was supported by NIH Grant HD-12714. Byk Gulden, Konstanz, Germany, provided recombinant SP-C surfactant. Commonwealth Scientific and Industrial Research Organization, Park Ville, Australia, provided recombinant ovine interleukin- 6 and -8 .

Correspondence and requests for reprints should be addressed to Alan $H$. Jobe, M.D., Ph.D., Children's Hospital Medical Center, Division of Pulmonary Biology, 3333 Burnet Avenue, Cincinnati, OH 45229-3039. E-mail: jobea0@chmcc.org

Am J Respir Crit Care Med Vol 165. pp 463-469, 2002

DOI: $10.1164 / \mathrm{rccm} .2011118$

Internet address: www.atsjournals.org permeability to protein relative to the mature lung (9). Therefore, the increased permeability that occurs in ventilated preterm lungs is thought to result from the effects of nonuniform inflation on a structurally immature and surfactant-deficient lung that contains insufficient collagen and elastin $(10,11)$. The immature lung also has decreased host defense surfactant protein (SP)-A and SP-D and has immature immune systems with depressed second messenger responses making it potentially more susceptible to endotoxin-induced injury $(12,13)$. Therefore, we hypothesized that intratracheal endotoxin would injure 130-d gestational age (GA) newborn lambs more than nearterm lambs. We assessed the effects of mechanical ventilation on the endotoxin-induced inflammation in the immature and near-term lung and the implications for systemic inflammation.

\section{METHODS}

\section{Study Design}

We evaluated the effects of intratracheal endotoxin on the lungs and systemic responses in lambs with two protocols. We delivered preterm lambs at $130 \mathrm{~d}$ GA and near-term lambs at $141 \mathrm{~d}$ GA from Suffolk ewes bred to Dorset rams (term gestation is $146 \pm 1 \mathrm{~d}$ ) (Figure 1). The protocols were approved by the Animal Care and Use Committee of the Children's Hospital Research Foundation. Based on our previous experiences with ventilation-induced lung injury in the preterm at $130 \mathrm{~d}$ GA (14-16), we gave surfactant before initiating ventilation and used a PEEP of $4 \mathrm{~cm} \mathrm{H}_{2} \mathrm{O}$ and continuous tidal volume monitoring and an initial target $\mathrm{PCO}_{2}$ of $50 \mathrm{~mm} \mathrm{Hg}$ to minimize lung injury. We maintained tidal volume (VT) at about $10 \mathrm{ml} / \mathrm{kg}$ even if the $\mathrm{PCO}_{2}$ increased during the $6 \mathrm{~h}$ of ventilation. We randomized the $130-\mathrm{d} \mathrm{GA}$ lambs to a high dose of $10 \mathrm{mg} / \mathrm{kg}$ endotoxin or a lower dose of $0.1 \mathrm{mg} / \mathrm{kg}$ endotoxin based on our observations that doses as high as $100 \mathrm{mg}$ of endotoxin given by intraamniotic injection did not harm the sheep fetus and doses less than $1 \mathrm{mg} / \mathrm{kg}$ did not consistently induce lung maturation in the fetal sheep $(17,18)$.

The near-term animals were randomized to receive a saline placebo or the same high dose of $10 \mathrm{mg} / \mathrm{kg}$ of endotracheal endotoxin at birth as given to the preterm lambs. Other term lambs received this dose together with high VT ventilation for 30 min after birth to evaluate if a brief period of increased lung stretch would alter the response to endotoxin. A separate group of near-term lambs was given intravascular endotoxin $(5 \mu \mathrm{g} / \mathrm{kg})$ to characterize the systemic response to the endotoxin. The near-term lambs were not surfactant treated.

\section{Delivery, Endotoxin, and Ventilation}

All animals were delivered by Cesarean section, and after exposure of the fetal head and neck, an endotracheal tube was tied into the trachea (16). The fetal lung fluid that could be easily aspirated by syringe was removed, and the lambs were delivered and weighed. The lambs then received either the endotracheal saline placebo or endotoxin before the initiation of mechanical ventilation. The 130-d GA lambs received the endotoxin mixed with $100 \mathrm{mg} / \mathrm{kg}$ surfactant (Venticute; Byk Gulden, Konstanz, Gemany) containing 2\% recombinant human SP-C in phospholipids (19). All animals were ventilated with time-cycled and pressure-limited infant ventilators (Sechrist Industries, Anaheim, CA) with the following initial ventilator setting: fraction of inspired oxygen $\left(\mathrm{F}_{\mathrm{O}_{2}}, 1.0\right.$; rate: 40 breaths/min; inspiratory time: $0.6 \mathrm{~s}$; PEEP: $4 \mathrm{~cm} \mathrm{H}_{2} \mathrm{O}$; peak inspiratory pressure (PIP) sufficient to yield a target $\mathrm{VT}_{\mathrm{T}}$ of $10 \mathrm{mI} / \mathrm{kg}$ but with pressure limited to 35 $\mathrm{cm} \mathrm{H}_{2} \mathrm{O}$. VT was monitored continuously (CP-100; Bicore Monitoring 


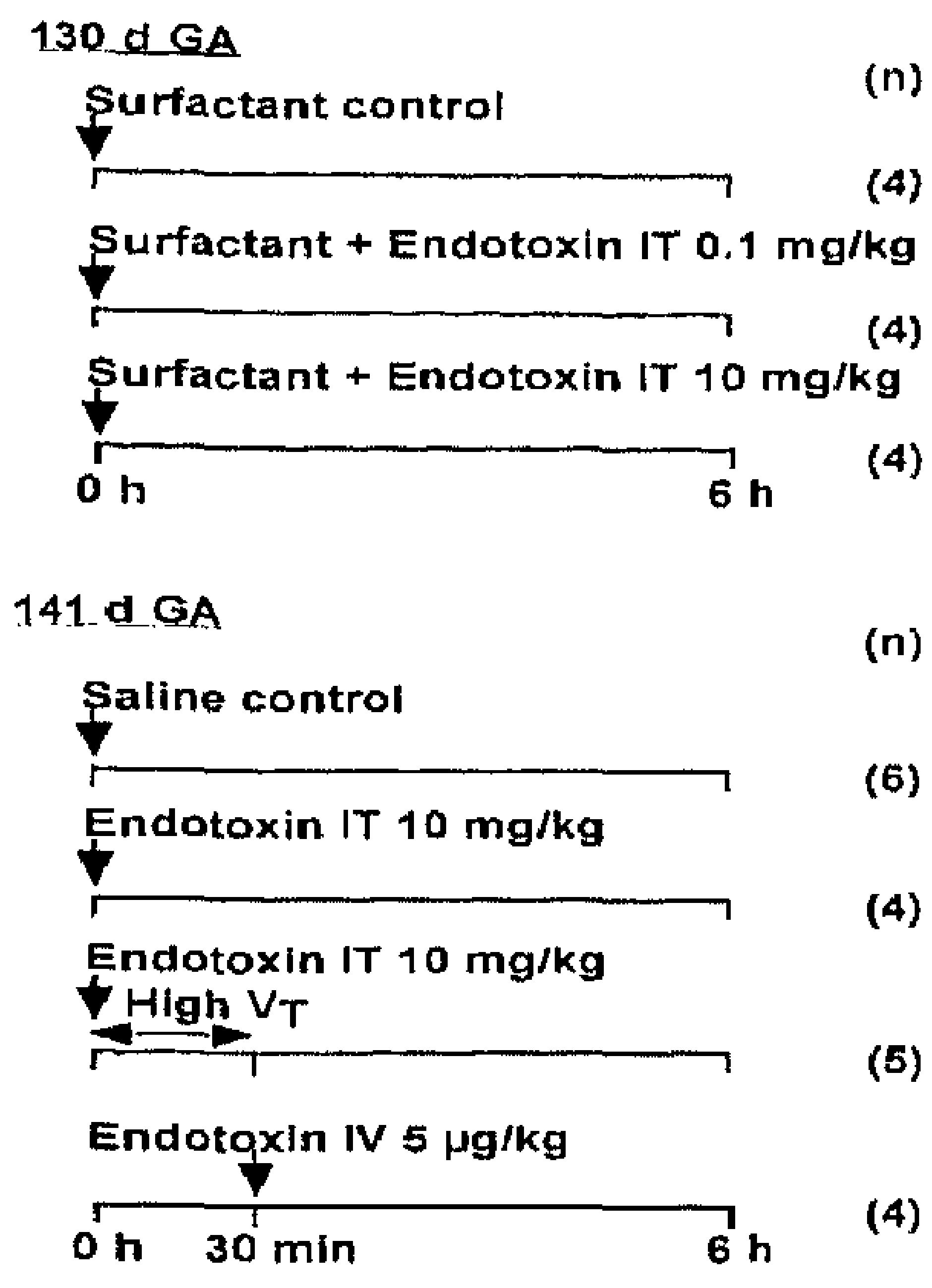

Systems, Anaheim, CA). Ventilation pressure and $\mathrm{FI}_{\mathrm{I}_{2}}$ were adjusted to achieve a target $\mathrm{Pa}_{\mathrm{CO}_{2}}$ of $45-55 \mathrm{~mm} \mathrm{Hg}$ and a $\mathrm{Pa}_{2}$ of $150-200 \mathrm{~mm}$ $\mathrm{Hg}$. For the 141-d GA lambs that werc ventilated to a $V_{T}$ target of 25 $\mathrm{ml} / \mathrm{kg}$ (high VT group) for $30 \mathrm{~min}$, supplemental $\mathrm{CO}_{2}$ was added to the ventilatory circuit to normalize the $\mathrm{Pa}_{\mathrm{CO}_{2}}$. A $5 \mathrm{~F}$ catheter was advanced into the aorta via an umbilical artery, and a $10 \mathrm{ml} / \mathrm{kg}$ transfusion of filtered fetal blood collected from the placenta was administered within 10 min of delivery.

Dynamic compliances were calculated from VT measured with a pneumotachometer that was nommalized to body weight and divided by the ventilatory pressure (PIP - PEEP) $(14,19)$. The ventilatory efficiency index (VEI) was calculated as VEI $=3,800 \div$ (respiratory rate $\times\left[\right.$ PIP - PEEP] $\left.\times \mathrm{Pa}_{\mathrm{CO}_{2}}\right)$, where 3,800 is a $\mathrm{CO}_{2}$ production constant $([\mathrm{ml} \times \mathrm{mm} \mathrm{Hg}] \div[\mathrm{kg} \times \min ])(20)$. Complete blood cell counts and differentials were performed for cord blood and for peripheral arterial blood at 2,4 , and $6 \mathrm{~h}$. The arterial catheter was used for blood gas, $\mathrm{pH}$, heart rate, and blood pressure recording and was infused with $10 \%$ dextrose $(100 \mathrm{ml} / \mathrm{kg} / \mathrm{d})$. Rectal temperature was monitored and kept at $38-39^{\circ} \mathrm{C}$ with heating pads and radiant heat. Supplemental ketamine $(10 \mathrm{mg} / \mathrm{kg}$ intramuscularly) and acepromazine $(0.1 \mathrm{mg} / \mathrm{kg}$ intramuscularly) suppressed spontaneous breathing. After $6 \mathrm{~h}$ each animal was deeply anesthetized with $25 \mathrm{mg} / \mathrm{kg}$ pentobarbital intravenously and ventilated briefly with $100 \%$ oxygen. The endotracheal tube was clamped for 3 min to permit oxygen absorption.

\section{Lung $\mathrm{G}$ as Volume at $40 \mathrm{~cm} \mathrm{H}_{2} \mathrm{O}$ and Lung Processing}

The thorax was opened, the lungs were inflated with air to $40 \mathrm{~cm} \mathrm{H}_{2} \mathrm{O}$ pressure for $1 \mathrm{~min}$, and maximal lung volume was recorded (14). Lung tissue of the right lower lobe was frozen in liquid nitrogen for RNA isolation. Bronchoalveolar lavage was performed on the left lung by filling with $0.9 \% \mathrm{NaCl}$ at $4^{\circ} \mathrm{C}$ until visually distended, and the lavage was repeated five times $(14,19)$. The bronchoalveolar lavage fluids (BALF) were pooled and aliquots saved for determination of total protein, cell number, and cell differential. Cell pellets were used for hydrogen peroxide assay and RNA isolation. Total protein in BALF was measured (21).

\section{Alveolar Cells}

BALF was centrifuged at $500 \times g$ for $10 \mathrm{~min}$, and the cells in the pellets were counted using trypan blue. Differential cell counts were performed on stained cytospin preparations (Diff-Quick; Scientific Products, McGaw Park, IN). Activation of the cells recruited to the airways was assessed by measuring hydrogen peroxide using an assay based on the oxidation of ferrous iron $\left(\mathrm{Fe}^{2+}\right)$ to ferric iron $\left(\mathrm{Fe}^{3+}\right)$ by hydrogen peroxide under acidic conditions (Bioxytech $\mathrm{H}_{2} \mathrm{O}_{2}-560$ assay; OXIS International, Portland, OR) (18).

\section{Cytokine Messenger RNA}

Total RNA was isolated from the right lower lung lobe, from BALF cells, and from the spleen by guanidinium thiocyanate-phenol-chlo- roform extraction (22). Spleen tissue was used to evaluate if the endotoxin induced a systemic inflammation. RNase protection assays were performed using RNA transcripts of ovine interleukin (IL)-1 $\beta$, IL-6, IL-8, IL-10, and tumor necrosis factor $\alpha$ (TNF- $\alpha$ ) that was described previously $(18,22)$. Ovine ribosomal protein L32 was the reference RNA. Densities of the protected bands were quantified on a phosphor imager using ImageQuant software (Molecular Dynamics Inc., Sunnyvale, CA).

\section{Plasma, Endotoxin, and Cytokines}

Endotoxin was quantified in plasma after $6 \mathrm{~h}$ ventilation with the Limulus amebocyte lysate assay (Bio Whittaker, Walkersville, MD). Enzymelinked immunosorbent assays (ELISA) were run for IL-6 and IL-8 with antibodies from Chemicon (Temecula, CA), and recombinant proteins were kindly provided by CSIRO (Parkville, Australia) (16).

\section{Data Analysis}

Results are given as means \pm SEM. Comparisons between endotoxin groups at each gestational age were by analysis of variance with Student-Newman-Keuls tests used for post hoc analyses. Comparison between $141 \mathrm{~d} \mathrm{GA}$ and $130 \mathrm{~d} \mathrm{GA}$ was by two-tailed $t$ tests for control and $10 \mathrm{mg} / \mathrm{kg}$ endotoxin groups. Significance was accepted at $\mathrm{p}<0.05$.

\section{RESULTS}

\section{0-d GA Lambs}

The 130-d GA lambs averaged $3.5 \pm 0.3 \mathrm{~kg}$ and mean weights were similar for the lambs in each group. In comparison with the control lambs, the lambs that received 0.1 or $10 \mathrm{mg} / \mathrm{kg}$ endotoxin and were ventilated with similar VT had higher $\mathrm{PCO}_{2}$ values and decreased oxygenation after $6 \mathrm{~h}$ ventilation (Table 1). Compliance and lung gas volumes were not changed by endotoxin exposure. Gas exchange as measured by the VEI and blood pressure decreased in the $10 \mathrm{mg} / \mathrm{kg}$ endotoxin group (Figure 2). Heart rate increased for both endotoxin-exposed groups. Protein in the BALF was increased from $69.6 \pm 8.4$ $\mathrm{mg} / \mathrm{kg}$ for control lungs to $86.3 \pm 5.1 \mathrm{mg} / \mathrm{kg}$ for the $10 \mathrm{mg} / \mathrm{kg}$ endotoxin group $(\mathrm{p}<0.05)$. Therefore, the endotoxin resulted in systemic effects without a large effect on lung mechanics.

The low and high doses of endotoxin caused inflammation in the lungs of the 130-d GA lambs. Neutrophils and hydrogen peroxide production by cells in the BALF were greatly increased (Figure 3), although there were no consistent changes in lymphocytes or macrophage numbers in the BALF (data not shown). Cytokine mRNA for IL-1 $\beta$, IL-6, and IL-8 increased in both cell pellets and lung tissue, with qualitatively higher mRNA expression for the higher dose of endotoxin (Figure 4).

Endotoxin could be quantified in the plasma of these ventilated preterm lambs (Figure 5). The intratracheal endotoxin at either dose also decreased peripheral neutrophils to very low numbers. Large increases in mRNA for IL-1 $\beta$, IL-6, and IL-8 were detected in the spleens of the lambs exposed to $10 \mathrm{mg} / \mathrm{kg}$ endotoxin (Figure 6). Plasma IL-6 and IL-8 levels also were increased in response to either dose of endotracheal endotoxin.

\section{1-d GA Lambs}

There were no differences in the mean birth weight of $4.4 \pm$ $0.2 \mathrm{~kg}$ between the groups of lambs. Lung mechanics and gas exchange after $6 \mathrm{~h}$ of mechanical ventilation were similar for control lambs and lambs given $10 \mathrm{mg} / \mathrm{kg}$ endotracheal endotoxin (Table 1). These lambs had a mean VT of $9.4 \mathrm{ml} / \mathrm{kg}$ at 30 min of age. In contrast the lambs that were ventilated with a $\mathrm{VT}_{\mathrm{T}}$ of $24 \pm 2 \mathrm{ml} / \mathrm{kg}$ at $30 \mathrm{~min}$ of age and were subsequently ventilated with a mean VT of $10 \mathrm{ml} / \mathrm{kg}$ had respiratory failure at $6 \mathrm{~h}$ of age. These lambs had higher ventilatory pressure requirements, decreased oxygenation, decreased gas exchange as indicated by the VEI, and decreased lung compliance and 
TABLE 1. PULMONARY FUNCTION AFTER $6 \mathrm{~h}$ OF MECHANICAL VENTILATION

\begin{tabular}{|c|c|c|c|c|c|c|c|}
\hline & \multicolumn{3}{|c|}{ Lambs at $130 \mathrm{~d}$ GA } & \multicolumn{4}{|c|}{ Lambs at $141 \mathrm{~d}$ GA } \\
\hline & Control & $0.1 \mathrm{mg} / \mathrm{kg}$ & $10 \mathrm{mg} / \mathrm{kg}$ & Control & $10 \mathrm{mg} / \mathrm{kg}$ & $\begin{array}{c}10 \mathrm{mg} / \mathrm{kg}+ \\
\mathrm{High} \mathrm{V}_{T}\end{array}$ & $\begin{array}{c}5 \mu \mathrm{g} / \mathrm{kg} \\
\text { Intravenously }\end{array}$ \\
\hline \multicolumn{8}{|l|}{ PIP - PEEP, } \\
\hline $\mathrm{cm} \mathrm{H}_{2} \mathrm{O}$ & $19.3 \pm 1.1^{*}$ & $21.3 \pm 1.7$ & $25.0 \pm 1.3^{* \dagger}$ & $13.2 \pm 1.2$ & $12.5 \pm 2.2$ & $21.5 \pm 4.6^{\dagger}$ & $21.3 \pm 2.6^{*}$ \\
\hline$V_{T}, \mathrm{ml} / \mathrm{kg}$ & $9.1 \pm 0.9$ & $11.1 \pm 1.2$ & $11.1 \pm 1.2$ & $9.9 \pm 0.7$ & $11.5 \pm 0.3$ & $10.3 \pm 0.8$ & $11.7 \pm 1.4$ \\
\hline $\mathrm{PCO}_{2}, \mathrm{~mm} \mathrm{Hg}$ & $53.1 \pm 2.0^{\star}$ & $70.5 \pm 9.3^{\dagger}$ & $75.8 \pm 12.1^{\star^{\dagger}}$ & $37.8 \pm 2.6$ & $34.5 \pm 3.5$ & $47.4 \pm 2.5^{\dagger}$ & $44.4 \pm 3.3$ \\
\hline $\mathrm{pH}$ & $7.28 \pm 0.02^{\star}$ & $7.08 \pm 0.03^{\dagger}$ & $7.08 \pm 0.06^{\star \dagger}$ & $7.37 \pm 0.01$ & $7.39 \pm 0.01$ & $7.26 \pm 0.04^{\ddagger}$ & $7.34 \pm 0.03$ \\
\hline $\begin{array}{l}\mathrm{PO}_{2} / \mathrm{Fl}_{\mathrm{O}_{2}} \\
\text { Compliance, }\end{array}$ & $297 \pm 36$ & $78 \pm 34^{\dagger}$ & $31 \pm 6^{* \dagger}$ & $370 \pm 62$ & $408 \pm 16$ & $128 \pm 70^{\dagger}$ & $177 \pm 31^{\dagger}$ \\
\hline $\mathrm{ml} / \mathrm{kg} \cdot \mathrm{cm} \mathrm{H}_{2} \mathrm{O}$ & $0.46 \pm 0.03^{*}$ & $0.52 \pm 0.05$ & $0.46 \pm 0.03$ & $0.78 \pm 0.08$ & $0.98 \pm 0.12$ & $0.51 \pm 0.07^{\dagger}$ & $0.53 \pm 0.14$ \\
\hline VEI & $0.097 \pm 0.009^{*}$ & $0.070 \pm 0.014$ & $0.055 \pm 0.009^{\star \dagger}$ & $0.215 \pm 0.022$ & $0.252 \pm 0.051$ & $0.102 \pm 0.027^{\dagger}$ & $0.103 \pm 0.014^{1}$ \\
\hline $\begin{array}{l}\text { Lung volume } \\
\text { at } 40 \mathrm{~cm} \mathrm{H} \mathrm{H}_{2} \mathrm{O} \\
\mathrm{ml} / \mathrm{kg}\end{array}$ & $38.0 \pm 2.0^{*}$ & $36.1 \pm 4.8$ & $37.4 \pm 3.9^{\star}$ & $66.6 \pm 4.3$ & $84.3 \pm 6.3^{\dagger}$ & $53.8 \pm 5.3^{\dagger}$ & $44.2 \pm 9.0^{\dagger}$ \\
\hline
\end{tabular}

Definition of abbreviations: $\mathrm{Fl}_{\mathrm{O}_{2}}=$ fraction of inspired oxygen; $G A=$ gestational age; PIP $-P E E P=$ ventilatory pressure (peak inspiratory pressure - positive end-expiratory pressure); $\mathrm{VEI}=$ ventilatory efficiency index; $\mathrm{V}_{T}=$ tidal volume.

${ }^{*} p<0.05$ versus corresponding group of lambs at $141 \mathrm{~d} \mathrm{GA}$.

$\dagger \mathrm{p}<0.05$ versus control.

lung volumes. The magnitude of the effect on lung function was similar to the lambs that received the intravascular endotoxin. The only lambs with decreased blood pressures were those that were endotoxin exposed and ventilated with high VT and those exposed to intravascular endotoxin (Figure 2).

The inflammatory responses in the lungs were similar for the three endotoxin-exposed groups. There were similar increases in neutrophils and hydrogen peroxide in the BALF (Figure 3), and cytokine mRNA for IL-1 $\beta$, IL-6, and IL-8 from cells in the BALF and lung tissue was increased (Figure 4). Total protein in BALF was $26 \pm 1 \mathrm{mg} / \mathrm{kg}$ for the control lambs, $58 \pm 5$ for the lambs that received the intravenous endotoxin, $72 \pm 17$ for the $10 \mathrm{mg} / \mathrm{kg}$ endotoxin group, and $88 \pm$ $20 \mathrm{mg} / \mathrm{kg}$ for the endotoxin plus high VT group (all values greater than control, $\mathrm{p}<0.05$ ). Therefore, a dose of $5 \mu \mathrm{g} / \mathrm{kg}$ of intravascular endotoxin caused the same inflammatory response in the lungs as did $10 \mathrm{mg}$ endotoxin given by endotra-

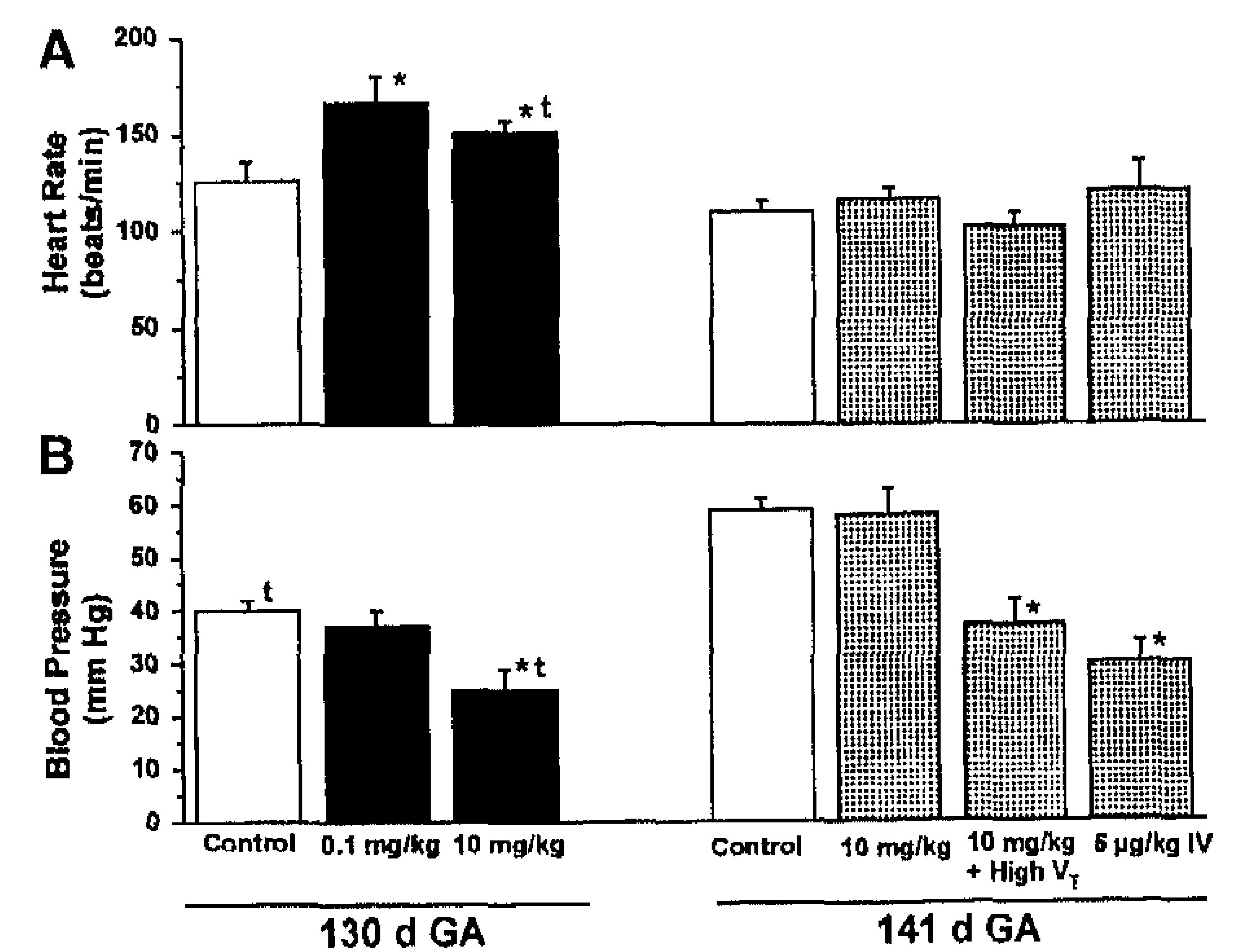

Figure 2. Heart rates $(A)$ and mean blood pressures $(B)$ after $6 \mathrm{~h}$ of ventilation. The control lambs at $130 \mathrm{~d} G A$ had lower mean blood pressures than the control lambs at $141 \mathrm{~d}$ GA. Endotoxin doses are indicated on the horizontal axis. Endotoxin increased heart rate and decreased blood pressure in the 130-d GA lambs. Endotoxin decreased blood pressure in the 141-d GA lambs when given by intravascular injection or when accompanied by high tidal volume $(\mathrm{Vr})$ ventilation for the first 30 min of life. ${ }^{*} p<0.05$ versus control at each GA; ${ }^{t} p<0.05$ verses corresponding group at $141 \mathrm{~d} G \mathrm{~A}$. cheal injection, and the high VT ventilation for $30 \mathrm{~min}$ did not alter the inflammatory response in the lungs.

The three endotoxin-exposed groups had decreased neutrophils in blood, with lower values for the animals given the high $\mathrm{VT}_{\mathrm{T}}$ for the first 30 min after birth and for the animals exposed to intravascular endotoxin (Figure 5). Endotoxin was not detected in the plasma of these 141-d GA lambs. Only the groups ventilated with the high $V \mathrm{~T}$ or given intravascular endotoxin had increases in mRNA for IL-1 $\beta$, IL-6, or IL-8 in the spleen and had elevated cytokine levels in plasma at $6 \mathrm{~h}$ (Figure 6). The plasma levels of IL-6 and interferon- $\gamma$ were increased in these two groups of lambs by $4 \mathrm{~h}$, and no increases were detected in control or the $10 \mathrm{mg}$ endotoxin groups (Figure 7). Therefore, $10 \mathrm{mg} / \mathrm{kg}$ of endotracheal endotoxin induced lung inflammation but minimal systemic effects in ventilated near-term lambs.

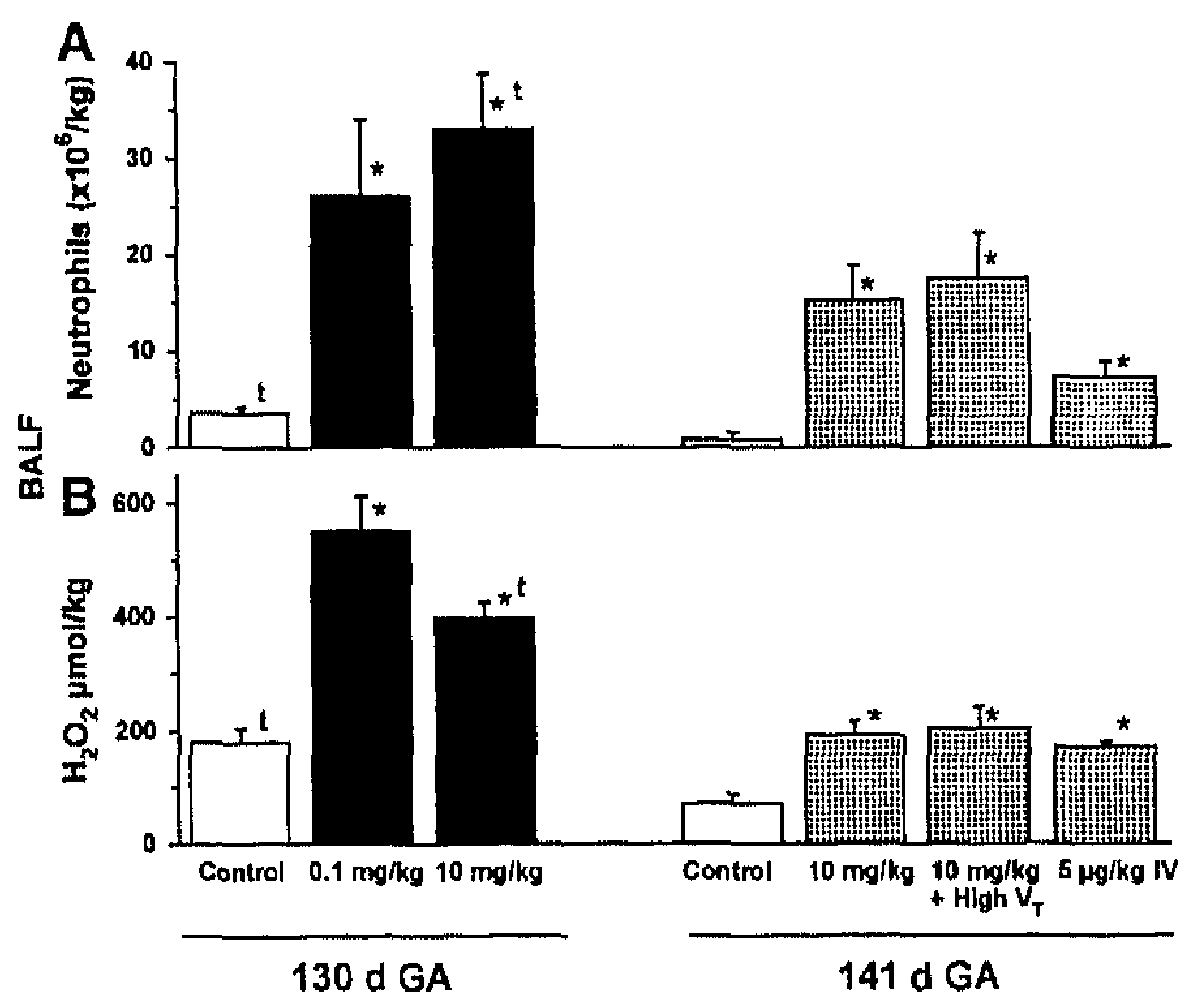

Figure 3. Neutrophils and production of hydrogen peroxide by cells in BALF. (A) Number of neutrophils in BALF/kg body weight. The number of neutrophils increased after endotoxin administration and high tidal volume $\left(V_{T}\right)$ ventilation did not further increase the neutrophils in 141-d gestation lambs. Neutrophils were higher in lambs at $130 \mathrm{~d}$ GA than in lambs at $141 \mathrm{~d}$ GA given $10 \mathrm{mg} / \mathrm{kg}$ endotoxin. (B) Hydrogen peroxide production by cells in BALF increased after intratracheal endotoxin in 130-d and 141-d GA lambs. Cells from lambs at $130 \mathrm{~d}$ GA produced more hydrogen peroxide than cells from lambs at $141 \mathrm{~d} \mathrm{GA.}{ }^{*} \mathrm{p}<0.05$ versus control; ${ }^{t} p<0.05$ versus corresponding group at $141 \mathrm{~d} G A$. 


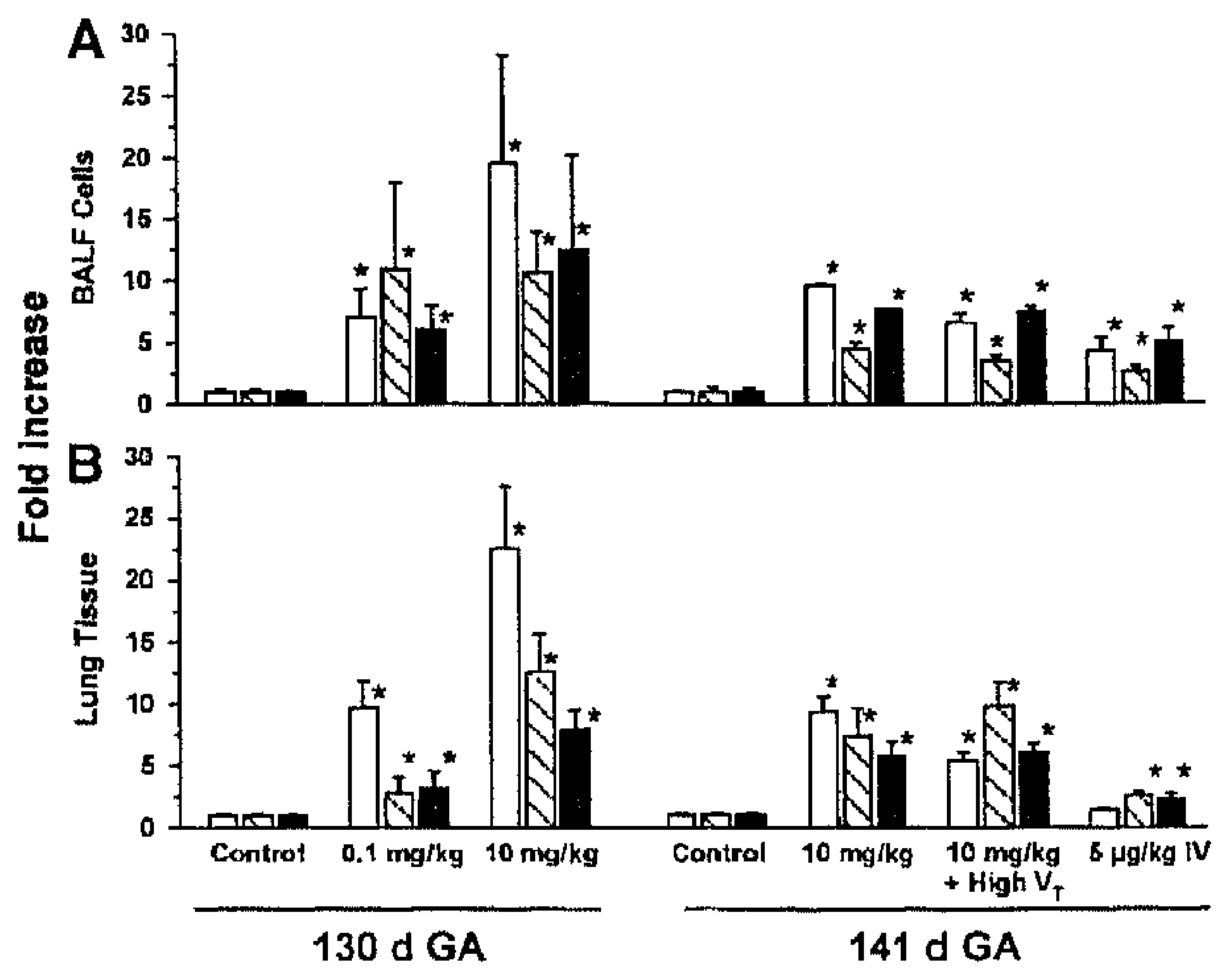

Figure 4. Proinflammatory cytokine mRNA in cells from BALF and in lung tissue. $(A)$ Cytokine mRNA in cells from BALF. Results are shown as fold increase relative to value of 1 for control groups. IL-1 $\beta, \mathrm{IL}-6$, and IL-8 mRNA were higher after intratracheal endotoxin in all groups. High tidal volume $\left(V_{T}\right)$ ventilation did not further increase the amount of mRNA in lambs at $141 \mathrm{~d}$ GA. (B) Cytokine mRNA in lung tissue. The mRNA for $\mathrm{IL}-7 \beta, \mathrm{IL}-6$, and $\mathrm{IL}-8$ were increased for endotoxin-exposed groups relative to their controls. ${ }^{*} p<0.05$ versus control. $\square$ IL-1 $\beta ; \mathbb{Q}$ IL-6; $\mathbf{D}$ IL-8.

\section{Comparison of Control and $10 \mathrm{mg}$ Endotoxin Groups at $130 \mathrm{~d}$ and $141 \mathrm{~d} \mathrm{GA}$}

In comparison with the control 141-d GA lambs, the control 130-d GA lambs required higher ventilatory pressures to achieve equivalent $\mathrm{VT}$, had higher $\mathrm{PcO}_{2}$ values, and had lower lung gas volumes (Table 1). Therefore, the 130-d GA lungs were more immature functionally despite surfactant treatment. The $10 \mathrm{mg} / \mathrm{kg}$ dose of endotoxin increased neutrophils, increased hydrogen peroxide, and tended to increase cytokine mRNA in BALF cells and lung tissue in the 130-d GA lambs more than in the 141-d GA lambs (Figures 3 and 4). At the equivalent high dose of $10 \mathrm{mg} / \mathrm{kg}$, the preterm lungs demonstrated more acute inflammation than did the near-term lungs. The 130-d GA lambs given $10 \mathrm{mg} / \mathrm{kg}$ intratracheal endotoxin had decreased mean blood pressures, a larger decrease in peripheral neutrophils, and endotoxin detected in the plasma, and these effects did not occur in the 141-d lambs (Figures 1 and 5). There were no increases in cytokine mRNA or in plasma cytokines in the $10 \mathrm{mg} / \mathrm{kg}$ endotoxin group at $141 \mathrm{~d}$ $\mathrm{GA}$, whereas large increases were measured for the corresponding group at $130 \mathrm{~d}$ GA (Figure 6). These systemic effects of the endotracheal endotoxin were similar for doses of 0.1 $\mathrm{mg} / \mathrm{kg}$ at $130 \mathrm{~d}$ GA. The pattern of responses indicates larger lung and systemic inflammatory responses of the ventilated preterm than the near-term lambs.

\section{DISCUSSION}

Preterm and term infants are susceptible to sepsis/pneumonia and infection acquired before birth (23). The majority of infants born before $30 \mathrm{wk}$ GA have been exposed to chorioamnionitis and aspiration of infected amniotic fluid or amniotic fluid containing proinflammatory mediators is common (4). Airway samples from these infants contain increased numbers of neutrophils and proinflammatory mediators (24). To simulate the clinical situation we used intratracheal endotoxin as a proinflammatory stimulus and assessed the effect of the initiation of ventilation at birth on the lung and systemic inflammation.

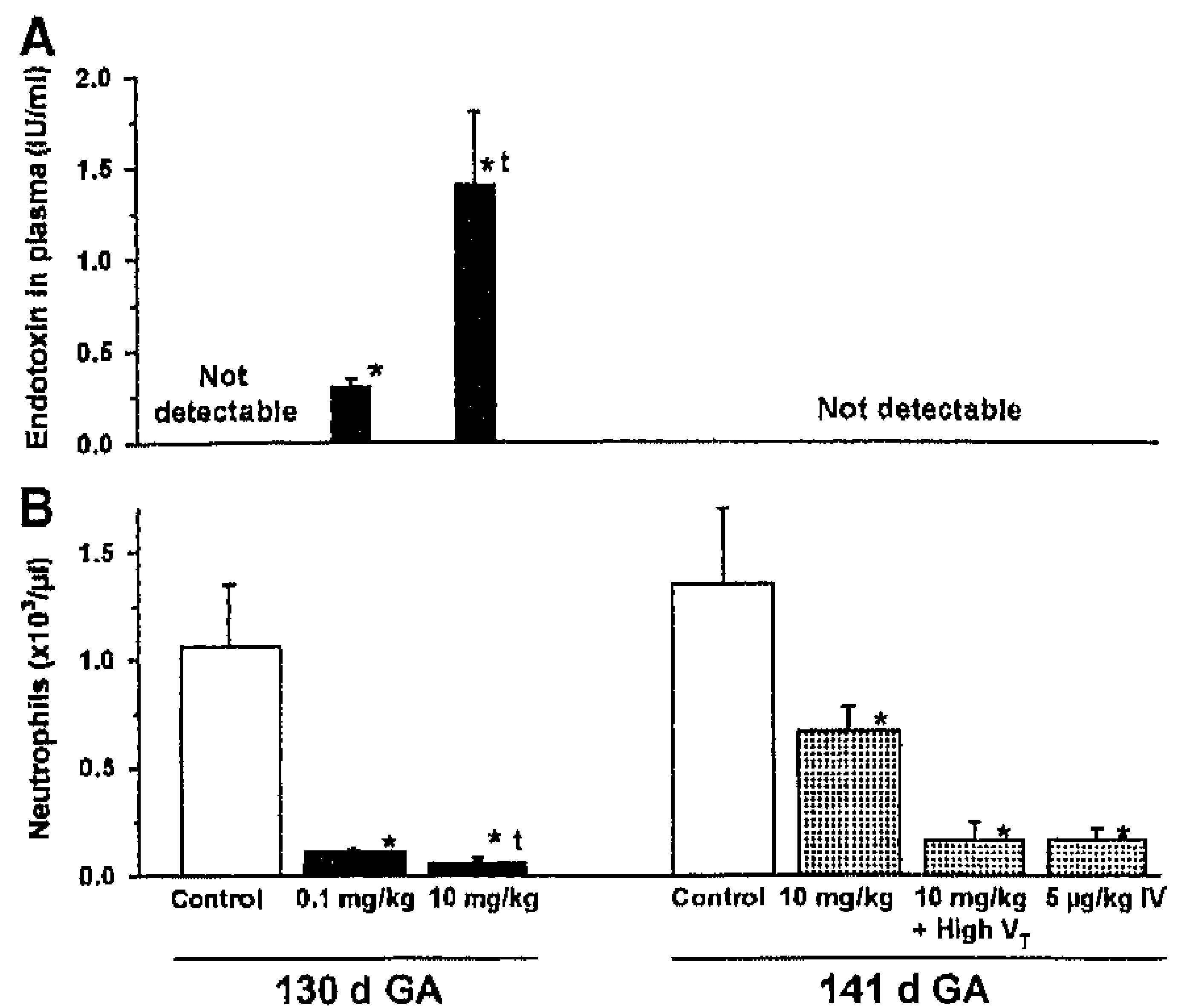

Figure 5. Endotoxin in plasma and blood neutrophils. (A) Quantification of endotoxin in plasma. Endotoxin was detectable in plasma from lambs at $130 \mathrm{~d}$ but not in lambs at $141 \mathrm{~d}$ GA. (B) Neutrophils in peripheral blood at $6 \mathrm{~h}$. The number of neutrophils decreased in all endotoxin-exposed groups. ${ }^{*} p<0.05$ versus control; ${ }^{t} p<0.05$ versus corresponding group at $141 \mathrm{~d}$ GA.

We demonstrated that the near-term lamb lung at $141 \mathrm{~d}$ GA can contain a very large dose of $10 \mathrm{mg} / \mathrm{kg}$ endotoxin for the $6-\mathrm{h}$ study period without a significant systemic response. We found that the low dose of $5 \mu \mathrm{g} / \mathrm{kg}$ endotoxin given by intravascular injection caused lung inflammation similar to the $10 \mathrm{mg} / \mathrm{kg}$ endotracheal dose of endotoxin. The systemic response was similar for the low intravascular dose or the high endotracheal dose of endotoxin in the lambs ventilated with a high $V_{T}$ for the first $30 \mathrm{~min}$ of life. The newborn lung at $141 \mathrm{~d}$ lost the ability to localize the inflammatory response if the lungs were stretched with the high $V_{T}$ for $30 \mathrm{~min}$. High tidal volumes are frequently used inadvertently with resuscitation and the initiation of mechanical ventilation in infants $(11,25)$. High tidal volumes injure adult animal lungs and have resulted in systemic responses to intratracheal infection or inflammatory mediators $(3,26,27)$. In a recent report, ventilation of adult rats with a VT of $42 \mathrm{ml} / \mathrm{kg}$ did not increase systemic cytokines unless the lungs were pretreated with intratracheal endotoxin (28). The high VT ventilation did not increase the endotoxin-induced inflammation in the lamb lung at $141 \mathrm{~d} \mathrm{GA}$ when compared with the normal $V_{T}$ ventilation and intratracheal endotoxin group. However, the high VT group had increased proinflammatory mRNAs in spleen and cytokines in the plasma. We did not allow the $\mathrm{PCO}_{2}$ to decrease in the high VT group because of the new information about the effects of $\mathrm{CO}_{2}$ on lung injury (29). The near-term ventilated newborn lung can protect the systemic circulation from endotoxin unless that lung is stretched with a high VT.

In contrast, ventilation with $\mathrm{V}_{\mathrm{T}}$ monitoring and avoidance of hyperventilation by targeting the $\mathrm{PCO}_{2}$ to $50 \mathrm{~mm} \mathrm{Hg}$ for the surfactant-treated 130 -d GA preterm lung resulted in a similar systemic inflammatory response to endotracheal endotoxin doses of 10 and $0.1 \mathrm{mg} / \mathrm{kg}$. We mixed the endotoxin with the surfactant to avoid giving endotoxin to regions of the lung that did not receive surfactant and might be more easily injured with mechanical ventilation (30). Endotoxin was detected in the plasma of the preterm lambs given either dose of endotracheal endotoxin. The lung at $130 \mathrm{~d}$ GA did not prevent loss of endotoxin to the circulation at a dose 100 times less than the lung at $141 \mathrm{~d} \mathrm{GA}$. The clinically relevant point is that ventilation of the infected or endotoxin/inflammatory mediator-exposed preterm lung may cause 


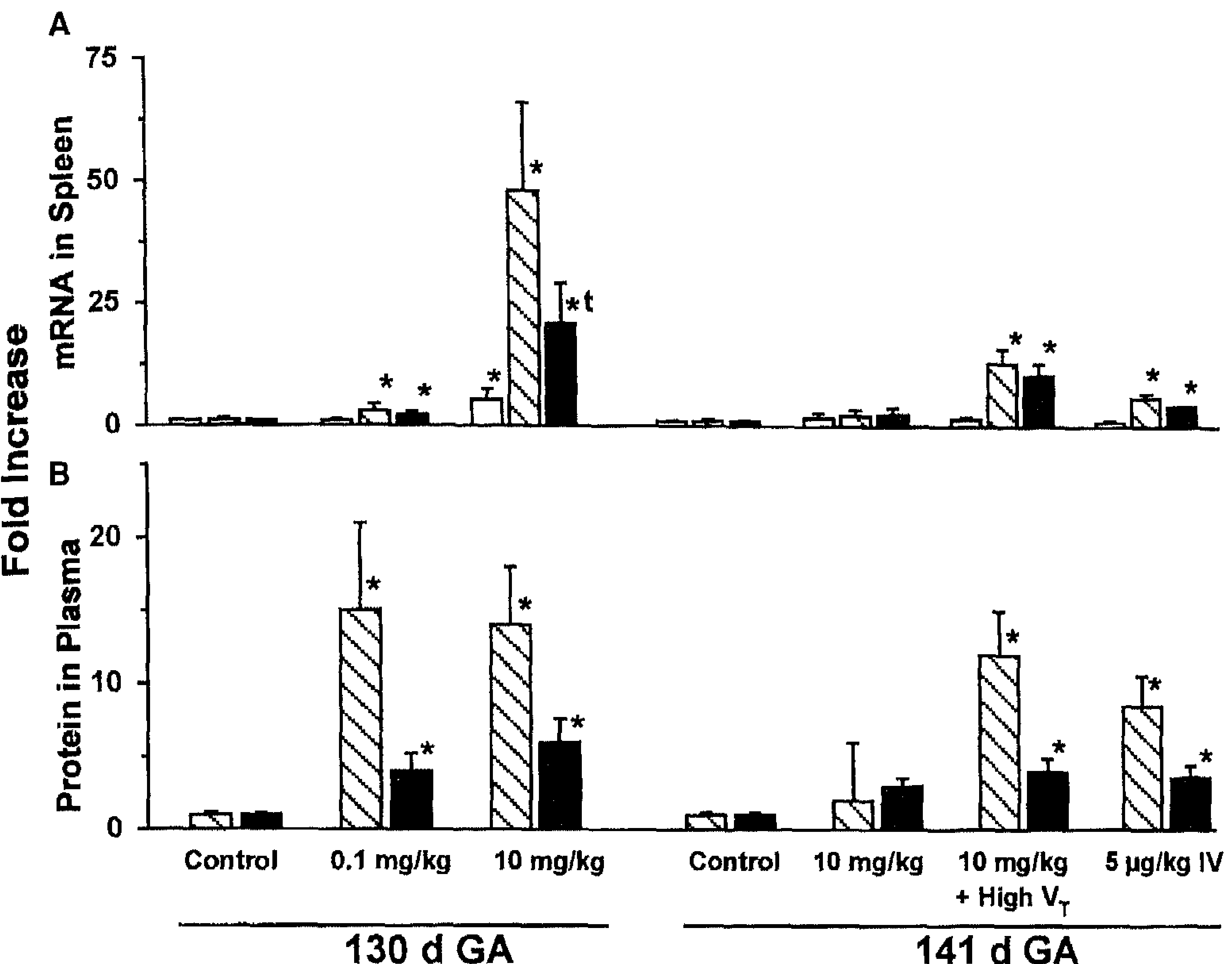

Figure 6. Proinflammatory cytokine mRNAs in spleen and cytokine concentrations in plasma. (A) Proinflammatory cytokine mRNAs in spleen were increased in 130-d lambs after either dose of endotoxin. IL-1 $\beta$, IL-6, and IL-8 mRNA were increased in the spleens of $141-d$ lambs after high tidal volume $(V T)$ ventilation plus intratracheal endotoxin or intravascular endotoxin. (B) IL-6 and IL-8 concentrations in plasma were increased in lambs at $130 \mathrm{~d}$ GA after either endotoxin dose and in 141-d lambs after high $\mathrm{V}_{T}$ ventilation plus intratracheal endotoxin and after intravascular endotoxin. ${ }^{*} p<0.05$ versus control; $p<0.05$ versus corresponding group at $141 \mathrm{~d}$ GA. $\square \mathrm{IL}-1 \beta ; \mathbb{Q}$ IL-6; IL-8.

130 d GA

showering of the systemic circulation with inflammatory mediators and result in a systemic inflammatory response. This finding helps explain the common occurrence of a sepsis syndrome with pneumonia or chorioamnionitis in sick preterm newborns (23). A caveat to our result is that the endotoxin was given with surfactant to the preterm lambs and the endotoxin was mixed with fetal lung fluid for the term lambs that were not surfactant treated. Either technique should result in a good distribution of the endotoxin (31).

The lung is susceptible to injury during the initiation of ventilation $(11,16)$. The airspaces are fluid filled and the newborn must clear fluid, establish a surfactant film at the rapidly expanding surface area of the air-fluid interface, and establish the appropriate functional residual capacity. We used mechanical ventilation for this transition but limited peak inspiratory pressures to less than $35 \mathrm{~cm} \mathrm{H}_{2} \mathrm{O}$ and $\mathrm{VT}_{\mathrm{T}}$ to about $10 \mathrm{ml} / \mathrm{kg}$, using a strategy that we found caused minimal lung injury with the initiation of ventilation in surfactant-treated preterm lambs $(15,16)$. Despite the adaptations required for transition from the fetal state to air breathing, the only systemic effect of exposure of the lamb lung at $141 \mathrm{~d}$ to the very high dose of $10 \mathrm{mg} / \mathrm{kg}$ endotoxin was lung inflammation that did not alter lung function and a decrease in blood neutrophils. This decrease in neutrophils probably resulted from neutrophil recruitment to the lungs $(32,33)$.

The lamb lung begins to alveolarize after about $110 \mathrm{~d} G A$ and lung volumes increase approximately linearly to term $(6,34)$. The preterm sheep lung at $130 \mathrm{~d}$ GA also is very surfactant deficient, and ventilation of the surfactant-deficient preterm lung causes nonuniform inflammation characterized by overinflation adjacent to regions of atelectasis (10). We treated the lambs with surfactant to minimize regional overdistention and to permit ventilation with lower pressures. Such a strategy decreases the bidirectional movement of protein between the alveolar and vascular spaces and decreases the protein content of lung lymph $(7,14,35)$. Nevertheless, total protein was higher in BALF of the preterm than the near-term lambs demonstrating more vascular to alveolar leak of protein. The surfactant treatment did not prevent the systemic effects of the low dose of endotracheal endotoxin probably because the surfactant treatment did not prevent some regional overdistention of the preterm lungs with an incompletely developed collagen and elastin matrix. The functional residual capacity was not measured in this experiment. However, a $10 \mathrm{ml} / \mathrm{kg} \mathrm{VT}$

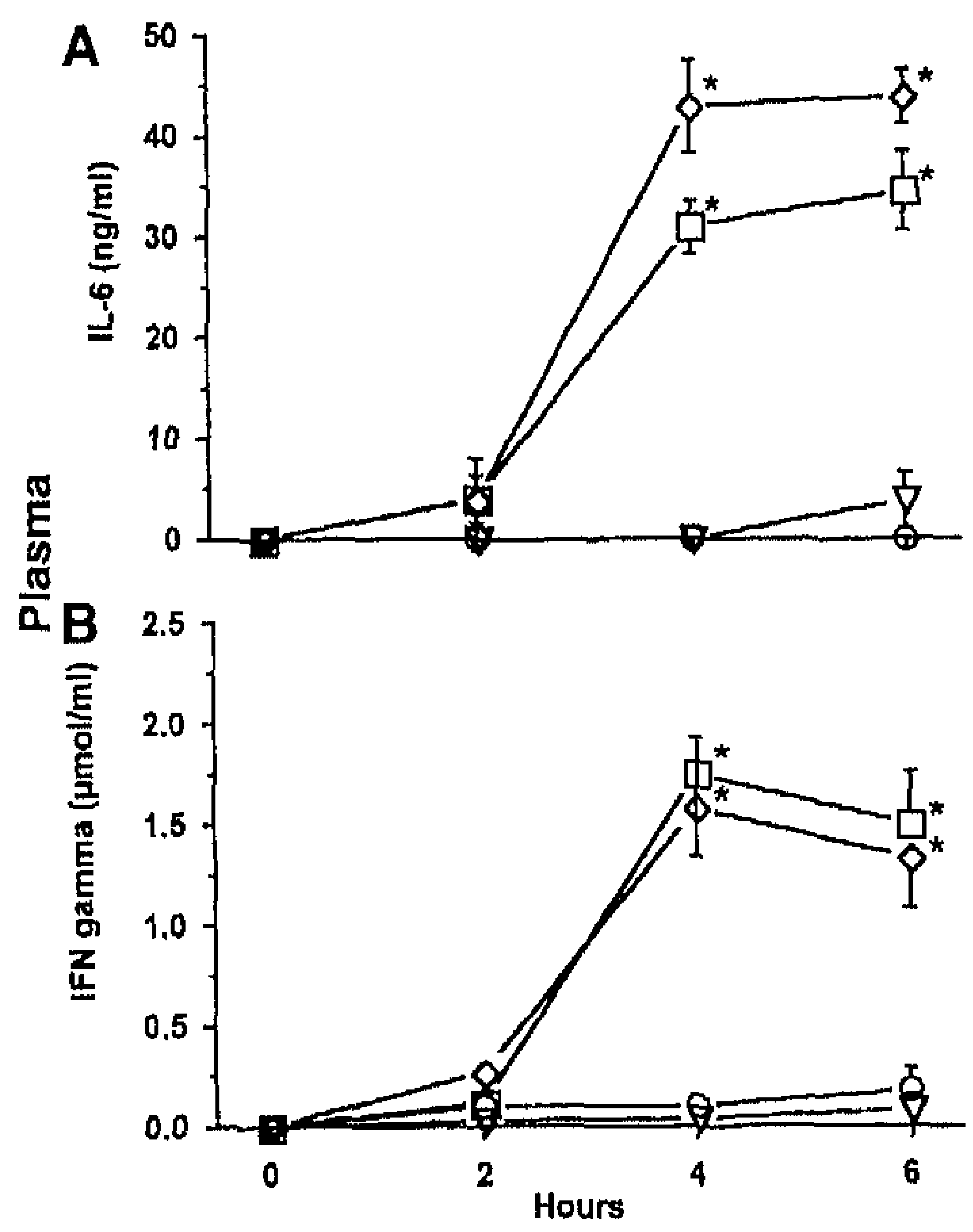

Figure 7. IL-6 and interferon- $\gamma$ in plasma of 141-d GA lambs. (A) IL-6 concentration increased at $4 \mathrm{~h}$ and remained high at $6 \mathrm{~h}$ after intratracheal endotoxin plus high tidal volume $\left(V_{T}\right)$ ventilation and after intravenous endotoxin. $(B)$ interferon- $\gamma$ increased in the same groups at 4 and $6 \mathrm{~h} .{ }^{*} \mathrm{p}<0.05$ versus values in cord blood at 0 time. O Control; $\nabla 10 \mathrm{mg} / \mathrm{kg} \mathrm{IT} ; \diamond 10 \mathrm{mg} / \mathrm{kg} \mathrm{IT}+$ High VT; $\square 5 \mu \mathrm{g} / \mathrm{kg} \mathrm{IV}$. 
applied to lung with an average total gas volume of $38 \mathrm{ml} / \mathrm{kg}$ is more likely to cause injury than the same $V_{T}$ applied to the 141-d GA lungs with a total gas volume of $67 \mathrm{ml} / \mathrm{kg}$ that have uniformly distributed endogenous surfactant.

The design of this study also allows us to compare pulmonary function and lung inflammation responses of the 130-d GA and 141-d GA lambs to $10 \mathrm{mg} / \mathrm{kg}$ endotoxin given intratracheally. The $10 \mathrm{mg} / \mathrm{kg}$ dose of intratracheal endotoxin did not alter lung mechanics in the 130-d GA lungs but gas exchange deteriorated. Although we did not measure cardiac output, heart rate increased and blood pressure fell, indicating that the likely explanation for the poor gas exchange was the sepsis syndrome. The 141-d GA lambs exposed to $10 \mathrm{mg} / \mathrm{kg}$ endotracheal endotoxin maintained lung mechanics and gas exchange. This result is consistent with the lack of a sepsis syndrome and the modest inflammation in the lungs by $6 \mathrm{~h}$ of age. We have no explanation for the increased lung volumes after the endotoxin in the 141-d GA lambs other than the possibility that the animals randomized to that group were somewhat more mature. The lungs at $130 \mathrm{~d}$ had a larger inflammatory response than did the lungs at $141 \mathrm{~d}$ GA. The preterms recruited more neutrophils to the lungs, the cells in the BALFs produced more $\mathrm{H}_{2} \mathrm{O}_{2}$, and more cytokine mRNA was expressed in alveolar cells and lung tissue. We had anticipated less inflammation in the preterm because of the immaturity of the immune system (36). A possible explanation is that the preterm is very deficient in the host defense proteins SP-A and SP-D (37). These proteins bind endotoxin and are known to modulate inflammatory responses in the lung (38). The surfactant that we used to treat the preterm lamb did not contain SP-A or SP-D.

The systemic inflammatory response in the lambs at $141 \mathrm{~d}$ GA initially ventilated with a high $V_{T}$ was similar to that resulting from the low dose of $5 \mu \mathrm{g} / \mathrm{kg}$ endotoxin given intravenously. However, the intravenous endotoxin resulted in a lung injury response similar to that measured with high VT ventilation plus intratracheal endotoxin. This result in lambs at $141 \mathrm{~d}$ $\mathrm{GA}$ is similar to the observation of Wiener-Kronisch and coworkers that the adult sheep lung is more sensitive to the endothelial damage from systemic endotoxin than from intratracheal endotoxin (39). This finding suggests how systemic inflammation and lung injury can occur in preterm newborns exposed to proinflammatory mediators in utero. Initiation of mechanical ventilation may transmit proinflammatory mediators from the lungs into the systemic circulation, initiating a systemic inflammation that injures the lung endothelium. The lung can be both the source and the target of the systemic inflammation (40). This study demonstrates that the surfactanttreated preterm lung that is not intentionally stretched or hyperventilated can transmit proinflammatory mediators from the lung to the systemic circulation.

Acknowledgment: The authors thank Dr. C. J. Bachurski and Dr. S. G. Kallapur for helpful suggestions.

\section{References}

1. Martin TR. Recognition of bacterial endotoxin in the lungs. Am $J$ Respir Cell Mol Biol 2000;23:128-132.

2. Chiumello D, Pristine G, Slutsky AS. Mechanical ventilation affects local and systemic cytokines in an animal model of acutc respiratory distress syndrome. Am J Respir Crit Care Med 1999;160:109-116.

3. Murphy DG, Cregg N, Tremblay L, Engelberts D, Laffey JG, Slutsky AS, Romanschin A, Kavanagh BP. Adverse ventilatory strategy causes pulmonary-to-systemic translocation of endotoxin. Am I Respir Crit Care Med 2000;162:27-33.

4. Goidenberg RL, Hauth JC, Andrews WW. Intrauterine infection and preterm delivery. $N$ Engl J Med 2000;342:1500-1507.

5. Jackson JC, Chi EY, Wilson CB, Truog WE, Teh EC, Hodson WA. Sequence of inflammatory cell migration into lung during recovery from hyaline membrane disease in premature newborn monkeys. Am Rev Respir Dis 1987;135:937-940.

6. Pringle KC. Human fetal lung development and related animal models. Clin Obstet Gynecol 1986;29:502-513.

7. Carlton DP, Cho SC, Davis P, Lont M, Bland RD. Surfactant treatment at birth reduces lung vascular injury and edema in preterm lambs. $P e$ diatr Res 1995;37:265-270.

8. Jobe A, Jacobs H, Ikegami M, Berry D. Lung protein leaks in ventilated lambs: effects of gestational age. J Appl Physiol 1985;58:1246-1251.

9. Egan EA, Olver RE, Strang LB. Changes in non-electrolyte permeability of alveoli and the absorption of lung liquid at the start of breathing in the lamb. $J$ Physiol 1975;244:161-179.

10. Pinkerton KE, Ikegami M, Dillard LM, Jobe AH. Surfactant treatment effects on lung structure and type II cclls of preterm ventilated lambs. Biol Neonate 2000;77:243-252.

11. Jobe AH, Ikegami M. Mechanisms initiating lung injury in the preterm. Early Hum Dev 1998;53:81-94.

12. Marshall-Clarke S, Reen D, Tasker L, Hassan J. Neonatal immunity: how well has it grown up? Immunol Today 2000;21:35-41.

13. Speer CP, Groneck P. Oxygen radicals, cytokines, adhesion molecules and lung injury in neonates. Semin Neonatol 1998;3:219-228.

14. Wada $\mathrm{K}$, Jobe AH, lkegami M. Tidal volume effects on surfactant treatment responses with the initiation of ventilation in preterm lambs. $J$ Appl Physiol 1997;83:1054-1061.

15. Michna J, Jobe AH, Ikegami M. Positive end-expiratory pressure preserves surfactant function in preterm lambs. Am J Respir Crit Care Med 1999;160:634-639.

16. Naik AS, Kallapur SG, Bachurski CJ, Jobe AH, Michna J, Kramer BW, Ikcgami M. Effects of ventilation with different positive end-expiratory pressures on cytokine expression in the preterm lamb lung. Am J Respir Crit Care Med 2001;164:494-498.

17. Jobe AH, Newnham JP, Willet KE, Moss TJ, Ervin MG, Padbury JF, Sly $\mathrm{PD}$, Ikcgami M. Endotoxin induced lung maturation in preterm lambs is not mediated by cortisol. Am J Respir Crit Care Med 2000;162:1656-1661.

18. Kramer BW, Moss T, Willet K, Newnham J, Sly P, Kallapur SG, Ikegami $\mathrm{M}$, Jobe A. Dose and time response after intra-amniotic endotoxin in preterm lambs. Am J Respir Crit Care Med 2001;164:982-988.

19. Davis AJ, Jobe AH, Häfner D, Ikcgami M. Lung function in premature lambs and rabbits treated with a recombinant SP-C surfactant. $A m J$ Respir Crit Care Med 1998;157:553-559.

20. Notter RH, Egan EA, Kwong MS, Holm BA, Shapiro DL. Lung surfactant replacement in premature lambs with extracted lipids from bovine lung lavage: effects of dose, dispersion technique, and gestational agc. Pediatr Res 1985;19:569-577.

21. Lowry OH, Rosebrough NJ, Farr AL, Randall RJ. Protein measurement with the Folin phenol reagent. J Biol Chem 1951;193:265-275.

22. Kallapur SG, Willet KE, Jobe AH, Ikegami M, Bachurski CJ. Intraamniotic endotoxin: chorioamnionitis precedes lung maturation in preterm lambs. Am J Physiol 2001;280:L527-L536.

23. Stoll BJ, Holman RC, Schuchat A. Decline in sepsis-associated neonatal and infant death in the United States, 1979 through 1994. Pediatrics 1998;102:c18.

24. Watterberg KL, Demers LM, Scott SM, Murphy S. Chorioamnionitis and early lung inflammation in infants in whom bronchopulmonary dysplasia develops. Pediatrics 1996;97:210-215.

25. Garland JS, Buck RK, Allred EN, Leviton A. Hypocarbia before surfactant therapy appears to increase bronchopulmonary dysplasia risk in infants with respiratory distress syndrome. Arch Pediatr Adolesc Med $1995 ; 149: 617-622$.

26. Tremblay LN, Slutsky AS, Dreyfuss D, Saumon G. Ventilator-induced lung injury: mechanisms and clinical correlates. In: Marini JJ, Slutsky AS, editors. Physiological basis of ventilatory support. New York: Marcel Dekker; 1998. p. 395-451.

27. Tremblay L, Valenza F, Ribeiro SP, Li J, Slutsky AS. Injurious ventilatory strategies increase cytokines and c-fos m-RNA cxpression in an isolated rat lung mode. $J$ Clin Invest 1997;99:944-952.

28. Ricard J-D, Dreyfuss D, Saumon G. Production of proinflammatory cy. tokines in ventilator-induced lung injury: a reappraisal. Am $J$ Respir Crit Care Med 2001;163:1176-1180.

29. Laffey JG, Tanaka M, Engelberts D, Luo X, Yuan S, Tanswell AK, Post $\mathrm{M}$, Lindsay $\mathrm{T}$, Kavangh BP. Therapeutic hypercapnia reduces pulmonary and systemic injury following in vivo lung reperfusion. Am J Respir Crit Care Med 2000;162:2287-2294.

30. Pinkerton KE, Lewis JF, Rider ED, Peake J, Chen W, Madl AK, Luu $\mathrm{RH}$, Ikegami M, Jobe AH. Lung parenchyma and type II cell morphometrics: cffect of surfactant treatment on pretcrm ventilated lamb lungs. J Appl Physiol 1994;77:1953-1960. 
31. Jobe A. Techniques for adminstering surfactant. In: Robertson B, editor. Surfactant therapy for lung discase. New York: Marcel Dekker, Inc.; 1995. p. 309-324.

32. Carlton DP, Albertine $\mathrm{KH}$, Cho SC, Lont M, Bland RD. Role of neutrophils in lung vascular injury and edema after premature birth in lambs. J Appl Physiol 1997;83:1307-1317.

33. Ferreira PJ, Bunch TJ, Albertine KH, Carlton DP. Circulating neutrophil concentration and respiratory distress in premature infants. $J \mathrm{Pe}$ diatr 2000;136:466-472.

34. Docimo SG, Crone RK, Davies P, Reid L, Retik AB, Mandell J. Pulmonary development in the fetal lamb: morphometric study of the alveolar phase. Anat Rec 1991;229:495-498.

35. Jobe A, Ikegami M, Jacobs H, Jones J, Conaway D. Permeability of premature lamb lungs to protein and the effect of surfactant on that permeability. J Appl Physiol 1983;55:169-176.
36. Speer CP, Johnston RB. Neutrophil function in newborn infants. In: Polin RA, Fox WW, editors. Fetal and neonatal physiology. Philadelphia: W.B. Saunders; 1998. p. 1954-1960.

37. Awasthi S, Coalson JJ, Crouch E, Yang F, King RJ. Surfactant proteins $A$ and $D$ in premature baboons with chronic lung injury. Evidence for an inhibition of secretion. Am J Respir Crit Care Med 1999;160: 942-949.

38. Wright JR. Immunomodulatory functions of surfactant. Physiol Rev 1997;77:931-962.

39. Wiener-Kronish JP, Albertine KH, Matthay MA. Differential responses of the endothelial and epithelial barriers of the lung in sheep to Escherichia coli endotoxin. J Clin Invest 1991;88:864-875.

40. Slutsky AS, Tremblay LN. Multiple system organ failure. Is mechanical ventilation a contributing factor? Am J Respir Crit Care Med 1998; $157: 1721-1725$. 


\section{CHAPTER 9}

Monocyte function in preterm, near term and adult sheep

Kramer, B.W., Jobe, A.H., Ikegami, M. 
0031-3998/03/5401-0052

PEDIATRIC RESEARCH

Copyright $\mathbb{C} 2003$ International Pediatric Research Foundation, Inc.

Vol. 54, No. 1, 2003

Printed in U.S.A.

\title{
Monocyte Function in Preterm, Term, and Adult Sheep
}

\author{
BORIS W. KRAMER, ALAN H. JOBE, AND MACHIKO IKEGAMI \\ Cincinnati Children's Hospital Medical Center, Division of Pulmonary Biology, Cincinnati, Ohio \\ 45229-3039, U.S.A.
}

ABSTRACT

\begin{abstract}
The preterm infant has functionally immature monocytes. The effects of common clinical interventions and exposures that might modulate inflammation were evaluated using monocytes isolated from blood of preterm lambs $[130 \mathrm{~d}$ gestational age (GA)], near-term lambs (141 d GA), and adult sheep. Endotoxin stimulated hydrogen peroxide production by adult monocyles, but monocytes from 130-d and 141-d GA lambs had a reduced and delayed hydrogen peroxide production. Endotoxin did not decrease apoptosis of monocytes from 130-d and 141-d GA lambs but decreased apoptosis of adult monocytes. Dexamethasone increased the phagocytosis of bacteria and apoptotic cells by adult monocytes by $35 \%$ but not by monocytes from 130 -d and 141-d GA lambs. Synthetic and natural surfactants and dipalmitoylphosphatidylcholine increased phagocytosis of apoptotic cells by monocytes from preterm, term, and adult sheep.
\end{abstract}

Multiple immune defects have been described for monocytes from preterm and term newborn infants and animals (1-3). Monocytes from newborns have a reduced oxidative burst after phagocytosis of bacteria, and the second messenger responses to exogenous stimuli are different from the responses measured in adult cells $(3,4)$. Few monocytes have differentiated to macrophages in the preterm fetus, resulting in altered acute responses to inflammation and depressed immune responses (5). The normal fetus is in an environment that is normally protected from inflammation and the need to mount immune responses. Immature monocyte function may alter injury responses of fetal and newborn organs when the fetus or preterm newborn is challenged to mount an inflammatory response (5). As an example, the lung is where the preterm fetus often first encounters inflammation. Chronic indolent chorioamnionitis is frequently associated with preterm labor and increased cytokine and inflammatory cells in the lungs at birth (6-8). Chorioamnionitis and the subsequent inflammation induced by

Received October 3, 2001; accepted February 18, 2003.

Correspondence: Machiko Ikegami, M.D., Ph.D., Professor of Pediatrics, Cincinnati Children's Hospital Medical Center, Division of Pulmonary Biology, 3333 Burnet Avenue, Cincinnati, OH 45229-3039; e-mail: machiko.ikegami@cchmc.org

Supported by National Institutes of Health Grant HD 12714.

DOI: 10.1203/01.PDR.0000066621.11877.33
Monocytes from preterm and term lambs differ from adult monocytes in tests of both the initiation and the resolution of inflammation. The reduced phagocytosis of apoptotic cells by monocytes from the preterm may contribute to prolonged inflammation in diseases such as bronchopulmonary dysplasia. (Pediatr Res 54: 52-57, 2003)
Abbreviations:
BPD, bronchopulmonary dysplasia
RDS, respiratory distress syndrome
SP, surfactant protein
$\mathbf{G A}$, gestational age
FITC, fluorescin isothiocyanate
DPPC, dipalmitoylphosphatidylcholine
DMEM, Dulbecco's modified Eagle medium

mechanical ventilation, oxygen, and nosocomial infection promote a persistent inflammatory response that often leads to the chronic lung disease called bronchopulmonary dysplasia (BPD) $(9,10)$.

Bone marrow-derived monocytes enter the fetal lung from the circulation in the last trimester of the pregnancy and are probably the major population of innate immune cells in the fetal lung because the majority of monocytes do not differentiate into macrophages until after term birth (11-14). Although the total number of monocyte-derived cells in the fetal lungs are not known, very few monocytes or macrophages can be recovered by alveolar lavage. Therefore, as a model system for in vitro testing, we used blood monocytes from preterm, near-term, and adult sheep to characterize monocyte responses to clinically relevant stimuli that occur in preterm infants who develop BPD. Because nosocomial infection is a risk factor for BPD (15), monocyte responses to endotoxin and phagocytosis of bacteria were evaluated. Phagocytosis of apoptotic cells was tested as a functional assay for the resolution of inflammation, because apoptotic cells that are not phagocytosed become necrotic and proinflammatory $(16,17)$. Dexamethasone and surfactant have anti-inflammatory properties that might modulate monocyte function $(18,19)$. Therefore, we evaluated the 
effects of dexamethasone and surfactant on phagocytosis of apoptotic cells.

\section{METHODS}

Cell isolation from alveolar lavage fluid. The protocols were approved by the animal use committee of the Cincinnati Children's Hospital Research Foundation. Cells were isolated from fetuses or newborn lambs from the mating of Suffolk sheep with Dorset rams. The preterm $[110 \mathrm{~d}$ gestational age (GA), $125 \mathrm{~d} \mathrm{GA}, 130 \mathrm{~d}$ GA] and near-term (141 d GA) lambs were delivered by cesarean section. Term newborn lambs delivered spontaneously at a gestational age of $146 \pm 1 \mathrm{~d}$ and were studied at $3 \mathrm{~d}$ of age. The adult sheep were approximately $2 \mathrm{y}$ of age. Each age group consisted of four animals. For estimating macrophage numbers, left and right lungs were weighed and the left lungs were lavaged five times with $4^{\circ} \mathrm{C}$ saline and all lavages were pooled (20). Alveolar lavage fluid was centrifuged at $500 \times g$ for $10 \mathrm{~min}$, and the pellet was resuspended in PBS. Total cells were stained with trypan blue and counted. Differential cell counts were performed on cytospin preparations after staining with Diff-Quick (Scientific Products, McGaw Park, IN, U.S.A.).

Alveolar monocytes were distinguished from macrophages by measuring autofluorescence with an argon laser emitting at $430 \mathrm{~nm}$ using a FACS caliber flow cytometer (Becton Dickinson, Mountain View, CA, U.S.A.) (21). Autofluorescence measured at $530 \mathrm{~nm}$ was high in macrophages but low in monocytes (21). We used alveolar macrophages and bloodderived monocytes from adult ewes to establish a gate and analyze the alveolar cells from preterm lambs.

Monocyte and thymocyte isolation. Monocytes were the predominant cell population in preterm and term newborn lungs. Because sufficient numbers of cells for study could not be collected from alveolar washes, we isolated monocytes from cord blood or peripheral blood. Cord blood was collected from the umbilical arteries from animals at $130 \mathrm{~d} \mathrm{GA}$ and $141 \mathrm{~d}$ GA after cesarean section. Blood from adult sheep was obtained by phlebotomy. The blood was diluted with PBS and layered onto a Percoll gradient (Amersham Pharmacia Biotech, Piscataway, NJ, U.S.A.) (22). After centrifugation for $40 \mathrm{~min}$ at $400 \times \mathrm{g}$ at $20^{\circ} \mathrm{C}$, the mononuclear cells were recovered, washed twice with PBS at $4^{\circ} \mathrm{C}$, centrifuged for $5 \mathrm{~min}$ at $400 \times g$ at $4^{\circ} \mathrm{C}$, and resuspended in culture media [Dulbecco's modified Eagle medium (DMEM)] supplemented with $10 \%$ heat-inactivated sheep serum (Sigma Chemical Co., St. Louis, MO, U.S.A.). Cells were counted with trypan blue used to evaluate viability and plated in culture dishes. After incubation at $37^{\circ} \mathrm{C}$ for $2 \mathrm{~h}$, nonadherent cells were removed and plates were washed twice with PBS. For estimating the monocyte number, the cells were scraped from the culture dish and differential cell counts were performed after staining with Diff-Quick. The adherent cell population was $91 \pm 2 \%$ monocytes for all age groups. Thymic tissue was dissociated with a metal mesh and filtered through a cell strainer (nylon, $70 \mu \mathrm{m}$; Becton Dickinson Labware, Franklin Lakes, NJ, U.S.A.) (23). Single thymocytes were cultured as described above.
Reagents. Endotoxin from Escherichia coli, serotype O55:B5 (Sigma Chemical Co.), was resuspended in saline and filtered through a $0.45-\mu \mathrm{m}$ filter. A concentration of $100 \mathrm{ng} / \mathrm{mL}$ yielded a robust response in alveolar macrophages. Dexamethasone (Sigma Chemical Co.) was solubilized in ethanol for a stock solution of $1 \mathrm{mmol}$. Dexamethasone was tested in cell culture at concentrations from $10^{-6}$ to $10^{-9}$ mol, which stimulated surfactant protein synthesis in vitro (24). Dipalmitoylphosphatidylcholine (DPPC; Sigma Chemical Co.) was resuspended in saline with glass beads (25). Surfactant (Venticute; Byk Gulden, Konstanz, Germany) contains $2 \%$ recombinant human SP-C in DPPC and palmitoyloleoylphosphatidylglycerol in at a 70:30 (wt/wt) ratio and 5\% palmitic acid (26). This surfactant was very effective when tested in preterm lambs and in lung injury models $(27,28)$. Natural sheep surfactant containing SP-A, SP-B, and SP-C was recovered from alveolar lavages of adult sheep by centrifugation (29). Lipid extracted surfactant containing SP-B and SP-C but not SP-A was made by extraction of natural sheep surfactant with chloroform-methanol (2:1). Extracts were dried by rotary evaporation and resuspended in $0.9 \% \mathrm{NaCl}$ using glass beads (25). All surfactant and DPPC preparations were used at final concentrations of $100 \mu \mathrm{g} / \mathrm{mL}$ phospholipids based on previous studies of surfactant catabolism by alveolar macrophages in vitro (30). All surfactant preparations tested negative for endotoxin contamination with the Limulus amebocyte lysate assay (Sigma Chemical Co.).

Hydrogen peroxide production. Hydrogen peroxide was measured for $1 \times 10^{6}$ monocytes using an assay based on the oxidation of ferrous iron $\left(\mathrm{Fe}^{2+}\right)$ to ferric iron $\left(\mathrm{Fe}^{3+}\right)$ by hydrogen peroxide under acidic conditions (Bioxytech $\mathrm{H}_{2} \mathrm{O}_{2}$ 560 assay, OXIS International, Portland, OR, U.S.A.). Control samples kept under identical incubation conditions were evaluated in all experiments (31).

Apoptotic cells and phagocytosis of apoptotic cells. Monocytes isolated as described were separated into aliquots containing the same cell numbers $\left(2 \times 10^{6} / \mathrm{mL}\right)$ for culture in sixwell plates for $24 \mathrm{~h}$. Endotoxin was added to separate wells to achieve a concentration of $100 \mathrm{ng} / \mathrm{mL} 6 \mathrm{~h}$ and $1 \mathrm{~h}$ before harvest. The control cells were cultured for $24 \mathrm{~h}$ in a separate well of the plate. The cells were scraped from the plates and centrifuged along with the medium at $400 \times g$ for 5 min at $4^{\circ} \mathrm{C}$. The cells were washed twice with PBS and resuspended in PBS, apoptotic cells were stained with fluorescent labeled annexin $\mathrm{V}$, and necrotic cells were counterstained with proprium iodide (32). The apoptotic and necrotic cells were counted by flow cytometry and expressed as a percentage of the total cell population recovered from the plates.

Apoptosis of thymocytes was induced by $10 \mathrm{~min}$ of UV radiation followed by 3-4 h of culture (33). Phagocytosis of apoptotic thymocytes was tested by adding $2 \times 10^{6}$ apoptotic thymocytes to the adherent monocytes that had been cultured for $12 \mathrm{~h}$ (33). Surfactant preparations at final concentrations of $100 \mu \mathrm{g} / \mathrm{mL}$ phospholipids were added $15 \mathrm{~min}$ before apoptotic thymocytes were added to the cell cultures. The monocytes and apoptotic thymocytes were incubated for $6 \mathrm{~h}$ at $37^{\circ} \mathrm{C}$, washed with cold PBS containing $0.5 \mathrm{mM}$ EDTA, and stained with hematoxylin and eosin. Phagocytosis was evaluated by count- 
ing 300 monocytes per well. Results were expressed as percentage of monocytes containing at least one ingested apoptotic cell.

Phagocytosis of E. coli. Monocytes were incubated with FITC-labeled E. coli (Sigma Chemical Co.) in the absence or presence of dexamethasone for $4 \mathrm{~h}$. Monocytes were resuspended, washed three times with PBS, and divided into two equal aliquots. The total bound and ingested bacteria were measured by flow cytometry. Trypan blue $(1.25 \mathrm{mg} / \mathrm{mL})$ was added to the second aliquot to measure ingested bacteria only. Trypan blue effectively quenches fluorescence of FITC labeled $E$. coli that are surface-bound but not ingested (34).

Data analysis. Results are given as means \pm SEM. Comparisons between treated groups and untreated controls were by ANOVA with Student-Newman-Keuls tests used for post hoc analyses. Significance was accepted at $p<0.05$.

\section{RESULTS}

Numbers of alveolar monocytes and macrophages. The numbers of alveolar macrophages and monocytes identified by autofluorescence were lower in preterm and term animals than in adult animals (Fig. 1). Alveolar macrophages and monocytes increased 4-fold between $141 \mathrm{~d} \mathrm{GA}$ and $3 \mathrm{~d}$ of age after spontaneous birth. Monocytes were the predominant cell population in the preterm and term newborn lung. In the adult lung, alveolar cells were predominantly macrophages with cell numbers almost 4-fold higher per kilogram of body weight than in 3-d-old lambs.
Monocyte responses to endotoxin. Hydrogen peroxide production by monocytes from 130-d GA lambs did not increase significantly until $24 \mathrm{~h}$ after endotoxin exposure (Fig. $2 A$ ). The hydrogen peroxide was increased for monocytes from $141-\mathrm{d}$ GA lambs by $6 \mathrm{~h}$. In contrast, endotoxin induced a large increase in hydrogen peroxide production by monocytes from adult sheep at $1 \mathrm{~h}$. Production of hydrogen peroxide by monocytes from 130-d and 141-d GA lambs was reduced and delayed relative to the adult monocytes.

The percentage of cells that were apoptotic after $24 \mathrm{~h}$ in culture were similar for monocytes from 130-d GA and 141-d GA lambs and adult animals without endotoxin exposure (Fig. $2 B$ ). The percentage of adult monocytes that were apoptotic were reduced after incubation with endotoxin for $1 \mathrm{~h}$ and $6 \mathrm{~h}$. This decreased apoptosis was not significant in monocytes from animals at $130 \mathrm{~d} \mathrm{GA}$ and $141 \mathrm{~d} \mathrm{GA}$, although there was a trend toward decreased apoptosis for monocytes from the 141-d GA lambs. Total number of cells recovered after $24 \mathrm{~h}$ of culture and the percentage of necrotic cells did not change.

Dexamethasone effects on phagocytosis. Fluorescentlabeled $E$. coli were added to the cultured monocytes containing different concentrations of dexamethasone (Fig. $3 A$ ). In the absence of dexamethasone, there was no difference in the phagocytosis of fluorescent-labeled bacteria for monocytes from all age groups. Dexamethasone increased the phagocytosis of bacteria in monocytes from adult animals by $35 \%$ and did not increase phagocytosis in monocytes from 130-d and 141-d GA lambs.

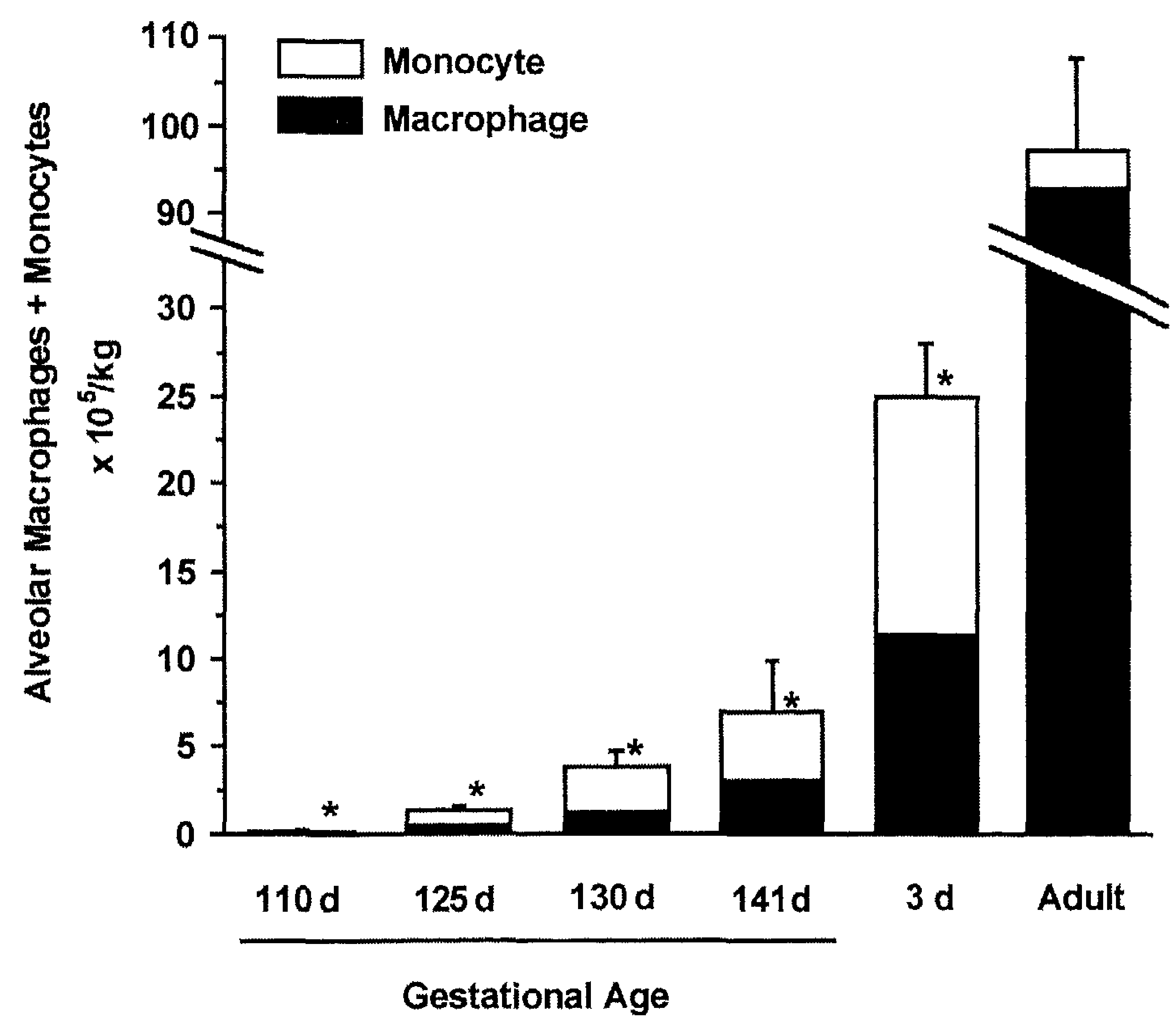

Figure 1. The numbers of alveolar macrophages and monocytes per kilogram body weight were measured in lambs at the indicated gestational ages and in 3-d-old newborn and adult sheep. Monocytes were distinguished from macrophages by autofluorescence. The number of alveolar macrophages and monocytes were lower in preterm and term animals than in newborn and adult animals. ${ }^{*} p<0.05$ versus adult 

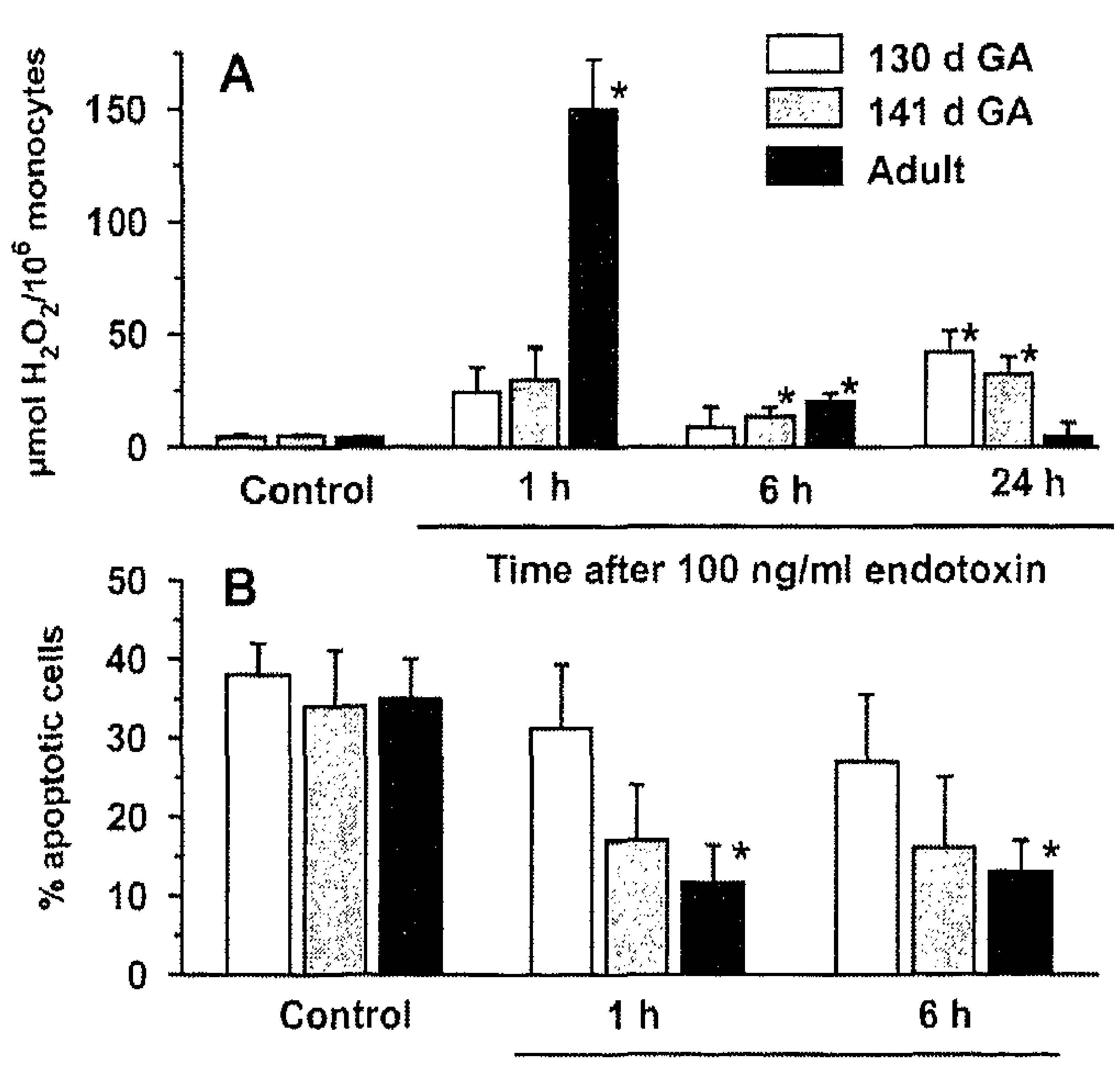

Time after $100 \mathrm{ng} / \mathrm{ml}$ endotoxin

Figure 2. Hydrogen peroxide $\left(\mathrm{H}_{2} \mathrm{O}_{2}\right)$ production and percentage of apoptotic cells after stimulation of monocytes with endotoxin. $A$, Hydrogen peroxide was measured in aliquots of $1 \times 10^{6}$ monocytes after stimulation with $100 \mathrm{ng} / \mathrm{mL}$ endotoxin. Monocytes from lambs at $130 \mathrm{~d} \mathrm{GA}$ and $141 \mathrm{~d}$ GA produced less hydrogen peroxide and at later times than did monocytes from adult sheep. $B$, The percentage of apoptotic cells was determined as percentage of total cells recovered from plates after $24 \mathrm{~h}$ of culture and after exposure to endotoxin for $1 \mathrm{~h}$ or $6 \mathrm{~h}$. The percentage of apoptotic cells in monocytes from adult animals decreased after stimulation with endotoxin. ${ }^{*} p<0.05$ versus control

Monocytes were incubated with apoptotic thymocytes as a model of T lymphocytes for the delayed hypersensitivity reaction. The phagocytosis of apoptotic thymocytes by monocytes from 130-d GA and 141-d GA lambs was reduced relative to monocytes from adult sheep (Fig. $3 B$ ). Incubation with dexamethasone did not increase the phagocytosis of apoptotic thymocytes by monocytes from lambs at $130 \mathrm{~d} \mathrm{GA}$ and $141 \mathrm{~d}$ GA. Dexamethasone increased phagocytosis of apoptotic thymocytes by adult monocytes.

Surfactant effects on phagocytosis of apoptotic cells. Evaluations of phagocytosis were done in the presence of natural sheep surfactant, lipid-extracted sheep surfactant, recombinant human SP-C surfactant, and DPPC. All surfactants and DPPC increased the phagocytosis of apoptotic thymocytes in the monocyte cultures (Fig. 4). There were qualitative differences in the phagocytosis with the different surfactants, probably as a result of the surfactant proteins. Natural surfactant containing SP-A, SP-B, and SP-C increased the phagocytosis more than DPPC alone in monocytes from adults and from lambs at $130 \mathrm{~d}$ GA and $141 \mathrm{~d}$ GA. Lipid-extracted surfactant containing SP-B and SP-C also increased the phagocytosis by monocytes from adult animals more than DPPC alone.

\section{DISCUSSION}

Alveolar macrophages initiate the innate inflammatory response and clear inflammation (17). We evaluated both functions in a model system using peripheral monocytes from

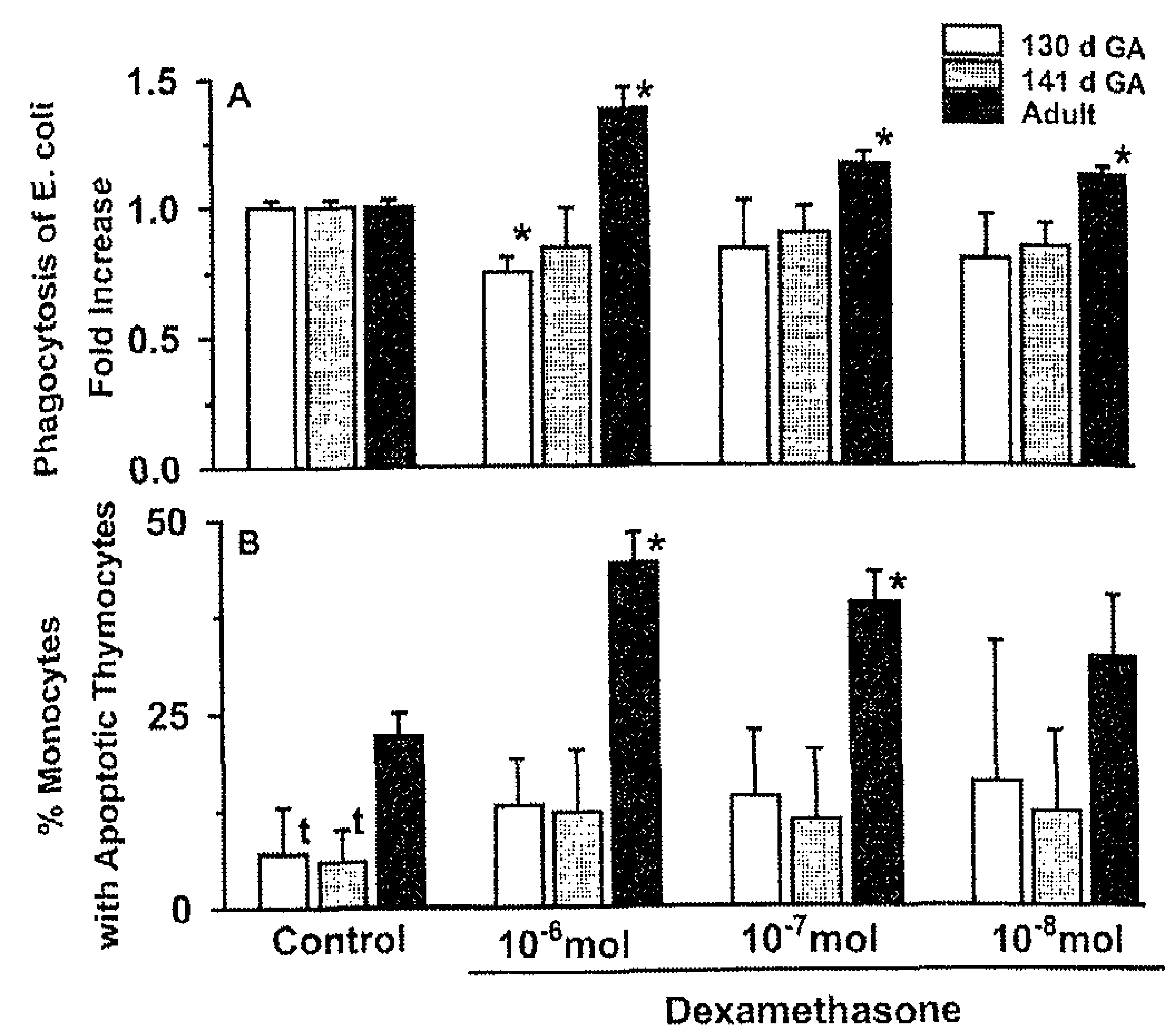

Figure 3. Effect of dexamethasone on phagocytosis. A, Monocytes were incubated with FITC-labeled $E$. coli in the presence or absence of dexamethasone. Phagocytosis of fluorescent-labeled bacteria is shown relative to the control value of 1. Dexamethasone increased the phagocytosis of fluorescentlabeled bacteria in monocytes from adult animals but not in monocytes from $130-\mathrm{d}$ and $141-\mathrm{d}$ GA animals ( ${ }^{*} p<0.05$ versus control). $B$, Results are given as percentage of monocytes that contained at least one apoptotic thymocyte. Phagocytosis of apoptotic thymocytes was lower in monocytes from lambs at $130 \mathrm{~d}$ GA and $141 \mathrm{~d}$ GA than from adult monocytes under control conditions. Incubation with dexamethasone did not increase the phagocytosis in monocytes from lambs at $130 \mathrm{~d}$ GA and $141 \mathrm{~d}$ GA but increased phagocytosis by monocytes from adult animals. ${ }^{*} p<0.05$ versus control; $\mathrm{t} p<0.05$ versus adult

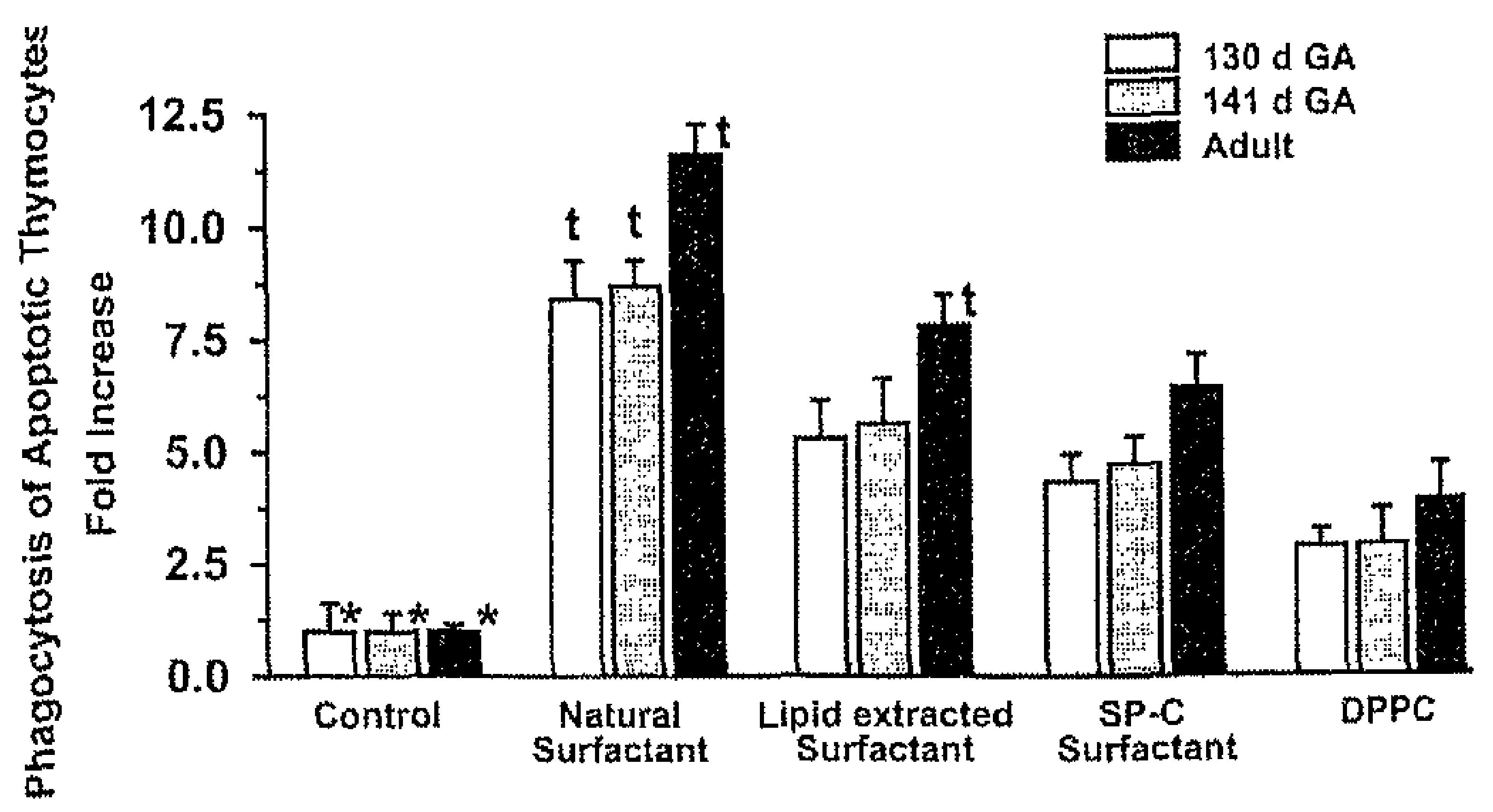

Figure 4. Effect of surfactants and DPPC on phagocytosis of apoptotic thymocytes. Phagocytosis of apoptotic cells are shown as increase over controls, which had a normalized value of 1 . The addition of different surfactant preparations and DPPC at $100 \mu \mathrm{g}$ phospholipid per milliliter of culture media increased the percentage of monocytes that phagocytosed apoptotic cells. Natural surfactant caused the largest increase. Natural surfactant increased the phagocytosis more than DPPC alone. ${ }^{*} p<0.05$ versus all other groups; $\mathrm{t} p<0.05$ versus DPPC

preterm, near-term, and adult sheep. The rationale for using monocytes from blood was that most of the cells recovered by alveolar lavage of preterm and term lambs were monocytes rather than macrophages, as has also been reported for other species $(11,12,35,36)$. A limitation to this study is the use of blood monocytes, which may differ from the monocyte pool in the fetal lung. Approximately $10 \%$ of the blood monocyte pool 
express homing receptors for the lung, which are up-regulated with infection or lung injury (13). Although pulmonary intravascular macrophages contribute to lung inflammation in adult ruminants and pigs, there are no pulmonary intravascular macrophages in newborn pigs and the number is low in term lambs (37). There is no information about pulmonary intravascular macrophage populations in preterm sheep. The differences between premature, newborn, and adult immune cells are mechanistically very complex. For example, phagocytosis of opsonized particles is normal in term human newborn neutrophils; however, the respiratory burst may be impaired (1). The second messenger responses to exogenous stimuli are different for immune cells from newborn and adult cells (4).

This study was designed to evaluate monocyte functions that might be relevant to clinical exposures and interventions for BPD. BPD develops after prolonged inflammation in the lung (38). This inflammation can be initiated prenatally by chorioamnionitis or can be initiated and sustained by postnatal treatments that have proinflammatory effects such as oxygen exposure, nosocomial infection, and mechanical ventilation $(31,39$, 40). The hydrogen peroxide responses of preterm and nearterm monocytes to endotoxin were reduced and delayed. Endotoxin exposure did not reduce the percentage of apoptotic monocytes from lambs at $130 \mathrm{~d}$ GA and $141 \mathrm{~d}$ GA. Dexamethasone increased the phagocytosis of bacteria and apoptotic thymocytes by monocytes from adult animals but not by monocytes from lambs at $130 \mathrm{~d} \mathrm{GA}$ and $141 \mathrm{~d}$ GA. Monocytes from lambs at $130 \mathrm{~d}$ GA and $141 \mathrm{~d}$ GA have a reduced capacity to clear inflammation by phagocytosis of apoptotic inflammatory cells. However, phagocytosis of apoptotic cells was increased by surfactant and DPPC. Our results suggest that once an inflammatory response is present, the clearance of inflammation may be prolonged as a result of a defect in the phagocytosis of apoptotic cells. Apoptotic cells become necrotic if they are not phagocytosed $(16,41)$, and necrotic cells release toxic contents and proinflammatory mediators that may sustain inflammation (42).

A new finding is that surfactant increased phagocytosis by monocytes from all ages of sheep. The enhanced phagocytosis of apoptotic cells may contribute to the anti-inflammatory properties of surfactant treatment (1). The phagocytosis of apoptotic cells by alveolar macrophages was previously reported to be enhanced by SP-A (43). There was a qualitative tendency for natural surfactant to enhance more effectively the phagocytosis of apoptotic cells compared with DPPC alone. The enhancement of phagocytosis by DPPC may result from the interaction of phospholipids with the phosphatidylserine receptor (44). Phosphatidylserine is exposed in the outer membrane of cells undergoing apoptosis (32), and the phosphatidylserine receptor mediates the phagocytosis of apoptotic cells (45). The enhanced phagocytosis by surfactant may be compromised in BPD because the surfactant from baboons developing BPD is deficient in SP-A and SP-D $(46,47)$. Increased apoptosis or necrosis of monocytes was not the reason for the reduced phagocytosis of apoptotic thymocytes.

Infants with BPD have been treated with dexamethasone to reduce inflammation and the duration of mechanical ventilation (48). We found that dexamethasone did not reduce the phago- cytosis of bacteria by monocytes from lambs at $130 \mathrm{~d}$ GA and $141 \mathrm{~d}$ GA. In contrast, dexamethasone increased the phagocytosis of both bacteria and apoptotic cells by adult monocytes, a response similar to that described previously for alveolar macrophages from newborn rat lungs (49). The effect of dexamethasone on phagocytosis by monocytes from preterm and nearterm lambs will not augment the immature immune system. The significance of this effect is unknown for humans who are being treated postnatally with dexamethasone for BPD.

We found that monocytes from preterm lambs are different from monocytes from adult sheep in both the initiation and the resolution of inflammation. There was no difference between the cells from 131- and 141-d lambs, indicating that the maturation of function is a postterm event. Inflammatory cells persisted in the lungs of preterm fetal lambs for weeks after a single exposure to intra-amniotic endotoxin (39). The reduced phagocytosis in preterm monocytes may contribute to the persistent lung inflammation after chorioamnionitis. Dexamethasone may not increase the clearance of bacteria or apoptotic cells in preterm lungs. The low amounts of surfactant and SP-A in preterm lungs and lungs developing BPD may also adversely affect phagocytosis $(46,47)$.

Acknowledgments. Byk Gulden, Konstanz, Germany, provided Venticute.

\section{REFERENCES}

1. Speer CP $2001 \mathrm{New}$ insights into the pathogenesis of pulmonary inflammation in preterm infants. Biol Nconate 79:205-209

2. Tomai MA, Fitzgerald TJ, Froberg MK 1992 Macrophage and lymphocyte functions are down-regulated in newborn rabbits. J Leukoc Biol 51:151-156

3. Weiss RA, Chanana AD, Joel DD 1986 Postnatal maturation of pulmonary antimicrobial defense mechanisms in conventional and germ-free lambs. Pediatr Res 20:496-504

4. Marshall-Clarke S, Reen D, Tasker L, Hassan J 2000 Neonatal immunity: how well has it grown up? Immunol Today 21:35-41

5. Lee PT, Holt PG, McWilliam AS 2000 Role of alvcolar macrophages in innate immunity in neonates: evidence for selective lipopolysaccharide binding protein production by rat neonatal alveolar macrophages. Am J Respir Cell Mol Biol 23:652-661

6. Goldenberg RL, Hauth JC, Andrews WW 2000 Intrauterine infection and preterm delivery. N Engl J Med 342:1500-1507

7. Schmidt B, Cao L, Mackensen-Haen S, Kendziorra H, Klingel K, Speer CP 2001 Chorioamnionitis and inflammation of the fetal lung. Am J Obstet Gynecol 185:173177

8. Yoon BH, Romero R, Moon JB, Shim SS, Kim M, Kim G, Jun JK 2001 Clinical significance of intra-amniotic inflammation in patients with preterm labor and intact membranes. Am J Obstet Gynecol 185:1130-1136

9. Jobe AH 1999 The New BPD: An arrest of lung development. Pediatr Res 46:641643

10. Jobe A, Bancalari E 2001 Bronchopulmonary dysplasia. Am J Respir Crit Care Med 163:1723-1729

11. Zeligs BJ, Nerurkar LS, Bellanti JA, Zeligs ID 1977 Maturation of the rabbit alveolar macrophage during animal development. I. Perinatal influx into alveoli and ultrastructural differentiation. Pediatr Res 11:197-208

12. Jacobs RF, Wilson CB, Palmer S, Springmeyer SC, Henderson WR, Glover DM, Kessler Jr DL, Murphy JH, Hughes JP, van Belle G, Chi EY, Hodson WA 1985 Factors related to the appearance of alveolar macrophages in the developing lung. Am Rev Respir Dis 131:548-553

13. Sherman MP, Truog WE 1999 The role of pulmonary macrophages in chronic lung disease of early infancy. In: Bland RD, Coaison JJ (eds) Chronic Lung Discase in Early Infancy. Marcel Dekker, New York, pp 813-839

14. Radzun HJ, Parwaresch MR, Kreipe H 1983 Monocytic origin of human alveolar macrophages. J Histochem Cytochem 31:318-324

15. Rojas MA, Gonzalez A, Bancalari E, Claure N, Poole C, Silva-Neto G 1995 Changing trends in the epidemiology and pathogenesis of neonatal chronic lung diseasc. J Pediatr 126:605-610

16. Grigg JM, Savill JS, Sarraf C, Haslett C, Silverman M 1991 Neutrophil apoptosis and clearance from neonatal lungs. Lancet 338:720 -722

17. Cox G, Crossley J, Xing Z 1995 Macrophage engulfment of apoptotic neutrophils contributes to the resolution of acute pulmonary inflammation in vivo. Am J Respir Cell Mol Biol 12:232-237 
18. Wright JR 1997 Immmunomodulatory functions of surfactant. Physiol Rev 77:931-962

19. Sinkin RA, Dweck HS, Horgan MJ Gallaher KJ Cox C Maniscalco WM, Chess PR, D'Angio CT, Guillet R, Kendig JW, Ryan RM, Phclps DL 2000 Early dexamethasone-attempting to prevent chronic lung disease. Pediatrics 105:542 - 548

20. Wada $K$, Jobe AH, Ikegami $M 1997$ Tidal volume effects on surfactant treatment responses with the initiation of ventilation in preterm lambs. J Appl Physiol 83:10541061

21. Skold CM, Eklund A, Hallden G, Hed J 1990 Different cell surface and phagocytic properties in mononuclcar phagocytes from blood and alveoli. A comparative study of blood monocytes and alveolar macrophages from human nonsmokers using flow cytofluorometry. APMIS 98:415-422

22. Kanof ME, Smith PD, Zola H 1996 Separation of peripheral blood mononuclear cells. In: Coligan JE, Kruisbeek AM, Margulies DH, Shevach EM, Strober W (eds) Current Protocols in Immunology. Wiley, New York, pp 711-717

23. Kruisbeek AM 1996 Isolation and fractionation of mononuclear cell populations. In: Coligan JE, Kruisbeek AM, Margulies DH, Shevach EM, Strober W (cds) Current Protocols in Immunology. Wiley, New York, pp 311-315

24. Shannon JM, Pan T, Nielsen LD, Edeen KE, Mason RJ 2001 Lung fibroblasts improve differentiation of rat type II cells in primary culture. Am J Respir Cell Mol Biol 24:235-244

25. Ikegani M, Korfhagen TR, Bruno MD, Whitsett JA, Jobe AH 1997 Surfactant metabolism in surfactant protein A-deficient mice. Am J Physiol 272:L479-L485

26. Davis $A J$, Jobe $A H$, Häfner D, Ikegami $M 1998$ Lung function in premature lambs and rabbits treated with a recombinant SP-C surfactant. Am J Respir Crit Care Med $157: 553-559$

27. Ikegami $M$, Jobe A 2002 Injury responses to different surfactants in ventilated premature lamb lungs. Pediatr Res 51:689-695

28. Lewis J, MeCaig L, Hafier D, Spragg R, Veldhuizen R, Kerr C 1999 Dosing and delivery of a recombinant surfactant in lung-injured adult sheep. Am $J$ Respir Crit Care Mcd 159:741-747

29. Ikcgami M, Jobe A, Jacobs H, Jones SJ 1981 Sequential treatments of premature lambs with an artificial surfactant and natural surfactant. J Clin Invest 68:491-496

30. Yoshida M, Ikegami M, Reed JA, Chroneos ZC, Whitsett JA 2001 GM-CSF regulates protein and lipid catabolism by alveolar macrophages Am J Physiol 280:L379-L386

31. Kramer BW, Moss TJ, Willet K, Newnham J, Sly P, Kallapur SG, Ikegami M, Jobe A 2001 Dose and time response after intra-amniotic endotoxin in preterm lambs. Am J Respir Crit Care Med 164:982-988

32. Vermes I, Haanen C, Steffens-Nakken H, Reutelingsperger C 1995 A novel assay for apoptosis. Flow cytometric detection of phosphatidylserine expression on carly apoptotic cells using fluorescein labelled Annexin V. J Immunol Methods 184:39-51

33. Hu B, Sonstein J, Christensen PJ, Punturieri A, Curtis JL 2000 Deficient in vitro and in vivo phagocytosis of apoptotic $T$ cells by resident murine alveolar macrophages. J Immunol 165:2124-2133
34. Hed J, Hallden G, Johansson SG, Larsson P 1989 Quantitative rather than qualitative differences between monocytes with respect to IgE Fe receptor expression as studied by flow cytofluorometry. Int Arch Allergy Appl Immunol 88:408-411

35. Sherman MP, D'Ambola JB, Aeberhard EE, Barrett CT 1988 Surfactant therapy of newbom rabbits impairs lung macrophage bactericidal activity. J Appl Physiol $65: 137-145$

36. Coalson JJ, Winter VT, Siler-Khodr T, Yoder BA 1999 Neonatal chronic lung disease in extremely immature baboons. Am J Respir Crit Care Med 160:1333-1346

37. Longworth KE, Albertine KH, Staub NC 1996 Ultrastructural quantification of pulmonary intravascular macrophages in newborn and 2-week-old lambs. Anat Rec 246:238--244

38. Groneck P, Specr CP 1995 Inflammatory mediators and bronchopulmonary dysplasia. Arch Dis Child 73:F1-F3

39. Kallapur SG, Willet KE, Jobe AH, Ikegami M, Bachurski C 2001 Intra-amniotic endotoxin: chorioamnionitis precedes lung maturation in preterm lambs. Am J Physiol 280:L527-L536

40. Bancalari $E 2001$ Changes in the pathogenesis and prevention of chronic lung discase of prenaturity. Am J Perinatol 18:1-9

41. Savill J, Fadok V, Henson P, Haslett C 1993 Phagocyte recognition of cells undergoing apoptosis. Immunol Today 14:131-136

42. Mann CL, Cidloski JA 1999 Signaling cascades of apoptosis. In: Winkler JD (eds) Apoptosis and Inflammation. Birkhäuser, Basel, pp 7-18

43. Schagat TL, Wofford JA, Wright JR 2001 Surfactant protein A cnhances alveolar macrophage phagocytosis of apoptotic neutrophils. J Immunol 166:2727-2733

44. Huynh M-L, Fadok VA, Henson PM 2001 TGFb1 secretion and resolution of pulmonary inflammation are increased after phosphatidylserine dependent in vivo ingestion of apoptotic cells. Am J Respir Crit Carc Mcd 163:A246

45. Fadok VA, Bratton DL, Rose DM, Pearson A, Ezekewitz RA, Henson PM 2000 A receptor for phosphatidylserine-specific clearance of apoptotic cells. Nature 405:85-90

46. Hallman M, Merritt TA, Akino T, Bry K 1991 Surfactant protein-A, phosphatidylcholine, and surfactant inhibitors in epithelial lining fluid: correlation with surface activity, severity of respiratory distress syndrome, and outcome in small premature infants. Am Rev Respir Dis 144:1376-1384

47. Awasthi S, Coalson JJ, Crouch E, Yang F, King RJ 1999 Surfactant proteins A and $D$ in premature baboons with chronic lung injury. Evidence for an inhibition of secretion. Am J Respir Crit Care Med 160:942-949

48. Bancalari E 1998 Corticosteroids and neonatal chronic lung disease. Eur J Pediatr $157: \$ 31-\$ 37$

49. Lortic C, King GM, Adamson IY 1990 Effects of dexamethasone on macrophages in fetal and neonatal rat lung. Pediatr Pulmonol 8:138-144 


\section{CHAPTER 10}

\section{Antenatal betamethasone changes cord blood monocyte responses to endotoxin in preterm lambs}

Kramer, B.W., Ikegami, M., Moss, T.J.M, Nitsos, I., Newnham, J.P., Jobe, A.H. 


\title{
Antenatal Betamethasone Changes Cord Blood Monocyte Responses to Endotoxin in Preterm Lambs
}

\author{
BORIS W. KRAMER, MACHIKO IKEGAMI, TIMOTHY J.M. MOSS, ILIAS NITSOS, \\ JOHN P. NEWNHAM, AND ALAN H. JOBE
}

\author{
University Children's Hospital, 97080 Würzburg, Germany [B.W.K.], Division of Pulmonary Biology, \\ Cincinnati Children's Hospital Medical Center, Cincinnati, Ohio 45229, U.S.A. [M.I., A.H.J.], and School \\ of Women's and Infants' Health, The University of Western Australia, Crawley, Western Australia 6009, \\ Australia [T.J.M.M., I.N., J.P.N.]
}

ABSTRACT

\begin{abstract}
Corticosteroids are routinely administered to women at risk for preterm delivery to induce fetal lung maturation. Antenatal corticosteroids have immunomodulatory effects on fetal immune cells that are poorly understood. We hypothesized that maternal betamethasone would alter in fetal monocytes both the initiation of inflammation in response to pro-inflammatory stimuli and the resolution of inflammation by phagocytosis of apoptotic neutrophils. Preterm lambs at 124 d gestation were delivered $15 \mathrm{~h}, 1 \mathrm{~d}$, $2 \mathrm{~d}$, or $7 \mathrm{~d}$ after $0.5 \mathrm{mg} / \mathrm{kg}$ maternal intramuscular betamethasone. Monocytes from cord blood were isolated and cultured and results were compared with monocytes from preterm lambs exposed to maternal saline or monocytes from adult sheep. Phagocytosis of Escherichia coli was not changed, however, phagocytosis of apoptotic neutrophils was low in fetal monocytes but increased after $7 \mathrm{~d}$ exposure to maternal betamethasone to the level found in adult monocytes. Hydrogen peroxide production after endotoxin stimulus was significantly reduced to $7.1 \pm 2.2$
\end{abstract}

Corticosteroids are potent modulators of fetal development, and antenatal corticosteroids are routinely used to decrease morbidity and mortality after preterm birth by inducing lung maturation (1). However, corticosteroids also are potent acute suppressors of immune/inflammatory responses (2). Fetal plasma corticosteroid levels are about $30 \%$ of the maternal levels after antenatal treatment with betamethasone (3). Fetal plasma corticosteroid concentrations decline rapidly within $4 \mathrm{~h}$ after maternal treatment with betamethasone (4). The effects of corticosteroids and their metabolites on fetal immune cells in vivo are poorly understood. In vitro exposure of fetal immune cells to corticosteroids acutely alters functions such as cell proliferation, apoptosis, phagocytosis, production of colony-

Received Junc 10, 2003; accepted November 20, 2003

Correspondence: Boris W. Kramer, M.D., University Children's Hospital, Josef-Schneider-Str.

2, 97080 Würzburg, Germany; o-mail: kramer_b@kinderklinik.uni.wurgburg.de

Supported by grants HL-65397 and HD-12714 from the National institutes of Health.

DOI: 10.1203/01.PDR.0000120678.72485.19 $\mu \mathrm{mol}$ at $5 \mathrm{~h}, 8.7 \pm 2.9 \mu \mathrm{mol}$ at $24 \mathrm{~h}$, and $4.1 \pm 1.9 \mu \mathrm{mol}$ at $48 \mathrm{~h}$ versus $16.4 \pm 3.6 \mu \mathrm{mol}$ in control animals; at $7 \mathrm{~d}$, the hydrogen peroxide production increased to $74.3 \pm 19.7 \mu \mathrm{mol}(p<0.05$, per $10^{6}$ monocytes). IL-6 production was reduced at $15 \mathrm{~h}$ after maternal betamethasone but at no other time point. Maternal betamethasone initially suppressed several fetal monocyte functions, however, at $7 \mathrm{~d}$, measurements of initiation and resolution of inflammation were increased to levels similar to monocytes from adult sheep. The time-dependent changes in maternal betamethasone modulation of the responses of fetal monocytes may influence immune function of the preterm lamb after delivery. (Pediatr Res 55: 764-768, 2004)
Abbreviations
BPD, bronchopulmonary dysplasia
GA, gestational age

stimulating factors, and anti-inflammatory cytokine production (5-9). We have previously used cord blood-derived monocytes to study agents in vitro that are frequently used in the treatment of pulmonary inflammation in preterm infants (10). Similar suppressive effects on fetal immune cell function also occur after maternal corticosteroid treatments in vivo, and examples are decreased granulocyte chemokines and decreased lymphocyte numbers $(11,12)$. In contrast, Kavelaars et al. (11), also found enhanced natural killer cell activity in cord blood after antenatal corticosteroid exposure. The few evaluations of immune cell responses after maternal corticosteroid treatments did not control for the time interval from corticosteroid exposure to delivery. Because corticosteroids cause both immunosuppression and maturation, we hypothesized that the responses of fetal cord monocytes would change with time after maternal corticosteroid treatment. An initial suppression might be followed by a functional change that could represent reprogramming that might alter subsequent immune responses. 
Therefore, we exposed fetal sheep to a maternal corticosteroid treatment for time intervals from $15 \mathrm{~h}$ to $7 \mathrm{~d}$. We evaluated fetal blood monocytes for phagocytosis of Escherichia coli, responses to endotoxin exposure by hydrogen peroxide production, and IL-6 production as the marker for fetal inflammatory response syndrome (13). The resolution of inflammation was tested by phagocytosis of apoptotic neutrophils.

\section{METHODS}

Animals. The animal component of the study was performed in Western Australia, as approved by the animal care and use committees of Cincinnati Children's Hospital Medical Center (Cincinnati, OH, U.S.A.) and the Western Australian Department of Agriculture. Lung development in sheep at $124 \mathrm{~d} \mathrm{GA}$ is in the saccular phase corresponding to human fetuses at 26-29 wk of gestation (14). A single dose of $0.5 \mathrm{mg} / \mathrm{kg}$ betamethasone induces lung maturation in preterm sheep (15). Injections were given at different gestational ages to deliver all animals at $124 \mathrm{~d}$ GA. Date-bred Merino ewes with singleton fetuses were randomly assigned in groups of five to nine animals. A single dose of maternal betamethasone $(0.5 \mathrm{mg} / \mathrm{kg}$ intramuscularly) (Celestone Chronodose, Schering-Plough Pty. Ltd., Baulkham Hills, NSW, Australia) was given 15 h, $1 \mathrm{~d}$, $2 \mathrm{~d}$, or $7 \mathrm{~d}$ before preterm delivery at $124 \mathrm{~d}$ GA. Control animals were concurrently given $0.9 \%$ saline injections at $15 \mathrm{~h}$, $1 \mathrm{~d}, 2 \mathrm{~d}$, or $7 \mathrm{~d}$ before delivery at $124 \mathrm{~d} \mathrm{GA}$.

Cell isolation and culture. Cord blood was collected from an umbilical artery from each fetus at the time of cesarean section. Jugular venous blood from healthy adult ewes also was collected $(n=10)$. Complete white blood counts were performed on umbilical cord blood samples. Fetal plasma cortisol concentrations were determined with a commercial RIA (Valeant Pharmaceuticals International, Costa Mesa, CA, U.S.A.). The blood was diluted with PBS and layered onto a Percoll gradient (Amersham Pharmacia Biotech, Inc., Piscataway, NJ, U.S.A.) (16). After centrifugation for $40 \mathrm{~min}$ at 400 $\times g$ at $20^{\circ} \mathrm{C}$, the mononuclear cells and granulocytes were recovered, washed twice with $\mathrm{PBS}$ at $4^{\circ} \mathrm{C}$, centrifuged for 5 min at $400 \times g$ at $4^{\circ} \mathrm{C}$, and resuspended in culture media (Dulbecco's modified minimal media) supplemented with $10 \%$ heat-inactivated FCS (Sigma Chemical, St. Louis, MO, U.S.A.). Cells were counted using trypan blue to evaluate viability and then plated in culture dishes. After incubation at $37^{\circ} \mathrm{C}$ for $2 \mathrm{~h}$, nonadherent cells were removed and plates were washed twice with PBS. To estimate the number of monocytes, cells were scraped from the culture dishes, and differential cell counts were performed on cytospin preparations stained with DiffQuick (Baxter Healthcare Corp., McGraw Park, IL, U.S.A.). The adherent cell population was $90 \pm 3 \%$ monocytes for all treatment and control groups. Monocytes in other culture dishes were cultured overnight, and the experiments were done the next day after about $16 \mathrm{~h}$ in culture.

Phagocytosis of E. coli. After overnight incubation, monocytes were washed with PBS and new culture media was added. Monocytes were exposed to FITC-labeled $E$. coli (Sigma Chemical) for $6 \mathrm{~h}$. The monocytes were resuspended, washed three times with PBS, and divided into two equal aliquots. The total bound and ingested bacteria were measured by flow cytometry. Trypan blue $(1.25 \mathrm{mg} / \mathrm{mL})$ was added to one aliquot to measure ingested bacteria only. Trypan blue quenches fluorescence of FITC-labeled $E$. coli that are surface bound but not ingested (17).

Hydrogen peroxide production and IL-6 concentration. After overnight incubation, monocytes were washed with PBS and new culture media was added. After $6 \mathrm{~h}$ incubation with endotoxin (100 ng/mL, E. coli, serotype 055:B5, Sigma Chemical) [a dose that induces a robust response in preterm monocytes (10)], monocytes were scraped from the culture dish, counted, and assessed for viability with trypan blue. Production of hydrogen peroxide by $1 \times 10^{6}$ monocytes was measured with an assay based on the oxidation of ferrous iron $\left(\mathrm{Fe}^{2+}\right)$ to ferric iron $\left(\mathrm{Fe}^{3+}\right)$ by hydrogen peroxide under acidic conditions (Bioxytech $\mathrm{H}_{2} \mathrm{O}_{2}-560$ assay, OXIS International, Portland, OR, U.S.A.). Control samples were exposed to saline instead of endotoxin and were included in all experiments (10). Concentrations of IL- 6 were determined in the supernatant of endotoxin-stimulated monocytes by an ovine-specific ELISA as previously described (18).

Induction of apoptosis and phagocytosis of apoptotic neutrophils. Neutrophils were isolated from adult animals. Contaminating erythrocytes were removed by osmotic lysis (16). Apoptosis in neutrophils was induced by $10 \mathrm{~min}$ of UV radiation followed by $3 \mathrm{~h}$ of culture (19). Apoptosis and necrosis were quantified by flow cytometry. Apoptotic cells were stained with fluorescent-labeled annexin V. Necrotic cells were stained with proprium iodide and the relative cell populations counted by flow cytometry (20). After overnight incubation, monocytes were washed with PBS and new culture media was added. Phagocytosis of apoptotic neutrophils was tested by adding $2 \times 10^{6} / \mathrm{mL}$ apoptotic neutrophils to the adherent monocytes in culture dishes (19). The monocytes and apoptotic neutrophils were incubated for $6 \mathrm{~h}$ at $37^{\circ} \mathrm{C}$ and washed with ice-cold PBS containing $0.5 \mathrm{mM}$ EDTA. Cells in the culture dishes were fixed and stained with hematoxylin and eosin. Phagocytosis was evaluated by counting apoptotic vesicles in 300 monocytes per well (10).

Data analysis. Results are presented as mean \pm SEM. Comparisons between betamethasone-treated groups and untreated controls were by ANOVA with Student-NewmanKeuls tests used for posthoc analyses. Results also were compared with monocytes from healthy sheep. Statistical significance was accepted at $p<0.05$.

\section{RESULTS}

Monocyte counts in complete white blood counts and plasma cortisol concentrations. Maternal betamethasone did not change the number of monocytes in umbilical cord blood in preterm lambs (Table 1). The fetal plasma cortisol concentrations were not different after maternal treatment with betamethasone (Table 1).

Phagocytosis. Although phagocytosis of $E$. coli by blood monocytes from adult sheep tended to be higher than for fetal sheep at $124 \mathrm{~d}$ gestation, the difference was not significant (Fig. $1 A$ ). Maternal betamethasone treatments had no effect on the 
Table 1. Number of monocytes in cord blood and cortisol concentration in cord plasma

\begin{tabular}{lccccc}
\hline & & \multicolumn{4}{c}{ Time after maternal betamethasone treatment } \\
\cline { 3 - 5 } & Control & $15 \mathrm{~h}$ & $1 \mathrm{~d}$ & $2 \mathrm{~d}$ & $7 \mathrm{~d}$ \\
\hline Monocytes $(\mathrm{per} \mu \mathrm{L})$ & $60 \pm 15$ & $35 \pm 25$ & $95 \pm 35$ & $120 \pm 40$ & $70 \pm 20$ \\
Cortisol $(\mu \mathrm{g} / \mathrm{dL})$ & $0.5 \pm 0.2$ & $0.7 \pm 0.3$ & $0.3 \pm 0.1$ & $0.4 \pm 0.1$ & $0.7 \pm 0.2$ \\
\hline
\end{tabular}

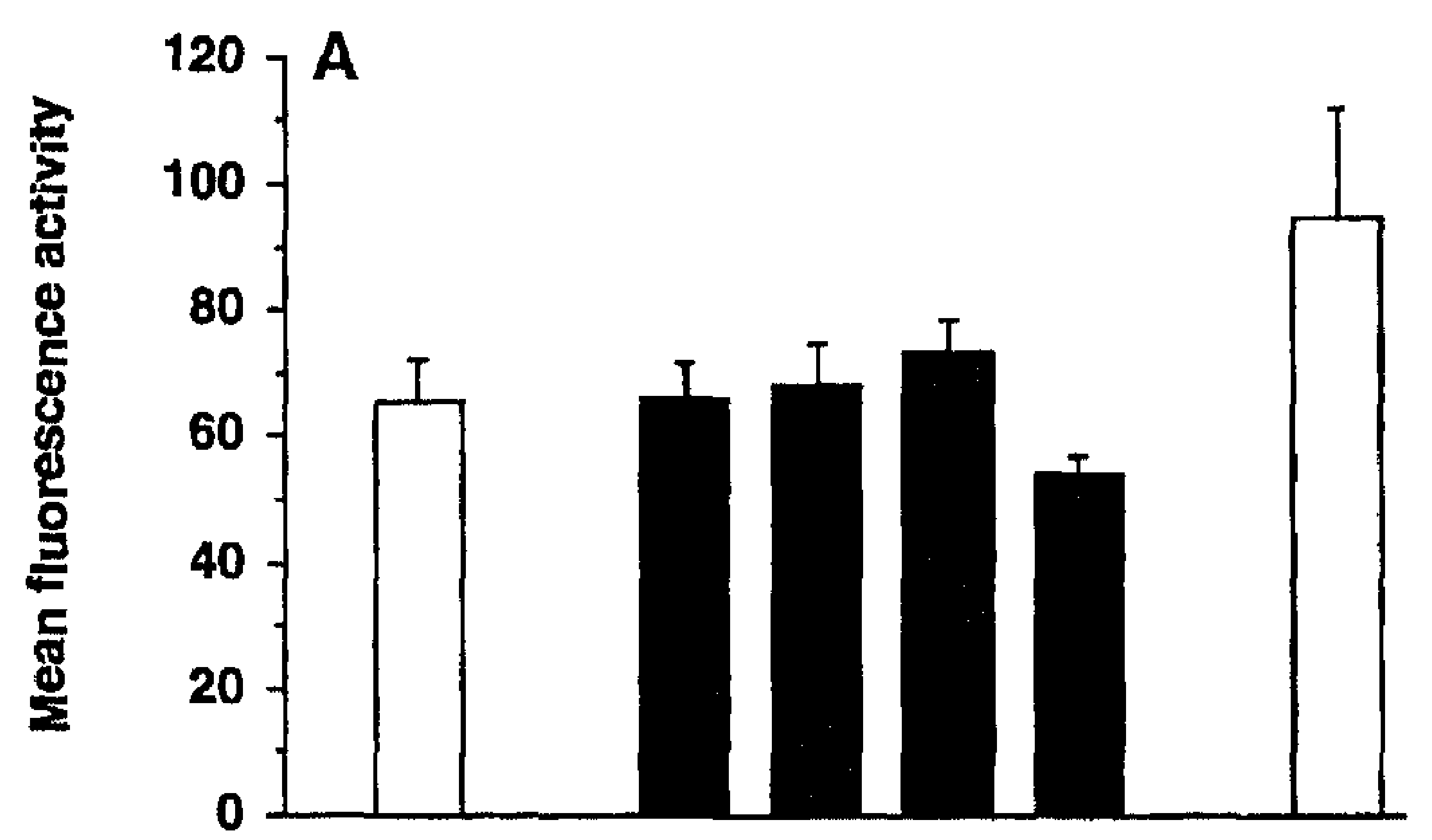

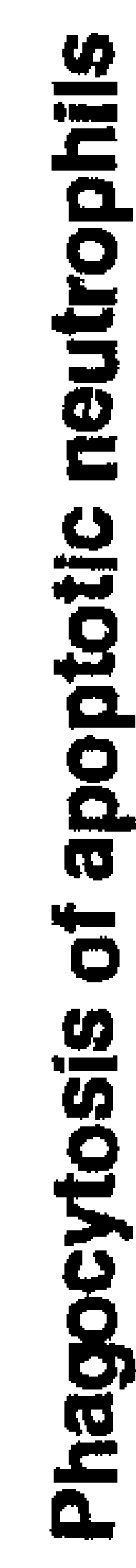

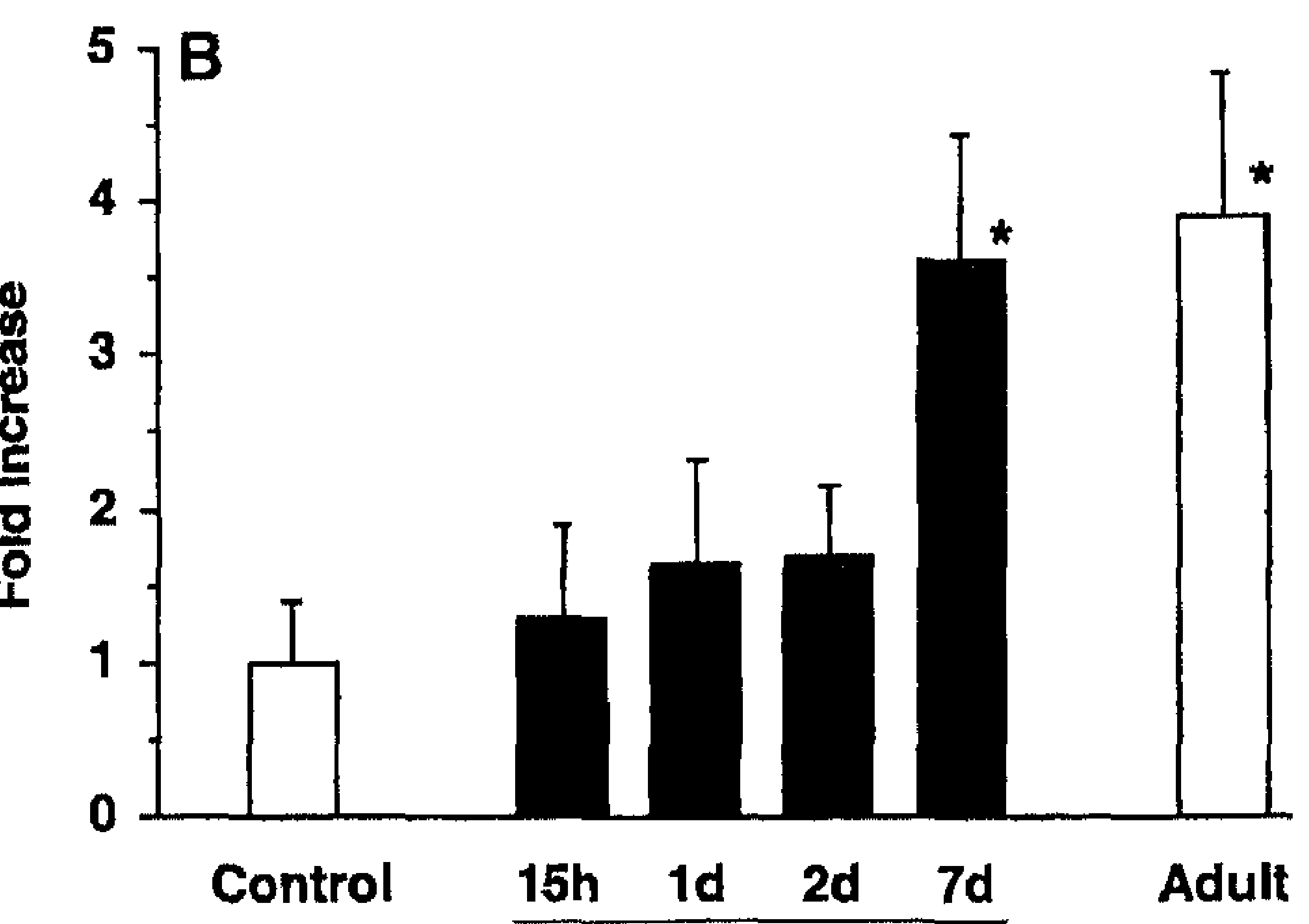

\section{Maternal Betamethasone}

Figure 1, $(A)$ Phagocytosis of fluorescent-labeled bacteria was not different between monocytes from preterm lambs $(n=9)$ and monocytes from adult sheep $(n=10)$. Phagocytosis was not changed by exposure to maternal betamethasone. The number of measurements were at $15 \mathrm{~h} n=5$, at $1 \mathrm{~d} n=$ 6 , at $2 \mathrm{~d} n=6$, and $7 \mathrm{~d} n=6$. (B) Phagocytosis of apoptotic neutrophils was quantified by counting apoptotic vesicles in monocytes. Results are shown as fold increase over control animals, which were set to 1 . The low phagocytosis in monocytes from preterm lambs increased $7 \mathrm{~d}$ after maternal betamethasone to a value similar to the phagocytosis of monocytes from adult sheep $(p<0.05$ vs control).

phagocytosis of $E$. coli by monocytes from the preterm lamb. However, phagocytosis of apoptotic neutrophils was increased in blood monocytes from adult sheep relative to the preterm lamb (Fig. 1B). The maternal betamethasone treatment did not change apoptotic neutrophil phagocytosis at $15 \mathrm{~h}, 1 \mathrm{~d}$, or $2 \mathrm{~d}$. However, phagocytosis increased 3 -fold to be similar to the value in the adult monocytes $7 \mathrm{~d}$ after maternal betamethasone treatment.

Endotoxin-stimulated $\mathrm{H}_{2} \mathrm{O}_{2}$ and $I L-6$ production. Monocyte activation was assessed after exposure of monocytes in culture to endotoxin. Blood monocytes from adult sheep produced about three times more $\mathrm{H}_{2} \mathrm{O}_{2}$ in response to endotoxin than did the monocytes from the preterm lambs (Fig. 2).

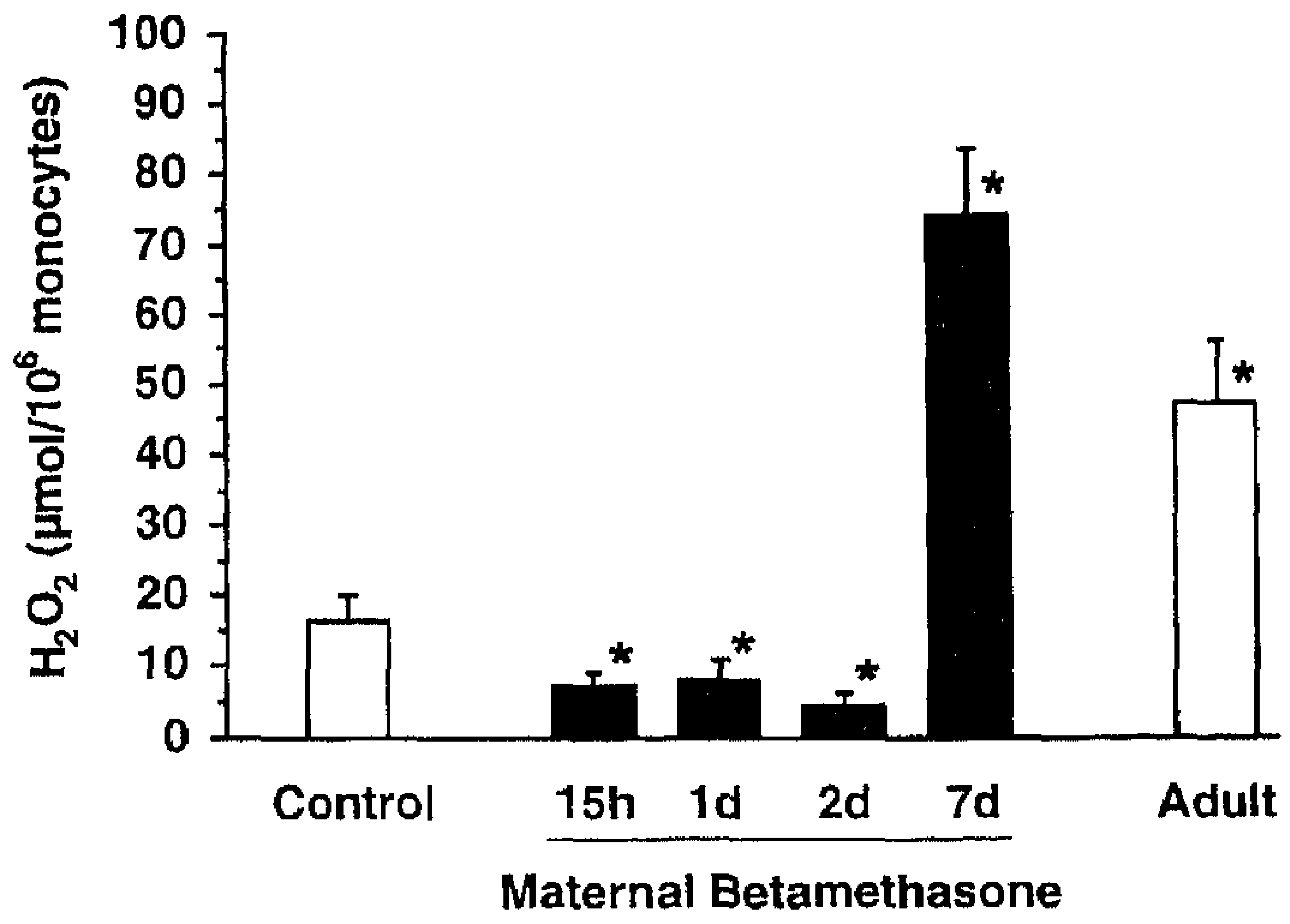

Figure 2. Production of hydrogen peroxide after stimulation with $100 \mathrm{ng} / \mathrm{mL}$ endotoxin. Production of hydrogen peroxide was lower in monocytes from preterm animals than in monocytes from adult sheep. Exposure to maternal betamethasone decreased production of hydrogen peroxide at $15 \mathrm{~h}, 1 \mathrm{~d}$, and $2 \mathrm{~d}$. At $7 \mathrm{~d}$ after maternal betamethasone exposure, hydrogen peroxide production was increased in monocytes from preterm animals and not different from monocytes from adult sheep ( $p<0.05$ us control).

Maternal betamethasone treatment suppressed $\mathrm{H}_{2} \mathrm{O}_{2}$ production at $15 \mathrm{~h}, 1 \mathrm{~d}$, and $2 \mathrm{~d}$. However, $7 \mathrm{~d}$ after the maternal treatment, the $\mathrm{H}_{2} \mathrm{O}_{2}$ production was similar to that of adult monocytes. IL- 6 secretion by the cultured monocytes was about 2.5 times higher for adult monocytes than for preterm monocytes (Fig. 3). Maternal betamethasone treatment initially

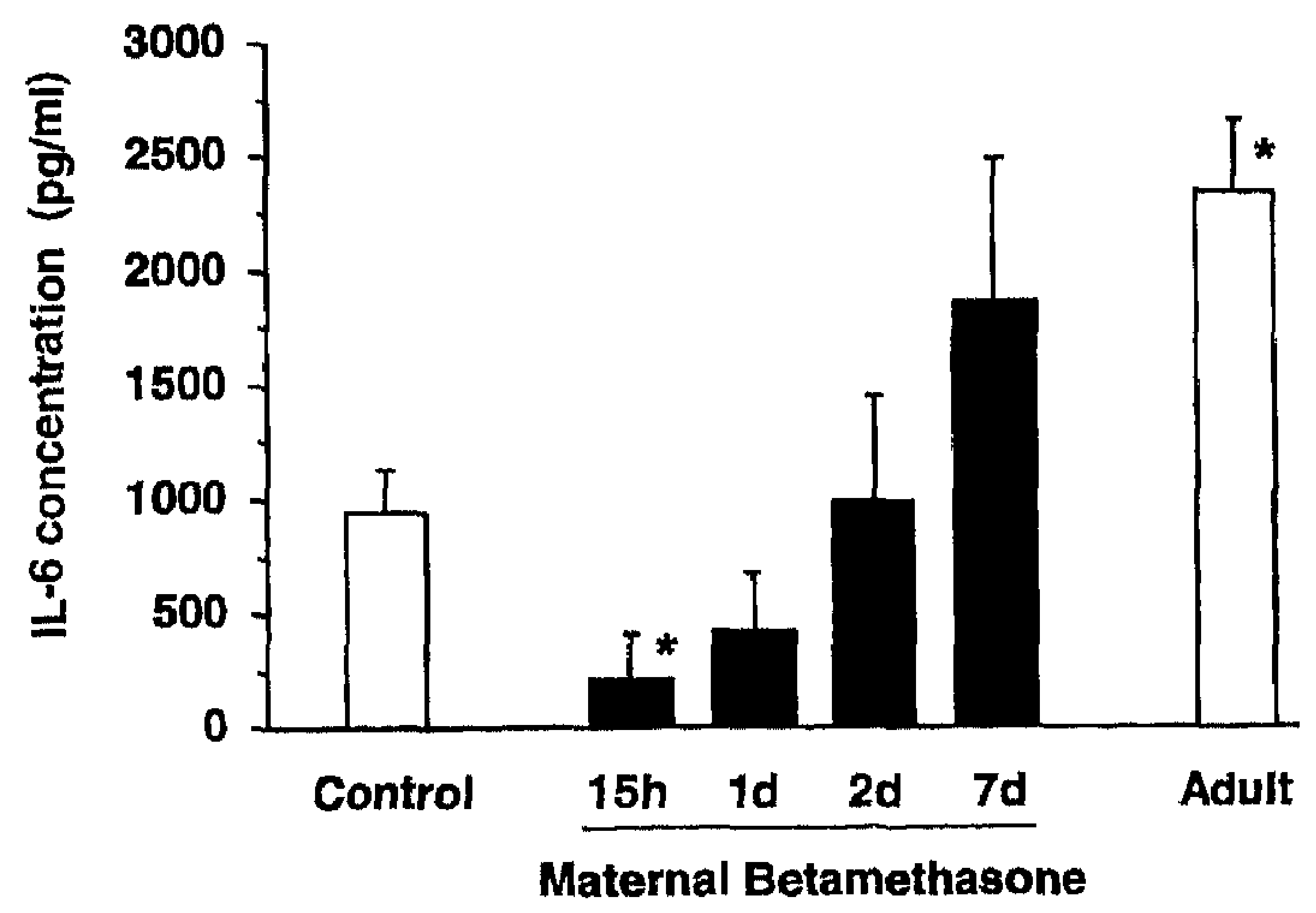

Figure 3. Concentrations of $\mathrm{IL}-6$ in culture media after stimulation with endotoxin. Concentrations were determined by ELISA. IL-6 concentrations were lower in monocytes from preterm sheep than in monocytes from adult sheep. Exposure to maternal betamethasone reduced IL-6 concentrations after $15 \mathrm{~h}(p<0.05 v s$ control). 
suppressed IL-6 after a $15 \mathrm{~h}$ exposure, and IL-6 was qualitatively increased to a value similar to the adult cell response at $7 \mathrm{~d}$.

\section{DISCUSSION}

We used a sheep model that allowed us to evaluate monocyte responses to antenatal corticosteroid exposures that are similar in dose and duration to the clinical use of maternal corticosteroid treatments. We and others have demonstrated that monocytes and macrophages from preterm subjects have multiple differences in responses from the adult blood monocytes $(10,21-25)$. The effects of antenatal corticosteroids on human monocytes have not been evaluated in detail, although corticosteroids can acutely modulate inflammatory responses when cord blood monocytes are exposed to corticosteroids in culture $(7,26,27)$. As would be anticipated from antiinflammatory effects, antenatal betamethasone suppressed $\mathrm{H}_{2} \mathrm{O}_{2}$ production for $2 \mathrm{~d}$ and $\mathrm{IL}-6$ production at $15 \mathrm{~h}$. The interesting responses were the augmented phagocytosis of apoptotic neutrophils, the increased $\mathrm{H}_{2} \mathrm{O}_{2}$, and the trend to increase IL- 6 secretion by the monocytes from the $7 \mathrm{~d}$ corticosteroid group. These monocytes have responses that are similar to monocytes from the adult animal. With the limited information that we have, it is not clear what these changes in responses are. It is too simplistic to say that the monocytes were initially suppressed and then matured by the corticosteroid because we do not know the fate or persistence of the changed responses. However, at least for an interval of $7 \mathrm{~d}$, a single corticosteroid exposure reprogrammed the responses of the fetal monocytes.

This finding adds to other effects of maternal corticosteroids on fetal immune cells. Several deficits in immune function have been reported after maternal corticosteroid treatment, such as decreased neutrophil chemotaxis (28) and decreased absolute numbers and proliferation of fetal lymphocytes with a reduced production of IL-2 $(12,29)$. This effect was not limited to the fetus but affected maternal lymphocytes as well (29). However, maternal corticosteroid effects are not exclusively immunosuppressive inasmuch as maternal treatment increased the activity of natural killer cells in preterm infants (11).

The effects of altered monocyte function in the fetus will depend on how other components of the immune/inflammatory system are altered by the antenatal corticosteroid exposure. There are several target organs for adverse immune/ inflammatory effects in the preterm infant. The brain may be injured as a consequence of a systemic inflammatory response (30). BPD is associated with chorioamnionitis and fetal infection and antenatal corticosteroids suppress alveolar septation in the developing lung (31). Assuming that blood monocytes populate the fetal lung and differentiate to become alveolar macrophages $(10,32,33)$, altering monocyte function to be more pro-inflammatory by increasing the capacity for $\mathrm{H}_{2} \mathrm{O}_{2}$ and IL-6 production could be detrimental. In a previous study, we used cord blood-derived monocytes to study agents in vitro that are used in the treatment of pulmonary disease in preterm infants (10). The phagocytosis of apoptotic cells by monocytes was increased in the presence of both surfactant proteins and phospholipids. As an example of interactive phenomena resulting in the potential for increased lung injury, we reported that fetuses exposed to intra-amniotic endotoxin $30 \mathrm{~d}$ before preterm delivery had increased numbers of monocytes in alveolar washes and more pro-inflammatory cytokine mRNA after mechanical ventilation than did control lambs (34). This experiment demonstrates that a fetal exposure can change a postnatal immune/inflammatory response. Antenatal corticosteroids decrease respiratory distress syndrome but do not decrease BPD (1). In the meta-analysis of Crowley (1), the relative risk of BPD after antenatal steroids was 1.38 (95\% confidence interval, 0.90-2.11) which was a trend toward increasing the risk of BPD. This unanticipated outcome has been explained by survival of the smaller and more marginal infants at highest risk for BPD. Banks et al. observed severe respiratory failure in some preterm infants after repetitive courses of antenatal corticosteroids (35). Perhaps antenatal corticosteroids can augment an inflammatory response to a second stimulus after birth and contribute to the development of BPD in some infants.

This concept of interacting signals amplifying a fetal response also has been demonstrated by the simultaneous exposure of fetal sheep to maternal corticosteroids and intraamniotic endotoxin. Intra-amniotic endotoxin is a model of the chronic chorioamnionitis that is frequently associated with preterm birth in humans (36). Intra-amniotic endotoxin causes chorioamnionitis and lung inflammation in fetal sheep $(15,18$, 37). Maternal corticosteroids suppress the acute inflammation for about $3 \mathrm{~d}$ after the intra-amniotic endotoxin, but there is a late inflammatory response that persists for $5-15 \mathrm{~d}$ (38). The late inflammation that follows the initial corticosteroid-induced suppression of inflammation may result in part from priming of the immature inflammatory response by corticosteroids.

We found that maternal corticosteroid had a biphasic immunomodulatory effect on blood monocytes in the fetal sheepsuppression of function followed by augmented function. We speculate that this augmented function represents reprogramming that could have long-term effects on subsequent immune responses in fetal and later life.

\section{REFERENCES}

1. Crowley P 2003 Prophylactic corticosteroids for preterm birth. Cochranc Database Syst Rev 2:CD000065

2. Schacke H, Docke WD, Asadullah K 2002 Mechanisms involved in the side effects of glucocorticoids. Pharmacol Ther 96:23-43

3. Jobe AH 2001 Glucocorticoids, inflammation and the perinatal lung. Semin Neonatol 6:331-342

4. Berry LM, Polk DH, Ikegami M, Jobe AH, Padbury JF, Ervin MG 1997 Preterm newbom lamb renal and cardiovascular responses after fetal or maternal antenatal betamethasone. Am J Physiol 272;R1972-R 1979

5. Bessler H, Kagazanov S, Punsky I, Sirota L 2001 Effect of dexamethasone on IL-10 and IL-12p40 production in newborns and adults. Biol Neonate 80:262-266

6. Schwarze J, Bartmann P 1994 Influence of dexamethasone on lymphocyte proliferation in whole blood cultures of neonates. Biol Neonate 65:295-301

7. Witek-Janusck L, Mathews HL 1999 Differential effects of glucocorticoids on colony stimulating factors produced by neonatal mononuclear cells. Pediatr Res 45:224-229

8. Schelonka RL, Infante AJ 1998 Neonatal immunology. Semin Perinatol 22:2-14

9. Caudle MR, Harbert GMJ, Singhas CA 1981 Effect of betamethasone on fetal macrophage function: depression of adherence of immunoglobulin-coated red blood cells, Am I Reprod Immunol 1:182-184

10. Kramer BW, Jobe AH, Ikegami M 2003 Monocyte function in preterm, near term and adult sheep. Pediatr Res 54:52-57

11. Kavelaars A, van der Pompe G, Bakker JM, van Hasselt PM, Cats B, Visser GH, Heijnen CJ 1999 Altered immune function in human newborns after prenatal administration of betamethasone: enhanced natural killer cell activity and decreased $\mathrm{T}$ cell proliferation in cord blood. Pediatr Res 45:306-312 
12. Chabra S, Cottrill C, Rayens MK, Cross K, Lipke D, Bruce M 1998 Lymphocyte subsets in cord blood of preterm infants: effect of antenatal steroids. Biol Neonate $74: 200-207$

13. Yoon BH, Romero R, Kim KS, Park JS, Ki SH, Kim BI, Jun JK 1999 A systemic fetal inflammatory response and the development of bronchopulmonary dysplasia. Am Obstet Gynecol 179:1254-1260

14. Pringle KC 1986 Human fetal lung development and related animals models. Clin Obstet Gynecol 29:502-513

15. Jobe AH, Newnham JP, Willet KE, Sly P, Ervin MG, Bachurski C, Possmayer $F$ Hallman M, Ikegami M 2000 Antenatal endotoxin and glucocorticoid effects on the lungs of preterm lambs. Am J Obstet Gynecol 182:401-408

16. Kanof ME, Smith PD, Zola H 1996 Separation of peripheral blood mononuclear cells. In: Coligan JE, Kruisbeek AM, Margulies DH, Shevach EM, Strober W (cds) Current Protocols in Immunology. Wiley-Interscience, New York, pp 7.1.1-7.1.7

17. Hed J, Hallden G, Johansson SG, Larsson P 1989 Quantitative rather than qualitative differences between monocytes with respect to IgE FC receptor expression as studied by flow cytofiuorometry. Int Arch Allergy Appl Immunol 88:408-411

18. Kramer BW, Moss TJ, Willet KE, Newnham JP, Sly PD, Kallapur SG, Ikegami M, Jobe AH 2001 Dose and time response after intraamniotic endotoxin in preterm lambs. Am J Respir Crit Care Med 164:982-988

19. Hu B, Sonstein J, Christensen PJ, Punturieri A, Curtis JL 2000 Deficient in vitro and in vivo phagocytosis of apoptotic $T$ cells by resident murine alveolar macrophages. J Immunol 165:2124-2133

20. Vermes I, Haanen C, Steffens-Nakken H, Reutelingsperger C 1995 A novel assay for apoptosis. Flow cytometry detection of phosphatidylserine expression on early apoptotic cells using fluorescin labeled Annexin V. J Immunol Methods $184: 39-51$

21. Marshall-Clarke S, Reen D, Tasker L, Hassan J 2000 Neonatal immunity: how well has it grown up? Immunol Today 21:35-41

22. Weiss RA, Chanana AD, Joel DD 1986 Postnatal maturation of pulmonary antimicrobial defense mechanisms in conventional and germ-free lambs. Pediatr Res 20:496-504

23. Zeligs BJ, Nerurkar LS, Bellanti JA, Zeligs ID 1977 Maturation of the rabbit alveolar macrophage during animal development. I. Pcrinatal influx into alveoli and ultrastructural differentiation. Pediatr Res 11:197-208

24. Nerurkar LS, Zeligs BJ, Bellanti JA 1977 Maturation of the rabbit alveolar macrophage during animal development. II. Biochemical and enzymatic studies. Pediatr Res 11:1202-1207
25. Zeligs BJ, Nenurkar LS, Bellanti JA 1977 Maturation of the rabbit alveolar macrophage during animal development. III. Phagocytic and bactericidal functions. Pediatr Res 11:1208-1211

26. Schultz C, Rott C, Temming P, Schlenke P, Möller JC, Bucsky P 2002 Enhanced interleukin- 6 and interleukin- 8 synthesis in term and preterm infants. Pediatr Res $51: 317-322$

27. Dembinski J, Behrendt D, Martini R, Heep A, Bartmann P 2003 Modulation of proand anti-inflammatory cytokine production in very preterm infants. Cytokine $21: 200-$ 206

28. Fuenfer MM, Herson VC, Raye JR, Woronick CL, Eisenfeld L, Ingardia CI, Block CF, Krause PJ 1987 The effect of betamethasone on neonatal neutrophil chemotaxis. Pediatr Res 22:150-153

29. Murthy KK, Moya FR 1994 Effect of betamethasone on maternal, fetal and neonatal rat cellular immunity. Early Hum Dev $36: 1-11$

30. Nelson KB, Dambrosia JM, Grether JK, Phillips TM 1998 Neonatal cytokines and coagulation factors in children with cerebral palsy. Ann Neurol 44:665-675

31. Jobe AH, Ikegami M 2001 Antenatal infection/inflammation and postnatal lung maturation and injury. Respir Res 2:27-32

32. Jacobs RF, Wilson CB, Palmer $S$, Springmeyer SC, Henderson WR, Glover DM, Kessler Jr DL, Murphy JH, Hughes JP, van Belle G, Chi EY, Hodson WA 1985 Factors related to the appearance of alveolar macrophages in the developing lung. Am Rev Respir Dis 131:548-553

33. Radzun HJ, Parwaresch MR, Kreipc H 1983 Monocytic origin of human alveolar macrophages. J Histochem Cytochem 31:318-324

34. Ikegami M, Jobe AH 2002 Postnatal lung inflammation increased by ventilation of preterm lambs exposed antenatally to Escherichia coli endotoxin. Pediatr Res $52: 356-362$

35. Banks BA, Cnaan A, Morgan MA, Parer JT, Mcrrill JD, Ballard PL, Ballard RA 1999 Multiple courses of antenatal corticosteroids and outcome of premature neonates. Am J Obstet Gynecol 181:709-717

36. Goldenberg RL, Hauth JC, Andrews WW 2000 Intrauterine infection and preterm delivery. N Engl I Med 342:1500-1507

37. Kallapur SG, Willet $\mathrm{KE}$, Jobe AH, Ikegami M, Bachurski CJ 2001 Intra-amniotic endotoxin: chorioamnionitis precedes lung maturation in preterm lambs. Am J Physiol 280:L527-L536

38. Kallapur SG, Kramer BW, Moss TJ, Newnham JP, Jobe AH, Ikegami M, Bachurski CJ 2003 Maternal glucocorticoids increase endotoxin induced lung inflammation in preterm lambs. Am J Physiol 284:L633-L642 


\section{CHAPTER 11}

Endotoxin induced chorioamnionitis modulates innate immunity of monocytes in preterm sheep

Kramer B.W., Ikegami M., Moss T.J.M., Nitsos I., Newnham, J.P., Jobe, A.H. 


\title{
Endotoxin-induced Chorioamnionitis Modulates Innate Immunity of Monocytes in Preterm Sheep
}

\author{
Boris W. Kramer, Machiko Ikegami, Timothy J. M. Moss, llias Nitsos, John P. Newnham, and Alan H. Jobe \\ University Children's Hospital, Wuerzburg, Germany; Division of Pulmonary Biology, Cincinnati Children's Hospital Medical Center, University \\ of Cincinnati, Cincinnati, Ohio; and the School of Women's and infants' Health, The University of Western Australia, Perth, Australia
}

\begin{abstract}
The preterm fetus is immune naive and has immature innate immune function. Although the preterm fetus is frequently exposed to chorioamnionitis, the effects of exposure of the fetal lung to inflammation on innate immune responses are unknown. Using the fetal sheep model of chorioamnionitis, cord blood monocytes were isolated from preterm lambs 1 to 14 days after intra-amniotic endotoxin injection, cultured for approximately 16 hours, and challenged with endotoxin in vitro. Compared with monocytes from adult sheep, the preterm monocytes produced less $\mathrm{H}_{2} \mathrm{O}_{2}$ and interleukin-6, and toll-like receptor 4 expression was decreased. Three days after intra-amniotic endotoxin exposure, preterm monocyte responses to in vitro endotoxin challenge demonstrated decreased $\mathrm{H}_{2} \mathrm{O}_{2}$ and interleukin-6 production and decreased $\mathrm{CD} 14$ and major histocompatibility complex class II expression. Preterm monocyte responses 7 to 14 days after endotoxin tended to exceed those of adults and preterm control animals indicating augmented function. In contrast, a second intra-amniotic endotoxin injection 7 days after the initial endotoxin exposure suppressed monocyte function at 14 days. The fetal monocytes demonstrated patterns of responses consistent with endotoxin tolerance (immune paralysis) as well as maturation of function. Modulation of fetal innate immune responses by exposure to inflammation may alter subsequent immune adaptation after birth.
\end{abstract}

Keywords: endotoxin tolerance; fetal immunity; nosocomial infection; priming

The fetus is generally recognized as immunologically naîve, but chronic indolent chorioamnionitis caused by commensal or low pathogenic organisms occurs in the majority of pregnancies complicated by preterm labor and delivery before 30 weeks gestation $(1-3)$. Fetal exposure to inflammation/infection or a fetal systemic inflammatory response increases neonatal morbidity and mortality and neurodevelopmental or lung injury (4-7). Approximately $30 \%$ of preterm infants with a very low birth weight also develop nosocomial infections that often have no identifiable source $(8,9)$. The innate immune system of the preterm is considered to be immature because multiple host defense proteins are low, immune cell numbers are low, and immune cell functions are low relative to cells from older children or adults (10).

Very little information is available about innate immune responses and their modulation in the fetus, although such responses may be central to a number of the injuries associated with preterm birth (7). Fetal exposure to inflammation might

(Received in original form June 13, 2004; accepted in final form September 25, 2004) Supported by grant A-27 of the interdisciplinary Center for Clinical Research, University of Wuerzburg/Germany, and HL-65397 and HD-12714 from the $\mathrm{Na}$ tional Institute of Health and the Women's and Infants' Research Foundation, Western Australia.

Correspondence and requests for reprints should be addressed to Boris W. Kramer, M.D., University Children's Hospital, Josef-Schneider-Str. 2, 97080 Wuerzburg, Germany. E-mail: kramer_b@kinderklinik.uni-wuerzburg.de

Am J Respir Crit Care Med Vol 171. pp 73-77, 2005

Originally Published in Press as DOl: 10.1164/rccm.200406-7450C on October 1, 2004 Internet address: www.atsjournals.org either increase or suppress subsequent immune responses (1). Immune responsiveness could be decreased by exposure to inflammatory products resulting in the fetal equivalent of endotoxin tolerance or innate immune paralysis. For example, plasma interleukin (IL) 6 levels are strikingly decreased in fetal sheep after repetitive injections of low dose Escherichia coli endotoxin (11). An example of increased responsiveness is the augmented production of $\mathrm{H}_{2} \mathrm{O}_{2}$ and phagocytosis by blood monocytes in fetal sheep 7 days after maternal betamethasone exposure (12).

Chorioamnionitis induced by intra-amniotic endotoxin is primarily a pulmonary exposure for the fetus and results in lung inflammation and striking lung maturation as a result of direct contact of endotoxin or IL-1 with the fetal lung (13-15). Fetal inflammation occurs mainly in the lung with a modest systemic inflammatory response (lower granulocytes, modest plasma elevations of IL-6) $(16,17)$. We hypothesized that a result of the modest systemic inflammatory response to intra-amniotic endotoxin-induced lung inflammation would be a modulation of the responses of blood monocytes to a later exposure to endotoxin. Altered monocyte function could affect subsequent immune function in the fetus and newborn. To test this hypothesis, we gave fetal sheep injections of intra-amniotic endotoxin for intervals from 1 to 14 days before preterm delivery. Monocyte function was evaluated by measuring phagocytosis of $E$. coli, hydrogen peroxide production, and IL-6 production in response to endotoxin stimulation in vitro. Several aspects of endotoxin binding and signal transduction were explored by quantification of endotoxin receptor (CD14) expression, expression of endotoxin signal transducing receptor (toll-like receptor 4 [TLR4]) and major histocompatibility complex (MHC) class II on the monocytes.

\section{METHODS}

\section{Animals}

The animals were sludied in Western Australia with approved protocols by the Cincinnati Children's Hospital (Cincinnati, $\mathrm{OH}$ ) and the Western Australian Department of Agriculture. Time-mated Merino ewes with singleton fetuses were randomly assigned in groups of five to seven animals to receive a single dose of $10 \mathrm{mg}$ endotoxin $(E$. coli $055: \mathrm{B} 5$; Sigma, St. Louis, MO) by intra-amniotic injection at $1,3,7$, or 14 days or at 7 and 14 days before cesarean delivery at 124 days gestational age (18).

\section{Monocyte Isolation and Culture}

Fetal cord blood drawn at delivery and blood from healthy pregnant ewes was used to isolate monocytes using Percoll gradients as described before $(12,19)$. Cells were counted using trypan blue to evaluate viability, and the cells were plated on culture dishes in RPMI 1640 media supplemented by heat-inactivated fetal calf serum. After incubation at $37^{\circ} \mathrm{C}$ for 2 hours, nonadherent cells were removed by washing. The adherent cell population was $89 \pm 4 \%$ monocytes for all treatment and control groups. Monocytes in other culture dishes were cultured overnight, and the experiments were done after approximately 16 hours in culture.

\section{Phagocytosis of E. coli}

After overnight incubation, monocytes were exposed to fluorescein isothiocyanate-labeled $E$. coli (Sigma Chemicals) for 6 hours. Monocytes 
were suspended, and trypan blue $(1.25 \mathrm{mg} / \mathrm{ml})$ was added to one aliquot to measure ingested bacteria only. The total bound and ingested bacteria were measured by flow cytometry $(12,19)$.

\section{Hydrogen Peroxide Production and IL-6 Concentration}

After overnight incubation, monocytes were exposed to 10 and $100 \mathrm{ng} / \mathrm{ml}$ E. coli endotoxin for 6 hours (20). Production of hydrogen peroxide by $10^{6}$ monocytes was measured with an assay kit (OXIS International, Portland, OR). Control samples were exposed to saline instead of endotoxin and were included in all experiments. IL- 6 was measured in the cell culture medium of endotoxin-stimulated monocytes with an ovinespecific ELISA (17).

\section{Expression of CD14, TLR4, and MHC II on Monocytes}

Sheep-specific CD14 endotoxin receptor and MHC II antibodies (VMRD Inc., Pullman, WA) and a species cross-reacting anti-TLR4 antibody (BD Biosciences, San Jose, CA) were used to measure these surface receptors by fluorescence-activated cell sorter analysis using appropriate secondary antibodies. Control staining was performed with isotype antibodies and with secondary antibody alone to evaluate background fluorescence (17).

\section{Data Analysis}

Results are presented as mean \pm SEM. Comparisons between endotoxintreated groups and untreated control animals were by analyses of variance with Student-Newman-Keuls tests used for post hoc analyses. Results were compared with monocytes from healthy adult sheep. Statistical significance was accepted at $p<0.05$.

\section{RESULTS}

\section{Description of Animals}

The birth weights of the animals in the control and intra-amniotic endotoxin-exposed groups were similar (Table 1). Intra-amniotic endotoxin increased total circulating white blood cells for the groups exposed 7 days or 7 and 14 days before delivery but not significantly at 14 days. Neutrophils accounted for the increase in total cell number, whereas blood monocyte numbers did not change with the in vivo endotoxin exposure.

\section{Phagocytosis}

Phagocytosis of $E$. coli by blood monocytes from adult sheep tended to be higher than for fetal sheep at 124 days gestation, but this difference was not statistically significant (Table 1). Intra-amniotic endotoxin had no effect on the phagocytosis of $E$. coli by cord blood-derived monocytes from the preterm lambs.

\section{$\mathrm{H}_{2} \mathrm{O}_{2}$ Production}

Endotoxin-stimulated blood monocytes from adult sheep produced more $\mathrm{H}_{2} \mathrm{O}_{2}$ than did cord blood monocytes from the control preterm lambs after stimulation with 10 or $100 \mathrm{ng} / \mathrm{ml}$ endotoxin (Figure 1). Monocytes from adult or fetal sheep produced very little $\mathrm{H}_{2} \mathrm{O}_{2}$. Monocytes from lambs exposed to intraamniotic endotoxin for 1 day and 3 days had suppressed $\mathrm{H}_{2} \mathrm{O}_{2}$ production when compared with monocytes from the preterm control animals. However, 14 days after the intra-amniotic endotoxin, the endotoxin-induced $\mathrm{H}_{2} \mathrm{O}_{2}$ production exceeded considerably that of both the control preterm and adult monocytes. In striking contrast to the 14-days endotoxin exposed group, $\mathrm{H}_{2} \mathrm{O}_{2}$ production was very low after fetal exposure to intraamniotic endotoxin 7 and 14 days before the in vitro endotoxin challenge.

\section{IL-6 Concentration}

Endotoxin concentrations of 10 or $100 \mathrm{ng} / \mathrm{ml}$ increased IL-6 concentration in the media of cultured monocytes from adult and preterm control sheep relative to the low IL-6 concentration without endotoxin stimulation (Figure 2). A prior exposure to intra-amniotic endotoxin 3 days before delivery reduced the concentration of IL- 6 in culture media after re-exposure to endotoxin in vitro. The IL- 6 concentrations in the media of monocytes exposed to 10 or $100 \mathrm{ng} / \mathrm{ml}$ endotoxin after the fetal endotoxin exposure were similar to the concentrations of IL-6 from monocytes from adult sheep. The 7- and 14-day repeated exposures of fetuses to intra-amniotic endotoxin had no effects on endotoxininduced IL- 6 concentration compared with preterm control animals.

\section{CD14, TLR4, and MHC II Expression}

CD14 expression was not different between monocytes from control preterm lambs and monocytes from adult animals after stimulation with $100 \mathrm{ng} / \mathrm{ml}$ endotoxin (Figure $3 \mathrm{~A}$ ). Similar results were obtained with $10 \mathrm{ng} / \mathrm{ml}$ endotoxin (data not shown). CD14 expression was decreased qualitatively 1 and 7 days after intraamniotic endotoxin exposure and significantly after 3 days. The signal-transducing molecule for endotoxin mediated cell activation, TLR4, had a different pattern of expression. TLR4 expression was higher by approximately twofold on monocytes from adult animals than those from preterm control animals (Figure 3B). The expression was increased in cord blood-derived monocytes 14 days after intra-amniotic endotoxin. The expression was not different at the other time points. MHC II expression was similar for adult and preterm control monocytes (Figure 3C). Expression was strikingly decreased 3 days after intra-amniotic endotoxin.

\section{DISCUSSION}

The temporary suppression of innate immune cell responses by endotoxin has been referred to as "endotoxin tolerance" $(21,22)$.

TABLE 1. DESCRIPTION OF ANIMALS

\begin{tabular}{|c|c|c|c|c|c|}
\hline Groups & $\begin{array}{c}\text { Animal } \\
\text { No. }\end{array}$ & $\begin{array}{c}\text { Birth Weight } \\
(\mathrm{kg})\end{array}$ & $\begin{array}{c}\text { WBCs in Cord } \\
\text { Blood } \\
\left(\times 10^{9} / \mathrm{L}\right)\end{array}$ & $\begin{array}{c}\text { Monocytes Cord } \\
\text { Blood } \\
\left(\times 10^{6} / L\right)\end{array}$ & $\begin{array}{c}\text { Phagocytosis by } \\
\text { Monocytes* }\end{array}$ \\
\hline Adult & 8 & - & & - & $104 \pm 19$ \\
\hline Preterm control & 7 & $2.7 \pm 0.1$ & $3.4 \pm 0.3$ & $95 \pm 30$ & $78 \pm 8$ \\
\hline $1 d$ & 7 & $2.8 \pm 0.2$ & $2.4 \pm 0.4$ & $300 \pm 100$ & $83 \pm 9$ \\
\hline $3 d$ & 6 & $2.9 \pm 0.1$ & $4.3 \pm 0.6$ & $230 \pm 40$ & $73 \pm 13$ \\
\hline $7 d$ & 6 & $2.7 \pm 0.1$ & $7.1 \pm 0.9^{\dagger}$ & $150 \pm 20$ & $85 \pm 14$ \\
\hline $14 d$ & 6 & $2.9 \pm 0.1$ & $5.1 \pm 0.5$ & $160 \pm 60$ & $93 \pm 15$ \\
\hline 7 and $14 d$ & 5 & $2.9 \pm 0.1$ & $5.9 \pm 0.7^{\dagger}$ & $280 \pm 40$ & $73 \pm 12$ \\
\hline
\end{tabular}

Definition of abbreviations: WBCs $=$ white blood cells.

* Mean fluorescent units of phagocytosed fluorescent $E$. coli by monocytes.

${ }^{\dagger} \mathrm{p}<0.05$ versus preterm control. 


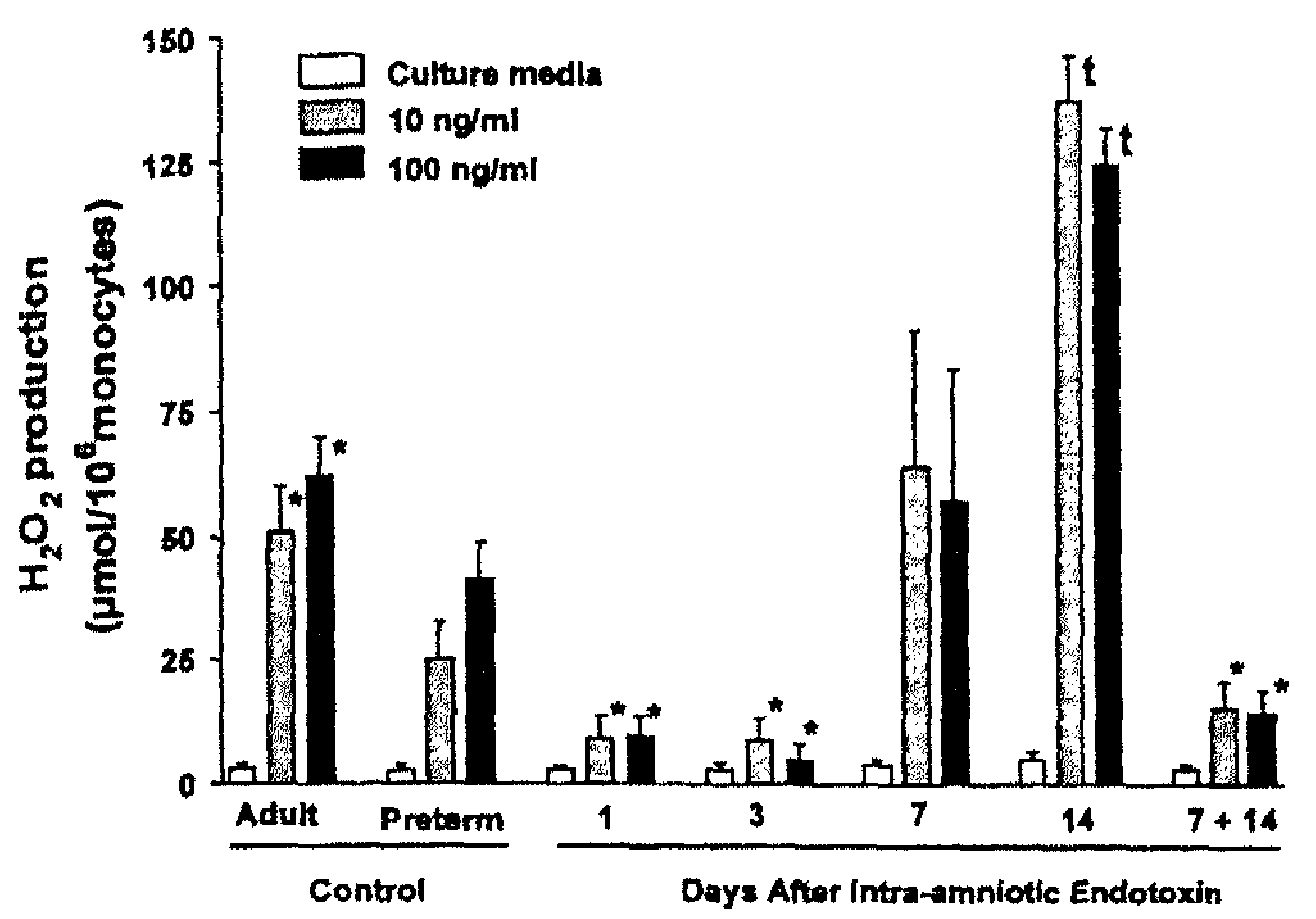

Figure 1. Production of hydrogen peroxide by monocytes after stimulation with 10 or $100 \mathrm{ng} / \mathrm{ml}$ endotoxin. Intra-amniotic endotoxin suppressed $\mathrm{H}_{2} \mathrm{O}_{2}$ production at 1 days, 3 days, and $7+14$ days when compared with preterm control animals. However, at 14 days after intra-amniotic endotoxin, the $\mathrm{H}_{2} \mathrm{O}_{2}$ production exceeded that of both preterm and adult monocytes. In comparison to the group after 14 days intra-amniotic exposure, $\mathrm{H}_{2} \mathrm{O}_{2}$ production was lower after a second dose of intra-amniotic endotoxin at 7 days. Monocytes in culture media alone produced very little $\mathrm{H}_{2} \mathrm{O}_{2}\left({ }^{*} \mathrm{p}<0.05\right.$ vs. endotoxin-stimulated preterm control animals; ${ }^{t} p<0.05$ vs. preterm and adult endotoxinstimulated control animals).

Endotoxin tolerance is used to describe in vivo models in which a normally lethal endotoxin dose can be tolerated by animals that were previously exposed to sublethal dose of endotoxin (21). Chronically catheterized preterm fetal sheep respond to intravascular endotoxin with a tolerance type response (11). Endotoxin tolerance/immune paralysis is a risk factor for multiorgan failure or sepsis in hospitalized patients (23). Preterm infants are extremely susceptible to nosocomial infections several weeks after preterm birth, at a time when they are often doing well (24). This clinical susceptibility to infection is consis-

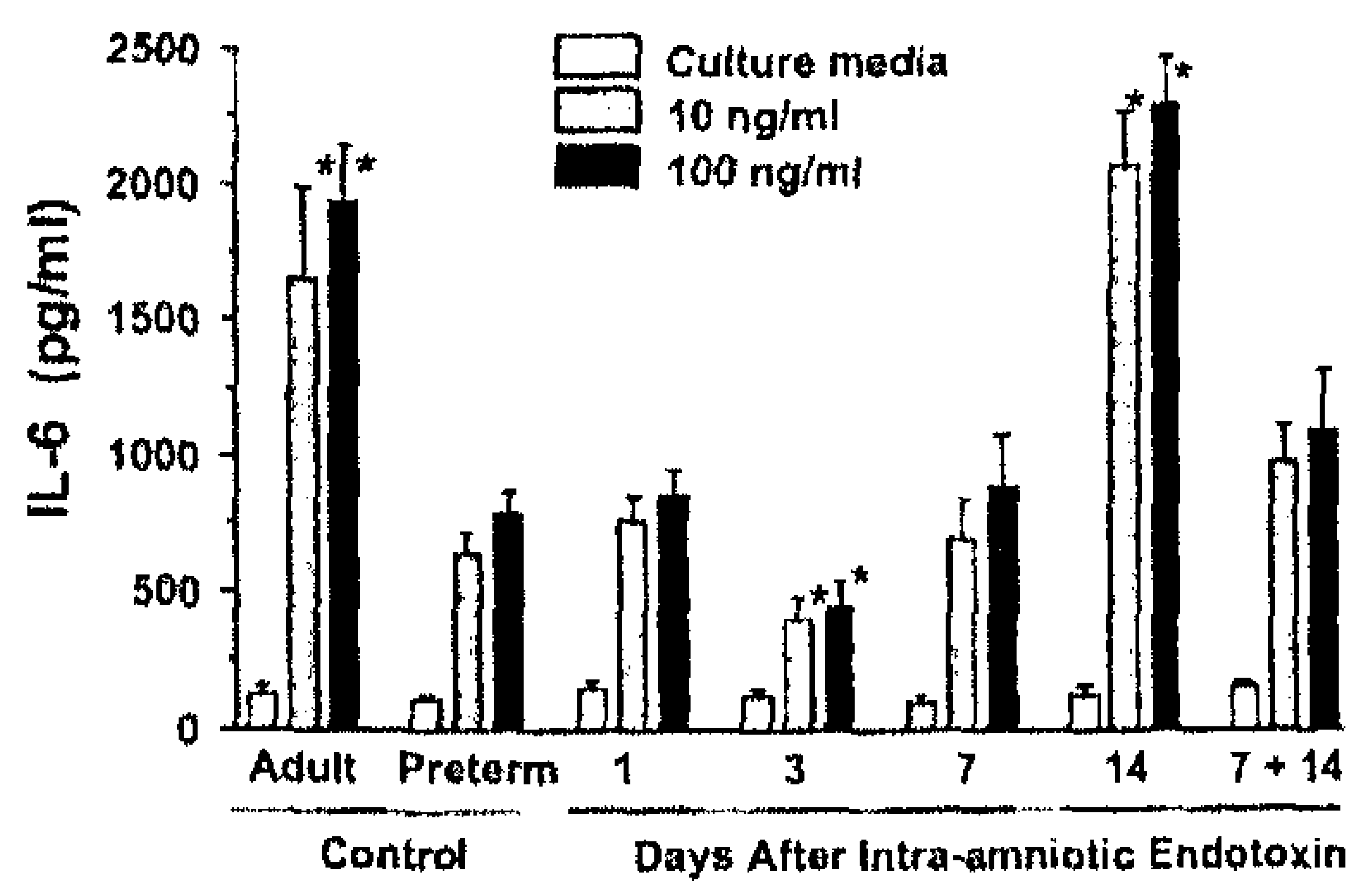

Figure 2. Concentrations of interleukin (IL)- 6 in culture media after stimulation of monocytes with 10 or $100 \mathrm{ng} / \mathrm{ml}$ endotoxin. The $1 \mathrm{~L}-6$ concentration was approximately three times higher for endotoxinstimulated adult monocytes than for endotoxin-stimulated preterm monocytes. Intra-amniotic endotoxin reduced the concentration of IL-6 in culture media 3 days after re-exposure to endotoxin. After 14 days of intra-amniotic endotoxin, the concentration of IL-6 increased to levels similar to monocytes from adult animals. The IL-6 concentration in culture media of monocytes from control animals was very low ${ }^{*} p<$ 0.05 vs. endotoxin-stimulated preterm control animals).

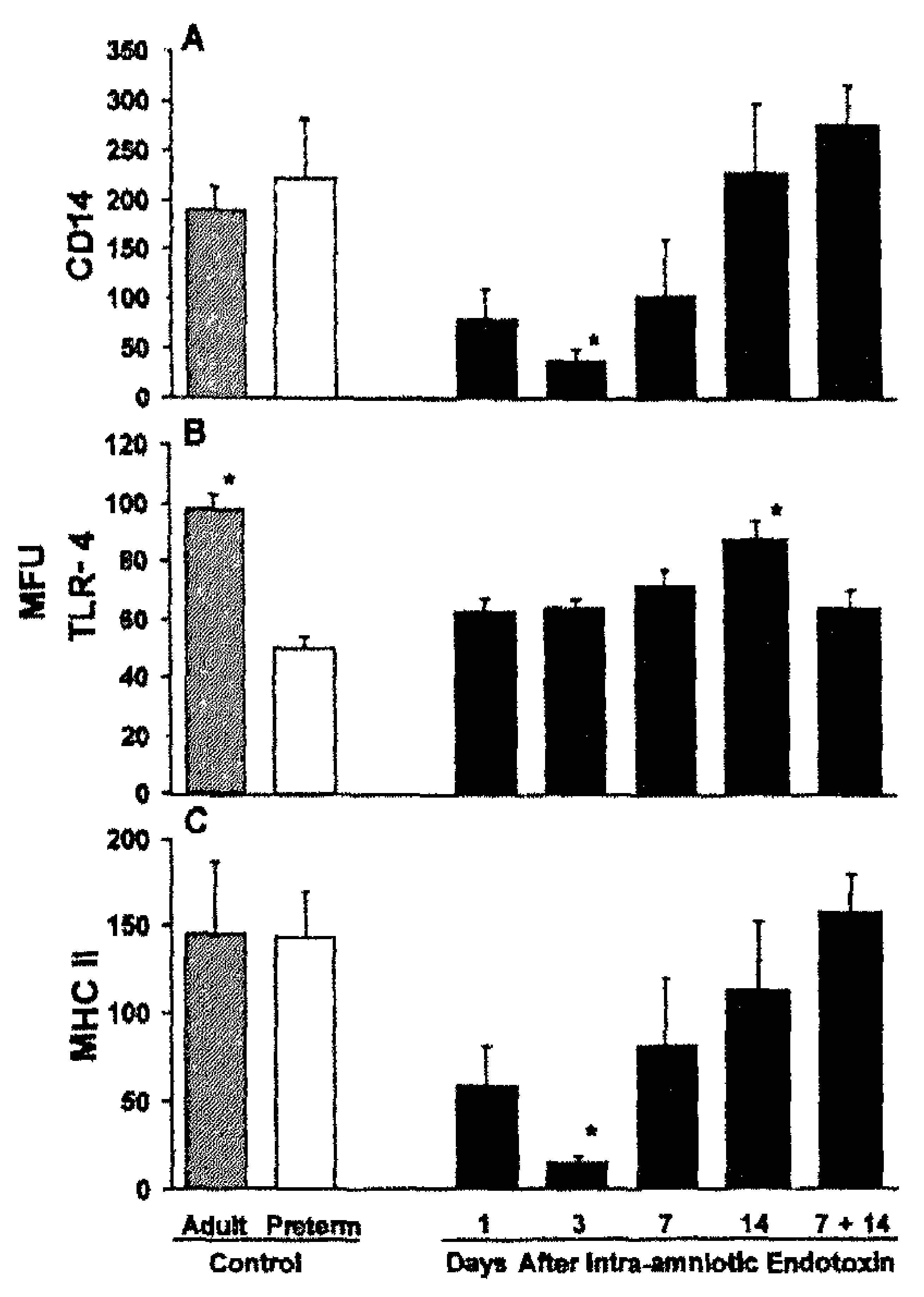

Figure 3. Expression of CD14, toll-like receptor 4 (TLR4), and major histocompatibility complex (MHC) II in mean fluorescent units (MFU) after stimulation with $100 \mathrm{ng} / \mathrm{ml}$ endotoxin. (A) Flow cytometry analysis of expression of receptor for complex of endotoxin and lipopolysaccharide binding protein (CD14) on cord blood monocytes after incubation with endotoxin in vitro. The signal was lower than in preterm control animals 3 days after intra-amniotic endotoxin exposure. (B) Expression of TLR4, the signal transduction molecule for endotoxin, on cord blood monocytes after incubation with endotoxin in vitro. TLR4 was higher on monocytes from adult animals than preterm control animals. The expression was increased 14 days after intra-amniotic endotoxin. (C) MHC II was similarly expressed on monocytes from preterm and adult control animals. The expression was reduced 3 days after endotoxin exposure ( $* p<0.05$ vs. preterm control animals).

tent with immune paralysis, but we are not aware of studies that address this possibility.

The responses of monocytes from fetal sheep to endotoxin are complex. The initial suppression of $\mathrm{H}_{2} \mathrm{O}_{2}$ and IL -6 and decreased CD14 and MHC II receptors are typical of endotoxin tolerance. In contrast, the increased production of $\mathrm{H}_{2} \mathrm{O}_{2}$ and IL-6 and increased TLR4 expression 14 days after endotoxin exposure indicate an augmented innate host response relative to the con* trol fetal monocytes. However, the repeated exposure at a 7-day interval resulted in profound suppression of $\mathrm{H}_{2} \mathrm{O}_{2}$ production. A similar pattern of response occurred with the different endotoxin concentrations tested in vitro. Clinically, chorioamnionitis is often indolent and persists for weeks or months (2). Our results suggest that chronic fetal exposure to inflammation could cause a profound and persistent tolerance +type response and thus put these infants at risk of nosocomial infection (25).

These experiments are a first evaluation of how fetal exposure to inflammation might modulate or affect innate immune responses. The concepts of endotoxin tolerance have been developed primarily in mice and the adult human. In adult mice, endotoxin exposure decreases tumor necrosis factor- $\alpha$ and in- 
creases IL-1 secretion by monocytes (21). The mechanisms proposed for endotoxin tole rance in humans and mice are controversial but may include downregulation of endotoxin receptors, lipopolysaccharide-binding protein, or CD14 and alterations in the signaling pathways to decrease nuclear factor- $\kappa B$ nuclear translocation as well as changes in the cytokine expression profile of the cells (21).

We did not use catheterized animals to avoid the stress of fetal surgery and the potential for infection in catheterized animals. These studies of the fetal innate immune system are unique because the immune system is naive and immature. An example of differences between the preterm and the adult is the observation that the fetal sheep does not respond to ovine tumor necrosis factor- $\alpha$ but has systemic and lung inflammatory responses to IL-1 $(13,26)$. Fetal responses to IL-6 have not been evaluated. The decrease in monocyte surface receptors and suppressed function with single or repetitive fetal endotoxin exposure are consistent with an immune paralysis-type response by immature monocytes (22). The enhanced response 14 days after intraamniotic endotoxin exposure may represent recovery from immune paralysis together with a maturation of monocyte function. A similar pattern of suppression followed by increased function occurs in response to maternal glucocorticoid exposure $(12,18)$. Fetal monocytes have inhibited function that resolves to resemble the function of adult monocytes by 7 days after maternal betamethasone exposure (12).

Another unique aspect of these studies is that the intra-amniotic exposure to endotoxin both induces lung maturation and impairs lung development (27-29). Lung maturation was induced in the fetal sheep by doses of endotoxin from 1 to $100 \mathrm{mg}$. Similar amounts of intra-amniotic endotoxin were used in murine models of fetal exposure to inflammation $(18,30)$. In contrast, intravascular endotoxin at a much smaller dose of $5 \mu \mathrm{g} / \mathrm{kg}$ causes either fetal death or tolerance to repeated intravascular doses of $1 \mu \mathrm{g} / \mathrm{kg}$ in fetal sheep (11). Despite the high amounts of intra-amniotic endotoxin given to fetal sheep, fetal well-being or growth were not impaired (18). The lung inflammation and maturation responses require the direct contact of endotoxin with the fetal lung, presumably by the mixing of fetal lung fluid with amniotic fluid as a result of fetal breathing (15). The intraamniotic endotoxin caused subtle changes in fetal circulating white blood cells, but the response was not characteristic of a systemic inflammatory response (17). Nevertheless, systemic monocytes were modified to have an immune paralysis-type phenotype by fetal lung inflammation. We previously found that fetal exposure to intra-amniotic endotoxin given 30 days before preterm delivery resulted in increased monocytes and lymphocytes in the alveolar lavages of preterm lambs (31). Therefore, intra-amniotic endotoxin can alter the subsequent immune function of the lung and the systemic monocytes. A cautionary note is that monocytes/macrophages from different tissue locations can respond differently after exposure to inflammation (32). The integrated fetal responses to inflammation remain to be explored.

The long-term implications of alterations in fetal immune responses are just beginning to be explored. Recently, increased cord blood levels of IL- 4 and interferon- $\gamma$ were associated with less atopy and asthma (33). The indirect evidence that increased maternal antibiotic use during pregnancy increases the risk of asthma in children supports the concept that fetal immune responses may change subsequent immune responses $(34,35)$. This fetal sheep model will be useful for future studies of long-term effects of lung and systemic innate immune modulation after preterm and term birth.

Conflict of Interest Statement: B.W.K. does not have a financial relationship with a commercial entity that has an interest in the subject of this manuscript; M.I. does not have a financial relationship with a commercial entity that has an interest in the subject of this manuscript; T.J.M.M. does not have a financial relationship with a commercial entity that has an interest in the subject of this manuscript; IN. does not have a financial relationship with a commercial entity that has an interest in the subject of this manuscript; J.P.N. does not have a financial relationship with a commercial entity that has an interest in the subject of this manuscript; A.H.J. does not have a financial relationship with a commercial entity that has an interest in the subject of this manuscript.

\section{References}

1. Marshall-Clarke S, Reen D, Tasker L, Hassan J. Neonatal immunity: how well has it grown up? Immunol Today 2000;21:35-41.

2. Goldenberg RL, Hauth JC, Andrews WW. Intrauterine infection and preterm delivery. $N$ Engl $J$ Med 2000;342:1500-1507.

3. Lahra MM, Jeffery HE. A fetal response to chorioamnionitis is associated with carly survival after preterm birth. Am J Obstet Gynecol 2004;190: 147-151.

4. Specr CP. Pre- and postnatal inflammatory mechanisms in chronic lung disease of preterm infants. Paediatr Respir Rev 2004; 5(Suppl A):S241S244.

5. Yoon BH, Romcro R, Jun JK, Park KH, Park JD, Ghezzi F, Kim BI. Arnniotic fluid cytokines (interleukin-6, tumor necrosis factor-alpha, interleukin-1 $\beta$, and interleukin-8) and the risk for the development of bronchopulmonary dysplasia. Am J Obstet Gynecol 1997;177:825-830.

6. Yoon BH, Romero R, Park JS, Kim CJ, Kim SH, Choi JH, Han TR. Fetal exposure to an intra-amniotic inflammation and the development of cerebral palsy at the age of three years. Am J Obstet Gynecol 2000;182:675-681.

7. Nelson KB, Dambrosia JM, Grether JK, Phillips TM. Neonatal cytokines and coagulation factors in children with cerebral palsy. Ann Neurol 1998;44:665-675.

8. Stoll BJ, Hansen N, Fanaroff AA, Wright LL, Carlo WA, Ehronkranz. RA, Lemons JA, Donovan EF, Stark AR, Tyson JE, et al. Changes in pathogens causing early-onset sepsis in vcry-low-birth- weight infants. $N$ Engl J Med 2002;347:240-247.

9. Adams-Chapman I, Stoll BJ, Prevention of nosocomial infections in the neonatal intensive care unit. Curr Opin Pediatr 2002;14:157-164.

10. Schelonka RL, Infante AJ. Nconatal immunology. Semin Perinatol 1998; 22:2-14.

11. Duncan JR, Cock ML, Scheerlinck JP, Westcott KT, McLean C, Harding $\mathrm{R}$, Rees SM. White matter injury after repeated endotoxin exposurc in the preterm ovine fetus. Pediatr Res 2002;52:941-949.

12. Kramer BW, Ikegami M, Moss TJ, Nitsos I, Newnham JP, Jobe AH. Antenatal betamethasone changes cord blood monocyte responses to endotoxin in preterm lambs. Pediatr Res 2004;55:764-768.

13. Willet KE, Kramer BW, Kallapur SG, Moss TJ, Newnham JP, Sly PD, Ikcgami $M$, Jobe AH. Intramamniotic injection of IL-1 induces inflammation and maturation in fetal sheep lung. Am J Physiol 2002; 282:L411-LA20.

14. Jobe AH, Newnham JP, Willet KE, Moss TJ, Ervin MG, Padbury JF, Sly $\mathrm{P}$, Ikegami M. Endotoxin-induced lung maturation in preterm lambs is not mediated by cortisol. Am J Respir Crit Care Med 2000; 162:1656-1661.

15. Moss TJ, Nitsos I, Kramer BW, Ikegami M, Newnham JP, Jobe AH. Intra-amniotic endotoxin induces lung maturation by direcl effects on the developing respiratory tract in preterm sheep. Am J Obstet Gynecol 2002;187:1059-1065.

16. Kallapur SG, Willet KE, Jobe AH, Ikegami M, Bachurski CJ. Intraamniotic endotoxin: chorioamnionitis precedes lung maturation in pretcrm lambs. Am J Physiol 2001;280:L527-L536.

17. Kramer BW, Moss TJ, Willet KE, Newnham JP, Sly PD, Kallapur SG, Ikegami $M$, Jobe AH. Dose and time response after intraamniotic cndotoxin in pretcrm lambs. Am J Respir Crit Care Med 2001;164:982988.

18. Jobe AH, Newnham JP, Willet KE, Sly P, Ervin MG, Bachurski C, Possmayer F, Hallman M, Ikegami M. Antenatal endotoxin and glucocorticoid effects on the lungs of preterm lambs. Am J Obstet Gynecol 2000;182:401-408.

19. Kramer BW, Jobe AH, Ikegami M. Monocyte function in preterm, near term and adult sheep. Pediatr Res 2003;54:52-57.

20. Peters AM, Bertram P, Gahr M, Speer CP. Reduced secretion of interleukin-1 and tumor necrosis factor-alpha by neonatal monocytes. Biol Neonate 1993;63:157-162.

21. West MA, Heagy W. Endotoxin tolerance: a review. Crit Care Med 2002; 30:S64-S73.

22. Tamandl D, Bahrami M, Wessner B, Weigel G, Ploder M, Furst W, Roth E, Boliz-Nitulescu G, Spittler A. Modulation of toll-like receptor 4 expression on human monocytes by tumor necrosis factor and 
interleukin-6: tumor necrosis factor evokes lipopolysaccharide hyporesponsiveness, whereas interleukin-6 enhances lipopolysaccharide activity. Shock 2003;20:224-229.

23. Heagy W, Nieman $K$, Hansen $C$, Cohen $M$, Danielson D, West MA. Lower levels of whole blood LPS-stimulated cytokine rclease are associated with poorer clinical outcomes in surgical ICU patients. Surg Infect (Larchmt) 2003;4:171-180.

24. Stoll BJ, Hansen N, Fanaroff AA, Wright LL, Carlo WA, Ehrenkranz RA, Lemons JA, Donovan EF, Stark AR, Tyson JE, et al. Late-onset sepsis in very low birth wcight neonates: the experience of the NICHD Neonatal Research Network. Pediatrics 2002;110:285-291.

25. Goldenberg RL, Jobe AH. Prospects for research in reproductive health and birth outcomes. JAMA 2001;285:633-639.

26. Ikegami M, Moss TJ, Kallapur SG, Mulrooncy N, Kramer BW, Nitsos I, Bachurski CJ, Newnham JP, Jobe AH. Minimal lung and systemic responses to TNF-alpha in preterm sheep. Am J Physiol Lung Cell Mol Physiol 2003;285:L121-L129.

27. Ikegami M, Jobe AH. Postnatal lung inflammation increased by ventilation of preterm lambs exposed antenatally to Escherichia coli endotoxin. Pediatr Res 2002;52:356-362.

28. Ikegami $\mathrm{M}$, Kallapur $\mathrm{SG}$, Jobe $\mathrm{AH}$. Initial responses to ventilation of premature lambs exposed to intra-amniotic endotoxin 4 days before delivery. Am J Physiol Lung Cell Mol Physiol 2004;286:L573-L579.

29. Willet KE, Jobe AH, Ikegami M, Brennan S, Newnham J, Sly PD.
Antenatal endotoxin and glucocorticoid effects on lung morphometry in preterm lambs. Pediatr Res 2000;48:782-788.

30. Rounioja S, Rasanen J, Glumoff V. Ojaniemi M, Makikallio K, Hallman M. Intra-amniotic lipopolysaccharide leads to fetal cardiac dysfunction: a mouse model for fetal inflammatory response. Cardiovasc Res 2003;60:156-164.

31. Moss TJ, Newnham JP, Willett KE, Kramer BW, Jobe AH, Ikegami M. Early gestational intra-amniotic endotoxin: lung function, surfactant, and morphometry. Am J Respir Crit Care Med 2002;165:805-811.

32. Melo RC, Fabrino DL, D'Avila H, Teixeira HC, Ferreira AP. Production of hydrogen peroxide by peripheral blood monocytes and specific macrophages during experimental infection with Trypanosoma cruzi in vivo. Cell Biol lnt 2003;27:853-861.

33. Macaubas C, de Klerk NH, Holt BJ, Wee C, Kendall G, Firth M, Sly D, Holt PG. Association between antenatal cytokine production and the development of atopy and asthma at age 6 years. Lancet 2003;362: 1192-1197.

34. McKeever TM, Lewis SA, Smith C, Collins J, Heatlie H, Frischer M, Hubbard R. Early exposure to infections and antibiotics and the incidence of allergic disease: a birth cohort study with the West Midlands General Practice Research Database. J Allergy Clin Immunol 2002; 109:43-50

35. McKeever TM, Lewis SA, Smith C, Hubbard R. The importance of prenatal exposures on the development of allergic disease: a birth cohort study using the West Midlands General Practice Database. Am I Respir Crit Care Med 2002;166:827-832. 


\section{CHAPTER 12}

\section{Summary and Outlook}

\section{Samenvatting}




\section{Summary}

\section{Lung injury following chorioamnionitis}

In chapter 3 and 4 a cascade of lung injury, lung inflammation, lung repair with apoptosis and subsequent cell proliferation and morphologic changes following intra-amniotic endotoxin injection is described. Findings are summarized in figure 1 . Within 5 hours of injection of intra-amniotic endotoxin, the fetal airways expressed heat shock protein-70 and inflammatory cells were increased in bronchoalveolar lavage fluid (chapter 4) (33). Within 24 hours, monocytes and granulocytes were increased many fold in the bronchoalveolar lavage, and mRNA for pro-inflammatory cytokines $\mathrm{IL}-1 \beta, \mathrm{IL}-6$ and $\mathrm{IL}-8$ were strikingly increased in lung tissue (chapter 3 ) (34). Apoptosis of lung cells increased 24 hours after intra-amniotic endotoxin and lung cell proliferation was higher after 72 hours. The acute inflammatory responses of the fetal lung had resolved by 7 days; however, residual inflammatory cells remained in the bronchoalveolar lavage (chapter 3) (34).

Inhibition of microvascular development is striking in the lungs of infants with BPD (1) and placentas with chorioamnionitis (32), and parallel responses occur in the fetal sheep lungs. IP-10 and MIG, chemokines associated with inflammation and angiostasis, are expressed highly by inflammatory cells and the bronchioles (21). The lungs have decreased expression of multiple markers of vascular development (endothelial nitric oxide synthase, vascular endothelial growth factor, platelet endothelial cell adhesion molecule, and VEGF receptor 2) for 1 to 4 days after exposure to intra-amniotic endotoxin (20). By 7 days the medial thickness of arteriolar walls has increased, alveolar size has increased and alveolar number has decreased relative to controls (52).

In chapter 5 , the role of transforming growth factor $\beta$ 1 (TGF- $\beta 1$ ) was studied in the chorioamnionitis model after intra-amniotic endotoxin injection. TGF$\beta 1$ is a key regulator of lung development, lung inflammation, wound healing and remodeling, which all contribute to the development of BPD (chapter 5) (35). Downstream of TGF- $\beta 1$, connective tissue growth factor (CTGF) modulates fibrosis as a result of TGF- $\beta 1$ activity and promotes in addition vascular development in mouse embryos (8). Endotoxin-in- duced chorioamnionitis induced a considerable expression of TGF- $\beta 1$ and activated Smad signaling in the fetal lung. However, CTGF expression was markedly reduced, probably mediated by an increase in TNF- $\alpha$ expression. This cytokine profile may contribute to the impaired alveolar and pulmonary vascular development, absence of fibrosis and limited lung inflammation that are hallmarks of BPD (figure 2) $(35,37)$. Therefore, intraamniotic endotoxin caused chorioamnionitis and altered the fetal lung anatomy similarly to the pathology of the lungs of infants with BPD (5).

\section{Intra-amniotic endotoxin causes lung maturation}

Despite fetal lung injury, the functional outcome after intra-amniotic endotoxin was lung maturation (2). The mRNA for surfactant proteins $A, B, C$ and $D$ were increased within 24 hours and the amounts of the surfactant proteins were increased by about 100 -fold in bronchoalveolar lavages by 7 days (chapter 3 ; figure 1 ). In parallel with the increases in surfactant, lung function of ventilated preterm lambs improved, with large increases in lung compliance, gas exchange and oxygenation $(18,19)$. Of note, cord plasma cortisol did not increase in response to intraamniotic endotoxin suggesting a mechanism of lung maturation distinct from that induced by glucocorticoids (18).

Endotoxin-induced increases in surfactant lipids and proteins are much greater than the increases achieved with corticosteroid treatments (19). The clinically relevant response of the fetal lung to chorioamnionitis is induced lung maturation, which will result in a decreased incidence and severity of RDS. In this experimental sheep model intra-amniotic doses of 1 to $100 \mathrm{mg} \mathrm{E}$. coli endotoxin induced similar inflammatory and lung maturation responses (19). No lung inflammation and no subsequent lung maturation was seen with lower doses (chapter 3) (34). In contrast, intra-allantoic endotoxin caused no chorioamnionitis or lung responses (40). No significant amount of intra-amniotic endotoxin enters the circulation of the fetus because intravascular doses as low as $1 \mu \mathrm{g}$ can kill the fetus (7). Thus, the fetal response to the inflammatory mediator 


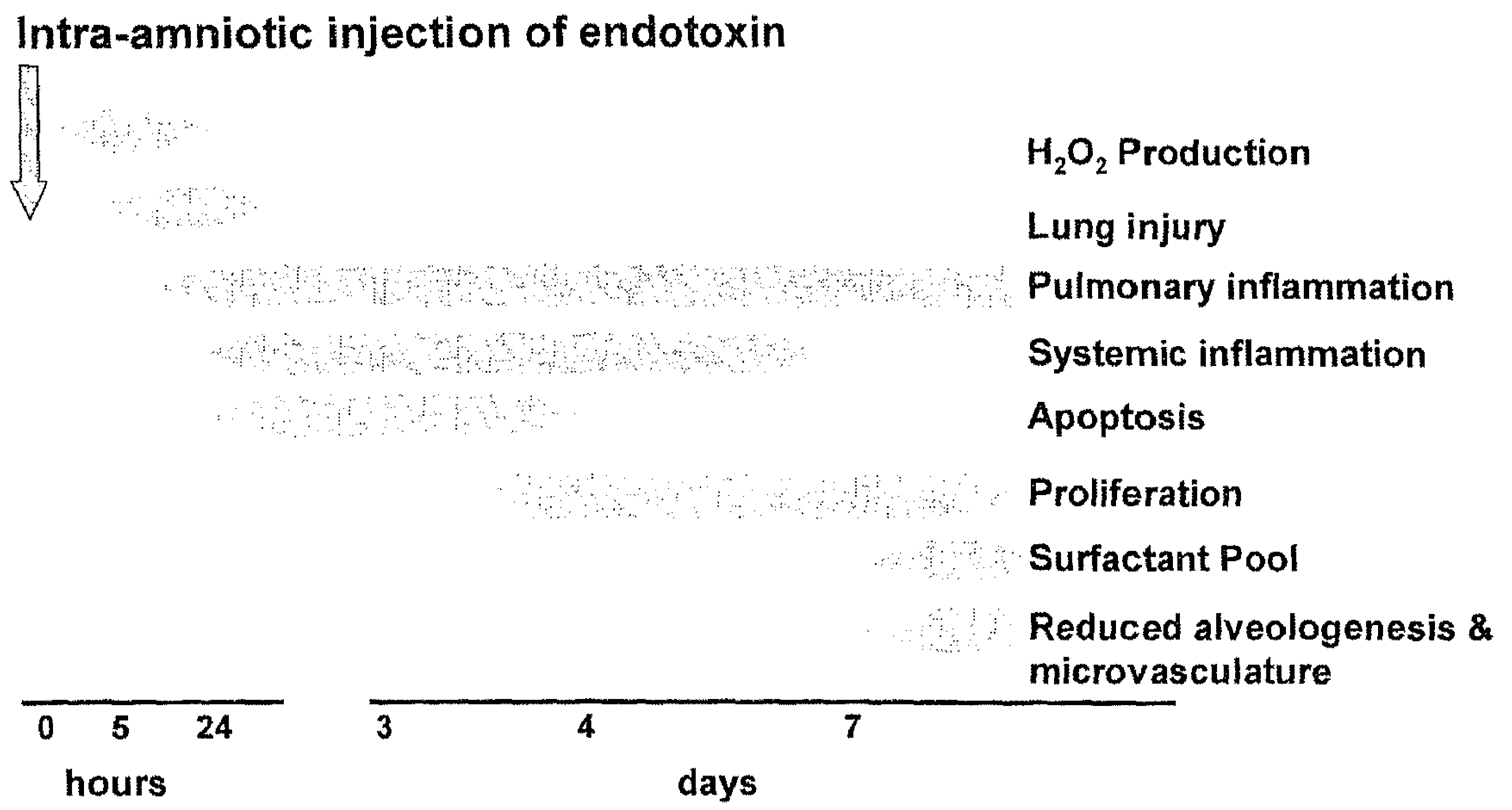

Figure 1: Summary of cascade that was induced by a single dose of endotoxin from E.coli, injected into the amniotic fluid at $117 \mathrm{~d}$ gestational. Lung injury with subsequent inflammation and an aberrant repair reaction was induced which resulted within 7 days in a mature lung phenotype with increased surfactant pool size but also with injury to alveologenesis and microvasculature development. This animal model yields within the 7 days of intra-uterine exposure to inflammation a mild phenotype of BPD (Summarized from chapter $3 \& 4(2,18-20,25,33,34,52))$

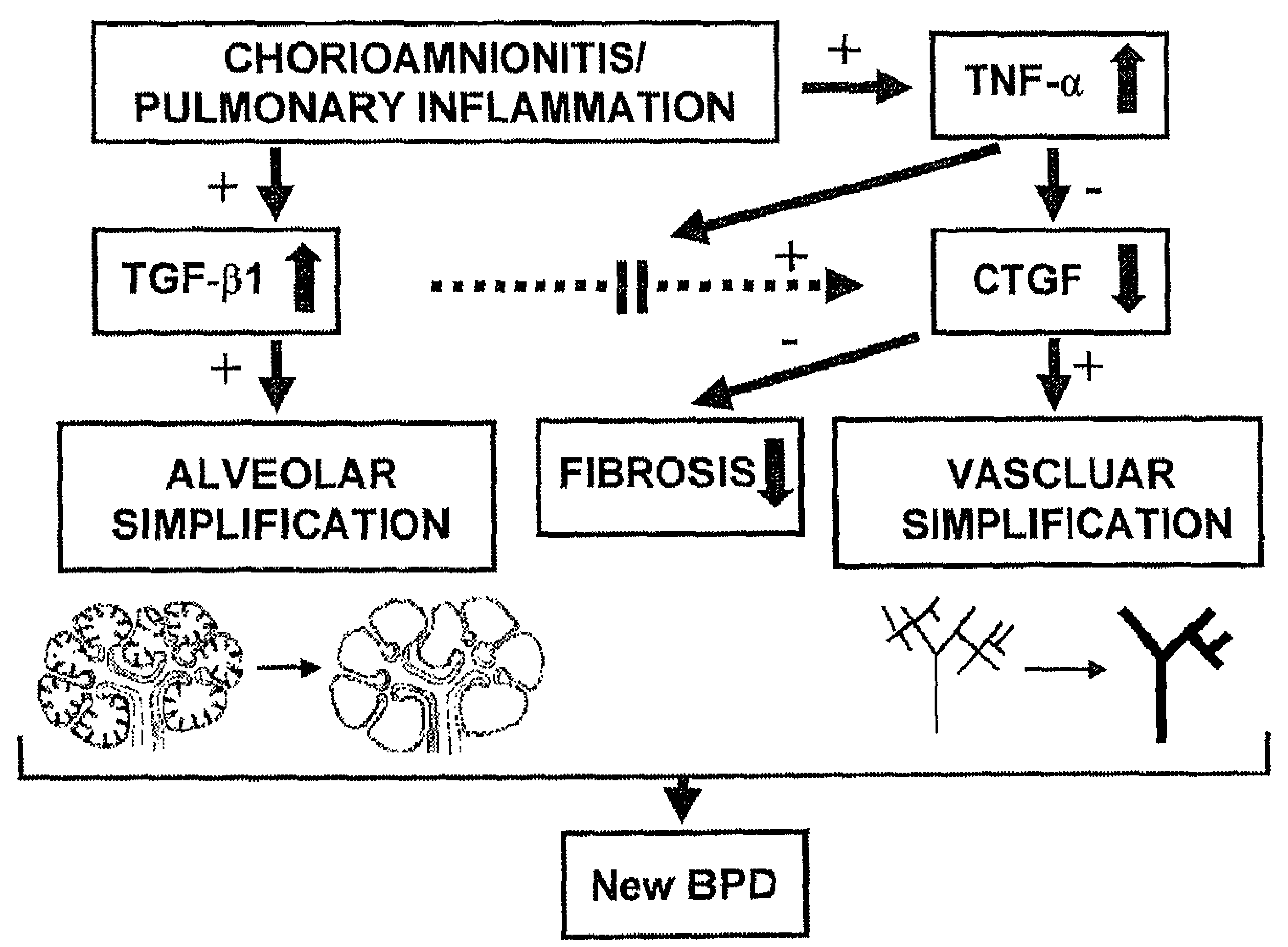

Figure 2: Schematic summary of cytokine effects after intra-amniotic endotoxin. Pulmonary inflammation results in increased TGFbeta 1 concentrations in the fetal lung (chapter 5). TGF- $\beta 1$ is essential for the ${ }_{\text {w }}$ wound remodeling or healing" after lung injury but increased TGF-beta 1 concentration impairs alveologenesis. In other models these effects are mediated in part by TGF-beta1 itself but the fibrosis is primarily mediated by CTGF. Furthermore, TGF-beta 1 reduces lung inflammation. TGF- $\beta 1$ and TNF- $\alpha$ were induced but CTGF was decreased in this model of endotoxin-induced chorioamnionitis. The downregulation of CTGF might be mediated by TNF- $\alpha$. Therefore, the reduced concentrations of CTGF might have limited fibrosis but also impaired microvasculature development since CTGF is involved in normal vascular development. Taken together, the cytokine profile may explain in an overly simplified way the findings of BPD in the fetal sheep lung. 


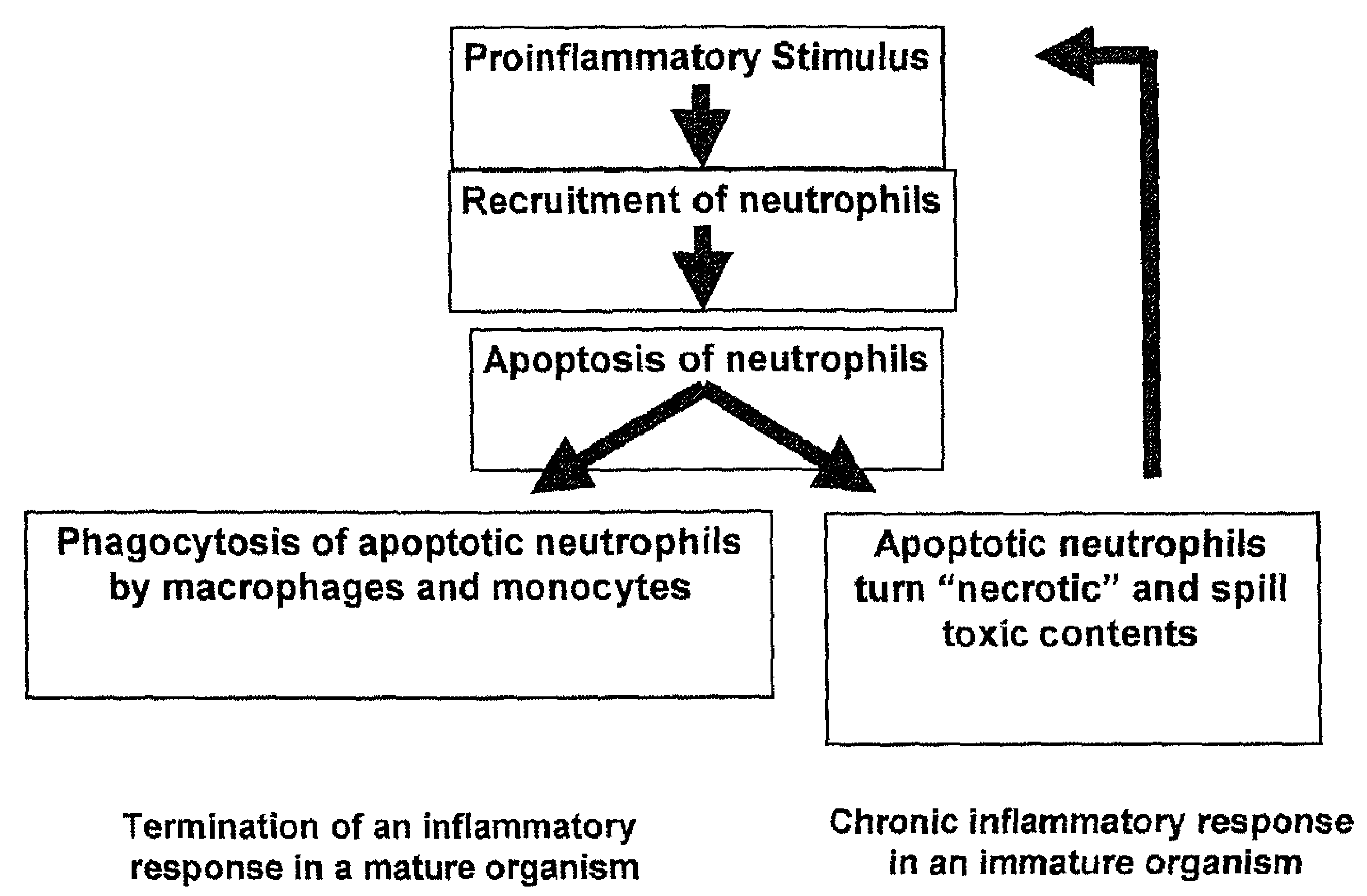

Figure 3: Hypothesis for the impaired regulation of a fetal inflammatory response. After the initiation of inflammation by a proinflammatory stimulus neutrophils are recruited into the tissue from the blood circulation. Neutrophils undergo apoptotic cell death. The apoptotic vesicles are usually readily phagocytosed by neighbouring cells, monocytes and macrophages. If apoptotic vesicles are not taken up in a timely fashion they become necrotic which means that they burst open and spill their contents which are a proinflammatory stimulus on their own. The fetal lung is deficient in monocytes and macrophages and those cells are deficient in their efficiency to phagocytose apoptotic vesicles which may explain the persistence of an inflammation in a fetal or prematurely born organism (chapter 9) (31).

was dependent on the compartment with the inflammation.

\section{How endotoxin signals lung maturation}

Endotoxin induced a cascade of pro-inflammatory mediators and recruited activated inflammatory cells to the chorioamnion (chapter 3; figure 1) $(25,34$, 39). Diffuse inflammation of the chorioamnion could release effector molecules into the fetal systemic circulation and indirectly induce lung inflammation and maturation. However, intra-amniotic endotoxin has very modest effects on circulating white blood cells and platelets (chapter 3$)(18,34)$. Pro-inflammatory cytokine mRNA in the fetal liver is inconsistently and minimally increased and plasma IFN $\gamma, \mathrm{IL}-6$ and IL-8 levels are minimally increased $(25,34,54)$. Also, cytokine mRNA levels in the placenta and gut do not increase appreciably (25). Therefore a diffuse fetal inflammatory response does not explain the local lung inflammation.

To identify the relationships between chorioamnionitis and the fetal lung, the fetal lungs were surgically separated from the amniotic fluid using tracheotomy and a silastic bag to collect lung fluid (39). Endotoxin in the amniotic fluid caused chorio- amnionitis but no lung inflammation or lung maturation (39). In contrast, a 24-hour infusion of endotoxin into the fetal trachea caused lung inflammation and subsequent lung maturation without chorioamnionitis. This result demonstrated that endotoxin can cause the inflammation/maturation sequence by direct contact with the fetal lung. Therefore, tidal fetal breathing must cause mixing of fetal lung fluid with amniotic fluid, which then signals the inflammation and maturation re sponses in the fetal lung (39). In addition, the clearance of endotoxin in the amniotic fluid is very slow. Measurements of endotoxin activity estimated the half-life to be approximately $41 \mathrm{~h}$ (41).

In the clinical scenario, the mediator of inflammatory effects on the lungs could be the TLR4 agonist endotoxin, some other TLR agonist, or an inflammatory product of chorioamnionitis (chapter 7) (29). The mRNA for $L-1 \beta$ is the cytokine which is most increased in the chorioamnion in sheep after intra-amniotic endotoxin similar to the findings in babies exposed to chorioamnionitis (6). The original description of lung maturation responses to intra-amniotic $\mathrm{IL}-1 \alpha$ in rabbits did not include an evaluation for chorioamnionitis (4). 
Intra-amniotic injections of sheep recombinant IL- $1 \alpha$ or IL-1 $1 \beta$ to ewes induced chorioamnionitis followed by striking lung maturation $(47,53)$. However, the fetus did not respond to sheep recombinant TNF $\alpha$ with chorioamnionitis or lung inflammation/lung maturation (16). Thus the fetal compartment seems to be exquisitively sensitive to $I L-1 \beta$, the endogenously produced $I L-1$, and quite unresponsive to other normally potent inflammatory cytokines.

In other experiments, an anti-CD-18 antibody blocked intra-amniotic endotoxin-mediated inflammatory cell recruitment to the fetal lungs and prevented lung maturation (23). Our current understanding is that the fetal lung responds to pro-inflammatory mediators in amniotic fluid with a recruitment of inflammatory cells, which may be the major source of $\mathrm{IL}-1 \beta$, which in turn initiates the maturational signals.

Recently, TGF- $\beta$ was reported to bind SP-A which may partially explain the controversial data that were obtained with different SP-A preparations (chapter 6) $(30,36)$. The link between surfactant and immunomodulation should be further studied because the immature lung is highly vulnerable by inflammation. In a set of experiments, lambs of differential gestational ages were intubated and endotoxin was given intratracheally. In very immature lambs the lung did not contain endotoxin but the endotoxin leaked into the systemic blood circulation causing a septic shock syndrome (chapter 8) (26). The same dose of endotoxin did not cause a systemic response in lambs close to term. The immaturity of the immune system is an essential component in this sheep model. Alveolar macrophages are not present in the fetal lung until close to term (chapter 9) (31). Blood-derived monocytes enter the fetal lung late in gestation, proliferate and differentiate into alveolar macrophages under the control of granulocyte-macrophage-colony stimulating factor (GM-CSF) and its downstream mediator transcription factor PU.1 (46). The monocytes from cord blood of preterm lambs are functionally less mature than monocytes from near-term lambs or adult sheep in response to proinflammatroy stimuli such as endotoxin (chapter 9 ).

\section{Glucocorticoids and chorioamnionitis}

The majority of women delivering before 30 weeks of gestation have clinically silent chorioamnionitis (10), and most of these women receive antenatal corticosteroids to induce lung maturation (11). The practice of corticosteroid treatment is supported by numerous clinical reports and a meta-analysis dem- onstrating decreased RDS, intra-ventricular hemorrhage (IVH) and death when corticosteroids are given to women with preterm rupture of membranes, a surrogate clinical indicator of chorioamnionitis (11). In preterm fetal sheep, maternal corticosteroids given 7 days before delivery do not improve lung function as effectively as intraamniotic endotoxin. The major difference is the much larger increase in surfactant induced by endotoxin $(18,52)$. Maternal betamethasone causes fetal growth restriction and fetal thymic involution but intra-amniotic endotoxin does not (42). Surprisingly, intra-amniotic endotoxin prevents betamethasone-induced fetal growth restriction and thymic involution when these interventions are combined (42). Betamethasone suppressed the lung inflammation induced by endotoxin for about 2 days (22). However, 5 and 15 days after both exposures, inflammatory cells and pro-inflammatory mediators were higher in the lungs exposed to both endotoxin and betamethasone than to endotoxin alone (22). A possible explanation for this result was suggested by the observation that maternal betamethasone treatments initially suppressed the inflammatory responses of fetal monocytes but those responses were strikingly augmented 7 days after maternal betamethasone treatment (chapter 10) (27). Thus maternal betamethasone may augment fetal lung inflammation induced by endotoxin by "maturing" the inflammatory potential of fetal inflammatory cells (chapter 10). There is no experimental information about how the fetal lung will respond to betamethasone superimposed on chronic chorioamnionitis, the more usual clinical scenario.

We also evaluated the function of fetal monocytes after repetitive exposures to proinflammatory agonists (chapter 11) (28). The initial exposure to a non-lethal dose endotoxin for example reduced the response of the immune cells to a second usually lethal dose of endotoxin in experimental animal models (51). This phenomenon is called endotoxin tolerance and is considered as a major cause for morbidity in adult intensive care units. We found that repetitive intra-amniotic injections of endotoxin did not increase lung maturation but rendered the fetal monocytes non-responsive or inert to a second exposure to the same endotoxin (chapter 11) (29). 


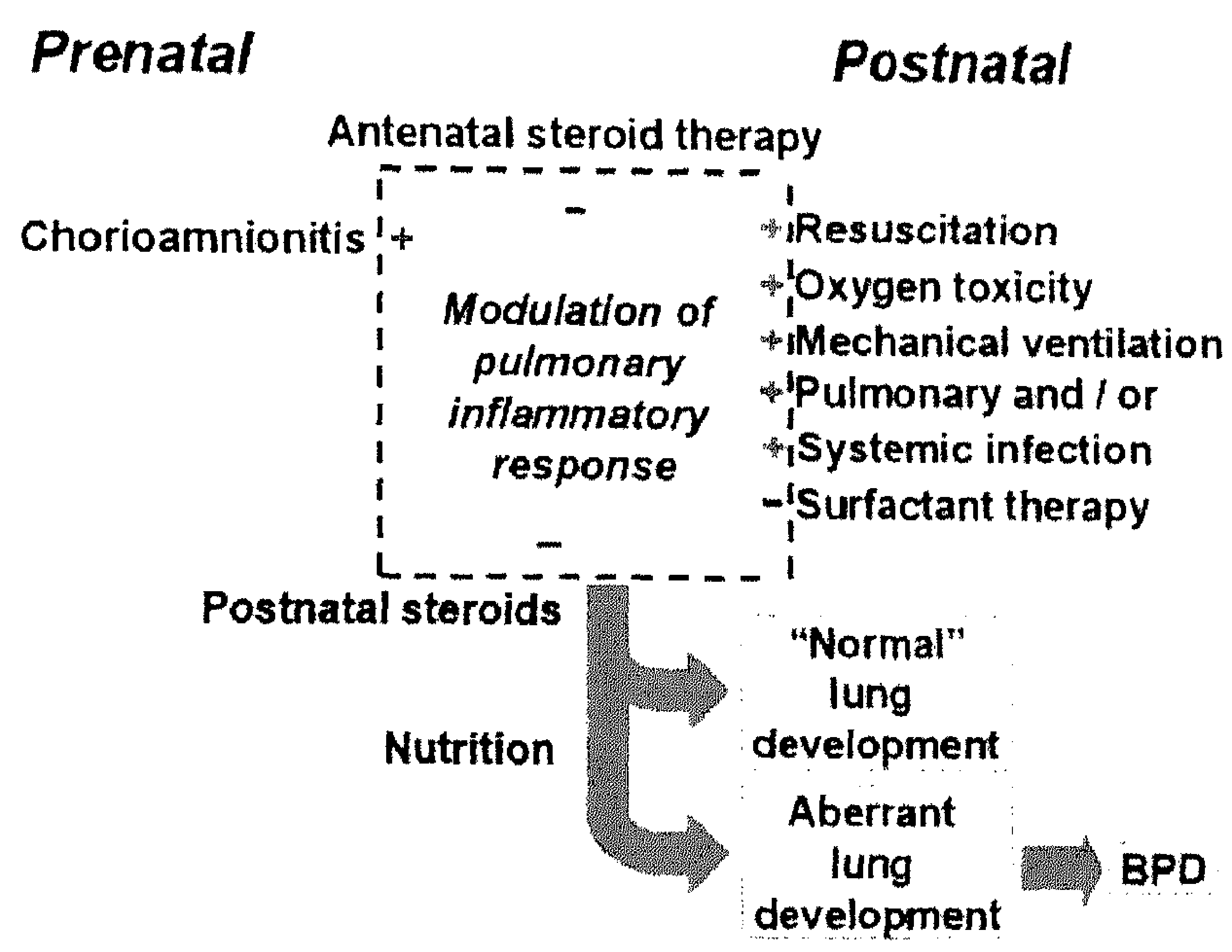

Figure 4: Multifactorial pathogenesis of BPD. Inflammation of the fetal airways may be induced in utero by chorioamnionitis Antenatal glucocorticoids given to the mother may have anti-inflammatory effects on the pulmonary inflammation in the airways. Postnatal management and ventilation strategies may sustain the inflammation. If the preterm baby manages to control or resolve inflammation and is given the necessary conditions for repair and lung growth the symptoms of BPD may not develop or resolve (48).

\section{Outlook - The clever fetus - controlling inflammation}

Clinical experience and experimental results indicate that fetal exposure to antenatal inflammation has both good and bad effects on the fetus. Chorioamnionitis induces lung maturation but also induces a simplification of the lung development. Many organs are affected by the exposure to antenatal inflammation, which suggests that chorioamnionitis induces "a multi-organ disease of the fetus". The unifying link between all affected organs is however the immune response. Increased survival after exposure to chorioamnionitis/antenatal steroids may in part be attributed to effects on the immune system. In addition, no lung maturation was seen after initiation of chorioamnionitis if the inflammatory response was small or blocked (chapter 3$)(23,34)$. Structural changes of the fetal airways and lungs after antenatal inflammation were not apparent in later gestation, although the pulmonary inflammation persisted nevertheless $(24,38)$. The fetal lung is able to "heal" the inflammation induced injury if given enough time.

Inflammation is marked by the recruitment of neutrophils into the tissue (figure 3) (12). Neutrophils undergo apoptotic cell death and form apoptotic vesi- cles within a short period of time (14). Apoptotic vesicles are usually phagocytosed quickly by neighbouring cells, monocytes or macrophages (50). If apoptotic neutrophils are not phagocytosed, they become necrotic which means that they burst open and spill their contents (13). The contents of these apoptotic neutrophils are a proinflammatory stimulus and may reinitiate the cascade of inflammation (figure 3 ).

The fetal lung is deficient in monocytes and macrophages which reduces the number of possible cells to phagocytose apoptotic neutrophils (chapter 9) $(31,43)$. The monocytes from preterm lambs are however less effective in phagocytosing apoptotic vesicles than monocytes from adult animals (chapter 9) (31). These two factors may explain why the fetal inflammation is resolved so poorly following intra-amniotic endotoxin. Commercial surfactant preparations seem to have anti-inflammatory properties $(3,49)$. Surfactant protein A was previously shown to enhance the phagocytosis of apoptotic vesicles (44, 45). Surfactant protein $A$ and other components of surfactant increased the phagocytosis of 
monocytes from preterm lambs were tested (chapter 9) (31). This is a new finding in the anti-inflammatory properties of surfactant and surfactant preparations.

BPD clearly is a multifactorial disease with the primary risk factors being delivery at early gestation, mechanical ventilation, supplemental oxygen exposure, and postnatal sepsis. Other than gestational age, these risk factors are pro-inflammatory (figure 4). Antenatal lung inflammation may initiate and potentiate a progressive inflammatory process that results in BPD (15). The preterm baby may recover from the initial hit by the absence from further aggravation of the existing inflammation (17). With favorable conditions for repair and lung growth the symptoms of BPD may not develop or resolve (48). There may be survival advantages by the inflammation-induced lung maturation for the fetus. The fetus must however control inflammation and avoid systemic inflammation which may be lethal (chapter 4) (26). Many factors come into play for the modulation of the inflammatory response (figure 4). Along with the immaturity of the preterm immune system (9), antenatal and postnatal factors may condition and modulate the pulmonary inflammation (48). Future research must aim at differentiating the beneficial and detrimental effects of antenatal inflammation to make prevention and therapy more effective.

\section{References}

1. Abman SH. Bronchopulmonary dysplasia: "a vascular hypothesis". Am J Respir Crit Care Med 164: 1755-1756, 2001.

2. Bachurski CJ, Ross GF, Ikegami M, Kramer BW, and Jobe AH. Intra-amniotic endotoxin increases pulmonary surfactant proteins and induces SP-B processing in fetal sheep. Am J Physiol Lung Cell Mol Physiol 280: L279-285, 2001.

3. Baur FM, Brenner B, Goetze-Speer B, Neu S, and Speer CP. Natural porcine surfactant (Curosurf) down-regulates mRNA of tumor necrosis factor-alpha (TNF-alpha) and TNF-alpha type II receptor in lipopolysaccharide-stimulated monocytes. Pediatr Res 44: 32-36, 1998.

4. Bry $K$, Lappalainen $U$, and Hallman $M$. Intraamniotic interleukin-1 accelerates surfactant protein synthesis in fetal rabbits and improves lung stability after premature birth. $J$ Clin Invest 99: 2992-2999, 1997.
5. Coalson JJ. Pathology of new bronchopulmonary dysplasia. Semin Neonatol 8: 73-81, 2003.

6. Dollner $H$, Vatten $L$, Halgunset $J$, Rahimipoor $S$, and Austgulen R. Histologic chorioamnionitis and umbilical serum levels of pro-inflammatory cytokines and cytokine inhibitors. Bjog 109: 534-539, 2002.

7. Duncan JR, Cock ML, Scheerlinck JP, Westcott KT, McLean $C$, Harding R, and Rees SM. White matter injury after repeated endotoxin exposure in the preterm ovine fetus. Pediatr Res 52: 941-949, 2002.

8. Friedrichsen $S$, Heuer $H$, Christ $S$, Winckler $M$, Brauer $D$, Baver $K$, and Raivich $G$. CTGF expression during mouse embryonic development. Cell Tissue Res 312: 175-188, 2003.

9. Gille C, Spring B, Tewes LJ, Loffler J, Dannecker GE, Hoffmann MK, Eichner M, Poets CF, and Orlikowsky TW. Diminished response to interleukin-10 and reduced antibody-dependent cellular cytotoxicity of cord blood monocyte-derived macrophages. Pediatr Res 60: 152-157, 2006.

10. Goldenberg $\mathrm{RL}$, Hauth $\mathrm{JC}$, and Andrews $\mathrm{WW}$. Intrauterine infection and preterm delivery. $N$ Engl $J$ Med 342: 1500-1507, 2000.

11. Halliday HL. Evidence-based neonatal care. Best Pract Res Clin Obstet Gynaecol 19: 155-166, 2005.

12. Haslett $\mathrm{C}$. Granulocyte apoptosis and its role in the resolution and control of lung inflammation. Am J Respir Crit Care Med 160: S5-11, 1999.

13. Hofman P. Molecular regulation of neutrophil apoptosis and potential targets for therapeutic strategy against the inflammatory process. Curr Drug Targets Inflamm Allergy 3: 1-9, 2004.

14. Hu B, Sonstein J, Christensen PJ, Punturieri $A_{1}$ and Curtis $\mathrm{JL}$. Deficient in vitro and in vivo phagocytosis of apoptotic $T$ cells by resident murine alveolar macrophages. J Immunol 165: 2124-2133, 2000.

15. Ikegami $M$ and Jobe $A H$. Postnatal lung inflammation increased by ventilation of preterm lambs exposed antenatally to Escherichia coli endotoxin. Pediatr Res 52: 356-362, 2002.

16. Ikegami M, Moss TJ, Kallapur SG, Mulrooney N, Kramer BW, Nitsos I, Bachurski CJ, Newnham JP, and Jobe AH. Minimal lung and systemic responses to TNF-alpha in preterm sheep. Am J Physiol Lung Cell Mol Physiol 285: L121-129, 2003.

17. Jobe $\mathrm{AH}$ and Ikegami M. Antenatal infection/inflammation and postnatal lung maturation and injury. Respir Res 2: 27-32, 2001. 
18. Jobe AH, Newnham JP, Willet KE, Moss TJ, Gore Ervin M, Padbury JF, Sly $P$, and Ikegami $M$. Endotoxin-induced lung maturation in preterm lambs is not mediated by cortisol. $A m$ J Respir Crit Care Med 162: 1656-1661, 2000.

19. Jobe $A H$, Newnham JP, Willet KE, Sly P. Ervin MG, Bachurski C, Possmayer F, Hallman $M$, and Ikegami M. Effects of antenatal endotoxin and glucocorticoids on the lungs of preterm lambs. Am J Obstet Gynecol 182: 401-408, 2000.

20. Kallapur SG, Bachurski CJ, Le Cras TD, Joshi SN, lkegami $M$, and Jobe $A H$. Vascular changes after intra-amniotic endotoxin in preterm lamb lungs. Am J Physiol Lung Cell Mol Physiol 287: L1178-1185, 2004.

21. Kallapur SG, Jobe $A H$, Ikegami $M$, and Bachurski CJ. Increased IP-10 and MIG expression after intra-amniotic endotoxin in preterm lamb lung. Am J Respir Crit Care Med 167: 779-786, 2003.

22. Kallapur SG, Kramer BW, Moss TJ, Newnham JP, Jobe AH, Ikegami $M$, and Bachurski $C J$. Maternal glucocorticoids increase endotoxin-induced lung inflammation in preterm lambs. Am J Physiol Lung Cell Mol Physiol 284: L633-642, 2003.

23. Kallapur SG, Moss TJ, Ikegami M, Jasman RL, Newnham $J P$, and Jobe $A H$. Recruited inflammatory cells mediate endotoxin-induced lung maturation in preterm fetal lambs. Am J Respir Crit Care Med 172: 1315-1321, 2005.

24. Kallapur SG, Nitsos I, Moss TJ, Kramer BW, Newnham JP, Ikegami $\mathrm{M}$, and Jobe $\mathrm{AH}$. Chronic endotoxin exposure does not cause sustained structural abnormalities in the fetal sheep lungs. Am J Physiol Lung Cell Mol Physiol 288: L966-974, 2005.

25. Kallapur SG, Willet KE, Jobe AH, Ikegami M, and Bachurski CJ. Intra-amniotic endotoxin: chorioamnionitis precedes lung maturation in preterm lambs. Am J Physiol Lung Cell Mol Physiol 280: L527-536, 2001.

26. Kramer BW, Ikegami $M$, and Jobe AH. Intratracheal endotoxin causes systemic inflammation in ventilated preterm lambs. Am J Respir Crit Care Med 165: 463-469, 2002.

27. Kramer BW, Ikegami M, Moss TJ, Nitsos I, Newnham JP, and Jobe AH. Antenatal betamethasone changes cord blood monocyte responses to endotoxin in preterm lambs. Pediatr Res 55: 764-768, 2004.

28. Kramer BW, Ikegami M, Moss TJ, Nitsos I, Newnham JP, and Jobe $\mathrm{AH}$. Endotoxin-induced chorioamnionitis modulates innate immunity of monocytes in preterm sheep. Am J Respir Crit Care Med 171: 73-77, 2005.

29. Kramer BW and Jobe AH. The clever fetus: responding to inflammation to minimize lung injury. Biol Neonate 88 : 202-207, 2005.
30. Kramer BW, Jobe AH, Bachurski CJ, and Ikegami M. Surfactant protein $A$ recruits neutrophils into the lungs of ventilated preterm lambs. Am J Respir Crit Care Med 163: 158-165, 2001.

31. Kramer BW, Jobe AH, and lkegami M. Monocyte function in preterm, term, and adult sheep. Pediatr Res 54: 52-57, 2003.

32. Kramer BW, Kaemmerer U, Kapp M, Herbst D, Marx A, Berg D, Groneck PA, and Speer CP. Decreased expression of angiogenic factors in placentas with chorioamnionitis after preterm birth. Pediatr Res 58: 607-612, 2005

33. Kramer BW, Kramer S, Ikegami M, and Jobe AH. Injury, inflammation, and remodeling in fetal sheep lung after intra-amniotic endotoxin. Am J Physiol Lung Cell Mol Physiol 283: L452-459, 2002.

34. Kramer BW, Moss TJ, Willet KE, Newnham JP, Sly PD, Kallapur SG, Ikegami $M$, and Jobe AH. Dose and time response after intraamniotic endotoxin in preterm lambs. Am J Respir Crit Care Med 164: 982-988, 2001.

35. Kunzmann $S$, Speer $C$, Jobe $A H$, and Kramer BW. Antenatal inflammation induced TGF-\{beta\}1 but suppressed CTGF in preterm lungs. Am J Physiol Lung Cell Mol Physiol 292: L223-231, 2007.

36. Kunzmann $S$, Wright JR, Steinhilber W, Kramer BW, Blaser $K$, Speer $C P$, and Schmidt-Weber C. TGF\{beta\}1 in SP-A preparations influences immune suppressive properties of SP-A on human CD4+ T lymphocytes. Am J Physiol Lung Cell Mol Physiol 291: L747-756, 2006.

37. Kwong $K Y$, Niang $S$, Literat $A$, Zhu NL, Ramanathan $R$, Jones $C A$, and Minoo P. Expression of transforming growth factor beta (TGF-b1) by human preterm lung inflammatory cells. Life Sci 79: 2349-2356, 2006.

38. Moss TJ, Newnham JP, Willett KE, Kramer BW, Jobe $\mathrm{AH}$, and Ikegami $\mathrm{M}$. Early gestational intra-amniotic endotoxin: lung function, surfactant, and morphometry. Am J Respir Crit Care Med 165: 805-811, 2002.

39. Moss TJ, Nitsos I, Kramer BW, Ikegami M, Newnham $\mathrm{JP}$, and Jobe AH. Intra-amniotic endotoxin induces lung maturation by direct effects on the developing respiratory tract in preterm sheep. Am J Obstet Gynecol 187: 1059-1065, 2002.

40. Moss TJ, Nitsos I, Newnham JP, Ikegami M, and Jobe $\mathrm{AH}$. Chorioamnionitis induced by subchorionic endotoxin infusion in sheep. Am J Obstet Gynecol 189: 1771-1776, 2003. 
41. Newnham JP, Kallapur SG, Kramer BW, Moss TJ, Nitsos I, Ikegami $M$, and Jobe $A H$. Betamethasone effects on chorioamnionitis induced by intra-amniotic endotoxin in sheep. Am J Obstet Gynecol 189: 1458-1466, 2003.

42. Newnham JP, Moss TJ, Padbury JF, Willet KE, Ikegami M, Ervin MG, Sly $P$, and Jobe $A$. The interactive effects of endotoxin with prenatal glucocorticoids on short-term lung function in sheep. Am J Obstet Gynecol 185: 190-197, 2001.

43. Radzun $H J$, Parwaresch $M R_{1}$ and Kreipe $H$. Monocytic origin of human alveolar macrophages. I Histochem Cytochem 31: 318-324, 1983.

44. Reidy MF and Wright JR. Surfactant protein A enhances apoptotic cell uptake and TGF-beta1 release by inflammatory alveolar macrophages. Am J Physiol Lung Cell Mol Physiol 285: L854-861, 2003.

45. Schagat TL, Wofford JA, and Wright JR. Surfactant protein $A$ enhances alveolar macrophage phagocytosis of apoptotic neutrophils. JImmunol 166: 2727-2733, 2001.

46. Shibata $Y$, Berclaz PY, Chroneos ZC, Yoshida M, Whitsett JA, and Trapnell BC. GM-CSF regulates alveolar macrophage differentiation and innate immunity in the lung through PU.1. Immunity 15: 557-567, 2001.

47. Sosenko IR, Kallapur SG, Nitsos I, Moss TJ, Newnham JP, Ikegami $M$, and Jobe AH. IL-1alpha causes lung inflammation and maturation by direct effects on preterm fetal lamb lungs. Pediatr Res 60: 294-298, 2006.

48. Speer CP. Inflammation and bronchopulmonary dysplasia: A continuing story. Semin Fetal Neonatal Med 11: 354-362, 2006.

49. Speer CP, Gotze B, Curstedt T, and Robertson B. Phagocytic functions and tumor necrosis factor secretion of human monocytes exposed to natural porcine surfactant (Curosurf). Pediatr Res 30: 69-74, 1991.

50. Vermes I, Haanen $C$, Steffens-Nakken $H$, and Reutelingsperger C. A novel assay for apoptosis. Flow cytometric detection of phosphatidylserine expression on early apoptotic cells using fluorescein labelled Annexin V. J Immunol Methods 184: 39-51, 1995.

51. West MA and Heagy W. Endotoxin tolerance: a review. Crit Care Med 30: S64-73, 2002.

52. Willet KE, Jobe $A H$, Ikegami $M$, Newnham J, Brennan $S$, and Sly PD. Antenatal endotoxin and glucocorticoid effects on lung morphometry in preterm lambs. Pediatr Res 48: 782-788, 2000.

53. Willet KE, Kramer BW, Kallapur SG, Ikegami M, Newnham JP, Moss TJ, Sly PD, and Jobe AH. Intra-amniotic injection of IL-1 induces inflammation and maturation in fetal sheep lung. Am J Physiol Lung Cell Mol Physiol 282: L411-420, 2002.
54. Wilson TC, Bachurski $C J$, Ikegami $M$, Jobe $A H$, and Kallapur SG. Pulmonary and systemic induction of SAA3 after ventilation and endotoxin in preterm lambs. Pediatr Res 58: 1204-1209, 2005. 


\section{Samenvatting}

Bronchopulmonaire dysplasie (BPD) is een ziektebeeld van vroeg geboren baby's, waarbij de ontwikkeling van de longen nog niet voltooid is. Vroeg geboren baby's hebben na de geboorte vaak toegenomen zuurstofbehoefte omdat het oppervlak voor de gasuitwisseling niet toereikend is om voldoende zuurstof op te nemen. De ontwikkeling van BPD is geassocieerd met een chronische ontsteking in de luchtwegen die gekenmerkt wordt door een afwijkende longanatomie zonder fibrosevorming. De oorzaak voor deze ontsteking kan antenataal zijn, bijvoorbeeld een ontsteking van de vliezen en het amnionvocht (chorioamnionitis) of postnataal, bijvoorbeeld reanimatie kort na de geboorte, zuurstoftoxiciteit, mechanische beademing of infectie.

In dit proefschrift zijn de effecten van chorioamnionitis in een proefdiermodel onderzocht. De gebruikte methode wordt beschreven in hoofdstuk 2. Chorioamnionitis wordt tijdens een echogeleide vruchtwaterpunctie bij zwangere schapen geïnduceerd door endotoxine van de $E$. coli bacterie in de amnionholte te injecteren. De foetale schapen aspireren de endotoxine, hetgeen een pulmonale ontsteking induceert.

In de hoofdstukken 3 en $\mathbf{4}$ wordt de cascade beschreven die veroorzaakt wordt door intra-amniotische toediening van endotoxine: longschade, ontsteking in de longen en herstel van de longen met apoptose en vervolgens celproliferatie met morfologische veranderingen. De bevindingen zijn samengevat in figuur 1: Binnen 5 uur na toediening van het endotoxine in het amnionvocht kwam in de foetale luchtwegen heat shock protein-70 tot expressie en in de bronchoalveolaire vloeistof namen de ontstekingscellen toe (hoofdstuk 4) (33). Binnen 24 uur was er een veelvoudige verhoging van het aantal monocyten en granulocyten in de bronchoalveolaire vloeistof en ook van het mRNA in het longweefsel voor de proinflammatoire cytokines IL-1B, IL-6 en IL-8 (hoofdstuk 3) (34). Apoptose van longcellen was verhoogd na 24 uur en na 72 uur was er sprake van een toegenomen proliferatie van longcellen. $\mathrm{Na} 7$ dagen was de acute ontstekingsreactie van de long uitgedoofd; echter, er bleven nog ontstekingscellen in de bronchoalveolaire vloeistof (hoofdstuk 3) (34).

In de longen van kinderen met BPD wordt een duidelijke simplificatie van de microvasculaire ontwikke- ling gezien (1). Dit wordt ook gezien in placenta's met chorioamnionitis (32). Analoge veranderingen zijn ook in foetale schapenlongen gevonden. $\mathrm{Na}$ intra-amniotische blootstelling aan endotoxine hadden de longen gedurende 1 tot 4 dagen een verminderde expressie van verschillende markers van vasculaire ontwikkeling (endotheliaal NO synthetase, vasculaire endotheliale groeifactor (VEGF), plaatjes endotheliale cel adhesie molecuul, en VEGF receptor 2) (20). Na 7 dagen was de media van de arteriolaire wanden verdikt, waren de alveolen groter en was het aantal alveolen afgenomen ten opzichte van controles (52).

In hoofdstuk 5 wordt de rol van transforming growth factor $B 1$ (TGF- $B 1$ ) beschreven in het chorioamnionitis model. TGF- $B 1$ is een belangrijke factor in de regulatie van de ontwikkeling van de longen, van ontsteking in de longen en van longherstel. Al deze processen spelen een belangrij$k e$ rol in de ontwikkeling van de BPD (hoofdstuk 5) (35). Ten gevolge van TGF-ß1 activiteit wordt de fibrosevorming veroorzaakt via connective tissue growth factor (CTGF), bovendien is hiervan bekend dat het de vasculaire ontwikkeling bevordert in muizenembryo's (8). Chorioamnionitis door toediening van endotoxine induceerde een duidelijke expressie van TGF- $B 1$ en signalering in de foetale long via geactiveerd Smad. Echter, de expressie van CTGF was duidelijk verlaagd, mogelijk gemediëerd door de verhoogde expressie van TNF- $\alpha$. Dit profiel van cytokines kan een rol spelen bij de gestoorde alveolaire en vasculaire ontwikkeling in de long, de afwezigheid van fibrose en de geringe inflammatie in de long, welke kenmerkend zijn voor BPD (figuur 2) $(35,37)$. Concluderend veroorzaakte een intra-amniotische toediening van endotoxine een chorioamnionitis die de anatomie van de foetale long veranderde vergelijkbaar met de pathologie van de longen van kinderen met $B P D(5)$.

\section{Intra-amniotische endotoxine veroorzaakt longrijping}

Ondanks het ontstaan van foetale longschade was de functionele uitkomst na intra-amniotische endotoxine toediening een toegenomen longrijping $(2,21,24)$. Het mRNA voor surfactant protëi- 


\section{Intra-amniotic injection of endotoxin}

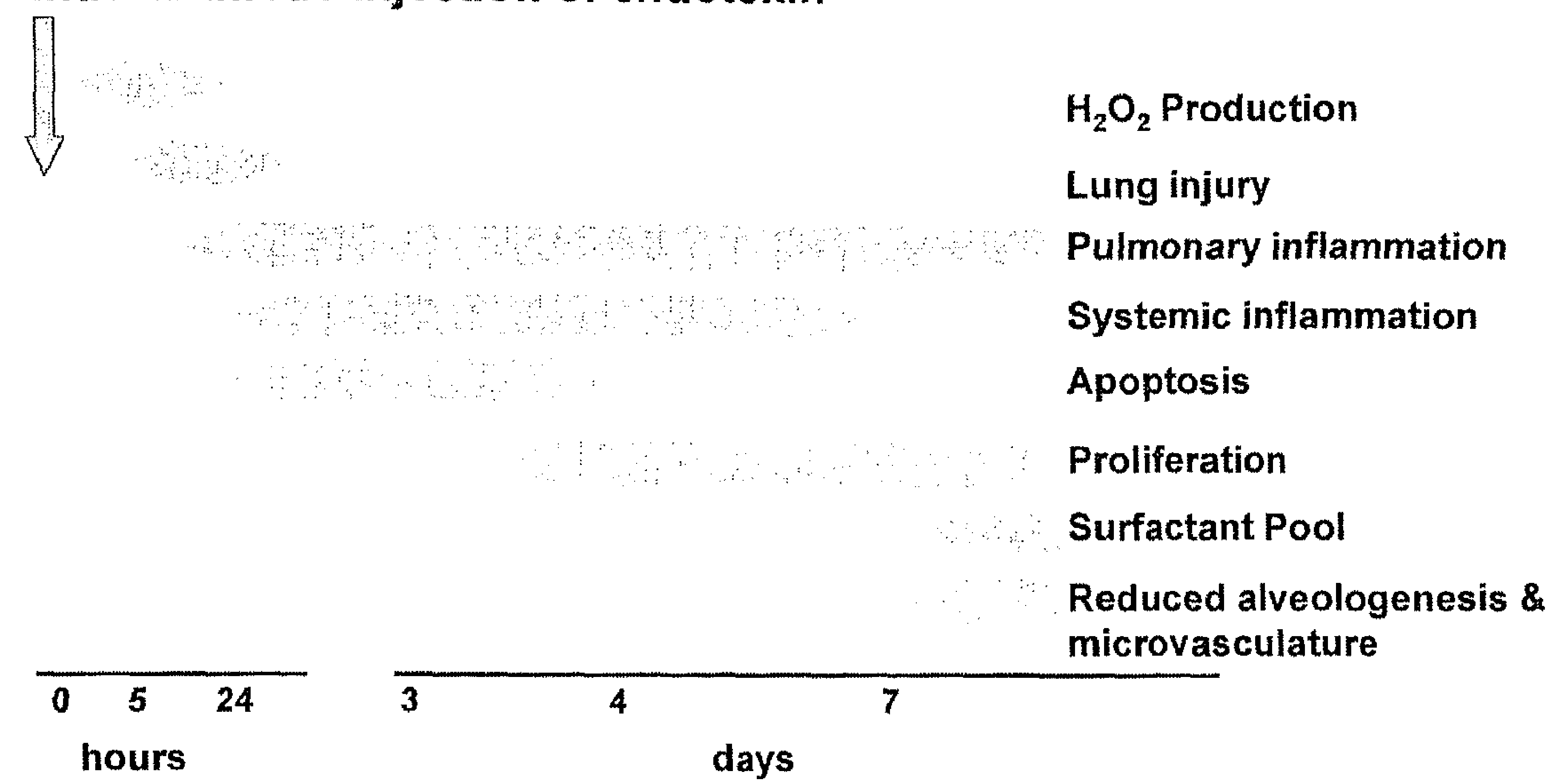

Figuur 1: Samenvatting van de cascade die geïnduceerd werd door toediening van een enkele dosis endotoxine van $E$. coli in het amnionvocht bij 117 dagen zwangere schapen. Longschade werd geïnduceerd met daaropvolgend ontsteking en een abnormale herstelreactie, resulterend na 7 dagen in een fenotype met mature longen en een verhoogde surfactant hoeveelheid, maar echter ook met abnormale ontwikkeling van de alveolen en het microvasculair vaatbed. Dit diermodel geeft binnen 7 dagen na intra-uteriene blootstelling aan ontsteking een mild fenotype van BPD (Samengevat van hoofdstuk 3 \& $4(2,18-20,25,33,34,52)$ )

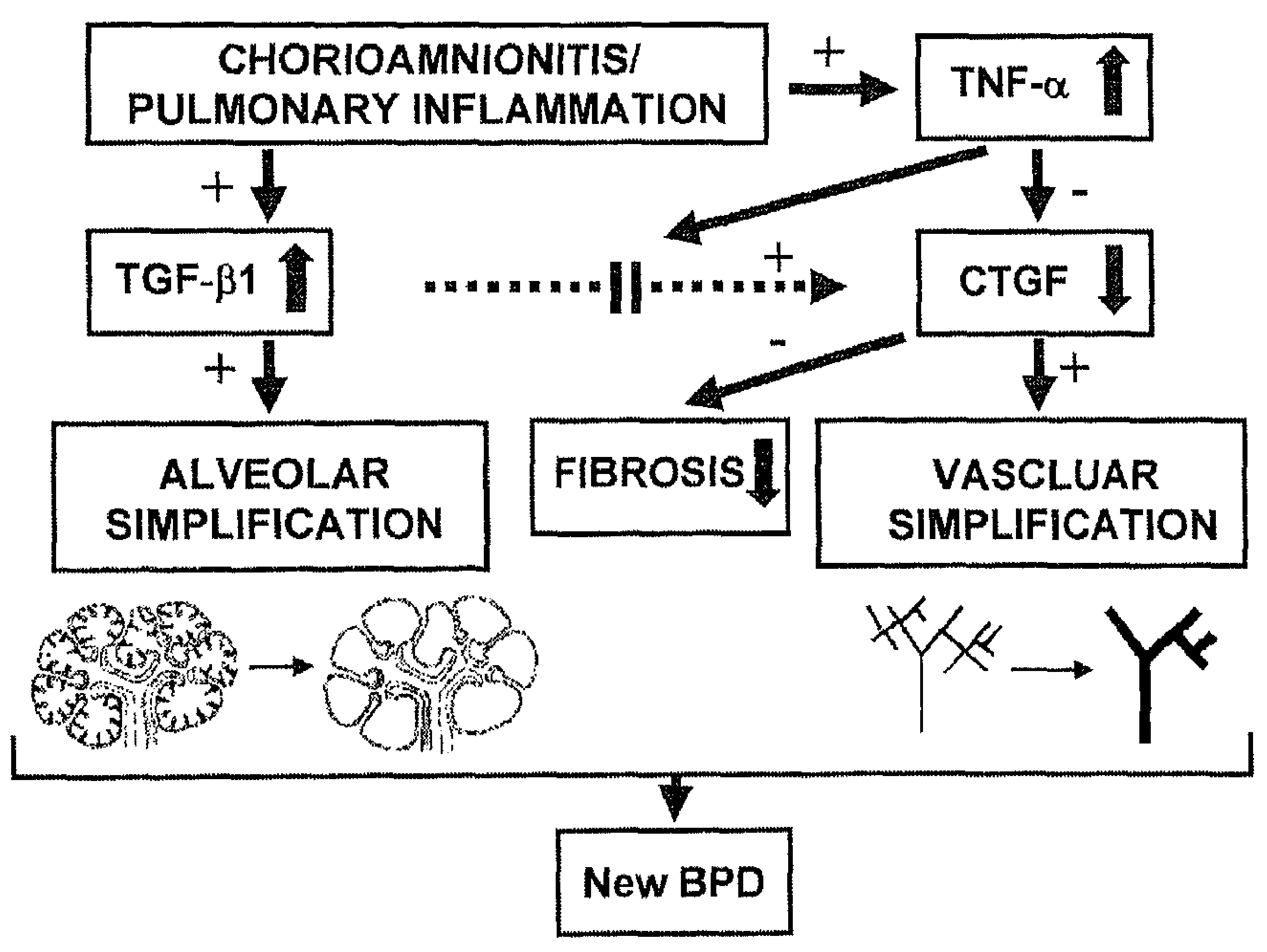

Figuur 2: Schematische samenvatting van de effecten van cytokines na het toedienen van endotoxine in het amnionvocht. Ontsteking in de longen resulteerde in verhoogde TGF- $\beta 1$ concentraties in de foetale long (hoofdstuk 5). TGF- $\beta 1$ is essentiëel voor "wondherstel" na longschade maar verhoogde TGF-B1 concentraties verstoren de alveolaire ontwikkeling. In andere modellen worden deze effecten gedeeltelijk gemediëerd door TGF-ß1 zelf maar de fibrose is vooral gemediëerd door CTGF. Bovendien verlaagt TGF-ß1 de ontsteking in de longen. In dit model van chorioamnionitis door endotoxine toediening werden TGF- $\beta 1$ en TNF- $\alpha$ geïnduceerd maar was CTGF verlaagd. De verlaging van CTGF was mogelijk het gevolg van het verhoogde TNF- $\alpha$. De verlaagde concentratie van CTGF limiteerde mogelijk de fibrosering, maar was wel de oorzaak voor de verstoorde ontwikkeling van het microvasculair vaatbed omdat het duidelijk is dat CTGF een rol speelt in de normale vasculaire ontwikkeling. Samengevat kunnen dus de cytokine profielen in dit sterk vereenvoudigd model de bevindingen van $B P D$ in het foetale longmodel verklaren. 
ne $A, B, C$ en $D$ was binnen 24 uur verhoogd en na 7 dagen waren de hoeveelheden surfactant eiwitten in bronchoalveolaire lavage vloeistof honderdvoudig toegenomen (hoofdstuk 3; figuur 1). Parallel aan de toename van surfactant verbeterde de longfunctie van de premature lammeren met een sterke toename van de longcompliantie en verbetering van de gasuitwisseling en oxygenatie $(18,19)$. Op te merken valt dat het plasma cortisol in navelstrengbloed niet verhoogd was na intra-amniotische endotoxine toediening, hetgeen suggereert dat er een ander mechanisme verantwoordelijk was voor de longrijping dan dat bij inductie door glucocorticoïden (18). De toename van zowel surfactant lipiden als eiwitten was veel groter na de endotoxine toediening dan na behandeling met corticosteroïden (19).

De klinisch relevante respons van de foetale long op chorioamnionitis is een toename in longrijping. Dit laatste zal resulteren in een verlaagde incidentie en ernst van RDS. In het gebruikte experimentele schapenmodel induceerden intra-amniotische doses van 1 tot $100 \mathrm{mg} E$. coli endotoxine gelijkwaardige ontstekingsreacties en longrijping (19). Met lagere doses werd geen longinflammatie en daaropvolgende longrijping gezien (hoofdstuk 3) (34). Vanuit de amnionholte kwam geen noemenswaardige hoeveelheid endotoxine in de circulatie van de foetus aangezien zelfs een zeer lage intravasculaire dosis van 1 $\mu \mathrm{g}$ de foetus kan doden (7). Toediening van endotoxine in het allantoïs veroorzaakte geen chorio-amnionitis en geen verandering in longstructuur (40). Dus kan men concluderen dat de foetale respons op de ontsteking afhankelijk is van het compartiment waarin de ontsteking optreedt.

\section{Hoe endotoxine longrijping signaleert}

Endotoxine toediening induceerde een cascade van ontstekingsmediatoren en trok geactiveerde ontstekingscellen naar het chorioamnion (hoofdstuk 3; figuur 1) $(25,34,39)$. De diffuse ontsteking in het chorioamnion kan effector moleculen afgeven in de foetale circulatie en zo indirect ontsteking in de longen veroorzaken met longrijping als gevolg. Echter, intraamniotische endotoxine toediening had slechts weinig effect op witte bloedcellen en bloedplaatjes in de circulatie (hoofdstuk 3) $(18,34)$. Messenger RNA's van pro-inflammatoire cytokines waren slechts minimaal en niet consistent verhoogd in de foetale lever en de concentraties van INF $\gamma$, IL-6 en IL-8 in plasma waren slechts minimaal verhoogd $(15,17,25,26,34$, $54)$. Ook de mRNA's van cytokines in de placenta en de darm waren niet duidelijk verhoogd (25). Dit alles wijst erop dat de locale ontsteking in de longen niet verklaard kan worden door een systemische ontstekingsreactie in de foetus.

Om de invloed van chorioamnionitis op de foetale long nader te kunnen bestuderen werden in een volgend model de foetale longen chirurgisch gescheiden van het amnionvocht door een tracheotomie te verrichten en het longvocht via een beademingstube in een plastic zak te verzamelen (39). Endotoxine toegediend in het amnionvocht veroorzaakte nu een chorioamnionitis zonder dat er een ontsteking optrad in de longen (39). Daarentegen veroorzaakte een 24-uur infuus van endotoxine in de foetale trachea wel ontsteking in de longen met daarna longrijping maar nu echter zonder chorioamnionitis. Deze resultaten tonen aan dat endotoxine de sequentie longontsteking - longrijping veroorzaakt door direct contact met de foetale long. Hiervoor is het dus noodzakelijk dat amnionvocht met het foetaal longvocht wordt gemengd door middel van foetale ademhalingsbewegingen. Bovendien is de klaring van endotoxine uit het amnionvocht zeer traag. Metingen van de endotoxine activiteit geven een geschatte half-waarde tijd van 41 uur (41).

In het klinische scenario zouden de inflammatoire effecten op de foetale longen veroorzaakt kunnen worden door het effect van het endotoxine op TLR4 receptoren, door stimulatie van andere TLR receptoren of door nog andere ontstekingsproducten van de chorioamnionitis (hoofdstuk 7) (29). Na intra-amniotische toediening van endotoxine was van alle gemeten cytokines het mRNA voor IL-1B het meest verhoogd in het chorioamnion van het schaap. Dit is vergelijkbaar met de bevindingen bij baby's die intrauterien bloot stonden aan chorioamnionitis (6). De originele beschrijving van longrijping na intra-amniotische toediening van IL-1 $\alpha$ in konijnen gaf geen omschrijving van de chorioamnionitis zelf (4). Intra-amniotische injecties met schapen recombinant IL- $1 \alpha$ of $\mathrm{IL}-1 \alpha$ bij zwangere schapen induceerde een chorioamnionitis gevolgd door een duidelijk rijping $(47,53)$. Echter, injecties met schapen recombinant TNF $\alpha$ gaf geen foetale respons met chorioamnionitis noch longontsteking, noch longrijping (16). Dus het foetale compartiment lijkt speciaal gevoelig te zijn voor $\mathrm{IL}-1$ en relatief ongevoelig 
voor andere ontstekingscytokines die normaal gesproken zeer potent zijn.

In andere proeven werd de influx van ontstekingscellen in de foetale longen na intra-amniotische toediening van endotoxine geblokkeerd door een anti-CD18 antistof. Hierdoor werd ook de longrijping geblokkeerd (23). Onze huidige opvatting is dat de foetale long reageert op ontstekingsmediatoren in het amnionvocht met een influx van ontstekingscellen die vervolgens de belangrijkste bron zijn van IL-1 $\alpha$ en de longrijping in gang zetten.

Recent werd aangetoond dat TGF- $\alpha$ gebonden wordt aan Surfactant Proteine-A (SP-A) (hoofdstuk 6) $(30,36,43-45)$. De invloed van de surfactant eiwitten op het imuunsysteem dient verder bestudeerd te worden aangezien de onrijpe long heel gevoelig is voor ontsteking $(3,9,12-14,48-50)$. In enkele experimenten werden lammeren van verschillende zwangerschapsleeftijden geïntubeerd en vervolgens werd endotoxine intra-tracheaal gegeven. Bij erg premature lammeren ( $80 \%$ zwangerschapsduur) bleef het endotoxine niet alleen in de longen maar lekte het ook in de systemische bloedcirculatie en veroorzaakte een septische shock syndroom (hoofdstuk 8) (26). Bij lammeren die meer (95\% zwangerschapsduur) tegen de à terme leeftijd waren veroorzaakte dezelfde dosis endotoxine geen systemische reactie meer. De rijpheid van het immuunsysteem lijkt dus een essentiële component in dit schapenmodel. In ons model konden in de foetale long geen alveolaire macrofagen aangetoond worden tot laat in de zwangerschap (hoofdstuk 9) (31). Laat in de zwangerschap migreren monocyten uit het bloed naar de longen, prolifereren en differentiëren vervolgens tot alveolaire macrofagen onder invloed van granulocyte-macrophage-colony stimulating factor (GM-CSF) en zijn transcriptie factor PU.1 (46).

Ook bleek dat in respons op endotoxine, monocyten uit navelstrengbloed van premature lammeren functioneel minder rijp waren in vergelijking met monocyten van lammeren die meer tegen de à terme leeftijd waren of die van volwassen schapen (hoofdstuk 9).

\section{Glucocorticoiden en chorioamnionitis}

Bij de meerderheid van de vrouwen die voor 30 weken zwangerschap bevalt, is er sprake van een subklinische chorioamnionitis (10). De meeste van deze vrouwen krijgen antenataal corticosteroïden toegediend om longrijping bij de foetus te induceren (11). De antenatale behandeling met corticosteroïden wordt ondersteund door vele klinische studies en systematische reviews. Indien antenataal corticosteroïden gegeven worden aan vrouwen met vroegtijdig breken van de vliezen, hetgeen als een surrogaat klinische marker voor chorioamnionitis beschouwd kan worden, is er een verlaagde incidentie van RDS, intraventriculaire bloedingen en overlijden bij de pasgeborene in vergelijking met placebo behandeling (11).

Maternale behandeling met corticosteroïden, 7 dagen voor de bevalling, verbeterde de longfunctie van de foetale schapen niet zo goed als een intra-amniotische toediening van endotoxine. Het grote verschil was een veel grotere toename van de hoeveelheid surfactant na intra-amniotische endotoxine toediening $(18,52)$. Maternale antenatale behandeling met het glucocorticoid betamethason, veroorzaakte tevens foetale groeivertraging en involutie van de thymus wat niet optrad na intra-amniotische toediening van endotoxine (42). Wanneer beide interventies werden gecombineerd, werd de groeirestrictie veroorzaakt door betamethason evenals de involutie van de thymus tot onze verbazing zelfs voorkomen (42). Betamethason onderdrukte de ontsteking in de longen, geïnduceerd door endotoxine, gedurende 2 dagen (22). Echter na 5 en 15 dagen waren de ontstekingscellen en ontstekingsmediatoren hoger in de longen blootgesteld aan zowel endotoxine als betamethasone dan in de longen blootgesteld aan endotoxine alleen (22).

Een mogelijke verklaring voor dit resultaat wordt gesuggereerd door onze bevinding dat maternale behandeling met betamethason aanvankelijk de ontstekingsrespons van de foetale monocyten onderdrukte, maar dat deze respons juist versterkt was na 7 dagen (hoofdstuk 10) (27). Dus maternale behandeling met betamethason kan wellicht de foetale ontsteking in de longen, veroorzaakt door endotoxine, versterken door de inflammatoire potentie van foetale ontstekingscellen te "rijpen". (hoofdstuk 10). Er zijn echter op dit moment geen experimentele gegevens beschikbaar over hoe de foetale long zal reageren op betamethason behandeling bovenop een chronische amnionitis, wat klinisch een gebruikelijker scenario is.

Ook werd de functie van foetale monocyten geëvalueerd na herhaalde blootstelling aan endotoxine (hoofdstuk 11) (28). De initiële blootstelling aan een niet-lethale dosis endotoxine verminderde de respons van immuuncellen op een tweede, wel lethale dosis endotoxine in dierexpe- 
rimentele modellen (51). Dit fenomeen wordt endotoxine tolerantie genoemd en het wordt beschouwd als een belangrijke oorzaak van morbiditeit op volwassen intensive care units. Herhaalde intra-amniotische toediening van endotoxine had geen toegevoegd effect op de longrijping maar maakte de foetale monocyten niet-responsief of zelfs inert aan een volgende blootstelling aan hetzelfde endotoxine (hoofdstuk 11) $(28,29)$.

\section{Conclusie}

Concluderend kan gezegd worden dat onze experimentele chorioamnionitis in het schapenmodel zowel positieve als negatieve effecten had voor de foetus. De longen rijpen versneld wat de kansen op overleving bij premature partus verhoogd. Daarentegen is de longstructuur sterk vereenvoudigd wat op de langere termijn BPD kan veroorzaken. Vervolgonderzoek zal de mechanismen van deze goede en schadelijke effecten nog verder moeten differentiëren om therapeutische en preventieve interventies mogelijk te maken.

\section{References}

1. Abman SH. Bronchopulmonary dysplasia: "a vascular hypothesis". Am J Respir Crit Care Med 164: 1755-1756, 2001.

2. Bachurski CJ, Ross GF, Ikegami M, Kramer BW, and Jobe $\mathrm{AH}$. Intra-amniotic endotoxin increases pulmonary surfactant proteins and induces SP-B processing in fetal sheep. Am J Physiol Lung Cell Mol Physiol 280: L279-285, 2001.

3. Baur FM, Brenner B, Goetze-Speer B, Neu S, and Speer CP. Natural porcine surfactant (Curosurf) down-regulates mRNA of tumor necrosis factor-alpha (TNF-alpha) and TNF-alpha type II receptor in lipopolysaccharide-stimulated monocytes. Pediatr Res 44: 32-36, 1998.

4. Bry $K$, Lappalainen $U$, and Hallman $M$. Intraamniotic interleukin-1 accelerates surfactant protein synthesis in fetal rabbits and improves lung stability after premature birth. $J$ Clin Invest 99: 2992-2999, 1997.

5. Coalson JJ. Pathology of new bronchopulmonary dysplasia. Semin Neonatol 8: 73-81, 2003.
6. Dollner $H$, Vatten L, Halgunset J, Rahimipoor $S$, and Austgulen R. Histologic chorioamnionitis and umbilical serum levels of pro-inflammatory cytokines and cytokine inhibitors. Bjog 109: 534-539, 2002.

7. Duncan JR, Cock ML, Scheerlinck JP, Westcott KT, McLean C, Harding R, and Rees SM. White matter injury after repeated endotoxin exposure in the preterm ovine fetus. Pediatr Res 52: 941-949, 2002.

8. Friedrichsen $S$, Heuer $H$, Christ $S$, Winckler $M$, Brauer $D$. Bauer $\mathrm{K}$, and Raivich G. CTGF expression during mouse embryonic development. Cell Tissue Res 312 : 175-188, 2003.

9. Gille C, Spring B. Tewes LJ, Loffler J, Dannecker GE, Hoffmann MK, Eichner M, Poets CF, and Orlikowsky TW. Diminished response to interleukin-10 and reduced antibody-dependent cellular cytotoxicity of cord blood monocyte-derived macrophages. Pediatr Res 60: 152-157, 2006.

10. Goldenberg RL, Hauth JC, and Andrews WW. Intrauterine infection and preterm delivery. $N$ Engl $J$ Med 342: 1500-1507, 2000.

11. Halliday HL. Evidence-based neonatal care. Best Pract Res Clin Obstet Gynaecol 19: 155-166, 2005

12. Haslett C. Granulocyte apoptosis and its role in the resolution and control of lung inflammation. Am J Respir Crit Care Med 160: S5-11, 1999.

13. Hofman P. Molecular regulation of neutrophil apoptosis and potential targets for therapeutic strategy against the inflammatory process. Curr Drug Targets Inflamm Allergy 3: 1-9, 2004.

14. Hu $B$, Sonstein J, Christensen PJ, Punturieri $A_{1}$ and Curtis $\mathrm{JL}$. Deficient in vitro and in vivo phagocytosis of apoptotic $T$ cells by resident murine alveolar macrophages. J Immunol 165: 2124-2133, 2000.

15. Ikegami $M$ and Jobe $A H$. Postnatal lung inflammation increased by ventilation of preterm lambs exposed antenatally to Escherichia coli endotoxin. Pediatr Res 52: 356-362, 2002.

16. Ikegami M, Moss TJ, Kallapur SG, Mulrooney N, Kramer BW, Nitsos I, Bachurski CJ, Newnham JP, and Jobe AH. Minimal lung and systemic responses to TNF-alpha in preterm sheep. Am J Physiol Lung Cell Mol Physiol 285: L121-129, 2003.

17. Jobe $A H$ and Ikegami $M$. Antenatal infection/inflammation and postnatal lung maturation and injury. Respir Res 2: 27-32, 2001. 
18. Jobe $A H$, Newnham JP, Willet KE, Moss TJ, Gore Ervin M, Padbury JF, Sly $P$, and Ikegami M. Endotoxin-induced lung maturation in preterm lambs is not mediated by cortisol. $A m$ J Respir Crit Care Med 162: 1656-1661, 2000.

19. Jobe $A H$, Newnham JP, Willet KE, Sly $P$, Ervin $M G$, Bachurski C, Possmayer F, Hallman M, and Ikegami M. Effects of antenatal endotoxin and glucocorticoids on the lungs of preterm lambs. Am J Obstet Gynecol 182: 401-408, 2000.

20. Kallapur SG, Bachurski CJ, Le Cras TD, Joshi SN, Ikegami $M$, and Jobe $A H$. Vascular changes after intra-amniotic endotoxin in preterm lamb lungs. Am J Physiol Lung Cell Mol Physiol 287: L1178-1185, 2004.

21. Kallapur SG, Jobe $A H$, Ikegami $M$, and Bachurski CJ. Increased IP-10 and MIG expression after intra-amniotic endotoxin in preterm lamb lung. Am J Respir Crit Care Med 167: 779-786, 2003.

22. Kallapur SG, Kramer BW, Moss TJ, Newnham JP, Jobe AH, Ikegami M, and Bachurski CJ. Maternal glucocorticoids increase endotoxin-induced lung inflammation in preterm lambs. Am J Physiol Lung Cell Mol Physiol 284: L633-642, 2003.

23. Kallapur SG, Moss TJ, Jkegami M, Jasman RL, Newnham $\mathrm{JP}$, and Jobe $\mathrm{AH}$. Recruited inflammatory cells mediate endotoxin-induced lung maturation in preterm fetal lambs. Am J Respir Crit Care Med 172: 1315-1321, 2005.

24. Kallapur SG, Nitsos I, Moss TJ, Kramer BW, Newnham JP, Ikegami $\mathrm{M}$, and Jobe $\mathrm{AH}$. Chronic endotoxin exposure does not cause sustained structural abnormalities in the fetal sheep lungs. Am J Physiol Lung Cell Mol Physiol 288: L966-974, 2005.

25. Kallapur SG, Willet KE, Jobe AH, Ikegami M, and Bachurski CJ. Intra-amniotic endotoxin: chorioamnionitis precedes lung maturation in preterm lambs. Am J Physiol Lung Cell Mol Physiol 280: L527-536, 2001.

26. Kramer $B W$, Ikegami $M$, and Jobe $A H$. Intratracheal endotoxin causes systemic inflammation in ventilated preterm lambs. Am J Respir Crit Care Med 165: 463-469, 2002.

27. Kramer BW, Ikegami M, Moss TJ, Nitsos I, Newnham JP, and Jobe AH. Antenatal betamethasone changes cord blood monocyte responses to endotoxin in preterm lambs. Pediatr Res 55: 764-768, 2004.

28. Kramer BW, Ikegami M, Moss TJ, Nitsos I, Newnham JP, and Jobe $\mathrm{AH}$. Endotoxin-induced chorioamnionitis madulates innate immunity of monocytes in preterm sheep. Am J Respir Crit Care Med 171: 73-77, 2005.

29. Kramer BW and Jobe AH. The clever fetus: responding to inflammation to minimize lung injury. Biol Neonate 88: 202-207, 2005.
30. Kramer BW, Jobe AH, Bachurski CJ, and Ikegami M. Surfactant protein $A$ recruits neutrophils into the lungs of ventilated preterm lambs. Am J Respir Crit Care Med 163: 158-165, 2001.

31. Kramer BW, Jobe AH, and Ikegami M. Monocyte function in preterm, term, and adult sheep. Pediatr Res 54: 52-57, 2003.

32. Kramer BW, Kaemmerer U, Kapp M, Herbst D, Marx A, Berg D, Groneck PA, and Speer CP. Decreased expression of angiogenic factors in placentas with chorioamnionitis after preterm birth. Pediatr Res 58: 607-612, 2005.

33. Kramer BW, Kramer S, Ikegami M, and Jobe AH. Injury, inflammation, and remodeling in fetal sheep lung after intra-amniotic endotoxin. Am J Physiol Lung Cell Mol Physiol 283: L452-459, 2002.

34. Kramer BW, Moss TJ, Willet KE, Newnham JP, Sly PD, Kallapur SG, Ikegami $M$, and Jobe $A H$. Dose and time response after intraamniotic endotoxin in preterm lambs. Am J Respir Crit Care Med 164: 982-988, 2001.

35. Kunzmann S, Speer C, Jobe AH, and Kramer BW. Antenatal inflammation induced TGF-\{beta 1 but suppressed CTGF in preterm lungs. Am J Physiol Lung Cell Mol Physiol 292: L223-231, 2007.

36. Kunzmann S, Wright JR, Steinhilber W, Kramer BW, Blaser $K$, Speer $C P$, and Schmidt-Weber C. TGF\{beta\} 1 in SP-A preparations influences immune suppressive properties of SP-A on human CD4+ T lymphocytes. Am J Physiol Lung Cell Mol Physiol 291: L747-756, 2006.

37. Kwong $K Y$, Niang $S$, Literat $A$, Zhu NL, Ramanathan $R$, Jones CA, and Minoo P. Expression of transforming growth factor beta (TGF-b1) by human preterm lung inflammatory cells. Life Sci 79: 2349-2356, 2006.

38. Moss TJ, Newnham JP, Willett KE, Kramer BW, Jobe $\mathrm{AH}$, and Ikegami $\mathrm{M}$. Early gestational intra-amniotic endotoxin: lung function, surfactant, and morphometry Am J Respir Crit Care Med 165: 805-811, 2002.

39. Moss TJ, Nitsos 1, Kramer BW, Ikegami M, Newnham $\mathrm{JP}$, and Jobe $\mathrm{AH}$. Intra-amniotic endotoxin induces lung maturation by direct effects on the developing respiratory tract in preterm sheep. Am J Obstet Gynecol 187: 1059-1065, 2002.

40. Moss TJ, Nitsos I, Newnham JP, Ikegami M, and Jobe $\mathrm{AH}$. Chorioamnionitis induced by subchorionic endotoxin infusion in sheep. Am J Obstet Gynecol 189: $1771-1776,2003$ 
41. Newnham JP, Kallapur SG, Kramer BW, Moss TJ, Nitsos I, Ikegami $M$, and Jobe $A H$. Betamethasone effects on chorioamnionitis induced by intra-amniotic endotoxin in sheep. Am J Obstet Gynecol 189: 1458-1466, 2003.

42. Newnham JP, Moss TJ, Padbury JF, Willet KE, lkegami M, Ervin MG, Sly $P$, and Jobe $A$. The interactive effects of endotoxin with prenatal glucocorticoids on short-term lung function in sheep. Am J Obstet Gynecol 185: 190-197, 2001.

43. Radzun HJ, Parwaresch MR, and Kreipe H. Monocytic origin of human alveolar macrophages. $J$ Histochem Cytochem 31: 318-324, 1983.

44. Reidy MF and Wright JR. Surfactant protein A enhances apoptotic cell uptake and TGF-beta1 release by inflammatory alveolar macrophages. Am J Physiol Lung Cell Mol Physiol 285: L854-861, 2003.

45. Schagat TL, Wofford JA, and Wright JR. Surfactant protein A enhances alveolar macrophage phagocytosis of apoptotic neutrophils. J Immunol 166: 2727-2733, 2001.

46. Shibata Y, Berclaz PY, Chroneos ZC, Yoshida M, Whitsett $\mathrm{JA}_{\text {, }}$ and Trapnell BC. GM-CSF regulates alveolar macrophage differentiation and innate immunity in the lung through PU.1. Immunity 15: 557-567, 2001.

47. Sosenko IR, Kallapur SG, Nitsos I, Moss TJ, Newnham JP, Ikegami $M$, and Jobe AH. IL-1alpha causes lung inflammation and maturation by direct effects on preterm fetal lamb lungs. Pediatr Res 60: 294-298, 2006.
48. Speer CP. Inflammation and bronchopulmonary dysplasia: A continuing story. Semin Fetal Noonatal Med 11: 354-362, 2006

49. Speer CP, Gotze B, Curstedt T, and Robertson B. Phagocytic functions and tumor necrosis factor secretion of human monocytes exposed to natural porcine surfactant (Curosurf). Pediatr Res 30: 69-74, 1991.

50. Vermes I, Haanen $C$, Steffens-Nakken $H$, and Reutelingsperger $C$. A novel assay for apoptosis. Flow cytometric detection of phosphatidylserine expression on early apoptotic cells using fluorescein labelled Annexin V. J Immunol Methods 184: 39-51, 1995

51. West MA and Heagy W. Endotoxin tolerance: a review. Crit Care Med 30: S64-73, 2002.

52. Willet KE, Jobe AH, Ikegami M. Newnham J, Brennan S, and Sly PD. Antenatal endotoxin and glucocorticoid effects on lung morphometry in preterm lambs. Pediatr Res 48: 782-788, 2000.

53. Willet KE, Kramer BW, Kallapur SG, Ikegami M, Newnham JP, Moss TJ, Sly PD, and Jobe AH. Intra-amniotic injection of IL-1 induces inflammation and maturation in fetal sheep lung. Am J Physiol Lung Cell Mol Physiol 282: L411-420, 2002

54. Wilson TC, Bachurski $C J$, Ikegami M, Jobe $A H$, and Kallapur SG. Pulmonary and systemic induction of SAA3 after ventilation and endotoxin in preterm lambs. Pediatr Res 58: 1204-1209, 2005. 


\section{Acknowledgement}

Prof. Dr. Luc Zimmermann has offered me the opportunity to pursue my research in the favorable settings of the University of Maastricht for which I am very grateful. He has been very generous in supporting new models and has a holistic approach to recruitment, research, teaching and clinical care. The clinical expertise and the research pursuits of my colleagues Dr. Pieter Degrauwe, Dr. Danilo Gavilanes, Dr. Mark van de Hoeven, Dr. Twan Mulder and Dr. Eduardo Villamor make the setting in Maastricht unique!

Prof. Dr. Alan Jobe from the Division of Pulmonary Biology, Cincinnati Children's Hospital, Cincinnnati, Ohio, USA, has been a great mentor, teacher and friend in science and academics. He has encouraged me to develop new ideas during my research fellowship and his generous support has made scientific work with his unique animal model possible for me. Besides, Prof. Dr. Alan Jobe has been a great role model as a researcher facing the small and major problems in research.

I want to thank Prof. Dr. Christian Speer, University Hospital Würzburg, Germany, for his clinical training, scientific mentoring and support which paved the way to an academic career. He recruited me as a student by showing scientific mechanisms in clinical practice. His teaching at the bedside inspired my enthusiasm for neonatology for which I am very grateful.

The research work has been done in Würzburg by PD Dr. S. Kunzmann, S. Seidenspinner, D. Herbst, $K$. Glogger and A. Ladenburger. I am very thankful for their help, ideas and comments!
The collaboration with PD Dr. Dr. Y. Garnier and Dr. M. Gantert from the University of Cologne, Germany, has set up new models and approaches which have been very promising.

Prof. Dr. Suhas Kallapur (Cincinnati Children's Hospital, Cincinnati, Ohio, USA), Prof. Dr. John Newnham, Dr. Jane Pillow, Dr. Timothy Moss, Dr. llias Nitsos, and Dr. Graeme Polglase (University of Western Australia, Perth, Australia) have provided me the support, help, guidance and friendship to plan experiments at the other end of the world and to be able to execute them in a small period of time.

Dr. Freek van Iwaarden has been organizing the pulmonary laboratory which is developing into a thriving entity. I thank him very much for his help, generous support and guidance in beginning a new endeavor at the University of Maastricht.

The advice and support in daily research life by Drs. Jasper Been, Nico Klosterboor, Rob Moonen, Bea Zoer, Lilian Kessels and Coen Willems have helped me a lot to get started - for which I want to say: "Dank u wel"!

My wife and children have supported me incredibly! I want to thank them for their support, understanding and patience - and the courage to move to a new place! Without them nothing would be possible - and with them everything is possible! My parents have nurtured my interest and pursuit in science. They have put their own interests aside to support the young family in the pursuit of a balance of family life and professional development for which I will be forever grateful. 


\section{Curriculum vitae}

Boris W. Kramer was born on October 8th, 1970, in Böblingen, Baden-Württemberg, Germany. He grew up in Gäufelden-Öschelbronn, a village close to the Black Forrest ("Schwarzwald"), where he attended primary school. After secondary school education in the Schickhardt-Gymnasium in Herrenberg he fulfilled his general service obligation with the GermanFrench Brigade in Böblingen and the University Hospital Tübingen, Germany. He enrolled in medical school at the Eberhardts-Karl-Universität Tübingen, Germany from which he graduated in 1997 after internships at the Kantonsspital Luzern, Switzerland, the Mayo Medical School, Rochester, USA, the University of Sydney, Australia, and the Kinderspital Zürich, Switzerland. He did a medical thesis with summa cum laude entitled "Functional characterisation of a binding protein for coxsackievirus B3" with Prof. Dr. R. Kandolf, Molecular Pathology, in
Tübingen. He started his residency training in pediatrics with Prof. Dr. C.P. Speer at the University Hospital Tübingen, Germany, from where he went for a two year research fellowship to Prof. Dr. A. H. Jobe in Cincinnati Children's Hospital Research Foundation, Ohio, USA. He returned to continue his clinical training in Würzburg, Germany, with Prof. Dr. C. P. Speer, where he completed his training in pediatrics and neonatology. He was head of a junior research group and submitted his Habilitationsschrift at the University of Würzburg and was promoted to "Privatdozent" (junior faculty). Prof. Dr. L.J.I. Zimmermann recruited him to the University Hospital of Maastricht, the Netheriands, as neonatology staff to implement an ovine animal model for perinatal research.

\section{AWARDS \& SCHOLARSHIPS}

Scholarship of the Studienstiftung des deutschen Volkes (National Fund to support the top 1\% students in Germany, 1991-1997)

Scholarship of the Alumnies of the University of Tübingen, Germany, 1992-1997

Research Fellowship, Deutsche Forschungsgemeinschaft (National Research Fund of Germany, 1999-2000)

Honorary Research Fellow of the Women and Infants Research Foundation of Western Australia, Perth, Australia (since 2001)
Scientific Award of the German-Austrian Society for Neonatology and Pediatric Intensive Care Medicine (2003)

Young Investigator Award of the European Society for Pediatric Resarch (2003)

Travel Award for the Scientific Meeting of the European Society for Pediatric Research 2003 in Bilbao/Spain

Scientific Award of the German Society for Perinatal Medicine (2003) 


\section{List of Publications}

\section{a) Original papers}

1) Raab de Verdugo, U., Selinka, H.-C., Huber, M., Kramer, B., Kellermann, J., Hofschneider, P. H., Kandolf, R. (1995). Characterization of a 100kilodalton binding protein for the six serotypes of coxsackie B viruses. J. Virol. 69: 6751-6757.

2) Kramer, B., Huber, M., Kern, C., Klingel, K., Kandolf, R., Selinka, H.-C. (1997). Chinese hamster ovary cells are non-permissive towards infection with coxsackievirus B3 despite functional virus-receptor interactions. Virus Research 48: 149-156.

3) Kramer, B., Viebahn, R., Petersen, D., Klockgether, T. (1998). Durch FK 506 (Tacrolimus) induzierte Leukenzephalopathie. Akt. Neurologie 25: 76-79.

4) Kramer, B., Speer, C.P. (1999). Die Lungenhypoplasie: eine unterschätzte Diagnose? Z. Geburtsh. Neonatol. 203: 143-151.

5) Kramer, B.W., Martin, T., Henn, W., Lal, S., Speer, C.P. (2000). Lung hypoplasia in a patient with del(2)(q33-q35) demonstrated by chromosome microdissection. Am. J. Med. Genet. 84: 184-188.

6) Kramer, B.W., Ikegami, M., Jobe, A.H. (2000). Surfactant phospholipid catabolic rate is pool size dependent in mice. Am. J. Physiol. 279: L842-L848.

7) Kramer, B.W., Jobe, A.H., Bachurski, C.J., Ikegami, M. (2001). Surfactant protein A recruits neutrophil granulocytes into the lungs of ventilated preterm sheep. Am. J. Respir. Crit. Care Med. 163: 158-165.

8) Bachurski, C.J., Ross, G.F., Ikegami, M., Kramer, B.W., Jobe, A.H. (2001). Intra-amniotic endotoxin increases pulmonary surfactant proteins and induces SP-B processing in fetal sheep. Am. J. Physiol. 280: L279-L285.
9) Kramer, B.W., Jobe, A.H., Ikegami, M. (2001) Exogenous surfactant changes the phenotype of alveolar macrophages in mice. Am. J. Physiol. 280: L689-L694.

10) Naik, A.S., Kallapur, S.G., Bachurski, C.J., Jobe, A.H., Michna, J., Kramer, B.W., Ikegami, M. (2001) Effects of ventilation with different PEEP on cytokine expression in the preterm lamb lung. Am. J. Respir. Crit. Care Med. 164: 494-498.

11) Kramer, B.W., Moss, T.J., Willet, K.E., Newnham, J.P., Sly, P.D., Kallapur, S.G., lkegami, M., Jobe, A.H. (2001) Dose and time response after intraamniotic endotoxin in preterm lambs. Am. J. Respir. Crit. Care Med. 164: 982-988.

12) Willet, K.E., Kramer, B.W., Kallapur, S.G., Moss, T.J., Newnham, J.P., Sly, P.D., Ikegami, M., Jobe, A.H. (2002) Intraamniotic injection of IL-1 induces inflammation and maturation in fetal sheep lung. Am. J. Physiol. 282: L411-L420.

13) Kramer, B.W., Ikegami, M., Jobe, A.H. (2002) Intratracheal endotoxin induces systemic inflammation in ventilated preterm lambs. Am. J. Respir. Crit. Care Med. 165:463-469.

14) Moss, T.J., Newnham, J.P., Willet, K.E., Kramer, B.W., Jobe, A.H., Ikegami, M. (2002) Intra-amniotic endotoxin at early gestation improves lung function in preterm lambs. Am. J. Respir. Crit. Care Med. 165: 805-811.

15) Newnham, J.P., Moss, T.J., Kramer, B.W., Nitsos, I., lkegami, M, Jobe, A.H. (2002) The fetal maturational and inflammatory responses to different routes of endotoxin infusion in sheep. Am. J. Obstet. Gynecol. 186: 1062-1068. 
16) Kramer, B.W., Kramer, S., Ikegami, M., Jobe, A.H. (2002) Injury, inflammation and remodeling in fetal sheep lung after intraamniotic endotoxin. Am. J. Physiol. 283: L452-L459.

17) Jobe, A.H., Kramer, B.W., Moss, T.J., Newnham, J.P., Ikegami, M. (2002) Decreased indicators of lung injury with continuous positive expiratory pressure in preterm lambs. Pediatr. Res. 52: 387-392.

18) Moss, T.J., Nitsos, I., Kramer, B.W., Ikegami, M., Newnham, J.P., Jobe, A.H. (2002) Intraamniotic endotoxin induces preterm lung maturation by direct effects on the developing respiratory tract in sheep. Am. J. Obstet. Gynecol. 187: 1059-1065.

19) Kallapur, S.G., Kramer, B.W., Moss, T.J.M., Newnham, J.P., Jobe, A.H., Ikegami, M., Bachurski, C.J. (2003) Maternal glucocorticoids increase endotoxin induced lung inflammation in preterm lambs. Am. J. Physiol. 284: L633L642.

20) Kramer, B.W., Speer, C.P. (2003) Die Surfactantproteine $A$ und $D$ : wesentliche Faktoren des pulmonalen Abwehrsystems. $Z$. Geburtsh. Neonatol. 207: 41-47.

21) Ikegami, M., Moss, T.J.M., Kallapur, S.G., Mulrooney, N., Kramer, B.W., Nitsos, I., Bachurski, C.J., Newnham, J.P., Jobe, A.H. (2003) Minimal lung and systemic responses to TNF $\alpha$ in preterm sheep. Am. J. Physiol. 285: L121-L129.

22) Kramer, B.W., Jobe, A.H., Ikegami, M. (2003) Monocyte function in preterm, near term and adult sheep. Pediatr. Res. 54: 52-57.

23) Newnham, J.P., Kallapur, S.G., Kramer, B.W., Moss, T.J.M., Nitsos, I., Ikegami, M., Jobe, A.H. (2003) Betamethasone effects on chorioamnionitis induced by intra-amniotic endotoxin in sheep. Am. J. Obstet. Gynecol. 189: 1458-66.
24) Kramer, B.W., Ikegami, M., Moss, T.J.M, Nitsos, I., Newnham, J.P., Jobe, A.H. (2004) Antenatal betamethasone changes cord blood monocyte responses to endotoxin in preterm lambs. Pediatr. Res. 55:764-768.

25) Kramer B.W., Götz R., Rapp U.R. (2004) Use of mitogenic cascade blockers for treatment of $\mathrm{C}$-Raf induced lung adenoma in vivo: $\mathrm{Cl}$ 1040 strongly reduces growth and improves lung structure. BMC Cancer 4: 24.

26) Götz R., Kramer B.W., Camarero G., Rapp U.R. (2004) BAG-1 haplo-insufficiency impairs lung tumorigenesis. BMC Cancer 4:85

27) Kramer B.W., Ikegami M., Moss T.J.M., Nitsos I., Newnham, J.P., Jobe, A.H. (2005) Endotoxin induced chorioamnionitis modulates innate immunity of monocytes in preterm sheep. Am. J. Respir. Crit. Care Med.: 171: 73-77

28) D'Alquen D., Kramer B.W., Seidenspinner S., Marx, A., Berg D., Groneck, P., Speer C.P. (2005) Activation of umbilical cord endothelial cells and fetal inflammatory response in preterm infants with chorioamnionitis and funisitis. Pediatr. Res. 57: 263-269

29) Kallapur S.G., Nitsos I., Moss T.J., Kramer B.W., Newnham J.P., Ikegami M., Jobe A.H. (2005) Chronic endotoxin exposure does not cause sustained structural abnormalities in the fetal sheep lungs. Am. J. Physiol. 288: L966-974

30) Kramer B.W., Kaemmerer U., Kapp M., Herbst D., Marx A., Berg D., Groneck P.A., Speer, C.P. (2005) Decreased expression of angiogenic factors in placentas with chorioamnionitis after preterm birth. Pediatr. Res. 58: 607-612

31) Kramer B.W., Jobe A.H. (2005) The clever fetus: responding to inflammation to minimize lung injury. Biol. Neonate. 88: 202-207 
32) Nitsos I., Rees S.M., Duncan J., Kramer B.W., Harding R., Newnham J.P. Moss T.J.M. (2006) Chronic exposure to intra-amniotic lipopolysaccharide affects the ovine fetal brain. J. Soc. Gynecol. Investig. 13: 239-247.

33) Kunzmann S., Wright J.R., Steinhilber W., Kramer B.W., Blaser K., Speer C.P., SchmidtWeber C. (2006) TGF-beta1 in SP-A preparations influence immune suppressive properties of SP-A on human CD4+ T lymphocytes. Am. J. Physiol. 291, L747-756.

34) Kunzmann S., Speer C.P., Jobe A.H., Kramer B.W. (2007) Antenatal inflammation induced TGF-beta1 but suppressed CTGF in preterm lungs. Am. J. Physiol. 292, L223-231.

35) Kunzmann S., Schmidt-Weber C., Zingg J.-M., Azzi A., Kramer B.W., Blaser K., Akdis A.C., Speer C.P. (2007) Connective tissue growth factor expression is regulated by histamine in lung fibroblasts: potential role of histamine in airway remodelling. J. Allergy \& Clin. Immunol. $119,1398-1407$.

36) Kadyrov, M., Garnier Y., Gantert M., Kramer B.W., Huppertz B. (2007) Cytokeratin antibodies as differential markers of trophoblast and fetomaternal syncytial plaques in the sheep placentome. Placenta, in press.

37) Kramer B.W., Joshi S.N., Newnham J.P., Sindelar R., Jobe A.H., Kallapur S.G. (2007) Endotoxin-induced maturation of monocytes in preterm fetal sheep lung. Am. J. Physiol., 293: L345-53.
38) Ceteci F., Ceteci S., Karreman C., Kramer B.W., Asan E., Götz R., Rapp U.R. (2007). Disruption of Tumor Cell Adhesion Promotes Angiogenic Switch and Progression to Micrometastasis in RAF-Driven Murine Lung Cancer. Cell Cancer, 12: 145-159.

39) Hillman N., Moss T.J.M., Kallapur S.G., Bachurski C., Pillow J.J., Polglase G., Nitsos I., Kramer B.W., Jobe A.H. (2007) Brief, large tidal volume ventilation initiates lung injury and a systemic response in fetal sheep. Am. J. Respir. Crit. Care Medicine, in press.

40) Kramer B.W. (2007) The respiratory distress syndrome (RDS) in preterm infants: physiology, prophylaxis and new therapeutic approaches. Intensivmed. in press

\section{b) Book chapters/ congress reports}

Selinka, H.-C., Klingel, K., Huber, M., Kramer, B., Kämmerer, U., Kandolf, R. (1997). Molecular pathogenesis of myocarditis and cardiomyopathy: Analysis of virus-receptor interactions and tyrosine phosphorylation events. In: H. P. Schultheiss and P. Schwimmbeck (eds), The role of immune mechanisms in cardiovascular disease. pp 17-26. Springer. Berlin.

Kramer B.W. (2003) "Recent advances in neonatal medicine", 18-20 October 2002, Würzburg, Germany. Z. Geburtshilfe Neonatol.; 207: 74-76

Kramer B.W. (2006) "Recent advances in neonatal medicine", 6-9 October 2005, Würzburg, Germany. Z. Geburtshilfe Neonatol.; 210: 25-30 